\title{
ISSN 1833-3850
}

International

Journal of

Business and

Management

Vol. 4, No. 4

April 2009

CCSE

Canadian Center of Science and Education 


\section{Editorial Board}

Balakrishnan Parasuraman Universiti Malaysia Sabah, Malaysia

Benjamin James. Inyang University of Calabar, Nigeria

David H. Kent Golden Gate University, USA

Dennis Yao Dzansi Central University of Technology, South Africa

Donald Henry Ah Pak Xi'an Jiaotong-Liverpool University, China

Fulford Richard Edith Cowan University, Australia

Goi Chai Lee Curtin University of Technology, Malaysia

Guneratne Wickremasinghe Victoria University, Australia

Hafizi Muhamad Ali Universiti Utara Malaysia, Malaysia

Kevin James Daly University of Western Sydney, Australia

K. G. Viswanadhan NSS College of Engineering, India

Lisa Wang Canadian Center of Science and Education, Canada

Mahdi Salehi Zanjan University, Iran

Matthew M.Chew Hong Kong Baptist University, Hong Kong

Muhammad Madi Bin Abdullah Universiti Teknologi Malaysia, Malaysia

Roberto Bergami Vitoria University, Australia

Sathya Swaroop Debasish Fakir Mohan University, India

Selcuk Burak Hasiloglu Pamukkale University, Turkey 


\section{Contents}

The Mediating Effect of Empowerment in the Relationship between Transformational Leadership and

Service Quality

Azman Ismail, Farida Abd Halim, Dayang Nailul Munna Abang Abdullah, Ahmad Sofian Shminan, Agatha

Lamentan Anak Muda, Shairazi Samsudin \& Antonia Girardi

Corporate Customers' Adoption of Internet Banking: Case of Klang Valley Business Firm in Malaysia

Syed Shah Alam, Rosidah Musa \& Faridah Hassan

The Pricing of Luxury Goods: A BPM Approach

Qiang Du

Parent Control Dynamics and International Joint Venture Performance

Nguyen Huu Le

Performance Evaluation of Organizations: An Integrated Data Envelopment Analysis and Balanced

Scorecard Approach

Seyyed Asghar. Ebnerasoul, Hossein Yavarian \& Mehdi Amir Azodi

China's Education Market and Foreign Suppliers of Education Services

Jian Xu

Corporate Social Responsibility Assessment of Chinese Corporations

Jingfu Guo, Likun Sun \& Xueli Li

Readiness toBe K-workers among Students of Engineering Education Institution in Malaysia

Mohd Yusop Ab.Hadi, Jailani Mohd Yunos \& Noraini Kaprawi

The Relationship among Knowledge Management, Organizational Learning, and Organizational

Performance

Shu-hsien Liao \& Chi-chuan Wu

A Research on the Influences of Transnational Merger and Acquisition on China's Industry Security

Jianhong Huang

Inevitability and Necessity to Develop SWFs in China

Jing Xiang, Susheng Wang, Zhaokun Kong \& Wenhu Li

Performance Evaluation of Selected Private Commercial Banks in Bangladesh

Tanbir Ahmed Chowdhury \& Kashfia Ahmed

A Case for Performance Management in the Public Sector in Nigeria

Bassey B. Esu \& Benjamin J. Inyang

Innovation Fund: a Booster of Science and Technology SME Development

Yurong Chen, Liuying Xu \& Weixing Wang

The Application of Control Chart in the Measurement System Analysis

Yueyi Zhang \& Zhijun Han

Knowledge Sharing in a Knowledge Intensive Organisation: Identifying the Enablers

Hazman Shah Abdullah, Aliza Abu Hassim \& Razmi Chik

Analysis on Local Government Support in Agricultural Industriazation-Based on the Reflection of

Dumping Milk in Zhaodong City of Heilongjiang Province

Yukun Zhang 


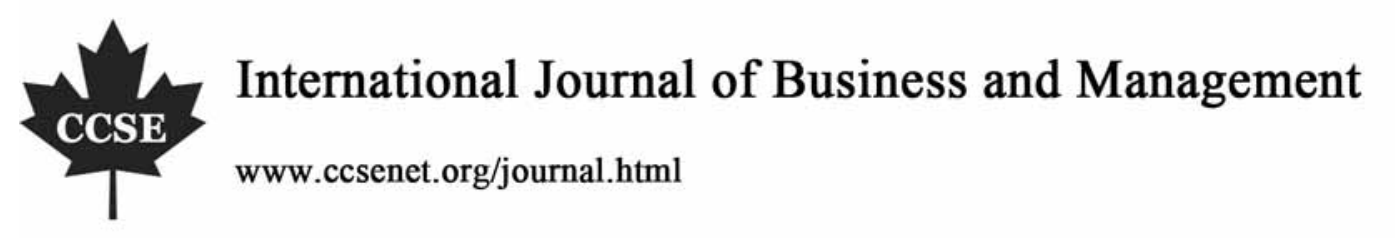

Vol. 4, No. 4

April 2009

\section{Contents}

An Attitude Approach to the Prediction of Entrepreneurship on Students at Institution of Higher Learning in Malaysia

Mohd Noor Mohd Shariff \& Mohammad Basir Saud

The Change of Financial Environment and the Evolvement of Financial Goals

136

Jianhui Jian

An Investigation of Consumer Decision-Making Styles of Young-Adults in Malaysia

140

Safiek Mokhlis

Study on the Evaluation Criterions and Methods for the Supermarket Food Suppliers Based on IAHP

Xiaoping $L i$

Study on the Countermeasures for Developing China's International Logistics Industry

Dan Tan

Emotional Intelligence and Employee Performance as an Indicator for Promotion, a Study of Automobile Industry in the City of Belgaum, Karnataka, India

Praveen M.Kulkarni, B. Janakiram \& D.N.S. Kumar

The Quality of Learning Environment and Academic Performance from a Student's Perception

Rohana Kamaruddin, Nor Rashidah Zainal, Zaidi Mohd Aminuddin \& Kamaruzaman Jusoff

Research on Evaluation of Intensive Use of Agricultural Landunder the New Countryside Construction

Hongxia Xue

The Root Analysis and the Impact on China of Sub-loan Crisis

Lei Zhang \& Yuanyuan Yu

Analysis and Strategy of the Chinese Logistics Cost Reduction

Xiaofeng Zhao \& Qi Tang

Impact of Trade Liberalization and SAFTA on Pakistan's Economy by Using CGE Model

F.M.Shaikh \& M.Saleem Rahpoto 


\title{
The Mediating Effect of Empowerment in the Relationship
}

\section{between Transformational Leadership and Service Quality}

\author{
Azman Ismail (Corresponding author), Farida Abd Halim, Dayang Nailul Munna Abang Abdullah, Ahmad Sofian \\ Shminan, Agatha Lamentan Anak Muda \& Shairazi Samsudin \\ Faculty of Cognitive Sciences and Human Development, Universiti Malaysia Sarawak \\ Kota Samarahan 94300, Sarawak, Malaysia \\ Tel: 60-82-581-558_E-mail: iazman@fcs.unimas.my
}

Antonia Girardi

Murdoch Business School, Murdoch University

South Street. Murdoch. Western Australia 6150, Australia

Tel: 61-08- 9360-6980Ｅ-mail: a.girardi@murdoch.edu.au

\begin{abstract}
Transformational leadership has two salient characteristics: intellectual stimulation and individualized consideration. Recent studies in this area reveal that the effect of such leadership characteristics on job performance is indirectly affected by empowerment. The nature of this relationship is interesting, but little is known about the mediating effect of empowerment in leadership management models. Therefore, this study was conducted to measure the effect of transformational leadership characteristics and empowerment on service quality by using 110 usable questionnaires gathered from employees working in a city based local authority (CBLAUTHORITY) in Sarawak, Malaysia. Outcomes of a stepwise regression analysis showed that the relationship between empowerment and selected transformational leadership characteristics (i.e. intellectual stimulation and individualized consideration) is positively and significantly correlated with service quality. The result confirms that empowerment does act as a full mediating variable in the leadership model of the organization under study. This paper also discusses implications and limitations, as well as directions for future research.
\end{abstract}

Keywords: Transformational leadership, Empowerment, Service quality

\section{Introduction}

In the early development of human resource literature, the internal properties of organizational leadership were given much attention (Spreitzer, 1995; Yammarino \& Dubinsky, 1994). Many scholars, such as Bass (1988; 1990), Bass and Avolio (1993), Hartog, Muijen and Koopman (1997), discuss transactional leadership and transformational leadership as two salient organizational leadership styles that affect organizational effectiveness. Transactional leadership believes that an exchange of commodities (e.g., rewards) between leaders and followers is an important instrument to achieve job targets (Howell \& Avolio, 1993; Pounder, 2002). In this exchange process, leaders often promise to fulfill followers' needs (e.g. wages, promotion) if they comply with their wishes (Bass, 1990, 1994, Jabnoun \& AL-Rasasi, 2005). In this era of global competition, many organizations have shifted their management style paradigms from transactional to transformational in order to achieve their strategies and goals (Bass, 1990, 1994; Howell \& Avolio, 1993; Humphrey, 2002). Transformational leadership believes that relationships between leaders and followers must focus on developing the followers' full potentials, higher needs, good value systems, moralities and motivation. If this development is properly done this may motivate followers to unite, change goals and beliefs (Bass, 1990, 1994; Bycio, Hacket \& Allen, 1995), and look forward beyond fulfilling their self interests (Hartog et al., 1997; Keller, 1995).

Existing research in this area shows that the ability of leaders to properly implement transformational styles may have significant impact on service quality (Humphreys, 2002, Pounder, 2002). Several scholars, such as Bass and Avolio (1994), Jabnoun and AL Rasasi (2005), identify intellectual stimulation and individualized consideration as the most salient transformational leadership characteristics. Intellectual stimulation is often seen as the extent to which a leader 
encourages followers to exhibit intelligent, rational, logical and careful problem solving behaviors in organizations (Dionne, Yammarino, Atwater and Spangler, 2003). This approach is frequently implemented through stimulating followers to re-examine traditional ways of doing things, and encourage them to try novel and creative approaches (Bass \& Avolio, 1994; Yammarino \& Dubinsky, 1994). Individualized consideration is the extent to which leaders care about their followers' concerns and developmental needs. This concept encourages leaders to develop followers' potentials through proper coaching and mentoring, continuous feedback thus linking followers' needs to organizational strategies and goals (Bass \& Avolio, 1994; Avolio, Zhu, Koh \& Bhatia, 2004).

Many quality management scholars, such as Parasuraman, Zeithmal and Berry (1985), Parasuraman, Zeithmal and Berry (1988), Jabnoun and Al Rasasi (2005) and Jun, Peterson and Zsidisin (1988) interpret service quality as a multidimensional concept where it is often related to delivering products that meet five generic quality features: reliability, responsiveness, tangibility, assurance and empathy. Reliability is often associated with the willingness of a service provider to perform the service dependably and accurately. Responsiveness is usually seen as the willingness of a service provider to be helpful and punctual in providing services. Tangibility is referred to the physical appearance of service facilities, equipments, staff and communication materials. Assurance is viewed as a service provider's knowledge, courtesy and ability in conveying trust and confidence. Empathy is often related to the readiness of a service provider to increase the level of care and individual attention when dealing with customers. Within a transformational leadership framework, the ability of leaders to properly stimulate followers' intellect and to develop their potentials in performing duties and responsibilities (Bass, 1994; Bass \& Avolio, 1994; Avolio et al., 2004) may directly increase the quality of service deliveries, such as customers' satisfaction and retention (Spreng, MacKenzie \& Olshavasky, 1996; Rust \& Olivier, 1994) therefore eliminating complaints and continuing relationships with customers (Jabnoun \& AL Rasasi, 2005; Pounder, 2002).

A thorough review of such relationships reveals that the effect of transformational leadership characteristics on service quality is indirectly affected by empowerment (Bartram \& Casimir, 2007; Klidas, van den Berg \& Wilderom, 2007). Empowerment is often seen as a proactive and strategic management practice that exist in an organization to promote high commitment HR practices (Menon, 2001; Spreitzer, 1995) and refers to the willingness of leaders to delegate power and responsibility of making decisions to their followers in managing organizational functions (Bowen \& Lawler, 1992; Honold, 1997; Sternberg, 1992; Lashley, 1999). In a transformational leadership context, many scholars such as Bartram and Casimir (2007), and Klidas, van den Berg and Wilderom (2007) opined that intellectual stimulation, individualized consideration, empowerment and service quality are distinct but highly interrelated constructs. For example, leaders who stimulate employees' intellect and develop their potentials will enable employees practice empowerment in their jobs therefore leading to an increased service quality in organizations. The nature of this relationship is interesting but little is known about the mediating role of empowerment in transformational leadership models (Bartram \& Casimir, 2007; Klidas et al., 2007; Ismail, Samsudin \& Ibrahim, 2008).

Many scholars reveal that previous studies in the field of leadership emphasized more on the internal properties of transformational leadership (e.g., conceptual debate) but the importance of human psychological factors such as empowerment in influencing the effect of transformational leadership on service quality have been less emphasized (Bartram \& Casimir, 2007; Klidas et al., 2007). In addition, past research have relied very much on segmented research approaches less emphasizing multidisciplinary research approaches in developing organizational leadership models. These conditions fail to capture the dynamic nature of transformational leadership development therefore decreasing the abilities of past research findings to explain how and why transformational leadership styles affect service quality through empowerment in dynamic organizations (Bass \& Avolio, 1993; Bycio, Hacket \& Allen, 1995; Ismail et al., 2008). With this in mind, this study was primarily conducted to examine the effect of transformational leadership characteristics (i.e., intellectual stimulation and individualized consideration) and empowerment on service quality that occurs in one city based local authority (CBLAUTHORITY) in Sarawak, Malaysia. For confidential reasons, the name of the organization is kept anonymous.

\section{Context of the study}

CBLAUTHORITY is a state owned agency that has been established to realize the organization's vision of maintaining an attractive, clean and safe city. Aligned with this vision is the organizational mission that emphasizes on continually improving the delivery of services for enhancing the quality of life of its community. The researchers conducted in-depth interviews with four experienced employees to understand the role of leadership in achieving the organization's mission and vision. The information gathered from the interview reveals that staff of the organization can be divided into two major categories: management employees and supporting employees. Management employees are leaders (i.e. department heads, assistant department heads and supervisors) who are given duties and responsibilities to plan, organize, lead and monitor employees' jobs in the organization. Supporting employees are followers (e.g., general administration assistants, personal assistants to department heads and technicians) who are hired to assist their bosses in achieving the organizational and job targets. At the departmental levels, management employees often use policies and 
procedures set up by the stakeholders (i.e., senior management team, board of directors, government and a central government agency) as guidelines to ensure integrity and accountability in implementing management functions, such as general service, human resource, finance, and technical activities.

These guidelines provide limited authority to management employees in designing broad policies and procedures but they are given opportunities to stimulate followers' intellect and develop their potentials in achieving organizational and job targets. For example, management employees promote intellectual stimulation through encouraging followers to think and try new ways in completing tasks (e.g., human resource information system, internet, automations and machineries), asking followers' opinions in making decisions (e.g., enforcing rules and regulations), and motivating followers to use their capabilities in doing challenging works (e.g., applying knowledge, skills and attitudes gained from training programs). Besides that, management employees emphasize individualized consideration by conducting one-on-one conversation about the progress of work (e.g., teamwork), assist followers to complete work when needed (e.g., physical facilities and work schedules) and appreciating the strengths and weaknesses of each follower (e.g., skill based courses). If management employees can properly implement such transformational styles this will increase the followers' empowerments in planning and performing their jobs. Consequently, it may lead to an increased service quality (e.g., followers care 24-hours tele-service to receive reports from customers, courtesy when dealing with the customers, take action for minor complaints received within 24 hours, and perform action for major complaints received within three days).

\section{Literature review}

The mediating role of empowerment in the leadership management model of the CBLAUTHORITY is consistent with transformational leadership studies conducted in Western and Eastern organizational settings. For example, Jabnoun and AL Rasasi (2005) had conducted a study on transformational leadership in six UAE hospitals. This study found that intellectual stimulation and individualized consideration had increased service quality in these organizations. Bartram \& Casimir (2007) examined transformational leadership constructs based on a sample of 150 customer service operators in an Australian call-centre. This study found that the abilities of leaders to properly implement intellectual stimulation and individualized consideration have increased employees' empowerments in performing their jobs. As a result, it could lead to higher service quality. Further, Klidas, van den Berg and Wilderom (2007) surveyed the role of empowerment with 356 frontline employees of 16 luxury hotels in European countries. The study found that properly implemented intellectual stimulation and individualized consideration had increased followers' empowerment in delivering services. As a result, it could lead to higher service quality in the organization.

The leadership research literature gained strong support from the notion of leadership theories, namely Burns' (1978) transformational leadership theory and Bass's (1985) transformational leadership theory. Specifically, Burns' (1978) transformational leadership theory highlights that mutual understanding between leaders and followers when managing organizational functions may increase their moralities. Besides that, Bass's (1985) transformational leadership theory posits that the interaction between leaders and followers in managing organizational functions can inspire followers to go beyond their self-interests in supporting the organization's interests. Application of these theories in an organizational leadership framework show that followers' moralities and concern about organizational interests can be developed if leaders stimulate their followers' intellect and develop their potentials in managing organizational functions (Bass, 1990, 1994; Bycio et al., 1995; Dionne et al., 2003; Hartog et al., 1997). When such leadership styles are properly implemented this will increase followers' empowerments to perform job better because they believe that they can use their creativities and innovations to achieve difficult goals (Lashley, 1999; Locke \& Latham, 1991; Pounder, 2002; Waldman, 1993). As a result, it may lead to improved service quality in organizations (Bartram \& Casimir, 2007; Klidas et al., 2007).

Supporting literature was used as foundation to develop a conceptual framework for this study (Figure 1).

Based on this framework, it seems reasonable to assume that a high degree of empowerment in performing a job will influence CBLAUTHORITY employees just as this practice had influenced Western and Eastern employees. Transformational leadership theories suggest that if CBLAUTHORITY employees have high empowerment opportunities in performing their jobs, this may lead to higher service quality. Therefore, it was hypothesized that:

H1: Empowerment mediates the effect of intellectual stimulation on service quality.

H2: Empowerment mediates the effect of individualized consideration on service quality.

\section{Methodology}

This study used a cross-sectional research design that allowed the researchers to integrate training management literature, in-depth interviews, a pilot study and the actual survey as main procedures to gather data. The use of such methods may gather accurate and less biased data (Cresswell, 1998; Sekaran, 2000). This study was conducted at a city based local authority (CBLAUTHORITY) in Sarawak, Malaysia. At the initial stage of this study, in-depth interviews were conducted involving four experienced employees, namely HR manager, training executive and two experienced 
supporting staff in the Human Resource Department of the organization. Information gathered from the interviews was used to develop the content of a pilot survey questionnaire. Next, a pilot study was done by discussing the survey questionnaire with the participants to further understand leadership styles, empowerment characteristics, service quality characteristics and the relationship of such variables in the organization under study. This information was used to verify the content and format of survey questionnaires for the actual study.

The survey questionnaire has 4 sections. First, the intellectual stimulation section had 10 items and individualized consideration section had 10 items that were modified from the multi factor leadership questionnaires (Bass, 1990, 1994; Bycio et al., 1995; Dionne et al., 2003; Hartog et al., 1997). The items used to measure intellectual stimulation were: (1) provides me with assistance in exchange for my efforts, (2) re-examines critical assumptions to questions whether they are appropriate, (3) encourage me to seek different perspective when solving problems, (4) goes beyond self-interest for the good of the group, (5) considers the moral and ethical consequences of decisions I make regarding my work, (6) gets me to look at problems from many different angles. (7) suggest new ways of looking at how to complete an assignment, (8) encourage me to do more than I expected to do, (9) effective in representing me to higher authority, and (10) increase my willingness to try harder. The items used to measure individualized consideration were: (1) talk optimistically about the future, (2) instill pride in me for being associated with him/her, (3) talks enthusiastically about what needs to be accomplished, (4) specifies the importance of having strong sense of purpose, (5) spends time teaching and coaching, (6) treats me as individual rather than just as a member of a group, (7) articullate compelling vission of the future, (8) considers me as having different needs, abilities, and aspirations from others, (9) helps me to develop my strength, and (10) heightens my desire to succed.

Second, empowerment was measured by using 7 items modified from the service management literature (Klidas et al., 2007). The items used to measure this variable were: (1) confident in my ability to do my work, (2) the work that I do is important to me, (3) come up with creative ways to please customers, (4) the support and authority to make the decisions necessary for accomplishing assigned task, (5) take initiatives beyond what is expected of me in order to please the customer, (6) rely on my own judgement to make most of the decisions required in my job, and (7) enough involvement in decisions that affect my work.

Finally, service quality was measured by using 12 items modified from the SERVQUAL questionnaire (Parasuraman et al., 1985, 1988). The items used to measure this variable were: (1) provide services based on the organization's policies, (2) show a sincere interest in helping customers when they are having a problem, (3) deliver my service correctly at any time, (4) inform the customers when services will be performed, (5) give prompt services to the customers, (6) never be too busy to respond to customers' request, (7) the appropriate knowledge to answer customers' questions, (8) be consistently courteous to the customers, ( 9 instill confidence in the customers when providing services, (10) give personal attention to the customers when I provide services, (11) understand the needs of the customers, and (12) the customers' best interest at heart. All items used in the questionnaires were measured using a 7-item scale ranging from "strongly disagree" (1) to "strongly agree" (7).

Demographic variables were used as controlling variables because this study focused on employees' attitudes. The back translation technique was used to translate the survey questionnaires in Malay and English and this may help to increase the validity and reliability of the instrument (Van Maanen, 1983; Wright, 1996).

The targeted population of this study was employees of the CBLAUTHORITY. This organization has 1,007 officers employed with 35 professional full time staff, 696 support staff and 276 daily paid workers. In this study, a convenience sampling technique was used to gather data from employees in the organization. This sampling technique was used because the researchers were not given the list of registered employees due to confidentiality reasons. The researchers were not allowed to personally distribute survey questionnaire to employees who work in different departments. They were asked to give survey questionnaires to the HR manager, assistant HR managers and/or supervisors who later redistributed the survey instruments to employees. These constraints restricted the researchers in using random sampling techniques to choose participants for this study. Consequently, 260 survey questionnaires were distributed to employees through the contact persons. Of this number, 110 usable questionnaires were only returned to the researchers yielding a response rate of 42.31 percent. The survey questionnaires were answered by participants based on consent and voluntary basis. The number of sample exceeded the minimum sample of 30 respondents as required by probability sampling technique. Thus, the data collected can be analyzed using inferential statistics (Leedy \& Ormrod, 2005; Sekaran, 2000).

\section{Result}

Table 1 shows the sample profile of this study. The majority of respondents were females (56.4 percent) rather than males (43.6 percent), with ages above 40 years old (30.9 percent), were Malays ( 67.3 percent), possessing the Malaysia Certificate of Education (55.5 percent), and have worked more than 10 years (58.2 percent). 
Table 2 shows the results of the validity and reliability analyses for measurement scales. Factor analysis with direct oblimin rotation was done for four variables with 39 items, which were related to four variables namely intellectual stimulation (10 items), individualized consideration (10 items), empowerment ( 7 items), and quality service (12 items). Next, the Kaiser-Mayer-Olkin Test (KMO), which is a measure of sampling adequacy, was conducted for each variable and the results indicated that it was acceptable. Specifically, the results of these statistical analyses showed that (1) all research variables exceeded the minimum standard of Kaiser-Meyer-Olkin's value of 0.6 and were significant in the Bartlett's test of sphericity, (2) all research variables had eigenvalues greater than 1, (3) the items for each research variable exceeded factor loadings of 0.40 (Hair, Anderson, Tatham \& Black, 1998), and (4) all research variables exceeded the acceptable standard of reliability analysis of 0.70 (Nunally \& Bernstein, 1994). These statistical results confirmed the validity and reliability of measurement scales used for this study.

Table 3 shows the results of the Pearson correlation analysis and descriptive statistics. The means for the variables are from 5.24 to 5.91, signifying that the level of intellectual stimulation, individualized consideration, empowerment and service quality ranges from high (5.24) to highest (5.91). The correlation coefficients for the relationship between the independent variable (i.e., intellectual stimulation and individualized consideration), the mediating variable (i.e., empowerment), and the dependent variable (i.e. service quality) were less than 0.90 , indicating that the data wase not affected by serious collinearity problem (Hair et al., 1998).

Stepwise regression analysis was then undertaken to test the mediating hypothesis because it can assess the magnitude of each independent variable. This analysis can vary the relationship of the mediating variable between many independent variables and one dependent variable (Baron \& Kenny, 1986; Foster, Stine \& Waterman, 1998). According to Baron and Kenny (1986), the mediating variable can be considered when it meets three conditions. First, the predictor variables are significantly correlated with the hypothesized mediator. Second, the predictor and mediator variables are all significantly correlated with the dependent variable. Third, a previously significant effect of the predictor variables is reduced to non-significance or reduced in terms of effect size after the inclusion of mediator variables into the analysis (Wong, Hui \& Law, 1995). In this regression analysis, standardized coefficients (standardized beta) were used for all analyses (Jaccard, Turrisi \& Wan, 1990).

Table 4 shows the inclusion of empowerment in Step 3 of the process revealing that the relationship between empowerment and selected transformational leadership characteristic (i.e., intellectual stimulation and individualized consideration) is significantly correlated with service quality $(\beta=.63, \mathrm{p}=0.000)$. Therefore $\mathrm{H} 1$ and $\mathrm{H} 2$ were fully supported. This result demonstrates that before the inclusion of empowerment into Step 2, intellectual stimulation was found to be not significantly correlated with service quality $(\beta=.02, \mathrm{p}=0.892)$, while individualized consideration was found to be significantly correlated with service quality $(\beta=.48, \mathrm{p}=0.001)$. As shown in Step 3 (after the inclusion of empowerment into the analysis), the previous insignificant relationship between intellectual stimulation and service quality remained insignificant $(\beta=.04, p=0.72)$ while the previous significant relationship between individualized consideration and service quality changed to insignificant $(\beta=.11, p=.34)$. This implies that the inclusion of empowerment in Step 3 had explained 75 percent of the variance in the dependent variable. Therefore this result meets the requirements of Baron and Kenny (1986), and Wong, Hui and Law's (1995) mediating model testing which states that a previously significant effect of predictor variables (i.e., transformational leadership characteristics) is reduced to non-significance or reduced in terms of effect size after the inclusion of mediator variables (i.e., empowerment) into the analysis. Thus, the result of this study confirms that empowerment does act as a full mediating variable in the relationship between the transformational leadership characteristics and service quality in the organizational sample.

\section{Discussion, Implications, limitations and Directions for Future Research}

This study confirms that the effect of intellectual stimulation and individualized consideration on service quality is indirectly affected by empowerment in this organization. In CBLAUTHORITY, leaders have actively stimulated followers' intellectuals and potentials in implementing management functions. The majority of employees perceive that such leadership styles had increased their empowerment in planning and implementing their jobs. When employees perceive that their degree of empowerment is high, this may motivate them to increase service quality.

The implications of this study can be divided into three major aspects: theoretical contribution, robustness of research methodology, and contribution to practitioners. In term of theoretical contribution, this study revealed that empowerment does mediate the relationship between selected leadership features (i.e., intellectual stimulation and individualized consideration) and service quality. This outcome is consistent with studies by Bartram \& Casimir (2007), and Klidas, van den Berg \& Wilderom (2007). Therefore the findings of this study have supported and broadened leadership research literature mainly published in Western and Eastern organizational settings. Thus, the notion of empowerment has been successfully applied within the leadership management models of the organization under study. With respect to the robustness of research methodology, the data gathered using leadership management literature, in-depth interviews, pilot study and survey questionnaires have exceeded acceptable standards of validity and reliability analysis leading to accurate and reliable findings. 
The results of this study can be used as a guide by organizations' management to upgrade the effectiveness of leadership styles in their respective organizations. This objective might be achieved if the management consider the following suggestions. First, leadership styles will be sharpened if employees are continuously trained with updated date knowledge, relevant skills and universal moral values. These training programs can help to improve leaders when handling the needs and demands of employees from different socio-economic backgrounds. Secondly, participative leadership styles can be meaningful if followers are allowed to be involved in decision making. This might motivate employees to perceive that their contributions are appreciated therefore motivating them to use their own creativity and innovations in performing jobs. Finally, interactions between followers and leaders will increase positive subsequent personal outcomes (e.g., satisfaction, commitment, performance and ethics). If employers were to consider these suggestions, this may positively motivate followers and leaders to support organizational strategies and goals.

The conclusion drawn from the results of this study should consider the following limitations. First, the data was only taken one time during the duration of this study. Therefore, it did not capture the developmental issues such as personal development changes of individuals, restrictions of making inferences to participants and causal connections between variables of interest. Second, this study only examines the relationship between latent variables and the conclusion drawn from this study does not specify the relationship between specific indicators for the dependent variable, mediating variable and dependent variable. Third, this study only focused on particular elements of a leadership style and neglected other important factors (e.g., communication, encouragement, and contingent reward plan). Fourth, other transformational leadership outcomes (e.g., job satisfaction, job performance, job commitment, and job turnover) that are significant for organizations and employees are not discussed in this study. Fifth, although a substantial amount of variance in dependent measures explained by the significant predictors is identified, there are still a number of unexplainable factors that can be incorporated to identify the causal relationship among variables and their relative explanatory power (Tabachnick \& Fidell, 2001). Sixth, the respondents of this study were selected using a convenient sampling technique and their opinions might be influenced by several factors in terms of integrity, loyalty and willingness to answer questions truthfully. This might affect the ability to collect reliable data that represents the organization's environment. Finally, the sample for this study was taken from one organization that allowed the researchers to gather data via survey questionnaires. These limitations may decrease the ability of generalizing the results of this study to other organizational settings.

The conceptual and methodology limitations of this study need to be considered when designing future research. First, the organizational and personal characteristics as potential variables that can influence the effectiveness of leadership styles needs to be further explored. If organizational (e.g., division and ownership) and personal characteristics (e.g., gender, age, position, length of service, education level and position) are used, this may provide meaningful perspectives for understanding individual differences and similarities that affect leadership outcomes. Second, as suggested by prominent scholars, other important elements of leadership style such as communication, encouragement, and contingent reward plan to be added in a future study may represent the effectiveness of leadership roles in an organization (Avolio, Bass \& Jung, 1999; Bass \& Avolio, 1993, 1994; Casimir, Waldman, Bartram \& Yang, 2006; Dionne et al., 2003). Third, the weaknesses of cross-sectional research design may be overcome if longitudinal studies are used to collect data describing the patterns of change and the directions and magnitudes of causal relationships between variables of interest. Third, the findings of this study may produce different results if this study is done in other organizational sectors (e.g., manufacturing and construction companies). Finally, as an extension of this study, other theoretical construct such as trust in leaders needs to be considered in future research because it has been recognized as a link between the transformational leadership and performance outcome (Avolio et al., 2004; Bartram \& Casimir, 2007; Dionne et al., 2003; Moye \& Henkin, 2006; Politis, 2002). The importance of these issues needs to be further explored in future research.

\section{Conclusion}

This study confirms that empowerment does act as a full mediator in the relationship between intellectual stimulation, individualized consideration and service quality. This result had supported and extended leadership research literature mostly published in Western and Eastern organizational settings. Therefore, current research and practices within transformational leadership models needs to consider empowerment as a crucial aspect of organizational leadership styles where increasing followers' empowerments in planning and implementing their jobs may strongly induce positive subsequent personal outcomes (e.g., competency, performance, satisfaction, commitment, trust, and positive moral values). Therefore, these positive outcomes may motivate employees to sustain and support organizational strategy and goals.

\section{References}

Avolio, B.J., Bass, B.M., \& Jung, D.I. (1999). Re-examining the components of transformational and transactional leadership using the multifactor leadership questionnaire. Journal of Occupational and Organizational Psychology, 72 (4), 441-462. 
Baron, R.M \& Kenny, D.A (1986). This moderator-mediator variable distinction in social psychological research: Conceptual, strategic, and statistical considerations. Journal of Personality and Social Psychology, 51 (6), $1173-1182$.

Bartram, T. \& Casimir, G. (2007). The relationship between leadership and follower in-role performance and satisfaction with the leaders: The mediating effects of empowerment and trust in the leader. Leadership \& Organization Development Journal, 28 (1), 4-19.

Bass, B.M. (1985). Leadership and performance beyond expectations. Free Press New York. NY.

Bass, B.M. (1988). The inspirational process of leadership. Journal of Management Development, 7, 21-31.

Bass, B.M. (1990). Bass and Stogdill's handbook of leadership: theory research and managerial applications. 3rd ed. Free Press New York. NY.

Bass, B.M. (1994). Transformational leadership and team and organizational decision making. Sage Thousand Oaks. CA.

Bass, B.M., \& Avolio, B. (1993). Transformational leadership and organizational culture. Public Administration Quarterly, 17, 112-21.

Bass, B.M., \& Avolio, B. (1994). Improving organizational effectiveness through transformational leadership. Sage Thousand Oaks. CA.

Bowen, D.E., \& Lawler, E.E. (1992), The empowerment of service workers: What, why, how, and when. Sloan Management Review, 33 (3), 31-9.

Burns, J. (1978). Leadership. Harper \& Row New York. NY.

Bycio, P., Hacket, R.D. \& Allen, J.S. (1995). Further assessment of Bass's (1985) conceptualization of transactional and transformational leadership. Journal of Applied Psychology. 80, 468-478.

Casimir, G., Waldman, D., Bartram, T., \& Yang, S. (2006). Trust and the relationship between leadership and follower performance: Opening the black box in Australia and China. Journal of Leadership and Organizational Studies, 12, 72-88.

Cresswell, J.W. (1998). Qualitative inquiry and research design: choosing among five traditions. SAGE publications. London.

Dionne S.D., Yammarino F.J, Atwater L.E. \& Spangler W.D. (2003). Transformational leadership and team performance. Journal of Organizational Change Management, 17 (2), 177-193.

Foster, D.P., Stine, B., \& Waterman, R. (1998). Business analysis using regression: A casebook. Springer-Verlag.

Hair, J.F., Anderson, R.E., Tatham, R.L., \& Black, W.C. (1998). Multivariate data analysis. Prentice Hall International Inc. New Jersey.

Hartog, D.N.D., Muijen J.J. \& Koopman V. (1997). Transactional vs. transformational leadership: An analysis of the MLQ. Journal of Occupational and Organizational Psychology, 70: 19-34.

Honold, L. (1997). A review of the literature on employee empowerment. Empowerment in Organizations, 5 (4), 202-212.

Howell, J.M., \& Avolio, B.J. (1993). Transformational leadership, transactional leadership, locus of control and support for innovation: Key predictors of consolidated-business unit performance. Journal of Service Marketing, 16, $487-502$.

Humphreys, J. H. (2002) Transformational leader behaviour, proximity and successful service marketing. Journal of Service Marketing, 16 (6), 487-502.

Ismail, A., Samsudin, S., \& Ibrahim, Z. (2008). Selected transformational leadership characteristics and service quality: The mediating role of empowerment, the Proceeding of Trengganu International Business and Economic Conference (TiBEC08), 26-28 November, UiTM, Malaysia.

Jabnoun, N., \& AL Rasasi, A.J. (2005). Transformational leadership and service quality in UAE hospitals. Managing Service Quality, 15 (1), 70-81.

Jaccard, J., Turrisi, R. \& Wan, C.K (1990). Interaction effects in multiple regression, 72. SAGE Publications Inc. Newsbury Park California.

Jun, M., Peterson, R.T. \& Zsidisin, G.A. (1998). The identification and measurement of quality dimensions in the health care: focus group interview results. Health Care Management Review, 23 (4), 81-96.

Keller, R.T. (1995). Transformational leaders make a difference. Research Technology Management, 38 (3), $41-44$.

Klidas, A., van den Berg, P.T. \& Wilderom, C.P.M. (2007). Managing employee empowerment in luxury hotels in Europe. International Journal of Service Industry Management, 18 (1), 70-88. 
Lashley, C. (1999). Employee empowerment in services: A framework for analysis. Personnel Review, 28 (3), 169-191. Leedy, P.D. \& Ormrod, J.E. (2005). Practical research: Planning and design. Pearson Education Ltd.

Locke, E. A. \& Latham, G. P. (1990). A theory of goal setting and task performance. Englewood Cliffs. Prentice Hall. NJ.

Menon, S.T. (2001). Employee empowerment: an integrative psychological approach. Applied Psychology: An International Review, 50 (1), 153-80.

Moye, J., \& Henkin, B. (2006). Exploring associations between employee empowerment and interpersonal trust in managers. Journal of Management Development, 25, 101-117.

Nunally, J.C., \& Bernstein, I.H. (1994). Psychometric theory. New York:McGraw-Hill.

Parasuraman, A., Zeithmal, V.A. \& Berry L.L. (1988). SERVQUAL: A multiple-item scale for measuring consumer perceptions of service quality. Journal of Retailing, 64, 12-40.

Parasuraman, A., Zeithmal, V.A., \& Berry, L.L. (1985). A conceptual model of service quality and its implications for future research. Journal of Marketing, 49, 41-50.

Politis, J.D. (2002). Transformational leadership and transactional leadership enabling (disabling) knowledge acquisition of self-managed teams: The consequences for performance. Leadership and Organization Development Journal, 186-197.

Pounder, J. S. (2002). Employing transformational leadership to enhance the quality of management development instruction. Journal of Management Development, 22 (1), 6-13.

Rust, R.T., \& Oliver, R.L. (1994). Service quality: New directions in theory and practice. Sage: London.

Samsudin, S. (2008). Selected transformational leadership characteristics and service quality: A mediating role of empowerment. Unpublished Final Year Project Report. Universiti Malaysia Sarawak, Malaysia.

Sekaran, U. (2000). Research methods for business: A skill building approach. John Wiley \& Sins Inc. NY.

Spreitzer, G. (1995). Psychological empowerment in the workplace:Dimensions, measurement and validation. Academy of Management Journal, 38 (5), 1442-65.

Spreng, R.A., MacKenzie S.B. \& Olshavasky R.W. (1996). A re-examination of the determinants of consumer satisfaction. Journal of Marketing, 60, 15-32.

Sternberg, L.E. (1992). Empowerment: trust vs control. Cornell Hotel and Restaurant Administration Quarterly, 33 (1), 69-72.

Tabachnick, B.G., \& Fidell, L.S. (2001). Using multivariate statistics. Sydney: Allyn \& Bacon.

Vaan Maanen, J. (1983). Qualitative methodology. Sage Publications. Baverly Hills CA.

Waldman, D.A. (1993). A theoretical consideration for leadership and total quality management. Leadership Quarterly, 4 (1), 65-79.

Wong, C., Hui, C. \& Law, K.S. (1995). Causal relationships between attitudinal antecedents to turnover. Academy of Management Journal, 342-346.

Wright, I.L. (1996). Qualitative international management research. In B.J. Punnett, \& O. Shenker (Eds.), Handbook for international management research. BlackWell Publishers Inc. UK.

Yammarino, F.J., \& Dubinsky, A.J. (1994). Transformational leadership theory: using levels of analysis to determine boundary conditions. Personnel Psychology, 47, 787-811.

Table 1. Participants' characteristics $(\mathrm{N}=110)$

\begin{tabular}{|c|c|c|c|c|}
\hline Gender $(\%)$ & $\underline{\text { Race }(\%)}$ & Age (\%) & \multirow{3}{*}{$\begin{array}{l}\text { Education (\%) } \\
\text { SPM/MCE/Senior } \\
\text { Cambridge }=55.5\end{array}$} & Length of Service (\%) \\
\hline Male 43.6 & Malay $=67.3$ & $18-20=0.9$ & & $<1$ year \\
\hline \multirow[t]{5}{*}{ Female $=56.4$} & Chinese $=5.5$ & $21-25=17.3$ & & $1-3$ years $=20.9$ \\
\hline & Indian=0.9 & $26-30=11.8$ & $\mathrm{STPM} / \mathrm{HSC}=10.0$ & $4-6$ years $=6.4$ \\
\hline & Native $=23.6$ & $31-35=13.6$ & Diploma & $7-9$ years $=7.3$ \\
\hline & Others $=2.7$ & $36-40=25.5$ & Degree & $>10$ years $=58.2$ \\
\hline & & $>40=30.9$ & Others & \\
\hline
\end{tabular}

Note:

SPM/MCE/Senior Cambridge: Sijil Pelajaran Malaysia/Malaysia Certificate of Education

STPM/HSC: Sijil Tinggi Pelajaran Malaysia/High School Certificate 
Table 2. Validity and reliability analyses for measurement scales

\begin{tabular}{|c|c|c|c|c|c|c|c|}
\hline Measure & Item & $\begin{array}{c}\text { Factor } \\
\text { Loadings }\end{array}$ & KMO & $\begin{array}{c}\text { Bartlett's } \\
\text { Test of } \\
\text { Sphericity }\end{array}$ & Eigenvalue & $\begin{array}{c}\text { Variance } \\
\text { Explained }\end{array}$ & $\begin{array}{c}\text { Cronbach } \\
\text { Alpha }\end{array}$ \\
\hline $\begin{array}{c}\text { Intellectual } \\
\text { Stimulation }\end{array}$ & 10 & 0.72 to 0.87 & 0.920 & $\begin{array}{c}1055.19, \\
\mathrm{p}=.000\end{array}$ & 7.28 & 72.64 & 0.96 \\
\hline $\begin{array}{l}\text { Individualized } \\
\text { Consideration }\end{array}$ & 10 & 0.43 to 0.654 & 0.934 & $\begin{array}{c}1201.24, \\
\mathrm{p}=.000\end{array}$ & 7.57 & 75.73 & 0.96 \\
\hline Empowerment & 7 & 0.47 to 0.72 & 0.846 & 505.05, & 4.36 & 62.31 & 0.89 \\
\hline Quality Service & 12 & 0.68 to 0.84 & 0.903 & $\begin{array}{c}1088.25, \\
\mathrm{p}=.000\end{array}$ & 7.66 & 63.84 & 0.95 \\
\hline
\end{tabular}

Table 3. Pearson correlation analysis and descriptive statistics

\begin{tabular}{|c|c|c|c|c|c|c|}
\hline \multirow{2}{*}{ Variables } & Min & Standard & \multicolumn{3}{|c|}{ Pearson Correlation (r) } \\
& & Deviation & & 2 & 3 \\
\cline { 4 - 6 } & & & 1 & $(1)$ & & \\
\hline 1.Intellectual Stimulation & 5.29 & 1.12 & $0.79 * *$ & $(1)$ & & \\
\hline 2.Individualized Consideration & 5.24 & 1.11 & $0.42^{* *}$ & $0.53^{* *}$ & $(1)$ & \\
\hline 3. Empowerment & 5.66 & 0.73 & $0.39^{* *}$ & $0.48^{* *}$ & $0.73^{* *}$ & $(1)$ \\
\hline 4. Service Quality & 5.91 & 0.81 & & \\
\hline
\end{tabular}

Note:

Correlation Value is significant at $* \mathrm{p}<0.05, * * \mathrm{p}<0.01, * * * \mathrm{p}<0.001$

Reliability estimation are shown diagonally (value 1)

Table 4. Outcomes of stepwise regression analysis

\begin{tabular}{|c|c|c|c|}
\hline \multirow[b]{2}{*}{ Variables } & \multicolumn{3}{|c|}{ Dependent Variable } \\
\hline & Step 1 & Step 2 & Step3 \\
\hline \multicolumn{4}{|l|}{ Control Variables } \\
\hline Gender & 0.01 & -0.04 & 0.03 \\
\hline Age & -0.10 & -0.17 & -0.12 \\
\hline Race & -0.23 & -0.21 & -0.12 \\
\hline Education Level & 0.18 & 0.10 & 0.08 \\
\hline Length of Service & 0.18 & 0.30 & 0.20 \\
\hline \multicolumn{4}{|l|}{ Independent Variables } \\
\hline Intellectual Stimulation & & 0.02 & 0.04 \\
\hline Individualized Consideration & & $0.48 * *$ & 0.11 \\
\hline \multicolumn{4}{|l|}{$\underline{\text { Mediating Variable }}$} \\
\hline Empowerment & & & $0.63 * * *$ \\
\hline$R$ Square & 0.27 & 0.55 & 0.75 \\
\hline Adjust R Square & 0.03 & 0.25 & 0.53 \\
\hline $\mathrm{R}$ square change & 0.07 & 0.22 & 0.27 \\
\hline $\mathrm{F}$ & 1.65 & $6.16^{* * *}$ & $16.50 * * *$ \\
\hline $\mathrm{F} \Delta \mathrm{R}$ Square & 1.65 & $16.22 * * *$ & $62.76 * * *$ \\
\hline
\end{tabular}

Note: ${ }^{*} \mathrm{p}<0.02,{ }^{*} \mathrm{p}<0.01, * * * \mathrm{p}<0.001$ 


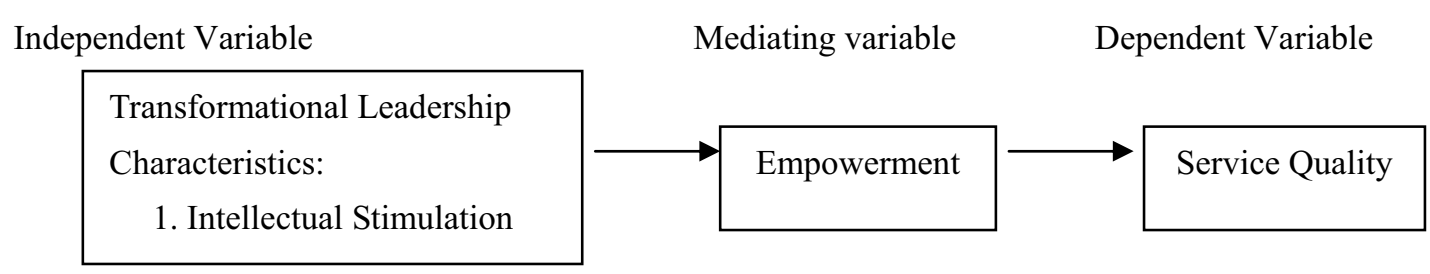

Figure 1. Empowerment Mediates the Effect of Transformational Leadership Characteristics on Service Quality 


\title{
Corporate Customers' Adoption of Internet Banking: Case of Klang Valley Business Firm in Malaysia
}

\author{
Syed Shah Alam (Corresponding author) \\ Faculty of Business Management, Universiti Teknologi MARA \\ 40450 Shah Alam, Selangor \\ Tel: 60-3- 5544- 4708 E-mail: syedshah@salam.uitm.edu.my \\ Rosidah Musa \\ Faculty of Business Management, Universiti Teknologi MARA \\ 40450 Shah Alam, Selangor \\ Tel: 60-3- 5544- 4715 E-mail: roshidahm@salam.uitm.edu.my \\ Faridah Hassan \\ Faculty of Business Management, Universiti Teknologi MARA \\ 40450 Shah Alam, Selangor \\ Tel: 60-3- 5544- 4760 E-mail: faridah387@salam.uitm.edu.my
}

\begin{abstract}
This paper summarizes academic literature on Internet banking drivers and found that there is a need to conduct research on corporate customer Internet banking adoption behaviour. The empirical data were collected from a questionnaire survey of 223 business firms selected from the telephone directory in Klang Valley area in Malaysia. This study examines the relationship between Internet banking adoption and its six factors, namely awareness, ease of use, security, cost, reluctance to change and accessibility. The results of this study show that four factors examined are significantly important to the adoption of Internet banking. However, perceive ease of use and reluctant to change are found to be insignificant in determining its adoption. This study provides insightful understanding of corporate customer's perception about Internet banking adoption in their banking transactions. Banks are interested in promoting online business may find these findings helpful in guiding their efforts.
\end{abstract}

Keywords: Internet banking, Corporate customers, Klang Valley, Malaysia

\section{Introduction}

Since the new millennium, Internet banking has experienced explosive growth in many countries and transformed traditional banking practice. Internet banking has changes the way of services provided by the banking sectors to their customers. By offering Internet banking services, traditional financial institutions seek to lower operating costs, improve customer banking services, retain customer, reduce their branch networks, and downsize the number of their service staff (Parisa, 2006).

Pang (1995) reported that the electronic banking started in Malaysia in 1970's. Automated Teller Machines (ATM) is the first electronic innovation used by the Malaysian banks in 1981. The ATMs to a large extent released banks from the constraints of time and geographical location. They presented banks with a more economical substitute for brick and mortar branches. Central Bank of Malaysia had given permission to the local bank to offer Internet banking services $1^{\text {st }}$ June 2000. On $15^{\text {th }}$ of June in 2000 Maybank, one of the pioneer bank in Malaysia offer Internet banking in Malaysia through its website www.maybank2u.com. The services provided to the consumers are banking enquiry functions, bill payment, credit card payment, fund transfers, account summary as well as on transaction history. Customer services are provided via e-mail as well as via telephone line are available from 6AM to 12 mid-nights. 
A review of the Malaysian banking sites in the Internet revealed that all domestic banks, which have been accorded an anchor bank status by the Central bank, have web presence. Almost all banks in Malaysia have web presence and yet to commence their Internet banking operations.

\section{Impact of Internet Banking on Customers}

Customers are expected to enjoy several benefits as a result of the implementation of Internet banking. Chan (2001) stated convenience as one of them. Johnson et al (1995) agrees that convenience is an important factor to customers. Devlin (1995) found that customers are now demanding greater conveniences and accessibility. This is reflected in longer branch banking hours and an increase in the choice of delivery mechanisms.

Baldock (1997) found that the implementation of Internet banking would remove the constraints of time, place and form. The reason is that transactions can be conducted from anywhere and anytime as long as they have access to a computer and connection to the Internet as banks would be "open" 24 hours a day and 7 days in a week (Chan, 2001; Johnson et al., 1995; Jeon and Rice, 1997; Baldock, 1997).

Birch and Young, (1997) asserted that consumers would also enjoy the privilege of access to far more providers of financial services. As a result of a wider choice of Internet bank service providers, the costs searching, negotiating and concluding deals will be lower as the comparison of products and services would be made easier over the Internet (Bakos, 1991; Malone et al., 1989, Peters, 1998). Information on pricing and returns is also far easier to gather (Birch and Young, 1997).

Chan (2001) also quoted that customers will be able to save of traveling to the branch and other intangible factors like avoiding the aggravation of traffic jams and long queues as the advantages of Internet banking. He also stated that with certain browsers, the "autofill" feature will help save time because frequently visited website addresses, login names and passwords need not be typed over and over again. Indeed Birch and Young (1997) highlighted, customers will be able to conduct their banking transactions at ease, because they would not be subjected to high-pressure sales tactics.

\section{Problem Statement}

This study focuses on the adoption of Internet banking services by corporate customers in Malaysia and aims to gain a deeper understanding of the factors influencing the adoption of Internet banking services by Malaysian, particularly in Klang Valley customers. The research question for this research can be formulated as:

What are main factors, which influence the adoption of Internet banking services?

In this context, the factors that affect the adoption rate of Internet banking which were considered in this study are listed as follows:

the awareness of the services and its benefits;

the ease of use;

the safety and security of transacting over the Internet ;

the cost of using Internet banking;

the reluctance to change from current traditional banking, and ;

the access to computer or Internet.

To this end, options were gathered from a broad base community in the Klang Valley paying particular attention to business customers of the banks. The Klang Valley is chosen as this is one of the most developed business and financial centre in the country. The focus of this research will be particularly to provide both bankers and policy makers with public opinion that could assist in the understanding and appreciation of the factors that affect the adoption of Internet banking in Malaysia, particularly in Klang Valley.

\section{Factors affecting the Internet Banking Adoption}

Sathye (1999) defines adoption as "the acceptance and continued use of a product, service or idea." The critical question is whether customers will accept the electronic form of receiving information and performing transactions. In the study of Ernst and Young (1998) found that financial institutions are not sure about customer acceptance of E-commerce and evidence shows that 3\% of Malaysian doing online retail transactions. Moreover, Mols et al. (1999) study reveals that the diffusion of electronic banking is more determined by customer's acceptance than by the seller offerings.

Davidson (1998) study found that there is little evidence of consumer demand for Internet banking services. Among the factors influencing the non-adoption of Internet banking by customers include the desire for personal interaction with banking staff, technology phobia, widespread network of existing branches and also low computer literacy among customers (Mols et al., 1999). O'Connell (1996) demonstrated that the explanation for slow growth of Internet banking is caused by security concerns, lack of knowledge about availability of such a service, Internet banking sites being not 
user-friendly and the lack of access to computers or the Internet. In this study six factors such as awareness, ease of use, safety and security, cost of Internet banking, reluctance and lack of computer or Internet access are focused. This is inline with Wallis (1997) whose report states that new technology adoption by the majority of the customers depends mainly on these factors.

\subsection{Awareness}

Adoption can be defined as the acceptance and continued use of a product, service or and idea. According to Rogers and Shoemaker (1971), consumers go through "a series of process in knowledge, conviction, decision and confirmation" before they are ready to adopt a new product or service. The adoption or rejection of an innovation begins when "the consumer becomes aware of the innovation" (Rogers and Shoemaker, 1971). Howard and Moore (1982) emphasized that adoption "consumers must become aware of new brand." Lack of awareness is the most important factor that negatively affect Internet banking adoption (Sathye, 1999). In this same context we are able to argue that if the average Malaysian consumers not adopting Internet banking services due to they unawareness of the availability of such a service and / or benefits it offers.

\subsection{Ease of Use}

Cooper (1997) identifies "ease of use" as on of the three important characteristics from customer's perspective for adoption of innovative service. Dover (1998) and Daniel (1999) studies in USA and UK respectively found that ease of use as one of the factors for customer acceptance electronic banking. In this same context, a study conducted by a company called Cyber Dialogue has revealed that as many as 3.1 million USA adults have discontinued their use of online banking because they found the service too complicated or were dissatisfied with the level of customer service. Katz and Aspden (1997), Walis (1997) and Mols (2000) suggested that it is crucial for the Internet to be easy to use to increase the adoption rate Internet banking. Scarbrough and Corbett (1992) identified the understanding of consumers as an important element for the diffusion of innovation technology.

For successful implementation of Internet banking, banks must ensure that the services are simple, easy and of sufficiently high quality to ensure customer satisfaction in order to maintain online customers.

\subsection{Security}

Security is one of the very important factors in determining the decision of consumers to use Internet banking. In a study ABF (1997) found that security concerns are keeping both consumers and bankers away from Internet banking. The Walls report (1997) also reported that unless security is improved, more households would be willing to conduct their transactions over the Internet. O'Connel (1997) conducted study in Australia found that security concerns were discovered as the main cause for the slow growth of Internet banking in the country. Polatoglu and Ekin (2001) established risk in terms of financial, physical and social characteristics. In USA, Thorton Consulting (1996) which conducted a survey focusing on banks concluded that 67 percent of US banks feel that "security concerns" is the major barriers for Internet banking. The same results obtained from the study of Booz et al. (1997), reveals that security concern among customers was the top-ranking obstacle for non-adoption of Internet banking in Latin America.

\subsection{Cost}

Price/costs is one of the single most important factor that influences the consumer adoption of innovation. Suganthy et al (2001) found that cost as a characteristics of Internet banking. Two types of costs are involved in the Internet banking, i.e. normal costs associated with Internet activities and second is the bank charge and cost (Sathye, 1999). If consumers are to use new technologies, the technologies must be reasonably priced relative to alternatives (Willis Report, 1997). Otherwise, the acceptance of the new technology may not be viable from the standpoint of the consumer. Virtual Society Project researcher (Buzz, 2000), point out that millions of users are now turning their backs on the Internet due to its limitations and high access charges.

\subsection{Reluctance to change}

Quinn and Mueller (1982) found that human beings try to resist change, especially towards technological innovations. According to Daniel (1999) also stated that there is a high level of customer inertia in changing their established banking arrangements. Sathye (1999) emphasized that customers, particularly the senior citizens, prefer personal interaction and that they have technology phobia. In Malaysia also at the same, bank customers till patronize bank branches and they remain to value personal interactions (Guru et al., 2000).

\subsection{Accessibility}

Finally, availability of access to computers/Internet is a prerequisite for adoption of Internet banking (Sathye, 1999). The more widespread the access to computer/Internet the greater the possibility of use of Internet banking adoption. O, Connell (1996) study found that lack of access to computers as one of the reason for slow adoption of Internet banking. Daniel (1999) study in UK reveals that lack of customer access to suitable PCs as the main reason for low usage of electronic banking. In the same view Ramsay and Smith (1999) found that accessibility as on of the main reasons for non-adoption of Internet banking. 


\section{Research Model and Hypotheses}

The purpose of this study is to test empirically the factors that influence Internet banking by consumers in Malaysia. We used Internet banking as the targeted technology. In this study, we hypothesized that accessibility, cost, reluctance to change, security ease of use, and awareness affect an individual's intention to use Internet banking technology. The research model for this study is shown in Figure 1.

There are six hypotheses in this study.

Hypothesis 1: Awareness positively affects the intention to use Internet banking

Hypothesis 2: Ease of use positively affects the intention to use Internet banking

Hypothesis 3: Security negatively affects the intention to use Internet banking

Hypothesis 4: Cost positively affects the intention to use Internet banking

Hypothesis 5: Reluctant to change negatively affects the intention to use Internet banking

Hypothesis 6: Accessibility positively affects the intention to use Internet banking

\section{Methodology}

\subsection{Sample and Data Collection}

Quantitative analysis was chosen to test the research model, as it is good for measuring how many and in what proportion. The method for collecting empirical data for the statistical analysis was customer survey. An in-depth interview was conducted with ten lecturers from one university before the final survey was conducted in order to identify the key elements to be asked in the questionnaire. Survey questionnaire were sent out to randomly selected business customer from the telephone and business directory using their telephone prefix identifier. The selection process was conducted until a sample of 250 is completed. Then they were contacted over telephone to ensure their participations. Upon obtaining their agreement to answer the survey questionnaire, it was then mailed to them. To ensure the feedback, three subsequent reminders were sent over telephone and the mail after the initial surveys were mailed. Telephone inquiries were conducted only two weeks later as a last resort for those respondents that had not responded.

\subsection{Data collection instrument}

The data for the study was gathered through a structured questionnaire. All variables were operationalized using the literature on online shopping (Sathye, 1999; Cooper, 1997; Katz and Aspden, 1997; Booz et al., 1997; Suganthy et al., 2001; Ramsay and Smith, 1999). The first part of the questionnaire included questions about Internet banking usage habits of the respondents such as preference of Internet banking usage, whether they have Internet access at their firms or not, and their feelings about the Internet banking security. The second part consisted of questions measuring all the variables including two questions which are used to measure the Internet banking. All the questions were utilizing on a Likert scale ranging from $1=$ strongly disagree to $6=$ strongly agree.

The questionnaire was pre-tested within the faculty and was send to three academics who are found to be expert in the field for the purpose of establishing face validity of the items. The aim of the pretest was to prevent any vagueness and misunderstanding with minor adjustment to the wording and sequence of the questions. The revised questionnaire was then administered to respondents with a cover letter explaining the academic purpose of the study. The third part consisted of questions regarding the demographic characteristics of the respondents firms.

All items intended to measure the variables in this study were adopted from previously validated instruments. Regression analysis was used to analyze the data. An exploratory factor analysis was performed with varimax rotation to assess the reliability and validity of the measurement model before the regression analysis.

\subsection{Reliability}

Reliability as suggested by Moore and Benbasat (1991) for the scale and Cronbach's alpha for scale reliability obtained for our sample. The internal reliability of the items was verified by computing the Cronbach's alpha (Nunnally, 1978). She suggested that a minimum alpha of 0.7 sufficed for early stage of research. The Cronbach alpha estimated for awareness was 0.7864 , ease of use was 0.8251 , the security was 0.7713 , cost was 0.7672 , reluctant to change was 0.8623 and accessibility was 0.7551 . Reliability from our sample showed a reasonable level of reliability $(\alpha>0.70)$.

\subsection{Validity}

Factor analysis generates a simple structure or pattern of result that each variable loads highly onto one and only one factor thus creating a data reduction. Rotated Factor Matrix shows the correlations between the variable and the factor. Correlations of 0.4 or less are considered as insignificant and not meaningful as it is of low correlations. In this analysis, variances with loadings of greater than 0.4 are accepted and the factor loadings for all items exceeded the minimum value of 0.4 considered for this study. Having minimum factor loadings of 0.4 , it was concluded that the result of the factor analysis suggest that the conditions of convergent and discriminant validity are satisfactory. 


\subsection{Normality of Data and Multi-collinearity}

This study involves a relatively large sample (200 respondents) and therefore, the Central Limit Theorem could be applied and hence there is no question on normality of the data. Two major methods were utilized in order to determine the presence of multicollinearity among independent variables in this study. These methodologies involved calculation of both a Tolerance test and Variance Inflation Factor (VIF) (Kleinbaum et al, 1988). The results of these analyzes are presented in Table 1. As can be seen from this data, i) none of the Tolerance levels is <or equal to .01; and ii) all VIF values are well below 10. Thus, the measures selected for assessing independent variables in this study do not reach levels indicate of multicollinearity. The acceptable Durbin - Watson range is between 1.5 and 2.5. In this analysis Durbin - Watson value of 1.589 , which is between the acceptable ranges, show that there were no auto correlation problems in the data used in this research. Thus, the measures selected for assessing independent variables in this study do not reach levels indicate of multicollinearity

\section{Results}

The survey results show that a large proportion of corporate customers would prefer to use Internet banking instead of the conventional delivery channel $(91.47 \%)$. Only about $8.53 \%$ of the respondents were not keen on the new delivery channel. Respondents who preferred to use Internet banking were local companies with local ownership (50.67\%) and local company with foreign ownership (23.31\%). The companies, which preferred Internet banking, were relatively small in size, having employees numbering 100 and below (39.91\%) and annual revenue of RM10 million and below $(36.32 \%)$.

Almost half of the corporate respondents (112 respondents) are currently subscribing PC banking as offered by the local banks. Out of this $64.13 \%$ of them are quite comfortable with the services provided through this channel. Most of the corporate customer subscribing PC banking services (82.06\%) felt secure using the service while 3.58\% felt unsecured.

Most of the respondents who preferred Internet banking already have Internet access in their organization (95.96\%) and had come to know of the Internet banking through books and magazines $(48.87 \%)$ and advertisement from the mass media (41.70\%). More than sixty percent of (69.95) indicated that they would switch to Internet banking when the local banks offer the service. Most of the respondents also agreed that employees must be empowered to act on behalf of the companies for transactions conducted online $(52.46 \%)$ if the organization were to use this new delivery channel.

\section{Hypotheses Testing}

The strength of the proposed relationship was assessed using the respective statistical analyses summarized in Tables 2 .

\section{Hypothesis 1: Awareness positively affects the intention to use Internet banking}

Awareness is the important factor that affects Internet banking adoption. The multiple regression result shows awareness have beta $=.239 ; \mathrm{p}$-value $=.001$. The results prove that, the null hypothesis that there is no relationship between awareness and Internet banking adoption could be rejected. Looking at the results obtained, it can be concluded that all the respondents in our survey are familiar about Internet banking. Thus, most common source of information to corporate customer seems to be the mass media (TV, Radio, Newspapers). The second most common information provider for Internet banking to the corporate customer are bank personnel and from word of mouth through friends and relatives.

\section{Hypothesis 2: Ease of use positively affects the intention to use Internet banking}

The results of this study show that the association between ease of use and Internet banking adoption is not significant. The results of this study (please refer Table III) show that there is no significant association between ease of use and Internet banking adoption. The hypothesis 2 could be rejected. It can be concluded that corporate customer found Internet banking is complex procedure.

\section{Hypothesis 3: There is a significant relationship between security and Internet banking adoption.}

Table III shows that the association between security and Internet banking adoption is significant at 0.05 level whereby the analysis result showed the beta $=-0.133$ and $\mathrm{t}$-value $=-2.220(\mathrm{p}=0.027)$. This implies that users are still doubtful of the confidentiality and safety of the technology. The support for hypothesis 3 reflects similar arguments in previous studies (Suganthy, 2001; O’Connel, 1997; Cooper, 1997; Ramsay and Smith, 1999; Guru et al., 2000) who found that security have greater impact on the adoption intent of Internet banking. This factor is a potential impediment to consumers transacting through Internet. This further confirmed the findings of Booz et al., (1997).

\section{Hypothesis 4: Cost positively affects the intention to use Internet banking}

The cost is another important factor that has significant effects on Internet banking. Referring to Table III, the fourth hypothesis tested the relationship between cost and Internet adoption intention. The regression result (beta $=.224$, $\mathrm{t}$-value $=2.992, \mathrm{p}$-value $=0.003)$ indicates that the association between cost and Internet banking adoption is significant at 0.01 level $(\mathrm{p}=0.003)$. 


\section{Hypothesis 5: Reluctance to change significantly affects the intention to adopt Internet banking}

Consumers are ready to adopting Internet banking from the conventional banking method. The results of this study show that the association between reluctance to change and Internet banking adoption is not significant. The multiple regression result shows reluctance to change have beta $=.139 ; \mathrm{p}$-value $=.072$. The results prove that, the null hypothesis that there is no relationship between reluctance to change and Internet banking could not be rejected. This is manifested in the finding, which shows that these customers have the tendency to deal with technology base banking system. This might be due to the advantage of being able to be a part of a meaningful personal relationship while such a thing does not happen through traditional banking. For example, in certain banks, they have priority banking consumers where valued customers are treated personally be tellers. This makes customers feel important to the bank, and therefore leads to loyalty towards the bank.

\section{Hypothesis 6: Accessibility significantly affects the intention to adopt Internet banking}

The findings also show that accessibility to computers and the Internet have influence their decision to adopt Internet banking. The relationship between accessibility and Internet banking adoption is significant and findings show that accessibility has a positive relationship with Internet banking adoption intentions (beta $=.303$, p-value $=.000$ ). One possible reason is that due to the support by the government and also cheaper cost of computer and Internet connectivity for Malaysians, most of the respondents already own computers and also have Internet access.

\section{Limitation of the study}

In this study, there are some limitations which are inevitable. They are as listed below:

Respondents were only selected from the Klang Valley. They might not represent the entire Malaysian business peoples. In order to get a more reliable representation, respondents should be gathered from all states around Malaysia.

This research managed to responses from 223 corporate customers. Their response might not reflect the actual perceptions and opinions of Klang Valley customers. A larger set of sample should be selected if more reliable results were to be obtained.

The opinions of bankers are not taken into consideration in this study.

\section{Recommendations}

This study makes significant contributions to knowledge in relation to customers' perception of factors affecting Internet banking adoption. Furthermore, it also provides an insight into the customers' needs and wants which may be essential for bankers in order to provide better services to customers. In the light of these findings, several recommendations will be made which may be useful for bankers and other related authorities.

Banks should make their customer more aware of their new products or services, in this, Internet banking, to encourage higher adoption rate. They can do so by having seminars, exhibitions or giving free-trial periods to allow customers to evaluate their new inventions. Besides that, education and publicity through mass media will also prove to be effective.

Banks should take security of their Internet banking sites into serious consideration since fraud and websites hacking still haunt most of the customers. Perhaps they can implement more advanced encryption methods and build stronger firewalls to prevent security infringement. Government authorities like Bank Negara Malaysia (BNM) can also play their role by issuing statements which reassure customer that the government recognizes Internet banking as secure.

Internet banking sites should be made as user-friendly as possible as not many consumers are familiar with computer and the Internet, especially the older generation. Providing online help and giving customer the choice of their preferred language will ease their transactions.

In order to receive greater response towards Internet banking, it is recommended that bankers target their promotional activities towards those in the younger business personnel who are computer literate, well educated and are quite well to do as they seem to be the most likely users of Internet banking as indicated in this study.

If possible, banks should not charge customer for their Internet banking services. This is because users have to incur other costs. However, if this does not appear to be feasible, they would have to make sure that the costs of transacting manually does not exceed the costs of Internet banking.

Despite all the frenzy about Internet banking, bank should not neglect their branch networks. Although these branches will play fewer roles in the future, they will still be needed in selling products and services where face-to-face communication is vital. Besides that, they are the only options of cash withdrawals and deposits.

\section{Conclusions}

The main objective of this study is to identify the factors affecting the adoption of Internet banking by corporate customer in the Klang Valley in Malaysia. This research able to identify that for the business people, awareness is the most important and security is seen as the least important and ease of use and reluctant to change are not important 
factors in influencing their adoption rate. This might be due to the fact that the users still think using Internet banking are complicated process. Almost all banks in Malaysia are providing advertisement through all types of channel. Even banks also communicating with their existing traditional customers regarding the online banking facilities provided by them. The only thing that deters them from using the online banking service is their reluctance to embrace delivery channel. This shows that, generally most business peoples are already aware of the service. In order to ease transactions over the Internet, customers would prefer banks to offer online help in circumstances where they experience any difficulties. Business customers feel that online transactions are not secure enough; and they are not willing to use it.

\section{References}

ABF. (1997). Banks Approach Market with Caution, Australian Banking and Finance, 6(13), 9-11.

Bakos, J.Y. (1991). A Strategic Analysis of Electronic Marketplaces, MIS Quarterly, (September), 295-310.

Baldock, R. (1997). The Virtual Bank: Four Marketing Scenarios for the Future. Journal of Financial Service Marketing, 1(3), 260-268.

Birch, D. \& Young, M.A. (1997). Financial Services and the Internet- What Does Cyberspace Mean for Financial Services Industry? Internet Research: Electronic Networking Applications and Policy, 7(2), 120-128.

Booz, Allen \& Hamilton. (1996). Internet Banking: A Global Study of Potential, Booz, Allen and Hamilton Inc. New York, NY.

Chan, L.M. (2001). Is Online Banking Safe, the Star (February), 42.

Cooper, R.G. (1997). Examining Some Myths About New Product Winners, in Katz, R., ed., The Human Side of Managing Technological Innovation, Oxford, pp. 550-560.

Cronbach, L. (1970). Essentials of Psychology Testing, Harper and Row, New York.

Daniel, E. (1999). Provision of Electronic Banking in the UK and the Republic of Ireland. The International Journal of Bank Marketing, 17(2).

Davidson, J. (1998). NAB Wakes Up to Online Banking, Australian Financial Review, (July), $16,34$.

Dover, P.A. (1988). The Effect of Technology Selection on Consumer Adoption of the In-home Computerized Banking. International Journal of Bank Marketing, 2, 31-37.

Guru, B.K., Vaithilingam, S., Ismail, N., \& Prasad, R. (2000). Electronic Banking in Malaysia: A Note on Evolution of Services and Consumer Reactions. Journal of Internet Banking and Commerce, 5(1).

Howard, J. \& Moore, W. ((1982). Changes in consumer Behavior Over the Product Life Cycle, in Tushman and Moore, ed.. Readings in the Management of Innovation, Pitman, 128.

Jeon, L. \& Rice, W.P. (1997). From Web Strategy to Implementation at Liberty Financial companies, in Cronin, M.J., ed., Banking and Finance on the Internet, John Wiley \& sons, New York, NY, 107-136.

Katz, J. \& Aspden, P. (1997). Motivations for and Barriers to Internet Usage: Results of a National Public Opinion Survey. Internet Research: Electronic Networking Applications and Policy, 7(3), 170-188.

Malone, T.W, Yates, J., \& Benjamin, R.I. (1989). The Logic of Electronic Markets. Harvard Business Review, (May-June), 166-172.

Mols, N.P., Bukh, P. \& Nielsen, J. (1999). Distribution channel Strategies in Danish retail Banking. International Journal of Bank Marketing, 27(1), 37-47.

Nunally, J.C. (1978). Psychometric Theory. $2^{\text {nd }}$ Edition, McGraw Hill, New York, NY.

O’Connell, B. (1996). Australian Banking on the Internet- Fact or Fiction? The Australian Banker, (December), 212-214.

Pang, J. (1995). Banking and Finance in Malaysia, Federal Publications Sdn Bhd. Malaysia.

Parisa, A (2006). Adoption of e-Banking Services by Iranian Customers, unpublished Msc thesis. Lulea University of Technology, Division of Industrial Marketing and E-Commerce.

Peters, L. (1998). The New Interactive Media: One-to-one, But to Whom? Marketing Intelligence \& Planning, 10(1), 22-30.

Quinn, R.B. \& Mueller, J.A. (1982). Transferring Research Results to Operations, in Tushman and Moore, ed., Readings in the Management of Innovation, Pitman, M.A, pp. 62.

Ramsay, J. and Smith, M., (1999) Managing Customer Channel Usage in the Australian Banking Sector. Managerial Auditing Journal, 14(7). 
Rogers, E.M. \& Shoemaker, F. (1971). Communications in Innovation, Free Press, New York, NY.

Sathye, M. (1999). Adoption of Internet Banking by Australian Consumers: An Empirical Investigation, International Journal of Bank Marketing, 17(7), 324-334.

Scarbrough, H. \& Corbett, J.M. (1992). Technology and Organization Power, Meaning and Design, Routledge, London, 147.

Thorton Consulting (1996). Internet Banking: A Success. Australian Banking and Finance, (July), 5(13), 2.

Wallis Report (1997). The Financial System Inquiry Final Report, AGPS, Canberra.

Table 1. Test of Collinearity

\begin{tabular}{ccc}
\hline Variable & Tolerance & VIF \\
\hline Awareness & .471 & 2.123 \\
Ease of use & .901 & 1.110 \\
Cost & .375 & 2.663 \\
Security & .589 & 1.698 \\
Reluctance to change & .355 & 2.814 \\
Accessibility & .349 & 2.868 \\
\hline
\end{tabular}

Table 2. Regression Results

\begin{tabular}{|c|c|c|c|}
\hline Variables & Beta & t-value & p-value \\
\hline Constant & & 2.086 & .038 \\
\hline Awareness & .239 & 3.572 & .000 \\
\hline Ease of use & .034 & .695 & .488 \\
\hline Security & -.133 & -2.220 & .027 \\
\hline Cost & .224 & 2.992 & .003 \\
\hline Reluctance to change & .139 & 1.806 & .072 \\
\hline Accessibility & .303 & 3.893 & .000 \\
\hline
\end{tabular}




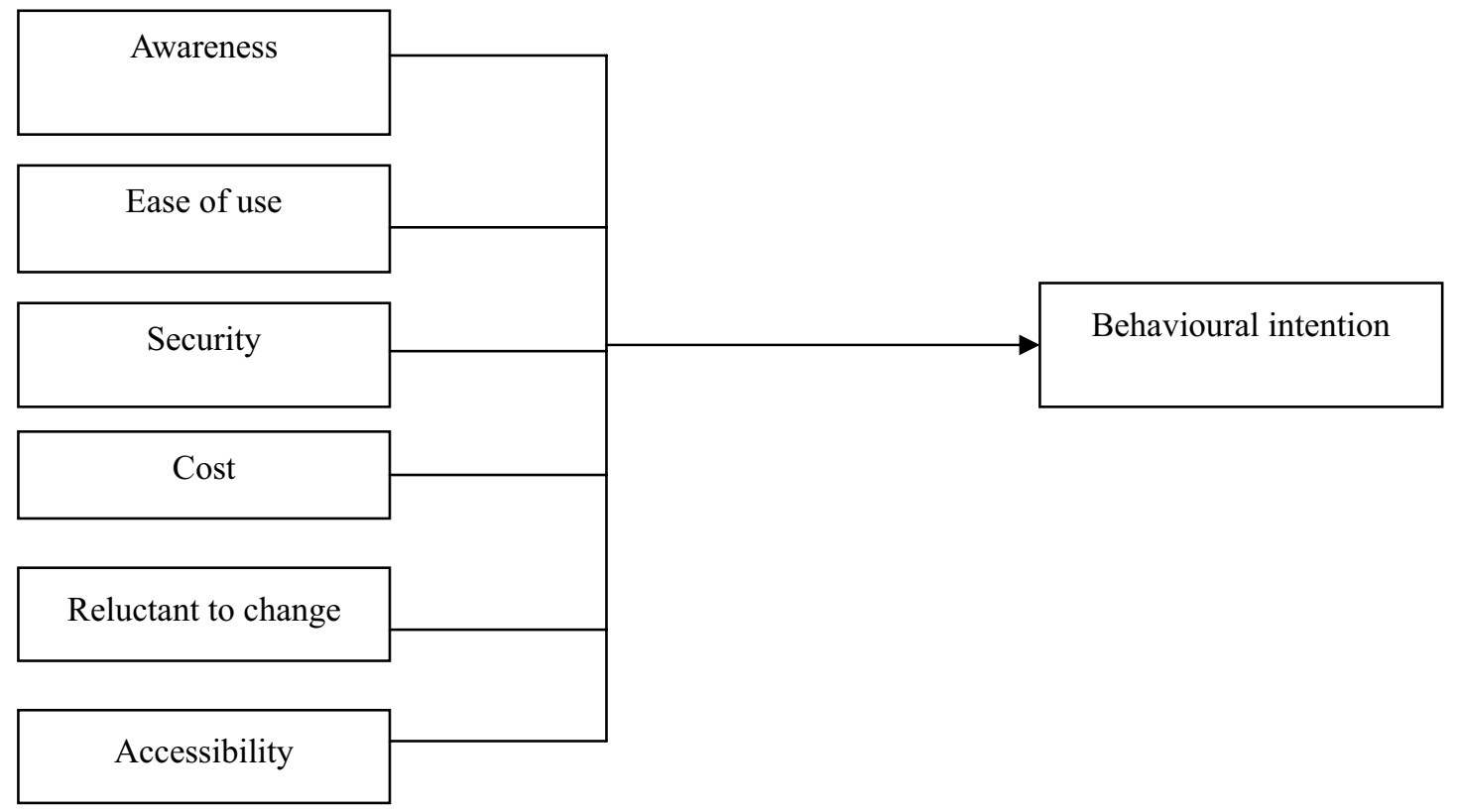

Figure 1. Research Model 


\title{
The Pricing of Luxury Goods: A BPM Approach
}

\author{
Qiang Du \\ Durham Business School, Durham University \\ Mill Hill Lane, Durham, UK, DH1 3LB \\ Tel: 86-21-6266-522Ｅ-mail: qiang.du@durham.ac.uk
}

\begin{abstract}
This paper discussed how to understand the price of a luxury good from BPM perspective. BPM provides us a comprehensive framework to explain the pricing mechanism of luxury goods. Based on BPM, an index (IVDI) was compiled to probe how much the price of a luxury good relies on the utilitarian reinforcement. IVDI also provides profound implications to marketers when they promote different luxury goods. Different parts of BPM are linked together, as a whole they will influence a customer's entire buying process.
\end{abstract}

Keywords: BPM, Price, Luxury goods, Behavior psychology

\section{Introduction}

My wife is a handbag lover. I noticed that sometimes she is able to buy a bag from a street stall at 10 US dollars however she has to pay more than 1500 US dollars when she decided to choose a new designed LV handbag from a franchised store.

What makes such huge difference behind? Is it quality, brand or both or even something else? One simple answer is: people are able to buy a low end commodity at relatively low cost while they have to pay much higher cost to obtain luxury goods. According to Collins English Dictionary, luxury is explained as "something that is considered an indulgence rather than a necessity". From academic perspective, this explanation is not perfect because it doesn't tell us how to define luxury goods, what a necessity is and what an indulgence is, so that we can not figure out how much we need to pay premium price than a necessity.

The paper tries to explain why luxury goods are able to charge premium price than normal commodities from pricing theory and customer behavior perspective.

\section{Literature Review}

Numerous studies have been conducted on pricing theory in the past, among which many researches emphasized that the microeconomic is the foundation of pricing theory (e.g. Hawkins 1954 and Nagle 1984). Not like Hawkins, Nagle points out that although economics are important base of pricing theories, there are some other subjects are also crucial to the development of pricing theory such as psychology and sociology. The classical microeconomic theory put price as variable in the function of margin, cost and demand. The goal of a pricing strategy is to figure out the point where the overall profit is maximum from marketer's perspective. On the individual customer side, the utility theory in microeconomics provides us a paradigm to explain individual buying behavior based on an equilibrium in which the customer believe the utility of the money he/she has to pay equals to the utility of the goods he/she will get.

Many scholars try to reveal the correlation between quality and price. Most of these researches are based on the assumption that quality is the basis of price or reversely, price is a proxy of quality. Riesz (1980) surmised the major previous researches on quality and price correlation. These researches point out that the customers tend to use price as the quality indictor if they don't have other choices. However Riesz argues that one of the classic researches conducted by McConnell (1967) is not demonstratively strong enough to support the conclusion that there is a solid correlation between price and customer perceptive quality. Some recent studies also give backup to this argument (Eunsang Yoon and Valerie Kijewski, 1997). It is interesting that Bowbrick (2007) argues that there is no relevancy at all between price and quality by criticizing previous studies from research method and argumentation logic.

A few scholars do noticed that besides quality, there are also some other factors largely influence the customer's perception of price and therefore the buying behavior. Monroe (1973) argues that the customer may consider reference price, price ranges and the last purchasing experience when they do the purchasing. Zeithaml (1988) argues that the customers take value into consideration and he points out that extrinsic cues, such as brand name and advertising level, rather than only intrinsic cues which is closely related to good's physical attributes, also play crucial role in customers' 
price perception and buying behavior. Chao and Schor (1998) did an empirical research on women's buying behavior in cosmetic purchasing. They argue that the customers make purchases in order to achieve relative position, namely status, so compared with the implication of social position, the good's physical attributes or quality is not as much important.

Although the researches mentioned above partially explained how customers evaluate the price and the way they make a buying decision, none of these researches provided a comprehensive framework to analyze a customer's buying behavior. Furthermore, most of these researches are weak specially when explain why customers would like to choose a luxury good even its prices may much higher than that of a commodity. Kemp (1998) tried to give us some hints in this field and tells us how to separate the luxuries from necessities through three studies. Frijters (1998)'s finding brought us more about pricing of luxury goods. He argues that the reason why the customers purchase luxury goods is because luxury goods are able to bring customers social status, to keep this status both customers and vendors are willing to maintain a higher price. In general, although luxury industry grew rapidly in the past years worldwide, few researches have done to deeply study how this market operates (Xiao and Nicholson, 2007) and why the luxury goods deviate from normal price-quality perception.

My understanding to the pricing of luxury goods is straightforward. Since the customer is the object who conducts the buying behavior, we should put the customer as our research subject rather than those external factors such as quality or even price. BPM (Behavior Perspective Model, Foxall, 1993, 1998, 2007) is a research framework on customer buying behavior based on economic psychology. Figure one below shows this model.

\section{Insert Figure 1 here}

In some recent literatures, BMP is represented below as Figure 2.

\section{Insert Figure 2 here}

Figure 1 and Figure 2 are the same in general while the only difference is that in figure 2, aversive stimuli is separated into two parts and described as punishment.

\section{Introduction of BPM}

Customer behavior setting refers to the environment in which antecedent events that influence the customer behavior occurred, it facilitates or inhibits the customer's choice. Four key stimuli may operate in it: physical, social, regulatory and temporal.

Learning history is the accumulative experience of a customer in the past which will influence current buying behavior it reflects the buying behavior difference among individuals as well.

Utilitarian and informational Reinforcement are direct satisfaction derived from buying and consuming the goods and indirect feedback on consumer's buying behavior.

Aversive stimuli are the cost of consuming economic goods on both utilitarian and informational punishment. For example, a customer must pay out money or may have to wait in a big queue when make a certain consumption.

\section{BPM and Price}

\subsection{Reinforcement and perceived value}

Reinforcement and punishment play crucial role in shaping a customer's buying behavior through value perception. Utility theory in microeconomics formulates that a customer will make judgment on a good's utility and compare it to the utility of the money, namely the price of this good, he/she has to pay out and if the latter one is bigger than the former one, the customer will feel it is a good deal and therefore make the purchase decision. If we consider utility theory from BPM perspective, we can see that in reality, a customer perceives the value of a good based on both utilitarian reinforcement and informational reinforcement. In other words, from a customer's point of view, the perceived value of a good has two parts, the first part is its usage value, traditionally named as the utility, the second part is its given social status value which is represented by informational reinforcement. The customers also take aversive stimuli into consideration when they evaluate the value of a good. We should understand that the utilitarian and informational reinforcement are not always positive, they can be negative when we call them aversive stimuli or utilitarian/ informational punishment. The perceived value is the total sum of positive reinforcements and potential negative punishments. For example, if a customer in China buys a BMW car, he/she gains high utilitarian reinforcement because of BMW's excellent driving performance, however since most Chinese people regard BMW as new-rich's favorite, the customer may suffer from negative informative punishments from others. So the perceived value of a BMW car based on this customer's point of view is sum of value from utilitarian reinforcement (which is positive + ) and value from informative punishment (which is negative -). See figure 3.

\section{Insert Figure 3 here}

In daily life we can see many types of luxury goods from lady's perfumes to private jet planes. All these luxury goods (actually all commercial goods) share one common feature, that is, usage value which can bring utilitarian 
reinforcement to the customer. Luxurious services, for example, a luxurious tourism service which is not a typical produce good, also caters to a customer's utilitarian needs through consuming tangible products such as delicious foods and intangible services such as SPA. So the utilitarian reinforcement endows the intrinsic value to a good and the study of how utilitarian reinforcement affects the price of luxury goods will bring us profound implications.

To study the relationship between utilitarian reinforcement and selling price of different luxury goods, we need to build an appraisal system and make a virtual product as the benchmark. We quantize the utilitarian reinforcement of our target luxury good and divide it to that of benchmark. Show below as formula 1.

$$
\mathrm{I}_{\mathrm{u}=} \mathrm{U}_{\mathrm{t}} / \mathrm{U}_{\mathrm{b}}
$$

In above formula, $U_{t}$ denotes the quantized utilitarian reinforcement of research target, $U_{b}$ represents the utilitarian reinforcement of benchmark of each product category. $I_{u}$ indicates the intrinsic value degree of research target to the benchmark.

To compare the prices between the target and the benchmark, we use price of the target divided by the price of the benchmark as an index. See formula 2.

$$
\mathrm{P}_{\mathrm{u}}=\mathrm{P}_{\mathrm{t}} / \mathrm{P}_{\mathrm{b}}
$$

In above formula, $\mathrm{P}_{t}$ is the price of research target; $\mathrm{P}_{\mathrm{b}}$ is the price of benchmark of each product category. $\mathrm{P}_{\mathrm{u}}$ tells us the ratio of the price of our research target versus the price of the benchmark.

Since $I_{u}$ indicates the intrinsic value of the research target and $P_{u}$ indicates its price level to that of the target, we can compare $I_{u}$ and $P_{u}$ to check whether intrinsic value of the research target is linear with its price based on virtual product reference frame. Formula 3 below shows the details.

$$
\frac{\mathrm{Iu}}{\mathrm{Pu}}=\frac{\mathrm{Ut} / \mathrm{Ub}}{\mathrm{Pt} / \mathrm{Pb}}=\frac{\mathrm{Ut} \times \mathrm{Pb}}{\mathrm{Ub} \times \mathrm{Pt}}
$$

According to above demonstration, we know that $\mathrm{I}_{\mathrm{u}} / \mathrm{P}_{\mathrm{u}}$ is able to indicate how much the price of our selected research target is based on its intrinsic value namely, utilitarian reinforcement, so here we define $\mathrm{I}_{\mathrm{u}} / \mathrm{P}_{\mathrm{u}}$ as Intrinsic Value Dependency Index (IVDI):

$$
\mathrm{IVDI}=\frac{\mathrm{U} \mathrm{t} \times \mathrm{Pb}}{\mathrm{Ub} \times \mathrm{P}_{\mathrm{t}}}
$$

The first step to calculate IVDI is to construct the benchmark based on abstract specifications from a certain product category. For illustration, I choose lady handbag as an example to show the steps.

The key specifications of a lady handbag are material, design and quality. However, each of these features has different weighting factor, some of the features are basic such as quality and others are value-added selling points such as fashion design. The benchmark product we construct should have most of these key features and normally it is the main stream model or design in the market. LV is a well known luxurious brand of lady handbag, therefore I choose LV as the research target. Below table shows features and weighting factors of a lady handbag as an example.

\section{Insert Table 1 here}

According to above table, $\mathrm{U}_{\mathrm{t}}=93$ and $\mathrm{U}_{\mathrm{b}}=58$, So $\mathrm{I}_{\mathrm{u}}=93 / 58=1.603$.

Now we need to figure out $P_{t}$ and $P_{b}$. Here we use the average price of middle end brands as $P_{b}$ and use average price of all LV serials as $P_{t}$. Based on my previous experience, $P_{b}$ is 1000RMB while $P_{t}$ here if we choose LV, is 8000RMB. So $\mathrm{P}_{\mathrm{u}}$ is 8 and IVDI $=1.603 / 8=0.201$.

Suppose one extreme case in which the research target is the same as the benchmark. In this case, $\mathrm{U}_{t}=\mathrm{U}_{\mathrm{b}} ; \mathrm{P}_{\mathrm{t}}=\mathrm{P}_{\mathrm{b}}$ so IVDI=1, which means 1) utilitarian reinforcement contributes all value to the goods 2) no price surplus for informational reinforcement. However if IVDI is 1 , we can not deduce that the good only has utilitarian reinforcement because if for example, $\mathrm{Ut} / \mathrm{Ub}=\mathrm{Pt} / \mathrm{Pb}=2$, we still can make IVDI $=1$. We only can predict that the price represents merely utilitarian reinforcement, informational reinforcement, if any, is not reflected by the price. When $U_{t} / U_{b}>P_{t} / P_{b}$, then IVDI $>1$, it means the price does not fully reflect the intrinsic value (utilitarian reinforcement); when $U_{t} / U_{b}<P_{t} / P_{b}$; the IVDI will be less than 1 which means the utilitarian reinforcement can not solely support the price, informational reinforcement also, on some extent, contributes to the price. If informational reinforcement supports most of the price, IVDI will be very small, such as above example of LV.

The value of IVDI helps us to identify which category a product belongs to. If IVDI equals to 1, it is a commodity; if $\operatorname{IVDI}<<1$, it is a luxury good. Refer to the figure 4 . 


\section{Insert Figure 4 here}

When IVDI is less than 1 , $I_{u}$ (i.e. $U_{T} / U_{b}$ ) can be small or relatively large. If $I_{u}$ is small, it means most value of the good comes from informational reinforcement, the utility does not play key role in the price setting. Some luxury goods follow this pattern such as handbag, apparel, pens etc. While if $I_{u}$ is relatively large, it indicates that although informational reinforcement still contributes much to the price, the good itself has high utility comes from design, advanced technology or superior processing. Some sophisticated luxury goods like luxurious car, private jet plane or luxurious yacht have high $\mathrm{I}_{\mathrm{u}}$ and small IVDI.

Since utilitarian reinforcement brings a good the intrinsic value, for a luxury good with low IVDI and low $\mathrm{I}_{\mathrm{u}}$, the manufacturers always try to enhance its utility by adding jewels or noble metals. On the opposite, high $\mathrm{I}_{\mathrm{u}}$, therefore strong utilitarian reinforcement, is a big differentiator of those sophisticated luxury goods with low IVDI. Image how many cars are able to speed up to 100KM per hour within 4 seconds while a Lamborghini can do so easily?

Also we can see the difference on luxury goods with different $I_{u}$ from marketing perspective. The marketing communication to luxury goods with low $I_{u}$ always focus on life style or elegance and such intangible concepts, while marketing to luxurious cars which $\mathrm{I}_{\mathrm{u}}$ is relatively high are more focus on uniqueness or state-of-the-art technology.

\subsection{Antecedents and perceived value}

In the BPM, customer behavior setting and learning history are called antecedents because both provide the customer some clues of behavior's performance.

Environment setting plays an important role in a customer's price perception, therefore we can see that all boutiques selling luxury goods from apparel to cars have cozy environment and provide warm one on one service. Also we can observe that luxury good shops always locate in premium areas with decent decoration. All these factors send out a message to the prospective customers that they are able to receive good services, obtain superior goods and get other people's admire. Here decent decoration and distinguished service are physical stimuli and premium location is the social stimuli to the customer. Customer behavior setting changes the customer's value perception and therefore the acceptance of price. However the way customer behavior setting changes customer's value perception is different from that of reinforcements (utilitarian and informational). Utilitarian reinforcement and informational reinforcement bring value to the goods the customer will buy while customer behavior setting brings value to the process of buying. The customers who buy luxury goods not only pay attention to the attributes of goods to be bought they also require an enjoyable buying experience which matches their social status.

Learning history however, not like environment setting, influences customer's perception from outside; it changes customer's mindset from customer's past experience and knowledge. The influence can come from several sources such as previous self buying experience, recommendations from friends, relevant book knowledge, common sense and advertisements. The marketers of luxury goods struggle to influence the customer though all channels mentioned above. So we can understand why they try to make buying experience sweet, care the words of mouth and promote noble advertisements.

Although we can study the price of luxury goods from different perspective, behavior setting, learning history and reinforcements are linked with each other. Behavior setting will change the customer's learning history, using the goods, therefore utilitarian and informational reinforcement also helps to build a customer's learning history. Utilitarian reinforcement of a good, on certain extension, determines how the customer be served and under what type of environment. The experience of buying a car and a handbag is totally different.

\section{Conclusion and discussion}

We discussed how to understand the price of a luxury good from BPM perspective in this paper. BPM provides us a comprehensive framework to explain the pricing mechanism of luxury goods. Based on BPM, an index (IVDI) was compiled to probe how much the price of a luxury good relies on the utilitarian reinforcement. IVDI also provides profound implications to marketers when they promote different luxury goods. Different parts of BPM are linked together, as a whole they will influence a customer's entire buying process.

Not many researches have been done to study the pricing of luxury goods from behavior psychology standpoint. This paper is one of these few attempts. However in this paper I only raised one possible view angle to analyze the pricing mechanism of luxury goods, although IVDI is well defined in the paper it is weak in explaining the real business cases.

Several difficulties need to be solved in the further researches. First, we should figure out how to build a fair benchmark system. In this paper I only gave a very simple example to illustrate how to make a benchmark, however in reality, most cases are much complicated than lady handbag. For instance, if we want to make a benchmark for a mobile phone, how can we set weighting factors? In other words, does a customer care the screen size more than GPS function? So to abstract a virtual benchmark product, we have to analyze the customer's preference to all attributes of a certain product. Second, we need a more clearly quantitative description to the implication of IVDI. In this paper I pointed out that if 
$\mathrm{IVDI}=1$ it means the product is a commodity, if $\mathrm{IVDI}<<1$, the product belongs to luxury goods. This description gives us a picture on quantitative analysis from BMP, however the reference data is still ambiguous, we do not know clearly from the value of IVDI on which point it predicts the feature of a good. Empirical data analysis is expected to be conducted so as to build a full panorama of correction between IVDI and product attributes.

I also think IVDI and $I_{u}$ can be applied to the marketing practice. Since IVDI and $I_{u}$ tell us the degree of how much intrinsic value contributes to the product price, markers are able to compare IVDI and $\mathrm{I}_{\mathrm{u}}$ of products from competitors and change their marketing strategy if necessary.

\section{References}

Angela Chao \& Juliet B. Schor. (1998). Empirical tests of status consumption: Evidence from women's cosmetics. Journal of Economic Psychology, 19, 107-131.

Edward R. Hawkins. (1954). Price Policies and Theory. The Journal of Marketing, Vol. 18, No. 3, pp. 233-240.

Eunsang Yoon \& Valerie Kijewski. (1997). Dynamics of the relationship between product features, quality evaluation, and pricing. Pricing Strategy \& Practice, Vol. 5, No. 2, pp. 45-60.

Gordon R. Foxall. (1993). A Behaviourist Perspective on Purchase and Consumption. European Journal of Marketing, Vol. 27, No. 8, pp. 7-16.

Gordon R. Foxall. (1998). The behavioural perspective model Consensibility and consensuality. European Journal of Marketing, Vol. 33, No. 5/6, 1999, pp. 570-596.

Gordon R. Foxall. (2003). The behavior analysis of consumer choice: An introduction to the special issue. Journal of Economic Psychology, 24 (2003) 581-588.

Kent B. Monroe. (1973). Buyers' Subjective Perceptions of Price. Journal of Marketing Research, Vol. 10, No. 1 (Feb.), pp. 70-80.

Manuscript of paper presented at the 3rd Annual Colloquium of the Academy of Marketing's Brand, Corporate Identity and Reputation Special Interest Group. London, UK. Sept 2007.

McConnell, J. D. (1967). A Behavioral Study of the Development and Persistence of Brand Loyalty for a Consumer Product, Ph.D. dissertation, Stanford University, \#67- 17459.

P. Bowbrick. (2007). Pseudo Research in Marketing: The Case of the Price/Perceived-Quality Relationship. European Journal of Marketing, 14, 8, 466-470.

Paul Frijters. (1998). A model of fashions and status. Economic Modeling, 15, 501-517.

Peter C. Riesz. (1980). A Major Price-Perceived Quality Study Reexamined. Journal of Marketing Research, Vol. 17, No. 2 (May, 1980), pp. 259-262.

Sarah Hong Xiao \& Michael Nicholson. (2007). Durham Business School, UK.

Simon Kemp. (1998). Perceiving luxury and necessity. Journal of Economic Psychology, 19, 591-606.

Thomas Nagle. (1984). Economic Foundations for Pricing. The Journal of Business, Vol. 57, No. 1, Part 2: Pricing Strategy (Jan., 1984), pp. S3-S26.

Valarie A. Zeithaml. (1988). Consumer Perceptions of Price, Quality, and Value: A Means-End Model and Synthesis of Evidence. The Journal of Marketing, Vol. 52, No. 3 (Jul., 1988), pp. 2-22. 
Table 1. Features and weighting factors (example)

\begin{tabular}{|cccc|}
\hline Feature & Weighting Factor & Benchmark Score & LV Score \\
Material & $40 \%$ & 20 & 35 \\
Design & $50 \%$ & 30 & 48 \\
Quality and & $10 \%$ & 8 & 10 \\
Durability & Total & 58 & 93 \\
\hline
\end{tabular}

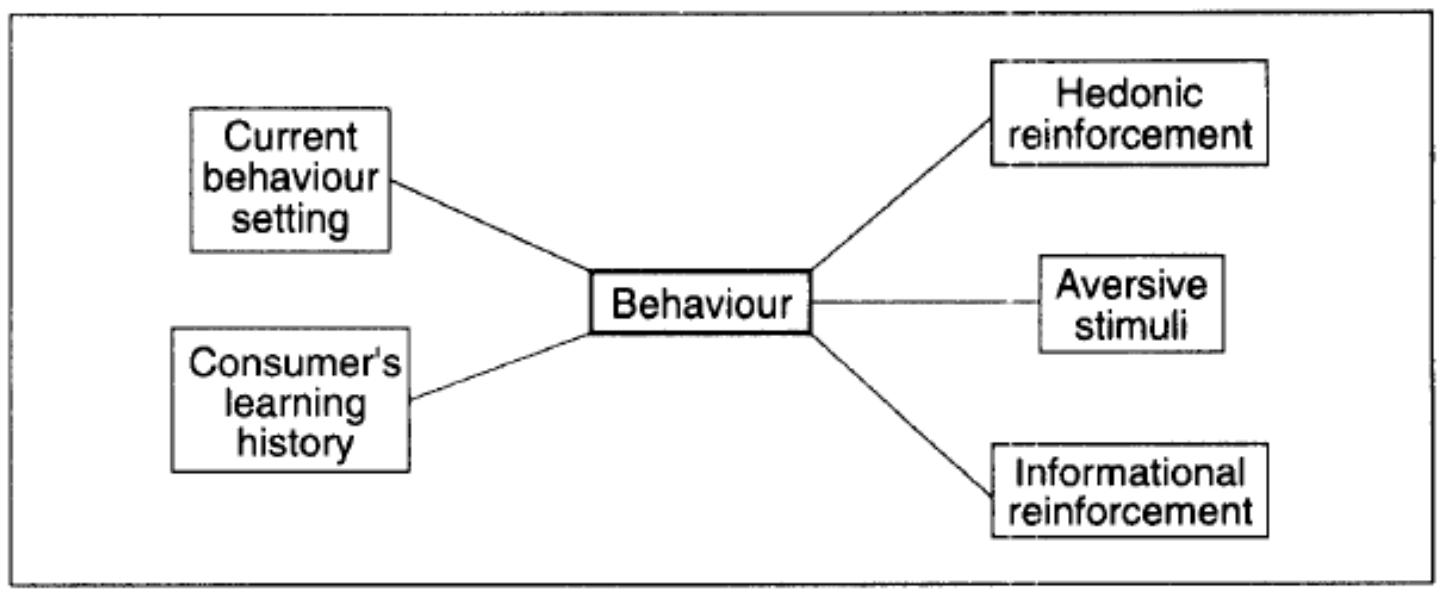

Figure 1. BPM (Foxall, 1993)

\section{The Behavioural Perspective Model}

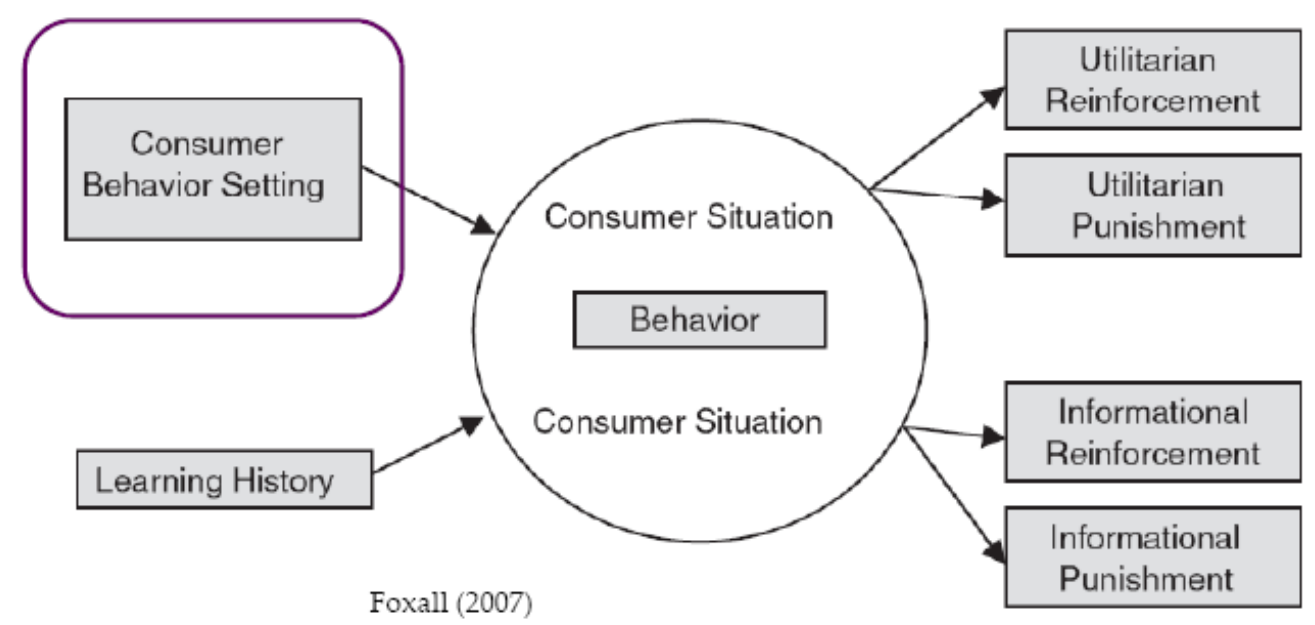

Figure 2. BPM 


\section{The Behavioural Perspective Model}

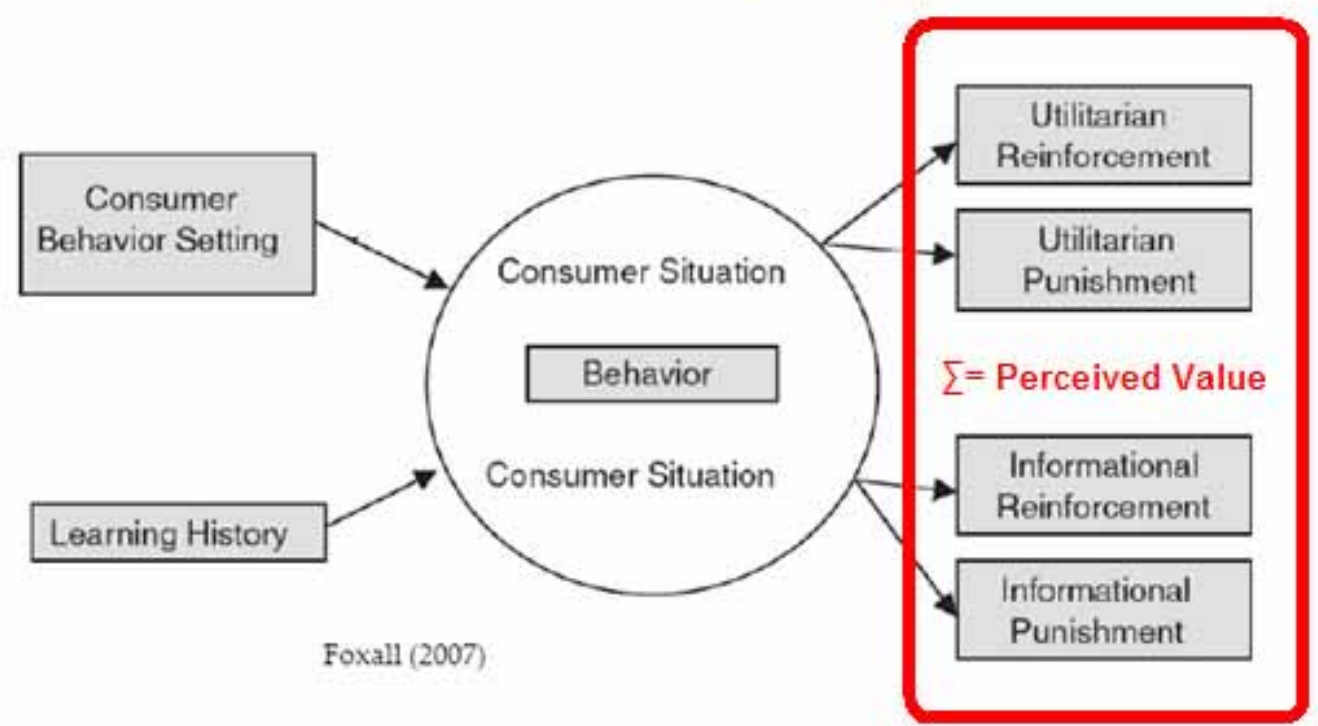

Figure 3. Perceived Value

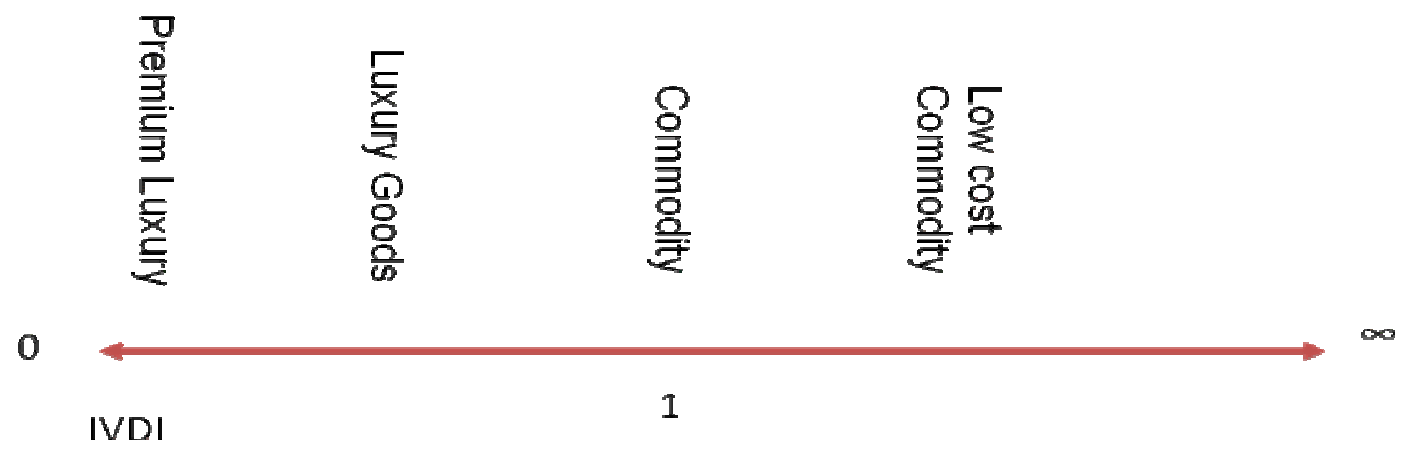

Figure 4. Implication of the value of IVDI 


\title{
Parent Control Dynamics and International
}

\author{
Joint Venture Performance
}

\author{
Nguyen Huu Le \\ Department of Marketing, University of Vaasas \\ PO Box 700, 65101 Vaasa, Finland \\ Tel: 358-6-324-5289Ｅ-mail: nghl@uwasa.fi
}

This project is a part of the "International joint venture behavior, strategies, and performance" project at the Department of Marketing, University of Vaasa funded by the Academy of Finland for the years 2006-2008. The project leader is Professor Jorma Larimo.

\begin{abstract}
This article examines the relationship between foreign parent control and International Joint Venture (IJV) performance over the lifecycle of the IJV. Following Geringer and Hebert (1989); Glaister, Husan, and Buckley (2005), Nguyen and Larimo (2008), the paper conceptualizes foreign parent control across three dimensions including mechanism, focus, and extent. The empirical evidence is based on an analysis of 49 Finnish IJVs established in the 1990s. The result shows that foreign parent firms who adopted a control dynamic approach will see better IJV performance. Broad, tight, and formal control exercised by foreign parent firms over their IJVs leads to better performance of those IJVs in the formation stage. When the performance of an IJV is viewed negatively, foreign parent firms who exercise more control over IJVs will see better IJV performance in the post-formation stage. In contrast, when IJV performance is positive in the formation stage, foreign parent firms are likely to exercise less control over the IJV in the post-formation stage.
\end{abstract}

Keywords: Control, Dynamics, Performance, Parent, International Joint Venture

\section{Introduction}

\subsection{Background}

In recent years, International Joint Ventures (IJVs) have become a critical part of corporate strategy and firm growth in global markets (Luo \& Park, 2004). However, IJVs often experience managerial difficulties in achieving of the intended goals (Park \& Ungson, 2001), and thus often have a greater than $50 \%$ failure rate (Parkhe, 1993). Researchers suggest that control problems are one of the primary causes of IJV failures (i.e. Groot \& Merchant, 2000). This is said to be due to the fact that in IJVs foreign parent firms are exposed to the risk of opportunism (Zhang \& Li, 2001). Furthermore, the operating environment in a foreign market often involves high degrees of uncertainty and risk. Through exercising control, foreign parent firms make sure that their strategies are effectively implemented and their resources are efficiently utilized (Lorange, Morton, \& Ghosal, 1986). Insufficient control may result in a leakage of knowledge, proprietary components and capability to outside group (Geringer \& Hebert, 1989) or a loss of competitive advantage to other parent firms (Hamel, 1991) or to the competitors (Reich \& Mankin, 1986).

\subsection{Research gaps and research questions}

The issue of IJV control was first raised by West (1959), then by Tomlinson (1970), Franko (1971), Behrman (1977), Rafii (1978). The early research on control elaborated the context of IJVs with respect to the relationship between the international strategy of Multinational Corporations, the strategy of local partners, and IJV control. These works, direct attention towards the need for control of IJVs, rather than towards the actual actions required to control and what to control (Geringer \& Hebert, 1989). IJV research was continued by the works of Killing (1983), Schaan (1983) and since then has become an important subject in IJV literature (Calantone \& Zhao, 2001; Lee \& Beamish 1995; Parkhe, 1993; Yan \& Gray 2001a). A substantial number of studies has addressed the importance of control to IJV performance (e.g., Beamish, 1988; Sohn, 1994). However, the results on the impact of parent firm control on IJV performance have been conflicting and inconclusive (Calantone \& Zhao, 2001; Chalos \& O'Connor, 1998; Geringer \& Hebert, 1989; Groot \& Merchant, 2000; Lecraw, 1984; Yan \& Gray, 2001b). Earlier studies on foreign parent dominant control and its relationship to performance show mixed results: that is, they are either 1) positive (Ding 1997; Killing 1983; Lee \& Beamish 1995; Luo, Shenkar \& Nyaw, 2001); 2) show no relationship (Calantone \& Zhao, 2001; Kogut, 1988;); 3) 
show a negative relationship (Boateng \& Glaister, 2002; Child, Faulkner \& Tallman, 2005; Isobe et al., 2000; Osland, 1994). In some other studies the results show a shared control between foreign and local parent firms as being positively related to IJV performance (Beamish, 1988, 1993). In their recent study, Beamish and Choi and Beamish (2004) find that split control between foreign parent firms and local parent firms has an IJV performance level better than that found in the shared and dominant control models. In addition, it has been noticed that the control and performance relationship may vary in IJVs.

Faced with this research puzzle, researchers suggest that future research should seek to deepen IJV control research along its three dimensions including mechanisms, extent, and focus and its relationship to IJV performance (Chalos \& O’Connor, 2004; Geringer \& Hebert, 1989; Raswamy, Gomes, \& Veliyath, 1998; Woodley, 2006). Furthermore, Shortell and Zajac (1988), Brouthers and Bamossy (2006), Nguyen and Larimo (2008), Nguyen and Larimo (2009) suggest the need to study IJV development processes such as control and performance outcomes. In addition, Kogut (2002) maintains that "no matter what the initial agreement on control and ownership may have been at the start of a venture, environmental change over time may shift the relative bargaining power among partners". This may lead to reconfiguration of the control design of IJVs as these environmental factors are crucial for an IJV's stability (Harrigan, 1985). Moreover, Yan and Zeng (1999) and Zhang and Li (2001) argued that the evolution of the control design is dependent on extraneous variables such as change in government policies, competitive environment. They explained that shifts in a partner's bargaining power may result from inter-partner learning, changes in resource contributions, industry structure, and the host government's regulations on foreign investments. These all lead to the continuously changing structure of organizations (Nielsen, 2007). As a result, IJV control design may not be stable over time and thus it is necessary to investigate how and why a parent firm's control structures implemented in their IJVs change during the lifecycle of the IJV.

The purpose of the present study is, therefore, addressed through the research question: (1) What are the relationships between foreign parent control and IJV performance during the formation stage of IJV lifecycle? (2) Why and how do these relationships change during the post-formation stage of the IJV life-cycle?

International Joint Ventures. Contractor and Lorange (1988) use the term "joint venture" for the creation of a separate corporation by two or more partners with expected proportional share of dividend as compensation. Hennart (1988) defines an equity joint venture as an independent legal entity that is formed when two or more sponsors bring specified assets to that entity and they are paid for some or all of their contributions from the profits earned by the entity. In the present study, an IJV is regarded as a separate entity located in a foreign market formed by one (or more) multinational firm (s) and one (or more) local firm (s) whether through greenfield or partial acquisitions in the target markets

IJV lifecycle has not been clearly defined and agreed in IJV literature. When focusing on the co-operative angle or inter-partner relations, researchers have often divided IJV life stages into three stages, as does Buechel (2000) with a formation stage, an adjustment stage, and an evaluation stage; Heide (1994) with a relationship initiation stage, a relationship maintenance stage, a relationship termination stage; Wood and Gray (1991) with a precondition stage, a process stage, and an outcome stage; and Ott (2003) with the three stages being a bargaining stage, a common agency stage, and a repeated games stage. While Kogut (2002) suggested three stages of the IJV lifecycle: creation, institutionalization, and termination, his research focused on only two stages: creation and termination. In contrast, when focusing on IJV success, researchers often distinguish only two IJV lifecycle stages, for example, formation and termination (Reuer, 2000), or pre-incorporation stage and post incorporation stage (Yeheskel, Newburry, \& Zeira, 2004), or a formation stage and stable development, or joint venture formation followed by breakdown (Chowdhury \& Chowdhury, 2001). In summary, there are different ways to structure IJV lifecycle stages, depending on the focus of the research. In the present study, the focus is on the control of IJVs and its relationship to IJV performance, therefore, the lifecycle stages of IJVS here include a formation stage and a post-formation stage. An IJV formed three to four years previously will often be ready to enter its post-formation stage and that could also be termed an evaluation or reformulation stage (Shortell \& Zajac, 1988).

The definition and measurement of organizational performance is always a controversial topic for academic researchers as well as practitioners in many different areas. While there have been many attempts to define and measure the performance of organizations, due to a lack of consensus on this concept, the extant empirical research has not produced a single theory of performance measurement that can be applied across organizations (Tatoglu \& Glaister, 1998). Furthermore, the hybrid nature of IJVs, the possibility of incongruence between partners, and the influence of different cultures in IJVs, all result in the valuation of performance becoming very complex and contribute to there being no consensus on the determinants of IJV performance (Child \& Yan, 2003: 283-284; Mohr, 2006; Zeng, 1998). Performance is the ultimate test of a firm's strategy (Schendel \& Hofer, 1979), a multidimensional construct (Vryza, 1997), and may be evaluated from a different perspective by each IJV partners (Duan \& Chuanmin, 2007). Therefore, different perspectives have been adopted in prior research to assess a venture's performance in previous research including a) a single parent firm (such as foreign parent ot local parent) perspective; or b) a dual parent firm perspective; 
and/or c) an IJV management perspectives. Geringer and Hebert (1991) find a significant correlation between a parent's assessment and that of the IJV manager. Further, Peng and Luo (2000) point out a high degree of correlation between self-reported data and archival data in China. Moreover, Beamish and Delios (1997) concluded from their review that perceptual and objective measures of IJV performance are generally correlated. Thus, in the present study, perceptual measures such as parent firm satisfaction with IJV total performance and financial performance are used to established performance of IJVs. The article is organized as follows: First, it conceptualizes IJV control. Then it analyzes the relationships between foreign parent control and IJV performance during an IJV's lifecycle. After that, the paper discusses the methodology, the sample, and the results of the study. Finally the study concludes with a discussion of the implications and potential directions of further study.

\section{The Conceptualization of IJV Control}

In the organizational literature, management control refers to the process by which an organization influences its members and its units to work in ways that meet the organizational objectives (Glaister \& Bluckley, 1998). According to Child et al. (2005:15), control is a central aspect of management, and essential in any system that holds the managers accountable for their actions and decisions. Ouchi (1977: 95) suggested that "control can be conceptualized as an evaluation process which is based on the monitoring and evaluating of behavior or of outputs". Thus, the organizational literature emphasizes how control can be used to manage individuals and subunits. In IJVs, because there are two or more parties involved, their management control is complex (Geringer \& Hebert, 1989). In this paper, the control of $I J V s$ is defined as the influence of the foreign parent firm on the IJV operations. Researchers have also acknowledged that control systems are complex and multidimensional (see e.g Berrell, 2007; Das \& Teng, 1998; Geringer \& Hebert, 1989; Glaister, 1995 Glaister, Husan, \& Buckley, 2005; Kumar \& Seth, 1998; Lu \& Hebert, 2005; Raswamy et al., 1998). Unfortunately, the existing research tends to focus on only one or two dimensions of control. In order to be able to capture the dynamic nature of the IJV and conduct IJV control research thoroughly, this study adopts the multidimensional approach to control developed by Geringer and Hebert's (1989). These control dimensions are elaborated upon below.

\subsection{Control mechanisms}

Control mechanisms are structural arrangements deployed to determine and influence what the members of the organization do (Fryxell et al., 2002; Geringer \&Hebert, 1989). Control mechanisms consist of a variety of instruments including formal and social controls that are available to firms to exercise effective control over their members (Behrman, 1977; Friedman \& Beguin, 1971). Formal control depends on hierarchies, standards, codified rules, procedures, goals, and regulations that specify desirable patterns of behavior (Das \& Teng, 1998). These regulations are explicit in their prescription of behavior and in their means of enforceability (Das \& Teng, 1998), aimed directly at protecting the assets of the parent firms (Fryxell et al., 2002). The formal control mechanisms help to decrease the potential for opportunism, by controlling the assets through hierarchical means (Mjoen \& Tallman, 1997). Formal control includes majority equity holding, determining the composition of the board of directors, rights to appoint key personnel, control of the planning and approval process for capital budgeting and resource allocation and the setting of routines for IJVs (see e.g. Makino, 1995; Mjoen, 1993; Lu \& Hebert, 2005).

Social control is designed to promote expectations and mutual commitments through which the JV managers learn to share the common attitudes and knowledge of the organization (Nonaka \& Takeuchi, 1995). Social control refers to various mechanisms such as informal communication, information exchange and training, mentoring, development of a common organizational culture, and establishment of personal relationship with IJV managers. These mechanisms foster shared values and norms, without explicitly restricting the behavior of the selected people through the social controls (Chalos \& O'Connor, 1998, Das \& Teng, 1998; Fryxell et al., 2002; Schaan, 1983). Compared to formal control mechanisms, social control mechanisms have the potential to reduce monitoring and contracting costs, and to support the flexibility and adaptability of the enterprise (Dyer, 1997).

\subsection{Control focus}

Control focus can be further divided into broad control and narrow control (Geringer \& Herbert, 1989). In control focus, the parent firms can choose to have a broad control focus and attempt to exercise control over the entire range of the IJV's activities, or they can have a narrow control focus and confine their control activities to the performance dimensions they consider to be critical (Geringer \& Hebert, 1989; Groot \& Merchant, 2000). Child et al. (2005) maintain that depending on several factors, including the parent firm's competencies and its evaluation of how critical activities are, parent firms may focus their control over activities related to technology in one instance but then focus on market related activities in another instance. The areas of control focus consist of marketing, sales and distribution, procurement, general management and operation, finance and accounting, R \& D and development, production and quality, and human resources. Geringer and Frayne (1990) suggest that one of the crucial areas that determine whether the parent firm's intended objectives are achieved is their focus on the control of human resource control. In this paper, 
the control focus is considered to be broad when parent firms exercise control over two or more areas, and narrow when they exercise control over only one or two areas.

\subsection{Control extent}

The control extent refers to the degree or tightness of control which is exercised over the venture (Geringer \& Hebert, 1989). Control extent consists of tight control and loose control. With loose control, the parent firms tend to use only one or two control mechanisms and focus their control on only one or two control areas exercised over the IJVs. Furthermore, with loose control, the parent firms are more flexible in their evaluation of the employees' behavior and their performance. IJV managers have to submit reports less frequently and there are fewer meetings between the parent firms and the IJV manager in loose control types. Tight control can be effected through any mechanism that provides the partner with a high degree of certainty that the personnel in the IJV will act as the given partner wishes. Control is tight from a partner's perspective if that partner has the right to make or approve the key decisions (Geringer \& Hebert, 1989). Tight control is also manifested if the IJV staff is held strictly accountable for adhering to a complete set of actions such as policies and procedures. Tight control is also related to highly frequent and precise reporting (Child et al., 2005). Control can be tightened through more intensive training of the IJV employees in production and management techniques (Van Sluys \& Schuler, 1994). However, tight control may also have adverse side effects. As Child et al. (2005) have argued, if control is exercised in a too domineering manner and/or too frequently, it is likely to lead to significant ill will and to the eventual breakdown of the IJV.

\section{Relational Dynamics between Control and Performance in an IJV's Lifecycle}

Performance is an important issue in strategic management (Venkatraman \& Ramanujam, 1986). Nielsen (2007) suggests that performance should be discussed in the context of the different stages of the development of an IJV. Previous research on the relationship between control and performance has been dominated by a static approach (Zhang $\& \mathrm{Li}, 2001)$. However, in order to understand the complex nature of the relationship, it is believed that the dynamic perspective may help to investigate how control dimensions affect performance and how performance, in turn, affects the IJV control decisions of parent firms. In addition, previous researchers propose that "the control system at a relatively young IJV should be viewed as embryonic and should evolve over the life of the venture" (Chalos \& O'Connor, 1998: 64). The paper continues by analyzing how foreign parent control structures in IJVs influence performance during the IJV formation stage. Then, the paper studies why and how foreign parent control systems in IJVs change under the influence of IJV performance in the post-formation stage.

\subsection{Foreign parent control choice in the formation stage of the IJV lifecycle and their effect on IJV performance}

Luo, Shenkar, and Nyaw (2001) find that broad control exercised by a foreign parent is an important contributor to its satisfaction with its IJV performance. Hoon-Halbauer (1994) maintains that the on-going management process of an IJV works better when foreign staffs possess dominant management control and holding the major decision making power. Brouthers and Bamossy (2006), studying the post-formation process of IJVs established by western and eastern European firms, find that high performance in IJVs is associated with broad control at an early stage of IJV formation. Moreover, Child, Markoczy and Cheung (1994) finds that IJVs in emerging markets like China, local managers are reluctant to make decisions and are afraid of accepting personal responsibility. It, therefore, appears in joint ventures at least local managers may need time to learn to take actions and accept responsibility in managing the IJVs. As a result, it is to be expected that broad control by foreign parent firms leads to better IJV performance during the formation stage.

Child et al. (2005) maintain that control is critical for the successful management and performance of any strategic alliance. Mjoen (1993) find that a tight degree of control was associated with better performance. Studying of IJVs in China, Chen (2004) maintains that tight control by local parent firms over IJVs has a negative impact on performance. This is because local parent firms usually do not advantageous expertise of management IJVs. In IJVs, local parent firms primarily contribute land, facilities, labor so they may not have a capability to control the technology and know-how contributed by foreign parent firms. In such situation, the result of tight control by local parent firms is a delay in the decision making process and to hinder implementation of best practices contributed by foreign parent firms, leading to a decrease in the competitive advantage of the IJVs. Therefore, a foreign parent firms should not let a local firm tighten control of an IJV but instead should exercise control itself (Chen, 2004). As a result, tight control by foreign parent firms leads to better IJV performance in formation stage.

Furthermore, Fryxell, Dooley, and Vryza (2002) find that formal control and IJV performance were positively related in younger IJVs but that this relationship became negative in more mature IJVs. As a result, formal control mechanisms are aimed at monitoring the behavior and performance of IJVs, which is critical for stability and efficiency during their early development stage (Larson, 1992). As a result, formal control by foreign parent firms leads to better IJV performance during the formation stage. In summary, we propose that: 
Hypothesis 1: Broad, tight, and formal control exercised by foreign parent firms over their IJVs leads to better performance in the formation stage.

\subsection{IJV performance during the formation stage and the changes in foreign parent control in the post-formation stage}

Lorange (1997) maintains that because IJVs evolves over time, the balance of a parent firm's control should be shifted accordingly. In the same vein, Brouthers and Bamossy (2006) argue that changes in IJV structure and control relationships may result in lower transaction costs and improved IJV performance. In managing IJVs, Lee, Chen, and Kao (1998) suggest that foreign parent firms need to adopt a flexible mindset. Groot and Merchant (2000) suggested that IJV performance is directly related to parents firms' attitudes toward control. Several studies have focused on how IJV performance affects IJV reconfiguration. Vaidya (2000) argues that control related failures are likely to occur if control practices are not re-evaluated and modified in response to changing circumstances. Simonin (1997) argues that a parent firm's competence at successfully designing subsequent control structures is ultimately reflected in future IJV performance. Killing (1983) observes that partners might loose or strengthen control over the IJV in response to the IJV's on going performance. According to Brouthers and Bamossy (2006: 8), control changes may lead to improved cooperation and performance.

In post-formation stage, when performance results carrying over from the formation stage are positive the use of formal control mechanisms to mitigate opportunism in the later stage may be short-lived (Fryxell et al., 2002). This is due to the fact that formal control mechanisms are based on formal contracts between parent firms, and therefore, valid for a certain period of time (Dyer, 1997). When a parent firm's needs and strategies for IJVs change, they often call for repeated contracts renegotiation, leading to very high transaction costs. In addition, in the post-formation stage of IJVs, when the relationship between foreign parent and local parent firms matures, formal control mechanisms can cause conflicts and promote distrust between parent firms (Ring \& Van de Ven, 1994). Consequently, in the post-formation stage of the IJV lifecycle, social control mechanisms (based on trust and commitment) are more economical, that is once the initial cost of establishing social controls averages out to become less than the cost of periodic contracting (Fryxell et al. 2002). Furthermore, Fryxell et al. (2002) find that social control and IJV performance were positively related only in the presence of effect-based trust between the parents, which is built during the development of IJVs. On the other hand, if parent firms rely totally on social control in the early in IJV lifecycle stage they may expose the potential for opportunism in the formation stage. Thus, trust often appears between parent firms in the post-formation stage rather than during the formation stage of the IJV lifecycle. In the post-formation stage, there is a need to find a balance between control and maintaining harmony between foreign parent and local parent firms. Kauser (2007) suggests that where there is a pre-existing trust, control should be monitored by social mechanisms. In the same vein Chen, (2004) maintains that in the later stage social control helps to increase a parent firm's confidence in its IJVs. This confidence can lead to high expectations of mutual learning and high degree of commitment by parent firms to the IJV and so promotes knowledge sharing and creates a more competitive bundle of resources (Dyer \& Nobeoka, 2000). In short, when IJV performance in the formation stage of the IJV lifecycle is positive, foreign parent firms tend to exercise social control over their IJVs in the post-formation stage.

Furthermore, in post-formation stage, local managers also learn how to manage and direct IJVs towards their targeted goals. Robins et al. (2002) suggest that "mature" ventures often use local personnel supplied by local partners at many levels, thus giving local parent firms broader control over IJVs. Further, previous research has suggested that IJVs require greater autonomy in order to adapt to the social, political, financial, legal and cultural expectations of the IJV host environment (Yeheskel, Newburry, Zeira, 2004). Moreover, Yeheskel et al. (2004) proposed that foreign parent firms that allow IJV managers to formulate and implement policies in functional areas that are sensitive to the host country would lead to better IJV performance. Superior performance of an IJV in post-formation stage is also achieved if foreign firms focus their control on their resource contribution not on the whole range of IJV activities (Yan \& Child, 2004). Moreover, during the post-formation stage of IJV as the level of trust increase between foreign and local firms, the need for control diminishes (Nielsen, 2007). Therefore, parent firms seek to focus their control over particular activities, rather than control all activities (Kauser, 2007). Merchant and Groot (2000) suggest that when recent IJV performance rates are relatively high, parents firms will utilize more looser control over the IJV and narrower control foci. As a result, when IJV performance in the formation stage of the IJV lifecycle is positive, foreign parent firms tend to exercise narrow control over their IJVs in the post-formation stage.

In addition, when an IJV has superior performance, the partners tend to loosen control since the IJV's management team has proved its expertise and that helps to maintain harmonious relations with the local parent firms (Child et al. 2005). Similarly, Chen (2004) proposed that over time, tight control activities exercised by foreign parent firms might decrease due to the influence of the IJV management getting stronger at the post-formation stage than it was in the formation stage. This is because it permits the expectations of labor unions, clients, suppliers, and other local stakeholders to be properly considered. This would positively affect worker commitment and productivity and increase the fit between the IJV and its host environment. As a result, this will increase the effectiveness of IJVs and leads to 
better IJV performance. Gaining more autonomy in the post-formation stage is also important for an IJV's survival. In foreign markets, IJVs often need to be able to react quickly to fast-changing markets by reducing long decision-making processes and bureaucracy. Supporting the argument for more autonomy for IJV management, Bleeke and Ernst (1991) contend that operating decisions are best made by those who are focused purely on the JV. Yeheskel et al. (2004) point out that foreign parent firms are willing to permit more autonomy when their IJVs operate under more certain and stable circumstances. In addition, Nielsen (2007) argues that the venture mature over time and partners are more familiar with each others' idiosyncrasies, thus the uncertainty within transactions decreases. Consequently, intensive control is not necessary. In addition, Dianne (1997) suggests that as the IJV has progressed well, foreign parent firms should have clarified the criteria and time frames for the gradual transfer of control and power to their local partners. As a result, when IJV performance during the formation stage of the IJV lifecycle is positive, foreign parent firms tend to exercise loose control over their IJVs in post-formation stage.

On the other hand, undesirable IJV performance prompts structural instability in control system (Yan, 1999). Poor IJV performance is often caused by at least one of the partner firms failing to achieve its objectives, thus creating stimuli for changing the ineffective existing control system. Yan and Gray (2001b) suggested that a factor that could produce change in an IJV is a shift in IJV performance. When investigating the evolution of IJVs, Child (2002) concluded that over time, foreign parent firms are likely to increase their equity share for the following reasons: a) the need to buy out unreliable partners; b) the unwillingness or inability of local partners to finance IJV expansion. In their study, Brouthers and Bamossy (2006) also found that tighter controls were normally instituted after poor results and/or misdeeds. As a result, when IJV performance in the formation stage of IJV lifecycle is negative, foreign parent firms tend to exercise more control by exercising broad, formal, and tight control over their IJVs in post-formation stage. In summary, we propose that:

Hypothesis 2: When IJV performance has been negative in the formation stage, foreign parent firms tend to exercise formal, broad, and tight control over their IJVs in the post-formation stage of the IJV lifecycle. In contrast, when IJV performance has been positive in the formation stage, foreign parent firms tend to exercise social, narrow, and loose control over their IJVs in the post-formation stage of the IJV lifecycle.

\section{Methodology and Results}

\subsection{Methodology}

To test the hypotheses, the study uses a survey research method to collect data for the empirical evidence. In the survey, the questions about joint venture control and performance were collected directly from those involved in IJV operations. The measurement of variables is based on a 5 point-scale. The methods used in this study to analyze the data are description statistics and the Chi-square test. The purpose of the methods is to determine how well an observed set of data fits an expected set of hypotheses. The method is particularly useful to find out whether an IJV control structure which is made up of different elements of the IJV control dimension (formal, social, broad, narrow, tight, and loose) has a normal distribution or whether the structure has been formed under the influence of performance factors.

\subsection{Data collection and measurement}

The study here is a part of an on-going research project focusing on IJV behavior, strategies, partner selection, control structure, and performance of Finnish firms. The target firms and investments were identified as follows: 1) The FDI data base collected by the project leader starting from the late 1980s based on press releases regarding IJVs published in several Finnish business magazines and newspapers, 2) Annual reports and websites of the 250 largest Finnish firms as reported by the leading business magazines, 3) based on the earlier surveys focusing on IJVs and wholly owned subsidiaries of Finnish firms conducted by the project leader. From the resources, we identified 340 qualifying IJVs formed by Finnish firms since 1985 and in operations until at least 2002. The 340 qualifying IJVs involved 250 Finnish parent firms. Of those 250 firms, several firms were very difficult to contact either because they had been restructured or because they had gone out of business. The aim of contacting the firms was primarily to identify the best informants. In some firms there was no longer anyone employed who had sufficient knowledge to further study. This left a total of 200 Finnish parent firms. Due to time and cost constraints a postal questionnaire and online web survey were used to gather the data.

The participants were those managers who directly involved in the establishment and operation of the IJVs. To enhance the quality of the data, the respondents were contacted by phone in December 2006 to explain the key points of the study and the questionnaires. In exchange for their cooperation with the study and to provide motivation and accurate responses, the respondents were assured of anonymity and were promised a summary report of the findings, and were also entered into a draw for three gifts. Following one reminder at the end of the January 2007, 54 questionnaires were collected from 49 participating firms at the end of February 2007, providing a response rate of 24,5\% which is relatively similar to that of earlier respective studies in Finland (see Larimo \& Rumpunen, 2006). The sample was carefully examined for any systematic response bias using t-tests. Respondents and non-respondents were compared by 
their age, size, international experience, and IJV experience. No statistically significant difference was found. Thus, there was no response bias to be found in the final sample. After taking out the uncompleted questionnaires, the final sample related to 49 IJVs.

Among these IJVs, 45\% were established 1988-1995, and 55\% 1996-2006; $53 \%$ through acquisitions, and 47\% through greenfield investment; $76 \%$ involved 2 partners and $24 \%$ involved 3 partners; $61 \%$ were established with an indefinite term, $22 \%$ with a duration of less than 5 years, and $17 \%$ stated to have an intended duration of more than 5 years; $41 \%$ had a degree of Finnish ownership of between 10\%-49\%, 10\% had equal ownership, and $49 \%$ had Finnish majority ownership upon establishment; $71 \%$ were located in emerging economies, and $29 \%$ in developed economies; $63 \%$ dealt with industrial products, $27 \%$ with consumer products, and $10 \%$ offered both consumer and industrial products.

All three control dimensions were measured with a 5 point-scale. Based on the list of different mechanisms and focus areas provided, the respondents were asked to assess 1) their method of monitoring and control, and 2) their focus of monitoring and control at the formation and post-formation stages (Cronbach's Alpha $=0.89$, and 0.92, respectively). The measure of IJV performance was also based on a 5 point-scale, the respondents were asked if they were satisfied with IJV performance on both financial and total performance scales with $1=$ "very dissatisfied" to $5=$ "very satisfied" at both formation stage and post-formation stage where Cronbach's Alpha values were $=0.91$ and 0.94 , respectively.

\subsection{Results}

\subsubsection{Parent firms' control choice and IJV performance in the formation stage of the IJV life-cycle}

Performance was measured using seven different subjective measures. Respondents were asked on a 5-point Likert scale, first to weight a suggested set of measures, and then to express their degree of satisfaction with each of the seven measures. The two most important measures of performance were total performance and financial performance. Among 49 respondents, 32 Finnish parent firms (65\%) exercised formal, broad, and tight control over their IJVs during the formation stage. The respective mean of the IJVs total performance was 4.6 (with $1=$ very dissatisfied to $5=$ very satisfied) and financial performance was 4.3 . The remaining 17 Finnish parent firms (35\%) exercised other control structure such as social, narrow, and loose control. Those parent firms demonstrate a respective total performance mean of 2.5, and one for financial performance of 2.4. Therefore, formal, broad, and tight control exercised by foreign parent firms in the formation stage of the IJV lifecycle leads to better IJV performance. Also, based on the chi-square test, $\chi 2=$ 16.5 the result was significant at $\mathrm{P}<0.005(\mathrm{df}=5)$ (see table 1). Thus, the results supported hypothesis 1 for both description statistic and chi-square test.

\subsubsection{IJV performance in the formation stage and parent control in the post-formation stage of the IJV life-cycle}

According to the respondents, $75 \%$ of foreign parent firms (37 firms) were satisfied with the IJV's total performance (mean 4.3) and financial performance (4.1) resulting from IJV operations in the formation stage of the IJV lifecycle. Of these 37 foreign parent firms, $95 \%$ foreign parent firms exercised social, narrow, and loose control over their IJVs in the post-formation stage of IJV lifecycle. On the other hand, the $25 \%$ of foreign parent firms (12 firms), who were not satisfied with their IJV performance in the formation stage of the IJV lifecycle, all exercised formal, broad, and tight control over their IJVs in the post-formation stage of the IJV lifecycle. In addition, according to a chi-square test $\chi^{2}=$ 15.27, the result was significant at $\mathrm{P}<0.01(\mathrm{df}=5$ ) (see table 1.). Thus, the results supported hypothesis 2 for both description statistics and chi-square test. So that if IJV performance in the formation stage of the IJV lifecycle has been positive, foreign parent firms tended to exercise social, narrow, and loose control over their IJVs in the post-formation stage of IJV lifecycle. In contrast, if IJV performance has been negative in the formation stage of an IJV's lifecycle, foreign parent firms tend to exercise formal, broad, tight control over their IJVs in the post-formation stage of IJV lifecycle.

All in all, the relationship between the design of the control structure and performance is not just one-way, but rather is reciprocal and dynamic. With an initial control system designed by a foreign parent firms, there will be two situations affecting IJV performance. In the first case, when the performance is negative, foreign parent firms will respond to this situation by exercising more control over IJVs to restore order and make sure that the IJVs achieve planned targets. However, control also carries costs, especially with broad control and tight control. In addition, foreign parent firms may also signal their distrust of local parent firms, by insisting on a lot of procedures and excessive paperwork that may flow from formal control and tight control. Therefore, when IJV performance is positive, foreign parent firms may prefer to exercise less control over IJVs to create trust with local parent firms and to reduce associated costs (see Figure 1.).

\section{Contribution and Conclusions}

With regard to control in IJVs, research has traditionally been modeled solely by the relative degree of ownership (Mjoen \& Tallman, 1997). However, ownership may not be the optimal means of control in every situation and may be but a minor issue in governance. Guide (2001) states that a firm does not need majority equity ownership to exercise managerial control. Sohn (1994: 299) points out that social knowledge may help MNCs reduce dependency on 
ownership as means of control over their subsidiaries. In addition, when control of IJVs was discussed separately from the ownership structure, most previous research focused on only one dimension of control, mainly control mechanisms (e.g. Mjoen, 1993; Vryza 1997; Xiansheng, 1998; Yan \& Gray 2001a). However, to be able to recognize the control issues within IJV clearly, Geringer and Hebert (1989) and Lu and Hebert (2005) and Raswamy, Gomes, and Veliyath (1998) proposed that future research should examine the multidimensionality of IJV control including control focus, control mechanisms, and control extent, and also the relationship of each one to IJV performance.

The first contribution of the present study to IJV theory is to fill this gap by providing a better understanding of the multidimensionality of parent firm control and each element's influence on IJV performance. In addition, the present study is the first to examine the change of IJV control during the IJV lifecycle since Zhang and Li (2001: 342) concluded "how control design of IJVs evolves over time remains unclear". This is important because it examines organizational process. The research of process makes an important contribution because it explains how managers can influence firm performance through organizational control (Chakravarthy \& Doz, 1992). In the relationship between $I J V$ control and performance the present study points out that the conflicting results from previous studies are, perhaps, because they have assumed a monotonic relationship between control and performance (Fryxell et al., 2002). As it takes one step further away from this approach, the present study proposes that the relationship between IJV control and performance depends both on which lifecycle stage IJVs are at, and on the results of IJV performance during the previous stage. In particular, the present study proposes that when foreign parent firms choose to exercise broad, formal, and tight control at the formation stage of the IJV lifecycle, IJV performance is likely to be positive. In contrast, if foreign parent firms choose to exercise narrow, social, and loose control over IJVs at the formation stage, IJV performance is likely to be negative.

In addition, foreign parent firms will redesign their control exercised over IJVs over time according to IJV performance. In the post-formation stage, when IJV performance is negative, foreign parent firms need to exercise more control over IJVs in an attempt to improve performance. When IJV performance is positive foreign parent firms may reduce their degree of control over IJVs in order to reduce the costs associated with control, and to promote a higher degree of trust, the potential for which had probably already been observed during the initial stage, and evidenced through strong performance. This finding is consistent with Zhang and Li (2001) who report that during IJV development process, IJV performance becomes a motivating force stimulating the evolution of IJV control design. The present study extends this by specifying which particular control structure is needed during the period of such changes. In short, it can be concluded that there is no optimal choice of IJV controls that are stable over time. Control of IJVs needs to be re-adjusted over time in accordance with IJV performance. As a result, this study may help to explain previous conflicting results, such as why in some cases dominant control forms yield better performance while in others they do not but instead minor control or shared prove effective control forms. This finding contradicts Glaister and Buckley's (1998) which maintains that the nature of management control does not vary with the development of IJVs.

This study does have several limitations. First, the sample size of the study is rather small and the analysis based only on data from foreign parent firms. For further studies, researchers could use the framework of this study with a bigger sample size and incorporate the viewpoints of both local and foreign parent firms to study the dynamics of parent firm control. In addition, the study defines an IJV lifecycle as consisting of two stages; further study could test the framework of this study using three or more stages. Finally, although performance is the main motive driving IJV control change, other factors should be taken into account. Future studies may wish to investigate control dynamics during the IJV lifecycle in accordance with the changes in operating environments of IJVs, the changes to parent strategies in IJVs, and the relationship development between local firms and foreign firms.

\section{References}

Beamish, P. W. (1988). Multinational joint ventures in developing countries, London: Routledge.

Beamish, P W. (1993). The characteristics of joint ventures in the People's Republic of China. Journal of International marketing, 1 (2), 29-48.

Beamish, P. and Delios, A. (1997). Improving joint venture performance through congruent measures of success. Cooperative Strategies: European Perspectives, New Lexington Press: San Francisco, 103-127.

Beamish, P. W. and Choi, C. B. (2004). Split management control and international joint venture performance. Journal of International Business Studies, 35, 201-215.

Berrell, M. (2007). The Nature of Power, Control, Trust and Risk in International Joint Ventures: Implications for Relationships and Performance. Business Networks and Strategic Alliances in China, Clegg S., Wang K., and Berrell M. (Eds.)Northampton, MA, USA, Edward Elgar, 29-55.

Behrman, J. (1977). National Interest and the Multinational Enterprise, Prentice Hall, New York.

Bleeke, I. and Ernst, D. (1991). The way to win in cross border alliances. Harvard Business Review 69 (6): 127-135. 
Boateng, A. and Glaister, W. K. (2002). Performance of international joint ventures: evidence for West Africa. International Business Review, 11, 523-541.

Brouthers, K. D. and Bamossy, G. J (2006). Post-Formation Processes in Eastern and Western European Joint Ventures. Journal of Management Studies, 43(2): 203-229.

Buechel, B. A. (2000). Framework of Joint Venture Development: Theory Building through Quality Research. Journal of Management Studies, 37 (5), 637-661.

Calantone, R. J. and Zhao, Y. S. (2001). Joint ventures in China: A comparative study of Japanese, Korean, and U.S. partners. Journal of International Marketing, 9 (1), 1-23.

Chakravarthy, B. S. and Doz, Y. (1992). Strategic process research: Focusing on corporate self-renewal. Strategic Management Journal, 13: 5-14.

Chalos, P. and O'Connor, N. G. (1998). Management controls in Sino-American joint ventures: a comparative case study. Managerial Finance, 24 (5), 53-72.

Chalos, P. and O'Connor, N. G. (2004). Determinants of the use of variations control mechanisms in US_Chinese joint ventures. Accounting , Organizations and Society, 29, 591-608.

Chen, D. (2004). Governing for success: An examination of different types of parent control in international joint ventures. Ph. D dissertation, Rutgers, The State University of New Jersey.

Child, J. (2002). A configurational analysis of international joint ventures, Organization Studies, Sep-Oct, 1-39.

Child, J., Markoczy, L., and Cheung, T. (1994). Managerial adaptation in Chinese and Hungarian strategic alliances with culturally distinct foreign partners, Advances in Chinese Industrial Studies, 4 (211-231).

Child, J. and Yan Y. (2003). Predicting the performance of international joint ventures: an investigation in China. Journal of Management Studies, 40 (2), 0022-2380.

Child, J., Faulkner, D., and Tallman, P. B (2005). Cooperative Strategy. Oxford University Press, 215-247.

Choi, C.B. and P.W. Beamish, P.W. (2004), Split management control and international joint venture performance. Journal of International Business Studies, 35, 201-215

Chowdhury, I. R. and Chowdhury, P. R. (2001). A theory of joint venture lifecycles. International Journal of Industrial Organization 19, 319-434.

Contractor, F. and Lorange, P. (1988). Competition vs. co-operation: A benefit / cost framework for choosing between fully-owned investments and co-operative relationships. Management International Review (Special Issue on Co-operative Issues in International Business), 28, 5-18.

Das, T. K. and Teng, B.-S. (1998). Between trust and control: developing confidence in partner cooperation in alliances. Academy Management Review, 23 (3), 491-512.

Dianne, J. (1997). Culture and control: The tale of East-West joint venture. Management International Review, 37(1), 127-147.

Ding, D. Z. (1997). Control, conflict, and performance: A study of U.S.-Chinese joint ventures. Journal of International Marketing, 5 (3), 31-45.

Duan, J. and Chuanmin, S. (2007). Ownership, control, and performance of U.S.-China joint ventures: A longitudinal study. Journal of Applied Management and Entrepreneurship, 12 (1) 25-35.

Dunning, J. 1995. Reappraising the eclectic paradigm in an age of alliance capitalism. Journal of International Business Studies, Third Quarter, 26(3):461-491.

Dyer, J. H. (1997). Effective interfim collaboration: how firms minimize transaction costs and maximize transaction value. Strategic Management Journal, 18, 535-556.

Dyer, J. H. and Nobeoka, K. (2000). Creating an managing a high-performance knowledge sharing network: The Toyota case. Strategic Management Journal, 21, 345-367.

Franko L. G. (1971). Joint venture survival in multinational corporations. Pager Publishers, New York.

Friedman, W. G. and J. P. Beguine (1971). Joint International Business Ventures in Developing Countries, Columbia University Press, New York.

Fryxell, G., Dooley, R. S., and Vryza, M. (2002). After the ink dries: The interaction of trust and control in US-based international joint ventures. Journal of Management Studies, 39 (6), 0022-2380.

Geringer, J. M. and Hebert, L. (1989). Measuring Performance of International Joint Ventures, Journal of International Business Studies, $2^{\text {nd }}$ quarter, 249-264. 
Geringer, J. M. and Frayne, C. (1990). Human Resource Management and International Joint Venture Control: A parent Company Perspective. Management International Review, 30, 103-119.

Geringer, J. M. and Hebert, L. (1991). Control and Performance of International Joint Ventures. Journal of International Business Studies, Summer, 235-254.

Glaister, K. W. (1995). Dimensions of Control in UK International Joint Ventures, British Journal of Management, 6, 77-96.

Glaister, K. W, and Buckley, P. J. (1998). Management-performance relationships in UK joint ventures. International Business Review, 7, 235-257.

Glaister, K. W., Husan, R., and Buckley, P. J. (2005). International joint ventures: an examination of the core dimensions. Journal of General Management, 30 (4), 43-72.

Groot, T and Merchant, K. A. (2000). Control of International Joint Ventures. Accounting, Organizations and Society, $25,579-607$.

Guidice, R. M. (2001). Managing joint ventures: The impact of experience, strategic interdependence and control on performance, Ph D dissertation, Washington State University, Washington.

Hamel, G. (1991). Competition for competence and inter-partner learning within international strategic alliances. Strategic Management Journal, 12 (special issue), 83-104.

Harrigan, K. R. (1985). Strategies for joint ventures, Lexington, MA: Lexington books.

Hennart, J.-F. (1988). A transaction costs theory of equity joint ventures. Strategic Management Journal, 9 (4), 361-374.

Heide, J. B. (1994). 'Interorganizational governance in marketing channels. Journal of Marketing, 58: 71-85.

Hoon-Halbauer, S. K. (1994). Management of Sino-foreign joint ventures. Lund University.

Isobe, T., Makino, S. and Montgomery, B. D. (2000). Resource commitment, entry timing, and market performance of foreign direct investments in emerging economies: the case of Japanese international joint ventures in China. Academy of Management Journal, 43 (3), 468-484.

Kauser S. (2007) Alliance Relationship Dynamics: Conflict, Structure and Control. Journal of Euromarketing, 16 (3), $5-25$.

Killing J. P. (1983). Strategies for joint ventures success. Praeger Publishers, New York.

Kogut, B. (1988). Joint ventures: theoretical and empirical perspectives. Strategic Management journal, 9, 319-332.

Kogut, B. (2002). A study of lifecycle of joint ventures, Book chapter in Cooperative Strategies in International Business, 169-185, edited by Contractor, F. J. and Lorange, P.

Kumar, S. and Seth, A. (1998). The design of coordination and control mechanisms for managing joint venture parent relationships. Strategic Management Journal, 19, 579-599.

Larimo, J. and Rumpunen, S. (2006). Partner selection in international joint ventures. Journal of Euromarketing, 16 $(1 / 2), 119-137$.

Larson, A. (1992). Network dyads in entrepreneurial settings: a study of the governance of exchange relationships. Administrative Science Quarterly, 37, 76-104.

Lecraw, D. J. (1984). Bargaining power, ownership, and profitability of transnational corporation in developing countries. Journal of International Business Studies, Spring/Summer, 27-43.

Lee, C. and Beamish, P.W. (1995). The characteristics and performance of Korean joint ventures in LDCs. Journal of International Business Studies, 26 (3), 637-654.

Lee, J., Chen, W. and Kao, C. (1998). Bargaining power and the trade-off between the ownership and control of international joint ventures in China. Journal of International Management, 4, 353-385.

Lorange, P., Morton, S. M. F. and Ghoshal, S. (1986). Strategic Control. St. Paul: West.

Lorange, P. (1997). Black-box protection of core competencies in strategic alliances, In Beamish, P. W. and Killing, J. P. (eds.), Cooperative Strategies: European Perspective. New Lexington Press, San Francisco, CA, 59-73.

Lu, W. J. and Hebert, L. (2005). Equity control and the survival of international joint ventures: a contingency approach. Journal of Business Research , 58, 736-745.

Luo, Y. and Park, S. H. (2004). Multiparty cooperation and performance in international equity joint ventures. Journal of International Business Studies, 35, 142-160. 
Luo, Y., Shenkar, O. and Nyaw, M.K-. (2001). A dual parent perspective on control and performance in international joint ventures: lessons from a developing economy. Journal of International Business Studies, 32 (1), 41-58.

Makino, S. (1995). Joint Venture Ownership Structure and Performance: Japanese Joint Ventures in Asia, Unpublished Ph D dissertation, The University of Western Ontario, Ontario, Canada.

Mjoen, H. (1993). Core competencies, equity, control, and performance: An integrated approach. Unpublished Ph D dissertation, David Eccles School of Business, the University of Utah, Salt Lake City.

Mjoen, H., and Tallman, S. (1997). Control and performance in international joint ventures. Organization Science, 8 (3), 257-274.

Mohr, A. T. (2006). 'A multiple constituency approach to IJV performance measurement. Journal of World Business, 41: 247-260.

Nguyen, H. L. and Larimo, J. (2008). Governing for Success: The Host Country Uncertainty and the Design of Foreign Parent Control in International Joint Ventures. Book chapter in Strategy and Governance of Networks: Cooperatives, Franchising, and Strategic Alliances 327-347, edited by Hendrikes, W., Tuunanen, M., Windsperger, J. Cliquet, G. Springer Publication.

Nguyen, H. L. and Larimo, J. (2009). Foreign Parent Strategies, Control and International Joint Venture Performance. International Business Research, 2 (1), 3-15.

Nielsen, B. B. (2007). Determining international strategic alliance performance: A multidimensional approach. International Business Review, 16, 337-361.

Nonaka, I. and Takeuchi, H., (1995). The knowledge creating company. Oxford University Press, New York.

Osland, G. E. (1994). Successful operating strategies in the performance of U.S.-China joint ventures, Journal of International Marketing, 2 (4), 53-78.

Ott, U. (2003). Games International Joint Ventures play during their lifecycle: Key factors for cooperation and conflict. Journal of International Business Studies, 2, 1-16.

Ouchi, W. G. (1977). The relationship between organizational structure and organizational control. Administrative Science Quarterly, 22, 95-113.

Park, S. H. \& Ungson, G. R. (2001). Rethinking limits of cooperation: a conceptual framework of strategic alliance failure. Organization Science, 12 (1), 37-53.

Parkhe, A. (1993). Strategic alliance structuring: A game theoretic and transaction cost examination of inter-firm cooperation. Academy of Management Journal, 36 (4), 794-829.

Peng, M. and Luo, Y. (2000). Learning to compete in a transition economy: experience, environment and performance. Journal of International Business Studies, 30, 269-296.

Rafii, F. (1978). Joint Ventures and the Transfer of Technology to Iran: The Impact of Foreign Control. Unpublished doctoral dissertation, Harvard University.

Ramaswamy, K. Gomes, L. and Veliyath, R. (1998). The performance correlates of ownership control: a study of U.S. and European MNE joint ventures in India. International Business Review, 7, 423-441.

Reich, R. B. and Mankin, E. D. (1986). Joint ventures with Japan give away our future. Harvard Business Review, 64 (2), 78-86.

Reuer, J. J. (2000). Parent Firms Performance across International Joint Venture Lifecycle Stages. Journal of International Business Studies, 31 (1), 1-20.

Ring, P. S. and Van de Ven, A. H. (1994). Developmental processes of cooperative inter-organizational relationships. Academy of Management Review, 19 (1), 90-118.

Robins, J. A., Tallman, S. and Fladmoe-Lindquist, K. (2002). Autonomy and dependence of international cooperative ventures: An exploration of the strategic performance of U.S. ventures in Mexico. Strategic Management Journal 23 (10), 881-898.

Schaan, J. L. (1983). Parent ownership and joint venture success: The case of Mexico. Unpublished doctoral dissertation, University of Western Ontario.

Schendel, D. E. and Hofer, C. W. (1979). Strategic Management: A new view of Business Policy and Planning, Boston: Little, Brown.

Shortell, S. M. and Zajac, E. J. (1988). International Corporate Joint Ventures: Development processes and performance outcomes. Strategic Management Journal, 9 (6), 527-542.

Simonin, B. L. (1997). The importance of collaborative know-how: An empirical test of the learning organization. Academy of Management Journal, 40: 1150-1174.

Sohn, J. H. D. (1994). Social knowledge as a control system: A proposition and evidence from the Japanese FDI behavior. Journal of International Business Studies, Second Quarter, 295-324. 
Taoglu, E. and Glaister, K. W. (1998). Performance of international joint ventures in Turkey: perspectives of Western firms and Turkish firms. International Business Review, 7 (6), 635-656.

Tomlinson, J.W.C., (1970). The joint venture process in international business: India and Pakistan. MIT Press, Cambridge, MA.

Vaidya, S. P. (2000). Factor affecting learning effectiveness in international joint ventures: An empirical analysis of Indian IJVs. Ph D dissertation, the University of Texas-Pan America.

Van Sluys, E. V. and Schuler, R. S. (1994). As the IJV grows: lessons and progress at Davidson-Marley BV. European Management Journal, 12 (3), 315-321.

Venkatraman, N. and Ramaujam, V. (1986). Measurement of business performance in strategy research: a comparison of approaches. Academy of Management Review, 11 (4), 801-814.

Vryza, M. (1997). Control mechanisms, inter-partner trust, and performance in international joint ventures: a transaction cost approach, $\mathrm{Ph} \mathrm{D}$ dissertation, the University of Tennessee, Knoxville.

West, M. W. (1959). Thinking ahead: The jointly owned subsidiary. Harvard Business Review, Jyly-August: 31-32.

Wood, D. and Gray, B. (1991). Toward a Comprehensive Theory of Collaboration. Journal of Applied Behavioral Science, 27 (2):139-162.

Woodley, J. A. (2006). Re-Visiting Control in International Strategic Alliances. Journal of Asia-Pacific Business ,7(1): 81-97.

Xiansheng, D. (1998). Ownership, Control, and Performance of International Joint Ventures: The Case of the People's Republic of China. Unpublished doctoral dissertation, University of Illinois at Urbana-Champaign.

Yan, A. (1999). Structural stability and reconfiguration of international joint ventures. Journal of International Business Studies, 29 (4), 773-776.

Yan, A. and Zeng, M. (1999). International joint venture instability: a critique of previous research, a re-conceptualization, and directions for future research. Journal of International Business Studies, 30 (2), $397-414$.

Yan, A. and Gray, B. (2001a). Antecedents and Effects of Parent Control in International Joint Ventures, Journal of Management Studies 38 (3), 393-420.

Yan, A. and Gray, B. (2001b). Negotiating control and achieving performance in international joint ventures: A conceptual model. Journal of International Management ,7, 295-315.

Yan, Y and Child, J. (2004). Investor's Resources and Management Participation in International Joint Ventures: A Control Perspective. Asia Pacific Journal of Management, 21, 287-304.

Yeheskel, O., Newburry, W. and Zeira Y. (2004). Significant differences in the pre- and post- incorporation stages of equity international joint ventures and international acquisitions and their impacts on effectiveness. International Business Review, 13, 613-636.

Zeng, M. (1998). The impact of structure on cooperation and performance in joint ventures: an empirical investigation of international joint ventures, Ph. D dissertation, University of Illinois at Urbana-Champaign, U.S.

Zhang, Y. and Li, H. (2001). The control design and performance in international joint ventures: a dynamic evolution perspective. International Business Review, 10, 341-362.

Table 1 . The results of the study based on chi-square test

$\begin{array}{llll}\text { Hypotheses } & \chi^{2} & \text { DF } & \text { Decisions }\end{array}$

Formation stage of IJV lifecycle (H1)

Parent control choice and result in IJV performance

$\mathrm{H} 1: \quad 16.5 \quad 5$

significant at 0.005

Formal, broad, tight control

$(+)$ performance

Post-formation stage of IJV lifecycle (H2)

IJV performance and change of parent control

H2: $15.27 \quad 5 \quad$ significant at 0.01

$(+)$ performance

( - ) performance
Social, narrow, loose control

Formal, broad, tight control 


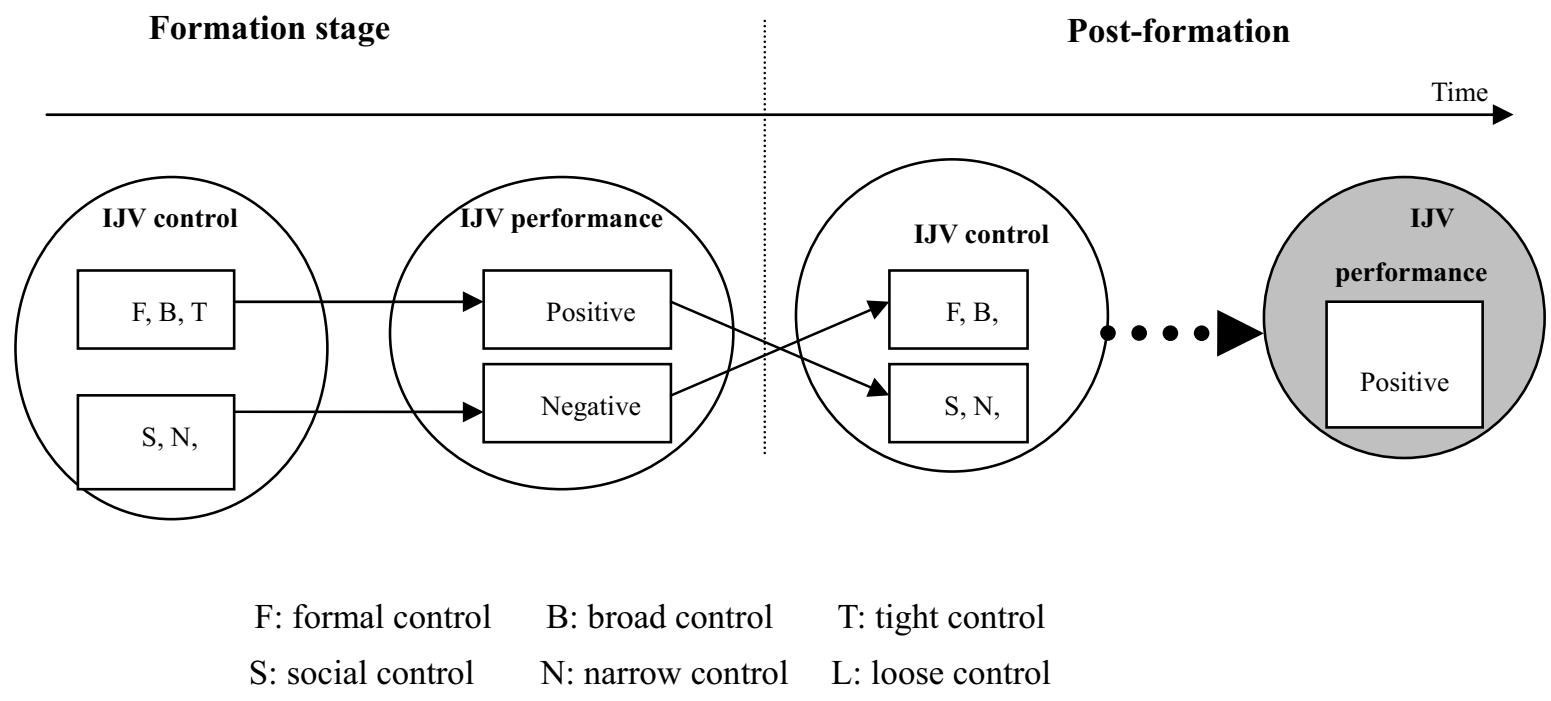

Figure 1. IJV Control model 


\title{
Performance Evaluation of Organizations: An Integrated Data Envelopment Analysis and Balanced Scorecard Approach
}

\author{
Seyyed Asghar. Ebnerasoul \\ Department of Industrial Engineering, University of Malek Ashtar \\ Imam Ali High way, Tehran, Iran \\ Tel: 98-21- 229 -52286 E-mail: ebnerasoul@yahoo.com \\ Hossein Yavarian (Corresponding author) \\ Faculty of Industrial Engineering, University of Science and Industry \\ No 210 Ali Naghi Nia St.107 St. Tehranpars 1st Sq, Tehran, Iran \\ Tel: 98-21-77902635_E-mail: hosseinyavarian@yahoo.com \\ Mehdi Amir Azodi \\ Faculty of Industrial Engineering, University of Science and Industry \\ Hengam St. Narmak, Tehran, Iran \\ Tel: 98-21-8826080 E-mail:m.azodi@gmail.com
}

\begin{abstract}
The method that we propose in this paper tries to improve the traditional data envelopment analysis (DEA) by proposing an artificial alternative as an "ideal unit" in order to evaluate and rank the other alternatives in proportion to this ideal unit. Our approach integrates the balanced scorecard (BSC) by DEA and develops an extended DEA model. The input and output measures for the integrated DEA-BSC model are grouped in "cards" which are associated with a "BSC for organizations". The BSC is embedded in the DEA model through a hierarchical structure of constraints that reflect the BSC balance considerations. Using a quantitative research method, we illustrate the proposed approach with an example.
\end{abstract}

Keywords: Data envelopment analysis, Balanced scorecard, Decision making process, Productivity analysis

\section{Introduction}

Most of managers are seeking ways to increase productivity in their subsystem. Thus, productivity assessment in organizations seems to be very important. As a matter of fact, productivity includes to main factors: efficiency and effectiveness. Therefore in order to assess productivity, mangers have to control these two parameters. Too many methods had been developed to assess organization's performance but the complication of modern organizations and their dependence to knowledge and information make traditional ways unsuitable. In this situation first, BSC was introduced as a new performance evaluation method, then it sets forward as a new approach to achieve strategies. This method has been very effectively in many organizations so that most of successful companies and institutions were ranked in fortune magazine, use BSC method as a powerful achievement tool.

On the other hand one of the techniques which is a good one to measure efficiency is data envelopment Analysis which tries to maximize efficiency by taking consideration of inputs and outputs. It is a mathematical programming technique that calculates the relative efficiency of multiple decision making units (DMUs) on the basis of observed inputs and outputs, which may be expressed with different types of metrics. The basic concept in DEA is to measure the efficiency of a particular DMU against a projected point on an "efficiency frontier". The usefulness of DEA in evaluating multi-criteria systems and providing improvement targets for such systems is expressed in the large number of its reported applications.

In this paper unlike CCR method which measures relative efficiency of units, we present a model to measure absolute efficiency of each unit in proportion to the best existence alternative. Thus, all inputs and outputs of DEA model will be 
determined by BSC perspectives first and then by performing DEA model we can assure that organization will move through its vision and achieve maximum efficiency as well. This new method can be useful for mangers and decision makers who are involving in process of organizational performance assessment and can be lead to improvement for those who applied lessons from the evaluation.

The rest of the paper is organized as follows: Section 2 provides a literature review. Sections 3and4 describe BSC and DEA approaches respectively. The integrated DEA-BSC model is presented in Section 5; Section 6 discusses an example that applies the DEA-BSC model. Finally, Section 7 presents concluding.

\section{Literature review}

Over the last few decades, the problem of performance evaluation has attracted significant attention that has led to a variety of methods. These methods seek to develop quantitative measures to assess the performance of organizations by systematically obtaining and integrating subjective and objective data. The methods range from simple screening procedures to sophisticated mathematical procedures.

More recently, some researchers have proposed DEA as a tool for evaluating organizations such as banks for instance Bergendahl \& Lindblom (2008) used DEA as method for evaluating the performance of Swedish banks according to service efficiency. And Giokas (2008) proposed a new model for assessing the efficiency in operations of a large Greek bank.

The other researchers provided DEA model for the efficiency and effectiveness in railway performance (Ming \& Erwin, 2008). They categorized the relevant measures of the evaluation as either inputs or outputs of the DEA model and used the efficiency scores to rank order the organizations. And finally Chen \& Chen (2007) proposed DEA performance evaluation for semiconductor industry and also Eliat et al. (2008) suggested an integrated DEA-BSC approach for R\&D projects evaluation. The method that we propose in this paper tries to improve the traditional DEA model (CCR) by proposing an artificial alternative as an "ideal unit" in order to evaluate and rank the other alternatives in proportion to this ideal unit. In this regard we propose the literature review of BSC and DEA methods.

\section{BSC template}

The balanced scorecard is a strategic planning and management system that is used extensively in business and industry, government, and nonprofit organizations worldwide to align business activities to the vision and strategy of the organization, improve internal and external communications, and monitor organization performance against strategic goals. It was originated by Drs. Robert Kaplan (Harvard Business School) and David Norton as a performance measurement framework that added strategic non-financial performance measures to traditional financial metrics to give managers and executives a more 'balanced' view of organizational performance. The balanced scorecard has evolved from its early use as a simple performance measurement framework to a full strategic planning and management system.

This new approach to strategic management was first detailed in a series of articles and books by Drs. Kaplan and Norton. Recognizing some of the weaknesses and vagueness of previous management approaches, the balanced scorecard approach provides a clear prescription as to what companies should measure in order to 'balance' the financial perspective. The balanced scorecard is a management system (not only a measurement system) that enables organizations to clarify their vision and strategy and translate them into action. It provides feedback around both the internal business processes and external outcomes in order to continuously improve strategic performance and results. Kaplan \& Norton (1996) describe the innovation of the balanced scorecard as follows:

"The BSC retains traditional financial measures. But financial measures tell the story of past events, an adequate story for industrial age companies for which investments in long term capabilities and customer relationships were not critical for success. These financial measures are inadequate, however, for guiding and evaluating the journey that information age companies must make to create future value through investment in customers, suppliers, employees, processes, technology, and innovation."

The balanced scorecard suggests that we view the organization from four perspectives, and to develop metrics, collect data and analyze it relative to each of these perspectives. The interrelationship between these perspectives is depicted in figure (1).

\section{DEA template}

\subsection{History}

Building on the ideas of Farrell (1957), the seminal work "Measuring the efficiency of decision making units" by Charnes, Cooper \& Rhodes (1978) applies linear programming to estimate an empirical production technology frontier for the first time. Since then, there have been a large number of books and journal articles written on DEA or applying DEA on various sets of problems. Other than comparing efficiency across DMUs within an organization, DEA has also been used to compare efficiency across firms. There are several types of DEA with the most basic being CCR based on Charnes et al. (1994) methodology. However there are also DEA which address varying returns to scale, either CRS (constant returns to scale) or VRS (variable). On the whole DEA has been so many used in field of performance measurement. 


\subsection{Techniques}

Data Envelopment Analysis (DEA) is a Linear Programming methodology to measure the efficiency of multiple Decision Making Units (DMUs) when the production process presents a structure of multiple inputs and outputs. Some of the benefits of DEA are:

a) No need to explicitly specify a mathematical form for the production function.

b) Proven to be useful in uncovering relationships that remain hidden for other methodologies.

c) Capable of handling multiple inputs and outputs.

d) Capable of being used with any input-output measurement.

e) The sources of inefficiency can be analyzed and quantified for every evaluated unit.

In the DEA methodology, formally developed by Charnes et.al efficiency is defined as a weighted sum of outputs to a weighted sum of inputs, where the weights structure is calculated by means of mathematical programming and constant returns to scale (CRS) are assumed.

The CCR model defines the relative efficiency of a specific DMU as the ratio between the sum of its weighted outputs and the sum of its weighted inputs. The variables, $u r>0$ and $v i>0$, are defined in a way that allows the unit in question to present itself in the most favorable way. The ratio, which is to be maximized for unit, leads to objective function shown in A (1) formulae.

The optimization problem in (A.1) is unbounded. Normalization constraints (one for each project) force the ratios of weighted outputs to weighted inputs of every project to be less than or equal to 1, as shown in A(2).

The constrained optimization problem defined by (A.1) and (A.2), including the positivity constraints of the weights, construct the original CCR model in its ratio form. The ratio formulation was transformed into an equivalent linear programming formulation known as the input-oriented CCR model (Note1) shown in (A.3). The constant $\varepsilon$ is a small positive number that functions as a lower bound for the multipliers.

In this formulation, no a priori values are assigned to the input-output weights. This means, for example, that an alternative, which is a superior producer of a marginally important output, might be diagnosed as efficient even if it performs poorly with respect to all other outputs. Furthermore, in evaluating different alternatives, the same factors may be assigned widely different weights for the same dimension.

\section{An Integrated DEA-BSC model}

Two main factors of productivity meaning efficiency and effectiveness should be improved together, so that it can raise productivity. If an organization has high efficiency but doesn't gain effectiveness then it does not move in through its strategy. Otherwise the effort of organization doesn't result in profitability and goal achievement.

On the other hand if the organization's effort is efficient but not to be effective, it moves slowly to achieve determined long term goals. Since the effectiveness and strategy achievement measured by BSC and efficiency of an organization measured by DEA technique, so both factors of productivity (effectiveness and efficiency) can be measured by combining two models simultaneously. As a result, organization's perspectives can be defined and promoted by BSC technique, and then with regard to these perspectives, which organization is seeking to achieve will be seen in horizon. Then inputs/outputs of ideal organization will be defined as which the organization has the best factors as a result to succeed. If the ideal organization enters to competitive arena with the others using DEA technique, it will definitely get the best point in terms of efficiency (1of 1) because it has the most proper factors to succeed. But the other organizations compare themselves to the ideal organization in terms of efficiency. While their efficiency is less than 100 percent they will try to approach to the ideal organization's specification by process changes, procedure revision, and using the other approaches in order to raise output. (Come closer to the ideal unit).

The decision makers have been always concerned about the definition of ideal unit. On the other hand one of DEA disadvantages is calculating relative efficiency and comparing DMUs with each other. By definition of ideal DMU, we will be able to compare the efficiency of other units to that of ideal point absolutely.

One simple way to define an ideal unit is to choose minimum of inputs of one type and select maximum output of its type as ideal unit specifications. So the model will be formulated as (A4).

To provide a new model, ideal unit specification and relevant constraint should be added to model, so unlike CCR model, efficient units (with the highest point) will not in result in several but one.

\section{Numerical Example}

In order to illustrate and motivate the method, we have developed the following example. Assume that there are twenty identical factories and all of them produce three kinds of products A, B\&C. We consider raw material and salary as inputs of these factories, and products of type A, B\&C as outputs. The relevant data are presented in Table 1. 
- Solving the problem by CCR model:

The problem should be formulized and then be solved without consideration of ideal unit specifications; the results are shown in Table 2.

- To dominate over the mentioned problem by integrated DEA-BSC model:

While the model is solved by consideration of ideal unit specifications and adding constraint of $80 u_{1}+67 u_{2}+65 u_{3}-2 v_{1}-3 v_{2} \leq 0$ to the linear programming, the results in Table 3 will be achieved.

\section{Conclusion}

In this paper, BSC and DEA methods which have been approved as powerful tools to analyze and evaluate the performance in management science have been used. Then by combination of two models and applying it to real situation, the decision makers will be aware from the deviation of real performance of organizations in comparison with the determined strategic plan.

The integrated DEA-BSC model addresses three common goals that firms are trying to accomplish:

1) Achieving strategic objectives (effectiveness goal).

2) Optimizing the usage of resources in generating desired outputs (efficiency goal); and

3) Obtaining balance.

The model is applicable for evaluating organizations (e.g., venture capital funds), as well as in non -profit organizations, such as government agencies charged with selecting R\&D projects.

The integrated model we represent in this paper has capabilities of both DEA and BSC methods. If the efficiency of total units doesn't reach 1, this subject can lead to double motivation for the other organizations to make efforts in order to decrease inputs and raise outputs to get closer to the ideal organization. Any organization as ideal one is outstanding from strategic point of view, so the other organizations try to follow it in order to achieve both effectiveness and efficiency. The integrated DEA-BSC method advantages are as below:

a) Definition of ideal unit: This item states that the efficiency of an organization can seldom reach to the highest point because inputs and outputs of ideal unit have been obtained through the best inputs and outputs selection of real organizations (artificially) but these results appeared in ideal organization, have come into a real existence in different organization. Therefore this matter causes to motivate continuous effort in order to acquire more efficiency and progress.

b) Next advantage of ideal unit shows real specifications (inputs/outputs): The specifications have occurred to the real one before and simultaneous combinations of them have been taken place in ideal organization (artificially). As a result this matter avoids presenting unreal figures. In addition, other organizations won't be hopeless to achieve highest level.

c) The improvement of ranking system: unlike CCR model, efficient units (with the highest point) will not in result in several but one. So other organizations can be ranked based on ideal organization (efficient unit). This advantage causes to rank organizations more accurately and fairly.

d) Motivating the other organizations: Only those organizations can perform efficiently (with the efficiency point of 1) that apply creativity and innovation to their processes, so these organizations strive enough to accomplish their routine activities greatly and achieve continuous improvement. This advantage makes the organization's staff to be motivated and in addition, to emphasize on continuous improvement and benchmarking.

\section{References}

Bergendahl, G. \& Lindblom, T. (2008). Evaluating the performance of Swedish banks according to service efficiency. European journal of operational research, 185, 1663-1673.

Charnes, A., Cooper,W.W., \&Rhodes,E. (1978).Measuring the efficiency of decision making units. European Journal of the Operational Research, Vol. 2, 429-44.

Charnes. A, Cooper .W.W, Lewin A, \& Seiford. L.M, (1994). Data envelopment analysis: theory, methodology and applications. Massachusetts: Kluwer Academic Publishers.

Chen,T.,\& Chen, L. (2007). DEA performance evaluation based on BSC indicators incorporated (The case of semiconductor industry). International Journal if productivity and performance management, Vol. 56, No. 4, 335-357.

Eilat, H., Golany,B. , \& Shtub, A. (2008). R\&D project evaluation: an integrated DEA and balanced scorecard approach. OMEGA international journal of management science, No 36, $895-912$.

Eilat, H., Golany,B. , \& Shtub, A.(2006).Constructing and evaluating balanced portfolios of R\&D projects with interactions: A DEA based methodology. European Journal of Operational Research, No. 172, 1018-1039.

Farrell, M.J. (1957). The measurement of productive efficiency. Journal of the Royal Statistical Society, Series A (General) No. 120, 253-28. 
Giokas, D.I. (2008). Assessing the efficiency in operations of a large Greek bank branch network adopting different economic behaviors. Economic Modeling, No. 25, 559-574.

Kaplan. R.S., \& Norton, .D.P., (1996).Translating strategy into action: The balanced scorecard. Boston, MA: Harvard Business School Press.

Ming, M.Y., \& Erwin, T.J. (2008). Efficiency and effectiveness in railway performance using multi-activity network DEA model. International journal of management science Omega, No. 36, 1005 - 1017.

Ramanathan, R. (2007). Performance of banks in countries of the Gulf Cooperation Council. International Journal of Productivity and Performance Management, Vol. 56, No. 2, 137-154.

\section{Notes}

Note 1. The CCR model admits both input-oriented and output-oriented models. While the input-oriented model focuses on savings of inputs, the output-oriented model concentrates on enhancement of outputs.

Table 1. Inputs/outputs of factories in a constant period of 1 month

\begin{tabular}{|c|c|c|c|c|c|}
\hline $\begin{array}{c}\text { Units } \\
\text { (Factories) }\end{array}$ & $\begin{array}{c}\text { Input1 } \\
(\text { salary }-1000 \$)\end{array}$ & $\begin{array}{c}\text { Input2 } \\
\text { (raw } \\
\text { material-1000\$) }\end{array}$ & $\begin{array}{c}\text { Output1 } \\
\text { (product A-Qty) }\end{array}$ & $\begin{array}{c}\text { Output2 } \\
\text { (product B- Qty) }\end{array}$ & $\begin{array}{c}\text { Output3 } \\
\text { (product C- Qty) }\end{array}$ \\
\hline $1 *$ & 3 & 5 & 40 & 55 & 30 \\
\hline 2 & 2.5 & 4.5 & 45 & 50 & 40 \\
\hline 3 & 4 & 6 & 55 & 45 & 30 \\
\hline 4 & 6 & 7 & 48 & 20 & 60 \\
\hline 5 & 2.3 & 3.5 & 28 & 50 & 25 \\
\hline 6 & 4 & 6.5 & 48 & 20 & 65 \\
\hline 7 & 7 & 10 & 80 & 65 & 57 \\
\hline 8 & 4.4 & 6.4 & 25 & 48 & 30 \\
\hline 9 & 3 & 5 & 45 & 64 & 42 \\
\hline 10 & 5 & 7 & 70 & 65 & 48 \\
\hline 11 & 5 & 7 & 45 & 65 & 40 \\
\hline 12 & 2 & 5 & 45 & 40 & 44 \\
\hline 13 & 5 & 7 & 65 & 25 & 35 \\
\hline 14 & 4 & 4 & 38 & 18 & 64 \\
\hline 15 & 2 & 3 & 20 & 50 & 15 \\
\hline 16 & 3 & 6 & 38 & 20 & 60 \\
\hline 17 & 7 & 11 & 68 & 64 & 54 \\
\hline 18 & 4 & 6 & 25 & 38 & 20 \\
\hline 19 & 3 & 4 & 45 & 67 & 32 \\
\hline 20 & 5 & 6 & 57 & 60 & 40 \\
\hline \multirow{2}{*}{ Ideal unit } & (Min column2) & (Min column3) & (Max column4) & (Max column5) & (Max column6) \\
\hline & 2 & 3 & 80 & 67 & 65 \\
\hline
\end{tabular}

* It means that first factory gives $3000 \$$ to its employees every month, pays $5000 \$$ for raw material and produce $40,55 \& 30$ sets of products type A,B\&C respectively. 
Table 2. CCR model results

\begin{tabular}{|c|c|c|c|c|c|}
\hline Unit & Efficiency & Unit & Efficiency & Unit & Efficiency \\
\hline 1 & 0.82 & 8 & 0.52 & 15 & 16 \\
\hline 2 & 0.94 & 9 & 0.96 & 17 & 0.91 \\
\hline 3 & 0.82 & 10 & 0.89 & 18 & 0.42 \\
\hline 4 & 0.65 & 11 & $1 *$ & 19 & 1 \\
\hline 5 & 0.95 & 12 & 0.83 & 20 & 0.84 \\
\hline 6 & 0.83 & 13 & 1 & & \\
\hline 7
\end{tabular}

* DMU with the efficiency of 1

Table 3. DEA-BSC model results

\begin{tabular}{|c|c|c|c|c|c|}
\hline Unit & Efficiency & Unit & Efficiency & Unit & Efficiency \\
\hline 1 & 0.54 & 8 & 0.33 & 15 & 0.74 \\
\hline 2 & 0.59 & 9 & 0.63 & 16 & 0.61 \\
\hline 3 & 0.34 & 10 & 0.41 & 18 & 0.27 \\
\hline 4 & 0.39 & 11 & 0.41 & 19 & 0.28 \\
\hline 5 & 0.64 & 12 & 0.67 & 20 & 0.75 \\
\hline 6 & 0.5 & 13 & 0.34 & Ideal unit & 1 \\
\hline 7 & 0.3 & 14 & 0.73 & 18 \\
\hline
\end{tabular}

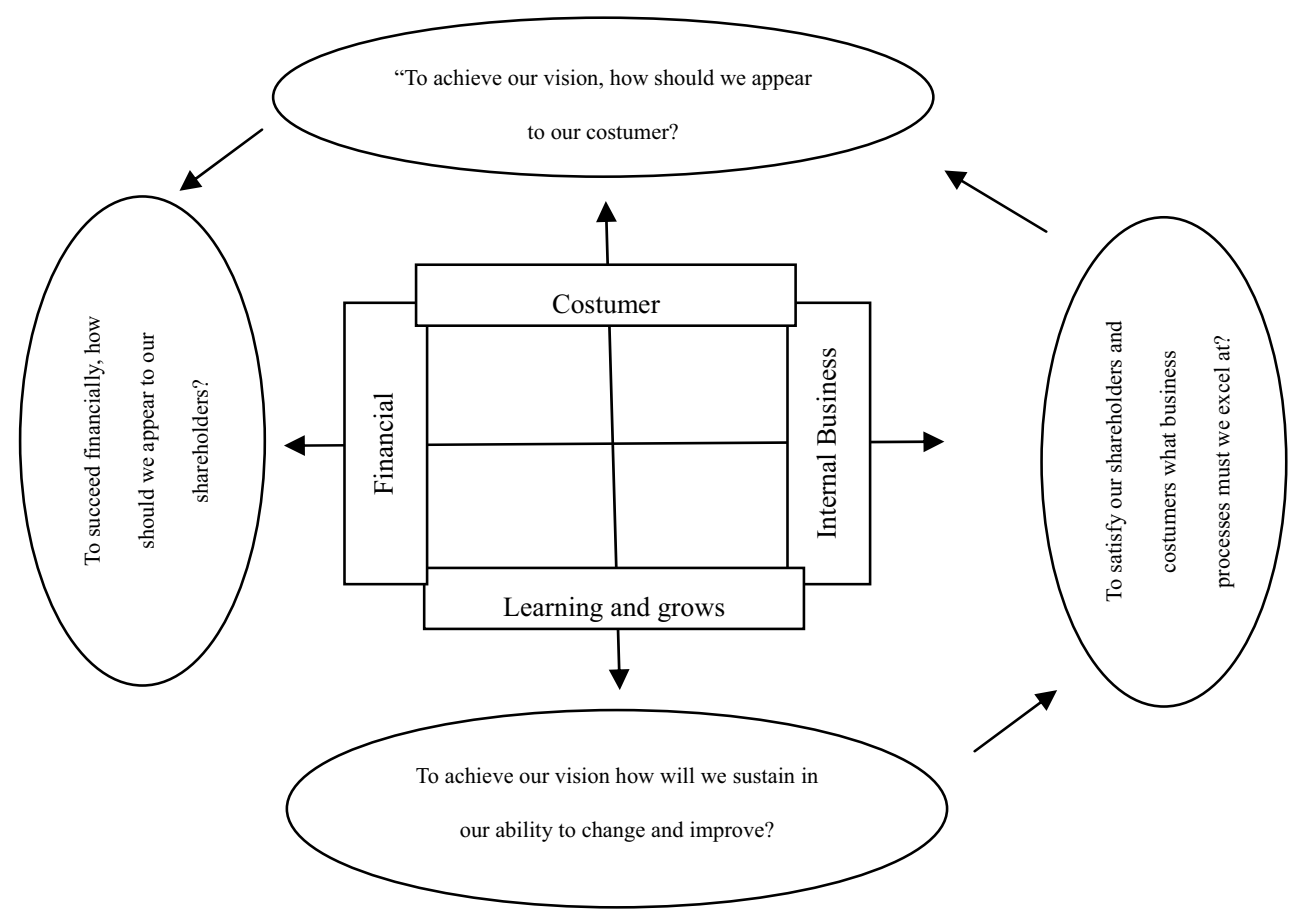

Figure 1. The interrelationship between perspectives of BSC model 


\section{Formulas}

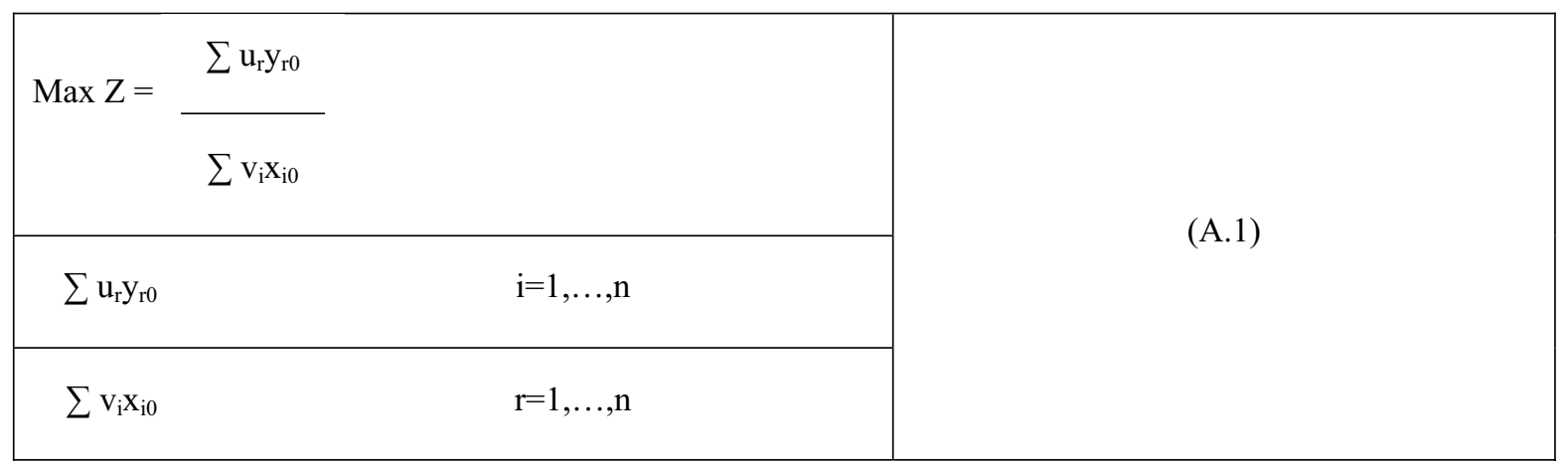

\begin{tabular}{|c|c|c|}
\hline$\sum \mathrm{u}_{\mathrm{r}} \mathrm{y}_{\mathrm{r} 0}$ & $<=1 \forall j$ & (A.2) \\
\hline$\sum \mathrm{v}_{\mathrm{i}} \mathrm{x}_{\mathrm{i} 0}$ & & \\
\hline
\end{tabular}

\begin{tabular}{|c|c|}
\hline $\operatorname{Maxz}_{1}=\sum \mathrm{u}_{\mathrm{r}} \mathrm{y}_{\mathrm{r} 0}$ & \\
\hline$\sum \mathrm{v}_{\mathrm{i}} \mathrm{x}_{\mathrm{i} 0}=1$ & (A.3) \\
\hline$\sum \mathrm{u}_{\mathrm{r}} \mathrm{y}_{\mathrm{r} 0}-\sum \mathrm{X}_{\mathrm{ij}}{ }^{*} \mathrm{v}_{\mathrm{i}}<=0 \quad \mathrm{j}=1,2,3 \ldots \mathrm{n}$ & \\
\hline $\mathrm{u}_{\mathrm{r}} \cdot \mathrm{v}_{\mathrm{i}}>=\dot{\varepsilon}$ & \\
\hline
\end{tabular}

\begin{tabular}{|c|c|}
\hline $\mathrm{Maxz}_{1}=\sum \mathrm{u}_{\mathrm{r}} \mathrm{y}_{\mathrm{r} 0}$ & \multirow{5}{*}{ (A.4) } \\
\hline$\sum \mathrm{v}_{\mathrm{i}} \mathrm{x}_{\mathrm{i} 0}=1$ & \\
\hline$\sum \mathrm{u}_{\mathrm{r}} \mathrm{y}_{\mathrm{r} 0}-\sum \mathrm{X}_{\mathrm{ij}} * \mathrm{v}_{\mathrm{i}}<=0 \quad \mathrm{j}=1,2$ & \\
\hline$\sum \mathrm{u}_{\mathrm{r}} \max \left(\mathrm{y}_{\mathrm{r} 1}, \mathrm{y}_{\mathrm{r} 2}, \ldots, \mathrm{y}_{\mathrm{rn}}\right)-\sum \mathrm{v}_{\mathrm{i}} \min \left(\mathrm{X}_{\mathrm{i} 1}, \mathrm{X}_{\mathrm{i} 2}, \ldots, \mathrm{X}_{\mathrm{in}}\right)<=0$ & \\
\hline $\mathrm{u}_{\mathrm{r}} \cdot \mathrm{v}_{\mathrm{i}}>=\dot{\varepsilon}^{\prime}$ & \\
\hline
\end{tabular}




\title{
China's Education Market and Foreign Suppliers
}

\section{of Education Services}

\author{
Jian $\mathrm{Xu}$ \\ Intensive Language Training Centre, Sichuan University \\ 24 Nanyiduan, Yihuanlu, Chengdu 610065, China \\ E-mail: xujian88@hotmail.com
}

\begin{abstract}
International trade in education services belongs to the category of international trade in services, which takes education services as its object. It has grown substantially over the past decades. Now it is a billion dollar industry including recruitment of international students, establishment of university campuses abroad, franchised provision and on line education. The education market in China is very large and still lack of development. It means opportunities to foreign suppliers of education services. WTO requires each member nation to make its own schedule of commitments in education services, and to explain its limitations on market access and national treatment as well as other limitations. Therefore, to understand China's education market, you must understand China's commitments in education services upon entry into WTO. This paper explains China's commitments in education services under the General Agreement on Trade in Services (GATS) and provides rough pictures about the meaning of China's commitments to foreign suppliers of education services that are eager to either enter into China's education market or absorb more Chinese students.
\end{abstract}

Keywords: Education market, Commitments, Cross-border supply, Consumption abroad, Commercial presence, Presence of natural persons

\section{Introduction}

Since 1990, international trade in education services has gained a giant development, which has brought much benefit to countries with advanced education systems. Unites States, Britain, Australia, Canada and New Zealand have all gained much income from education services. In China, although the educational services have also progressed very fast in recent years, the education market still needs developing. This will also give foreign suppliers of education services many opportunities to either develop their businesses in China or recruit more Chinese students. As required by WTO, each member nation must make its own schedule of commitments in education services, and to explain its limitations on market access and national treatment as well as other limitations. To understand China's education market, you must understand China's commitments in education services upon entry into WTO

\section{The main content of commitments in education services}

The related provisions of GATS on market access and national treatment are the legal basis on which WTO member nations can make specific commitments in education services.Therefore, the schedules of commitments of individual countries cover the commitments on market access and national treatment with respect to each of the four modes of supply of trade in education services: these are cross-border supply; consumption abroad; commercial presence; and presence of natural persons. That means for each of the four modes of supply of trade in education services, every WTO member nation should list out one by one in its schedule of commitments the restrictive measures it will take on the education services coming from other member nations.

The core part of schedules of commitments in education services is the four modes of supply of trade in education services; these are cross-border supply; consumption abroad; commercial presence; and presence of natural persons. That means for each of the four modes of supply of trade in education services, every WTO member nation should list out one by one in its schedule of commitments the restrictive measures it will take on the education services coming from other member nations. "With respect to the four modes of supply of education services, there are three basic ways of making commitments. First, 'no limitations'. That means a WTO member nation has committed not to impose any restrictive measures on the market access and national treatment of foreign suppliers of education services. Second, 'unbound'. That means a WTO member nation retains its control over trade in education services and doesn't assume any obligations, nor makes any commitments. It just acts according to its wishes. Third, 'limitations'. That means a 
WTO member nation has listed out the details of limitations on market access and national treatment in education services."(Wu, 2004) And with respect to each of the four modes of supply of education services, a WTO member nation has also made specific commitments on market access, national treatment.

In the schedules of commitments, commitments are split into two sections: First, "horizontal" commitments which stipulate limitations that apply to all of the sectors included in the schedule; these often refer to a particular mode of supply, notably commercial presence and the presence of natural persons. Any evaluation of sector-specific commitments must therefore take the horizontal entries into account. Second, specific commitments which apply to trade in services in a particular sector or subsector are listed. In short, Horizontal commitments are the basic commitments which apply to all sectors of education services. Specific commitments are further commitments based on the horizontal commitments with respect to specific sectors of education services. They are also the clarification of the specific commitments made with respect to the fore-mentioned four modes of supply of education services.

\section{China's commitments in education services}

\subsection{Horizontal commitments}

Chinese government allows foreign suppliers of education services to establish representative offices in China, provided that they do not engage in any profit-making activities. However, Chinese government has made no commitments on the establishment of branches by foreign suppliers of education services. In China, joint-ventures are divided into two types: equity joint ventures and contractual joint ventures. Foreign suppliers of education services can establish contractual joint ventures with their Chinese counterparts. And because the land in the People's Republic of China is owned by the government, any foreign suppliers of education services are required to obtain the land use rights before they can establish Sino-foreign joint ventures in education services with their Chinese counterparts. This is the basic requirement for foreign capitals to establish joint ventures in education services in China. The length of the validity of the land use rights of Sino-foreign joint ventures in education services is limited to fifty years. This is the maximum length of land use that Sino-foreign joint ventures in education services can have, and China's domestic suppliers of education services have the same treatment. And those managers, executives and specialists who are the senior employees of a foreign supplier of education services that has established a representative office in China, and who are temporarily moving as intra-corporate transferees, will be allowed to enter into China and have an initial stay of three years. Education services salespersons who are not based in China and receiving no remuneration from a source located within China, will be granted entry into China for up to ninety days, provided that they are only engaged in activities related to representing a foreign education service supplier for the purpose of negation for the sales of services of that supplier, and that such sales are not directly made to the general public and the salesperson himself is not engaged in supplying the service.

\subsection{Specific commitments}

Foreign suppliers of education services have to know that in China, compulsory education and special education (such as military, police, and political education etc.) are not included in the scope of education services, and that there are some limitations on market access for commercial presence of foreign suppliers of education services. For example, foreign suppliers of education services are not permitted to establish wholly-owned schools or other kinds of educational institutions within the territory of China. They can only establish joint schools with Chinese counter-parts, with foreign majority ownership permitted. Another thing that foreign suppliers of education services have to bear in mind is that China government can decide by itself whether to allow foreign suppliers of education services to enjoy the treatment equivalent to that of China's domestic suppliers of education services this is because Chinese government has made no commitments on the limitations on national treatment for commercial presence. The third thing that foreign suppliers of education services have to know is that Chinese government has made no limitations on market access and national treatment for consumption abroad, so there are no restrictions on Chinese people's going abroad to receive foreign education services. And because in China market access and national treatment for cross-border supply of education services are unbound, China is left to decide by itself the extent of permitting foreign suppliers of education services to provide Chinese people with education services like remote education and correspondence education, etc. The final thing that foreign suppliers of education services have to realize is that in China limitations on market access for presence of natural persons are unbound except as indicated in horizontal commitments, and that foreign individuals may enter into China to provide education services when invited or employed by Chinese schools and other education institutions. These individual must have a Bachelor's degree or above, and an appropriate professional title or certificate, with two years' or more related experiences.

China's commitments in education services took effect on $11^{\text {th }}$ December 2001 without any transition period and geographical limitation. However, since China reserves the approval power for foreign enterprises' access to relevant business, those commitments will not be implemented until relevant laws and regulations are officially promulgated. China also reserves the right to fix or guide the prices of education services by the government. 


\section{China's education services and foreign suppliers of education services}

China's commitments in education services upon its entry into WTO will have a major impact on its domestic education services. They also have huge effect on foreign suppliers of education services. While facing many challenges, China's education service industry has also gained a rare opportunity to absorb and introduce more foreign educational resources, and to speed up its development. Under the rules of WTO, foreign suppliers of education services are allowed to enter into China's education market, and China's education service institutions can also go out into the international education market to participate in the competition. Comprehensive and scientific analysis of China's commitments in education services will help foreign suppliers of education services seize the opportunity and make the initiative. Judging from the commitments in education services made by China, we can see that the main impact is on the four modes of supply of education services- "Commercial Presence, Consumption Abroad, Cross-border Supply and Presence of Natural Persons".

\subsection{Commercial presence}

With respect to commercial presence, on market access, China doesn't allow foreign suppliers of education services to establish wholly-owned schools or other kinds of educational institutions within the territory of China. However, foreign suppliers of education services can establish joint schools with Chinese counter-part, with foreign majority ownership permitted. Limitations on national treatment for commercial presence are unbound. They can set up joint schools with Chinese education service institutions either through introduction of foreign educational resources or in the form of capital investment. But limitations on national treatment for commercial presence in China are unbound. With the rapid development of Chinese economy, Chinese people's demand for education is increasing steadily. Foreign suppliers of education services can make most of this opportunity to enter China to get a share of China's education market. "As early as in 2004, there had been 165 Sino-foreign joint schools that could award foreign degrees. At present, there have been 1300 Sino-foreign joint schools and programmes."( Liu, Wei. 2006) Some overseas examination bodies are also showing strong interest in China's education market. In1982, TOEFL test and GRE test entered China. Afterwards, Japanese Language Proficiency Test (JPT), Business English Certificate Examination (BEC), International English Language Test System (IELTS), and Test of English for International Communication (TOEIC) have swarmed into China. So foreign test-related educational institutions can follow those overseas examination bodies and enter into China's education market by setting up joint schools with Chinese counterparts. They can hold pre-test intensive training programmes, publish test-preparing materials. These institutions are very competitive in terms of software and hardware. And because of their international background, they are very attractive to Chinese students in the age of economic globalization. Of course they will have to face the tough competition and challenge from the Chinese suppliers of education services

\subsection{Consumption abroad}

With respect to consumption abroad, China has no limitations on market access and national treatment. Since 1999, education service suppliers from the United Kingdom, Australia, New Zealand, Canada, the Netherlands and other countries have held education exhibitions in China's metropolises like Beijing, Shanghai, Guangzhou, Shenzhen, Xi'an, Shenyang, Dalian, Wuhan, Qingdao, Chengdu and other cities, attracting a large number of Chinese students and their parents. This has played a very good promotional role. There are no limits from Chinese government on Chinese citizens' going abroad to study, as long as they conform to the legal procedure, so there will be more Chinese citizens studying abroad. "In 2007, there were more than 150,000 Chinese people studying abroad, of whom 30,008 Chinese students obtained U.S.visas. According to statistics, each Chinese student spends on average $\$ 30,000$ in the United States each year. Therefore, in 2007, Chinese students studying in the United States spent 1.14 billion U.S dollars in this country."(news.xinhua.com 2008) Foreign suppliers of education services can make most of this trend and strengthen their contention for China's education market by attracting more Chinese students to their countries to receive education services.

While massive Chinese students' studying abroad has made China suffer from loss of talents and outflow of capital and has had a great impact on China's education services, China's suppliers of education services are also trying hard to enter into international education market to participate in the competition and recruit overseas students. Foreign suppliers of education services will have to face the stronger and stronger competition from China's education services. Any foreigners can come to China to receive education services so long as he or she meets the admission standards of China's education service institutions and does not violate the relevant laws of China. In the past, only a few Chinese universities and colleges were authorized by China's Ministry of Education to provide education services to foreign students. Now China' government has committed to lift restrictions on cross-border consumption. The number of Chinese universities and colleges that can recruit foreign students is growing very fast. "At the end of December 2006, there were a total of 162,695 foreign students from 184 countries studying in 519 universities, colleges and research institutions in China."(www.csc.edu.cn 2007) With the unique Chinese culture, low cost and strong economic development, China's education services are becoming more and more attractive to the students from Asian countries, 
especially eastern and southeastern Asian countries. Those suppliers of education services from eastern and southeastern Asian countries will have to readjust their strategies in order to protect their shares of the education market.

\subsection{Cross-border supply}

With respect to cross-border supply, many education materials from foreign suppliers of education services will enter China's education market, including various types of teaching books, audio-video teaching and learning materials, teaching equipment and computer teaching software. This will give foreign textbook publishing industry, audio-video publishing industry, teaching equipment manufacturing enterprises and the software industry great chances to develop their business in China and make huge profit. This is because China's textbook publishing industry, audio-video publishing industry, teaching equipment manufacturing enterprises and the software industry are still very weak. It's very hard for them to face the direct competition from foreign education services. At present, China's education market has been awash with foreign teaching and learning materials, advanced foreign audio-visual equipment and laboratory equipment. Although China's has made no commitments on market access and national treatment for cross-border supply, so theoretically speaking China can decide by itself the extent of permitting education services like remote education and correspondence education, etc. to be rendered to Chinese people by foreign suppliers of education services, it is still very hard for China's education authorities at different levels to control and manage foreign education service suppliers who manage to supply Chinese students with education services through computer networks or long-distance education. This means that foreign suppliers of education services can make use of modern information technology to provide education services to Chinese students through distance education services across borders.

\subsection{Presence of natural person}

With respect to presence of natural person, China has made no commitments on market access. But at the invitation of Chinese universities and other suppliers of education services, foreign individuals can enter into China as a natural person to provide education services. And this will not have a serious impact on China's domestic education services. It is good news for foreign individuals who want to come to China to help train a large number of high-level professionals. They can play a positive and facilitating role in improving the quality of China's education services, thus help China develop education services. In the future, there will be a substantial increase in the international flow of individuals among the suppliers of education services of both China and foreign countries. And the exchange between Chinese education service institutions and foreign education service institutions will also increase, so Chinese education service institutions will become more and more internationalized. On one hand, this will help foreign talented individuals to get employed in Chinese education service institutions. On the other hand, the present employees of Chinese education service institutions will have to face a higher demand on their personal qualities. Thus, foreign suppliers of education services, especially those from industrialized countries, will get opportunities to train those employees of their Chinese counterparts.

\section{Conclusion}

With China's entry into WTO, and because China has made commitments in education services, China's education market has been open to the outside world. This will inevitably cause the optimal allocation of educational resources, as China's market economy has gradually been established and perfected, bringing with it a unprecedented development to China's education services. This is a big industry. For example, within China, there is a huge market for language training. The total market value for English language training is estimated as being RMB 15 billion, a prosperous market indeed. And according to some experts, English language training will enjoy a quick development. By the year 2010, the total market value for English language training will reach RMB 30 billion. Therefore, for foreign suppliers of education services, there are a lot of opportunities in China's education market. Any foreign suppliers of education services can come to China to provide education services so long as they meet the requirements of China's government and do not violate the relevant laws of China. As long as they clearly see and timely seize the opportunities, foreign suppliers of education service will get a rapid development in China.

\section{References}

A Record High--The number of Chinese studying abroad has surpassed 150,000 in 2007. [Online] Available: http://news.xinhuanet.com/politics/2008-03/01/content_7697897.htm (Retrieved from 1 March 2008).

Guide to reading the GATS schedules of specific commitments and the list of article II (MFN) exemptions. [Online] Available: http://www.wto.org/english/tratop_e/serv_e/guide1_e.htm (Retrieved from 18 July 2008)

Liu, Wei. (2006). Look Ahead into Sino-Foreign Joint Schools under the Background of Globalization. Education in China, February 5.

MEMBER INFORMATION China and the WTO. [Online] Available: http://www.wto.org/english/the WTO_e/countries_china_e.htm (Retrieved from 15 September 2008) 
The Number of Foreign Students Studying in China Has Reached a Record High. [Online] Available: http://www.csc.edu.cn/gb/readarticle/readarticle.asp?articleid=2560 (Retrieved from 4 June 2007)

UNDERSTANDING THE WTO: BASICS. Principles of the trading system. [Online] Available: http://www.wto.org/english/theWTO_e/whatis_e/tif_e/fact2_e.htm (Retrieved from 28 October 2008)

UNDERSTANDING THE WTO: THE AGREEMENTS Services: rules for growth and investment. [Online] Available: http://www.wto.org/english/thewto_e/whatis_e/tif_e/agrm6_e.htm (Retrieved from 18 July 2008)

UNDERSTANDING THE WTO: THE ORGANIZATION. Members and Observers. [Online] Available: http://www.wto.org/English/thewto_e/whatis_e/tif_e/org6_e.htm (Retrieved from 5 August 2008)

Wu, Zhihui. (2004). Educational Globlization--China' Point of View and Problems. East China Normal University Press. Shanghai, p. 317. 


\title{
Corporate Social Responsibility Assessment
}

\section{of Chinese Corporations}

\author{
Jingfu Guo, Likun Sun \& Xueli Li \\ School of Economy and Management, Dalian Nationalities University \\ Dalian116600, China \\ E-mail:drguo@dlnu.edu.cn
}

This paper is supported by Liaoning Social Science Research Program (L07BJL011)

\begin{abstract}
This paper reviews the definitions of corporate social responsibility (CSR) in different contexts, combining current applications, we design a concise and effective set of assessment index system which can be used in assessing company social responsibility. The index system includes 6 first-level indexes and 32 second-level indexes and those Indexes reflect broad social concerns. We have collected data from 200 corporations in Dalian City area of China and applied the data to assess the companies' CSR. Our survey demonstrates that the CSR of the state owned enterprises is obviously better than that of foreign and private enterprises, the assessment is more superior in profitable enterprises than it in not profitable enterprises. With regarding to the question of employee interest, employees are not paid for the hours that they work overtime in many enterprises. The means to strengthen corporations' social responsibilities are discussed in details.
\end{abstract}

Keywords: Corporate social responsibility, Share-holder, Assessment index system

\section{Introduction}

Research of CSR has been the object of much study in recent decades with the advert of globalization and international trade. It is a concept that has attracted worldwide attention and acquired new resonance in the global economy. Moreover, while governments have traditionally assumed sole responsibility for the improvement of the living conditions of the population, society's needs have exceeded the capabilities of governments to fulfill them. Businesses do not operate independently of society and the earth; business impacts both the population and environment in which it operates. Mindful of its surroundings, a firm can control the triple-bottom-line, or the environmental, social and economic aspects of the firm's performance. Ultimately, responsibility to society links with environmental protection as concern for the earth grows among the public. Such concern is reflected in governmental regulation of the ecological factors.

Initially, the concept of CSR was exclusively associated with economic aspects, understood as the firm's obligation to maximize shareholder value. In this perspective we include Friedman's (1962) position, for whom corporate responsibility is simply carrying put actions that increase profits while respecting the rules of the game. However, Mcguire (1963) defends the idea that firms have responsibilities towards their environment that go beyond their legal and economic obligations. Another research stream thus appears relating the concept with marketing activities with a social dimension in areas such as environment protection, community development, resource conservation and philanthropic giving (Quazi and O’Brien, 2000). These approaches to social responsibility are quite narrow, however, since they are limited to particular aspects of the concept and do not take its multi-dimensional nature into account. Corporate social responsibility should be understood as a broad concept, since it takes in the whole set philosophical and normative issues relating to the role of business in society (Maignan and Ferrell, 2001), all the moral obligations that maximize the positive impact of the firm on its social environment and minimize the negative impact. These definitions have arisen in the management literature and more specifically from the research into corporate social actions. Of particular note is the Carroll's (1979) framework, one of the most widely accepted and used proposals to explain the construct. According to this model, firms have economic, legal, ethical and philanthropic obligations towards their environment, and these four dimensions make up corporate social responsibility. The first category is economic responsibility, providing a return on investment to owners and shareholders; creating jobs and fair pay for workers. Legal responsibility entails expectations of legal compliance and playing by the "rules of the game." Ethical responsibility portrays business as being moral, and doing what is right, just, and fair. The final type of responsibility is 
philanthropic contributions aimed at giving back to society.

Without centering on the content of corporate social behavior, stakeholder theory defines its field of application sustaining the idea that firms do not have responsibilities towards society in general, but rather they should only be concerned about individuals or groups that may be directly or indirectly affected by their activity. Specifically, employees, shareholders or investors, customers, suppliers, the government and the community in which the firm operates are included within the group of primary stakeholders; while the communications media and interest groups are regarded as secondary stakeholders, since they are not essential for the firm's survival. Taking both these theories into account, and from an integrative perspective, Maignan et al (1999) propose to define social responsibility as the degree to which firms assume economic, legal, ethical and discretionary responsibilities towards their stakeholders. The World Business Council for Sustainable Development defines CSR as "the commitment of business to contribute to sustainable economic development, working with employees, their families and the local communities", hence the fundamental idea of CSR is that business corporations have an obligation to work towards meeting the needs of a wider array of stakeholders (Waddock, S., C. Bodwell, 2002). At the core of the CSR debate is the idea that corporations should transition from a state of mere compliance to a mode of engagement, from harm minimization to value creation( Luetkenhorst, 2004). This view has become central to the CSR discourse. Also implied in the debate is the idea that the private sector is the dominant engine of growth the principle creator of value and managerial resources, and that it has an obligation to contribute to economic growth and opportunity-equitable and sustainable.

In this paper, we have collected data from 200 companies in Dalian City area and applied the data to assess the companies' CSR. The means to strengthen company social responsibilities are discussed in details. We hope our research provoke deeper thinking and greater rigor and attention to detail in this area of business research.

\section{Analysis on assessment of corporate social responsibility}

At present, in both domestic and international research, there is not a system of corporate social responsibility assessment index system which is popular, authoritative or acceptable, the research on corporate social responsibility mainly focuses on theoretical statements and absence of practical application. In this paper, we adopt the assessment index from reference (Guo Jingfu, 2008), this index system consists of six first-class indexes all of which are major concerns of society such as corporate economic responsibility, legal responsibility, stakeholder responsibility, social sustainable responsibility and so on. Meanwhile there are thirty two second-class index putting emphasis on employee benefits representing the essence of social responsibility of people oriented and paying more attention to employer's rights. The advantages of this index system lie in that this system almost considers every aspect of corporate social responsibility and is suitable to assess Chinese companies. From February to April in 2008, one survey was conducted to assess social responsibility condition of Dalian manufacturing corporations by questionnaires with the support of Dalian government and other relevant authorities. These questionnaires were given to 200 companies of which 156 companies answered it. We analyzed these questionnaires and reached conclusions as followings.

First, in regard to corporate property, $84.2 \%$ state-owned companies' answer with "yes", compared to $70.6 \%$ in full foreign-owned companies and $62 \%$ in privately-run companies. It is obvious that social responsibility condition of state-owned companies is better than foreign-owned companies and privately-run companies. The privately-run corporate has the poorest social responsibility.

Second, the companies with middle or small scale have poorer social responsibility in comparison with large scale ones. It proves that companies would have capability and motivation to carry out social responsibility only as their corporate attain to a certain size. Some companies have so small size, low management level and less fund that employee benefits can not be protected effectively and companies are absent of consciousness of social responsibility. Therefore companies should be encouraged to enlarge corporate scale through market annexation and acquisition, try to develop corporate management, improve competitiveness and strengthen corporate social responsibility consciousness and put it into practice in the meantime.

Thirdly, from the perspective of economic benefit, the companies with lower profitability have poorer social responsibility than those with high profitability. So profitability is the base to fulfill social responsibility. The corporate may be incapable to take some socially beneficial activities unless it operates well and has good profit. Whether the company runs well or not would have direct effect on every aspect of this company.

The fourth, we only take these into account and find that the most companies answer to economic index with "yes" and the percentage is almost $100 \%$. It means that the goal of any companies is to pursue economic benefit and profit maximization. The percentage of answer "yes" to the index of "public benefit" is lowest, only $32.3 \%$. It reflects that companies have no much enthusiasm to take part in socially beneficial activities. Concerning the index of "employee rights" which is the essential component of corporate social responsibility, especially the index of "working hours", we find state-owned companies follow national regulation, but almost $65 \%$ privately-run companies only have one holiday per week, even one day of rest for two weeks. In addition, the answer "no" to the index of "paying for overtime work" 
is over $50 \%$. So relevant labor administration should pay attention to such condition, strengthen supervision and protect employee rights.

\section{Ways to promote corporate social responsibility}

An enterprise's pleasant cooperation with its partners and its participation in charity and socially useful activities are beneficial for the shareholders to gain the maximum of profit and sustainable development.

\subsection{Cultivating enterprise managers' moral consciousness}

Enterprise managers' moral consciousness and personal ideas often affect their daily business management. Entrepreneurs' moral standards completely decide business ethics. Business ethics does not exist independently and abstractly, but exists in all aspects of business such as production, exchange, sale, distribution, and management, decision-making and so on. Meanwhile it is involved in all sectors of social life and has an impact on social moral atmosphere. Entrepreneurs' position in the enterprises determines that entrepreneurs play an key role in the process of enhancing corporate social responsibility. Therefore, efforts should be made to educate enterprise managers to establish a people-oriented and ethicized business philosophy and values.

\subsection{Constructing a reasonable framework for corporate social responsibility}

Social responsibilities are various and there should be a reasonable and integrated assessing system for them. Only by constructing an assessing system can we ensure a fair assessment of enterprises, eliminate the enterprisers and the public's misunderstanding of social responsibility and urge the enterprises to better fulfill their social responsibilities. It is of great necessity to construct a widely recognized and accepted assessing system for corporate social responsibility which is in line with China's national conditions and economic and social reality.

\subsection{Strengthening the guidance of government and the supervision of law}

Government, as the owner and manager of state-owned enterprises, puts forward normative requirements in the aspect of social responsibilities for state-owned enterprises. Meanwhile, it guides non-state-owned enterprises through policies, advocacy. Governments at all levels should become guidance of corporate social responsibility and build a systematic and complete platform to promote it. In addition, laws, as a state's mandatory means, have high authority. As a social member, enterprise is also under the supervision of it. Corporate social responsibility enforced by the state coercive power can gain itself general agreement from the society, increase its authority and become the principle accepted by all members of the society.

\subsection{Social environment and citizen oversight}

Environmental supervision is an indispensable means to promote social responsibility. It contains three ways. First, media and public opinion supervision, subjectively speaking, man and enterprise are self-serving economic man and economic organizations respectively. Objectively speaking, the contract can not be completed because of the prevalence of asymmetric information. These two factors working together can easily lead to the risk of moral hazard and adverse selection and may make business decision-making lack of fairness and justice. Enterprises or enterprise operators may use information superiority to pursue private interests at the expense of doing harm to others or the society or even violating the law. Information transparency can form public oversight, remind the enterprises to check their behavior frequently through the effect of public opinion, avoid self-serving, eliminate the grey areas and raise the standard of enterprises to promote the healthy development of enterprises. Second, interpersonal supervision, the mobility and unfamiliarity of interpersonal relationship in the enterprises increase correspondingly with the enlargement of the space of moral environment and increases of changes. Under such conditions, interpersonal supervision is in great need to be strengthened. Only by mutual supervision can we enable corporate behavior to further satisfy the ethical standard because business competitors, partners and clients are more and more and corporate behavior is more socialized. Meanwhile it is conducive to expand exchanges between enterprises and maintain normal social order. Third, citizen oversight, in addition to the management responsibility of government, as a citizen, every person also has obligations and responsibilities to do his or her bit so as to build a social environment which can give full play to public opinion supervision.

\subsection{Fostering entrepreneurial enthusiasm for charitable contributions}

Charities and relief can solve the problems of marketing behaviors; overcome the shortcomings in the first time distribution and make up for it in the second time distribution. In recent years, China has promulgated and implemented some charity related laws and policies that directly guarantee the development of charities. Meanwhile the reputation donation system should be established to encourage entrepreneurs to participate in donor activities. The private donors' donation acts can be encouraged by granting honorary title to them. According to the size of donations they give, different levels of honor will be granted to donors such as by setting up teaching posts in colleges and universities, establishing donor funds in research institutions to award honorary title. These also do goods to the development of enterprises. 


\section{Conclusion}

In the future, enterprises having international competitiveness should be those that are leading in technology, advanced in management and responsible for the society and those that integrate social, environmental and business stakeholders' responsibilities into corporate strategy, organizational structure and the process of management. In China, corporate social responsibility started relatively late, it is of necessity to strengthen the training and positive guidance of corporate social responsibility awareness, make the whole community, particularly the enterprises which mainly implement corporate social responsibilities, profoundly understand the rich connotation of it so as to promote the construction and implementation of corporate social responsibility.

\section{References}

Carroll, A. B. (1979). A Three-Dimensional Conceptual Model of Corporate Performance. Academy of management Review, 4(4), p. 497-505.

Friedman, M. (1962). Capitalism and Freedom, University of Chicago Press, Chicago.

Guo, Jingfu. (2008). A Discussion of Assessing and Strengthening Corporate Social Responsibility. Academic Exchange, P. 95-99.

Luetkenhorst, W. (2004). Corporate Social Responsibility and the Development Agenda. Intereconomics, 39(3), p. 157-168.

Maignan, et al. (1999). Corporate Citizenship: Cultural Antecedents and Business Benefits. Journal of the Academy of Marketing Science, 27(4), 455-469.

Maignan, I. \& O. C. Ferrell. (2001). Corporate Citizen as a Marketing Instrument-Concepts, Evidence and Research Directions. European Journal of Marketing, 35(3/4), p.457.

Mcguire,J. B. (1963). Business and Society, McGraw-Hill, New York.

Quazi \& O'Brien, Dennis. (2000). An Empirical Test of a Cross-national Model of Corporate Social Responsibility. Journal of Business Ethics, 25(1), p. 33-53.

Waddock, S., C. Bodwell. (2002). Responsibility: the new Business Imperative. The Academy of Management Executive, 16(2), p.132-147. 


\title{
Readiness to Be K-workers among Students
}

\section{of Engineering Education Institution in Malaysia}

\author{
Mohd Yusop Ab.Hadi, Jailani Mohd Yunos \& Noraini Kaprawi \\ Faculty of Technical Education, University of Tun Hussein Onn Malaysia \\ 86400 Parit Raja, Batu Pahat, Johor, Malaysia \\ Tel: 60-7453-8201_E-mail: yusop02@hotmail.com, yusop@uthm.edu.my
}

\begin{abstract}
Malaysia is a developing country and has been constructed a nation vision where the vision is to conceptualize the country become an industrial country in year 2020. Thus the country pertaining to calisthenics enough k-workers in sequence to fulfill human resources demand especially for industrial sector. However, industries organizational might be facing problems in getting k-worker pertinent with industrial needs. Therefore, getting and preparing k-worker is a challenge to engineering education institution. The aim of this research conducted is to identify the readiness of engineering education students to be emerged as competent k-workers in order to fulfill industrial needs. 638 of last semester engineering education students are randomly chosen as respondents. Eighty nine (89) items of readiness to be k-worker was validated by industrial authorities are applied for research instrument. Reliability of the instrument is 0.957. The finding shows that the level of students readiness is high but most of itemizes level of readiness could be increase to higher level and eight (8) itemizes founded fall into moderate level.
\end{abstract}

Keywords: Readiness, K-worker, Engineering education institution, Developing country

\section{Introduction}

As a developing country Malaysia is also not exempted from impacted of the tremendous volume of information and knowledge generated from all corners of the world. Developing countries are also impacted by the influences of the newly phenomenon which it is a borderless village concept. The concept emphasized that what ever changes outside the country will immediately effects the phenomena in the country. To secure from being the victims of developments, developing countries have to be proactive in implementing theory of globalization economic growth in the economic activities. This theory emphasizes on the development and value added of knowledge is essentials motivator for economic growth. According to Zalina, Raziah and Rizaudin (2001), cope with the knowledge are able to assist firm or industries to develop more effective production process approach and be capable to fulfill customers demand. Their statement was supported by Khairul Rizal (2004) who stated that new dimension in managing human resource is known as human capital management whereby industrial prominently utilize knowledge worker (k-worker) to achieve the production target. Engineering education system is believed by the developing country able to play rule in delivering the knowledge to the human resources (Abdullah, 2006) and (UNESCO, 2002).

\section{Background of the study}

Delahaye (2002) stated that most companies organization in the 90's since have had introduced learning organization concept and knowledge capital to administer industrial economy. The purpose of this concept is to be of assistance industrial organization chief executive officer to develop company's economy and to cope with global competition.

'Managers looked elsewhere for a long term solution. In 1990 Peter Senge, in his text The Fifth Discipline, popularized the concept of the learning organization - to survive, an organization had to continually learn and adjust to an ever changing environment. Chief executive officers, academics and researchers eagerly grasped this concept as a viable alternative to rational economic. However, the concept proved to be vast in its complexity and the writings of early 1990s, while providing important insights, had difficulty providing a sound, unifying and practical picture. Then in mid-1990s, the focus concentrated on an intriguing concept-the management of knowledge capital. It was suggested that the knowledge of an organization was remarkable and critical resource' (Delahaye, 2002).

Allee (1997) stated that 'Knowledge workers are continually learning, aware that knowledge has a limited shelf life' .His statement was advocated by Miller (1998) who described that k-workers are the workers who can utilize 
their intellectual and convert the idea into products, services or process. Allee (1997) views on the concepts of $\mathrm{k}$-worker, clearly showed that k-worker has the advantage of compliance to fulfill global job specification needs.

Engineering education institution, in this case, has a bigger role in preparing individuals with knowledge to generate a quality and competent task force. Che Mat (2000) founded that engineering education institution also have to provide trainees with the knowledge about preparation to enter job market. It will help trainees to be equipped amid

Realize self potential to operate career task given by industrial.

- Self development to fulfill job requirement.

- Ability to make decision.

- Willingness to execute work.

- Applied management skill in one's life.

Malaysia as one of the developing countries has also agreed with the views that the existing engineering education institutions has the responsibility to produce reliable k-workers in becoming industrial country by the year 2020 (Abdullah, 2006).

The target of creating engineering education institution in Malaysia is to produce human resources that equipped with of knowledge and skills as employee basic competence. There are several ministries in Malaysia given responsible to conduct the engineering education institution such as Ministry of Human Resources, Ministry of Entrepreneurial Development, Ministry of Youth \& Sport, Ministry of Agriculture and Agro-based Industry, Ministry of Home Affairs, Ministry of Defense, Ministry of Rural Development, Ministry of Unity and Social Development), and Ministry of Primary

Malaysia Industrial Training Institutes (MIT) is one of Malaysia's engineering education institutions, is also given role to produce industrial work force in order to fulfill the industrial demand (Human Resources Department, 2003). MIT was established by Ministry of Human Resources, Malaysia by the objective of to express expert industrial workers to assist developing the country. Till on April 2003 there are 14 MIT in Malayisa, and all MIT together enrolled the 8944 students in year 2003 and increase to 10028 in year 2005 (Human Resources Department, 2006).

\section{Problem statement}

Malaysia Industrial Training Institutes (MIT) as one of Malaysia's engineering education institutions, is also given role to produce industrial work force in order to fulfill the industrial demand (Human Resources Department, 2003). According to Nasta (1994) industrial companies and entrepreneurs are interested to identify whole engineering education system as a need for reengineering and improving the industrial weaknesses and strengthen the company economy. Therefore it is essential to conduct a comprehensive and deeper research to identify the readiness of MIT to be k-worker toward fulfills industrial need in developing country.

In the learning institution there are various factor will influence the quality of new knowledge accepted by the students. There are no assurances students will get all the knowledge and skills from learning institution even though they have ended their learning period. To mastering the knowledge among the students is also influenced by the teaching and learning process. This phenomena is also happen in engineering education institution. Storm (1996) suggested the need of engineering education institutions to build up students' self personality beside job competencies in order to fulfill the employer organizational requirement. In relation to this, a study should be conducted just before the students in engineering education complete their studies to join the job arena especially in the industrial sector. This is to identify the stage of their readiness to k-worker take in interest the progress of industrial need.

In short, the purpose of the research is to identify the readiness engineering education institution students to be k-worker to fulfill industrial need and the objective of the research is to identify the k-worker attributes which need to be increased in order to fulfill industrial requirement.

\section{Research methodology}

This is a survey quantitative research. The data collection method is through questionnaires only. The reliability of the questionnaires is high where is validated using Alpha Cronbach 0.957. The questionnaires contain of 89 items of readiness to be k-worker and the contain validity of the questionnaires was validated by industrial human resources management and management from engineering education institution.

Research respondent consists of 683 students of MIT selected randomly. They are studying in certificate programme of engineering education and in the last semester of final year. Respondent are required to identify their level of readiness to be k-worker by choosing one of the scales as shown in Table 1.

Data collected from students were analyzed by mean and standard deviation. The mean range to identify level of student's readiness to be k-worker is shown in Table 2. 


\section{Finding, discussion and suggestion}

Research finding showed that overall mean score of 89 items about engineering education students' readiness to be $\mathrm{k}$-workers are 3.889. This mean score is incorporated in high level mean range with sense that the level of engineering education students' readiness to be k-worker is high. The research implies MIT is succeeding in delivering knowledge and skills of k-worker to the students. In favor for Malaysia mastering in knowledge and skills of k-worker is highly demand to industrial management sequentially to activate industrial activities.

Although the level of engineering education students' readiness to be k-worker to fulfill industrial requirement are high, it still can be upgraded. These are based on the data collected from engineering education students that 13 out of 89 of $\mathrm{k}$-worker attributes are at the higher level. 68 out of $89 \mathrm{k}$-workers attributes are at the high level, 8 out of 89 are at the moderate level and no k-worker attribute at the low and lower level. 13 attributes of readiness to be k-worker among the engineering education at the higher level are shown in Table 3. On the other hand, eight attributes of readiness to be $\mathrm{k}$-worker among the engineering education students are at the moderate level. The attributes are shown in Table 4

Even though the general finding showed that the level of readiness to be k-worker among the engineering students is at the high level ( whole mean of the level of readiness to be k-worker is 3.889) nevertheless there are 76 attribute of $\mathrm{k}$-worker insist to increase for achieve at the higher level (higher level at mean value more than 4.5)

The increase of the atributes to be k-worker at the more higher level among the students is a need due to assist industrial capability in competing each other both from local and abroad companies. Readiness to be k-worker among the engineering education students are strongly needed especially in assisting the management of the company as worker in their company to be competitive thus attracting global investors to establish in the developing country. Malaysia, for example, the goverment are encouraging investor especially from multinational company to invest in Malaysia. In Penang the amount share invested from theUSA is about RM 1.5 billion, Japan RM976 million and Switzerland for RM 21 million. These enourmous capital are invested for industrial business activities in delivering product and services in the field of electrical and electronic, petroleum, metal design, food, textile and garment, non metal mineral, machine and tool tranportation and scientific instrument and tool. The connfident and trust investor in investing are influenced by effordable the country produce the k-worker that capable fulfill industries need (Wan Najib and Nurul Huda, 2007).

Increasing the level of readiness to be k-worker should be stressed and become the urgent agenda in the developing country. In Malaysia, it was recorded that the need of work force are deliberately increasing. In the year 2005 Malaysia required 1,430500 technician and professional assistance, and this amount are expected to be increased to 1,628700 in the year 2010 (Economic Plan Unit, 2006). Therefore the level of attributes to be k-worker below which can be found among the students' $\mathrm{k}$-worker attributes are suggested to be improved to highest level as depicted in Table 5. According to Moy (1999), workers whom are equipped with knowledge will help them to be excellent in accomplishing job task.

K-economy should be executed by k-worker. K-worker must be creative, imaginative and frequently in pursuing the recent ideas and be able to gain multiple skills. It is imperative to up grade the level k-worker attributes among engineering education students to be k-worker as confirmed by Fletcher (1977) who explained about the knowledge function in human life as knowledge will gear human to fulfill the quality of life in modern society.

Based on research finding it is showed that the level of readiness to be k-worker among the engineering education students have the opportunities and space to up grade to more higher level (the whole mean should increase up to over 4.5). The research finding below showed that the students are willing and desiring to upgrade their level of to be k-worker,

- 'Willing to learn new knowledge related to work '(mean 4.462).

- 'Must learn new technology due to rapid changes in technology' (mean 4.462).

- 'Willing to learn new technology related to work' (mean 4.38).

- 'Willing to accept comment/advise when making mistake' (mean 4.296).

- 'Can work in a team to achieve organizational goal' (mean 4.288).

These levels are pictured that they are willing and hoping will get more guidance from industries to be competence in working from industrial perspectives. These research finding are approximately similar to research finding by Armitage, et all. (2003) namely beginning worker are still need guidance and dependent to industrial management to assure they will do the right job but not too dependent on other workers, because it will effected to their working concentration and might troubled the effectiveness of industrial activities.

Research finding that showed readiness to be k-worker among the engineering education students should be up graded is also similar to research finding by Wexley and Latham (2002).They also suggested five steps of reducing gap 
between students' knowledge and the knowledge needed by industries which should be implemented in engineering education institution,

- Engineering education institution get job description from the industries.

- Identify any tasks and responsibilities job in the job description.

- Engineering education institution identifies knowledge, skills and abilities need by worker for accomplish the job task and responsibilities.

- Engineering education institution forms the engineering education program.

- Engineering education institution implement engineering education program.

Although the body of the knowledge and skill that formulating from the job description forecasted will reduce the gap between level of readiness to be k-worker among engineering education students and the level of readiness to be $\mathrm{k}$-worker need by industrial, teaching and learning process passing by students is also manipulated the effectiveness of learning. Meighan (1995) founded that beside contain of the subject the effectiveness of achieving learning out comes are also influenced by the teaching and learning process implemented to the students. Loose and Abdul Halim (2004) suggested in order to reach the effective of engineering education learning process, the institution have to exploit two popular training approach namely Competency-Based Education and Training and Experience-Based Education and Training.

\section{Conclusion}

Previous discussion about the research finding showed that the engineering education student in final year and last learning semester has fulfilled almost level of readiness to be k-worker need by industries. However the level value of readiness to be k-worker are able to up grade on ward and reinforcement until the students end their studying and going into job market.

Cooperativeness among engineering education institution and industrial management is compulsory as an effort to set up scope and type of knowledge for performing the readiness to be k-worker among the students in order to fulfill industrial need.

\section{References}

Abdullah, A, B. (2006). Malaysia Ninth Planning 2006-2010. Kuala Lumpur: Malaysia Information Ministry.

Allee,V. (1997). Twelve Principles of Knowledge Management. Training and Development. Journal of Knowledge Management, No.11, 71-75. [Online] Available: http://www.nelh.nhs.uk/knowledge management $/ \mathrm{km}$ 3/knowledgeworker.asp (Retrieved from November 1997).

Armitage, A., Bryant,R.,\& Dunhill,R. (2003).Teaching and Training in Post-Compulsory Education. (2 ${ }^{\text {nd }}$ ed). Philadelphia: Open University Press.

Che Mat (2000). Career Management. Kuala Lumpur: Malaysia News Publication.

Delahaye, B.L. (2000). Human Resource Development. Brisbane: John Wiley \& Son.

Economic Plan Unit (2006). Malaysian Ninth Planning. Putra Jaya, Malaysia.

Fletcher, S. (1997). Analysing Competence. Tools and Techniques for Analysing Jobs, Roles and Functions. London:Kogan Page.

Human Resources Department (2003). Industrial Training Institute Brochure. Kuala Lumpur, Malaysia. Human Resource Ministry.

Human Resources Department (2006). Enrollment Statistical Malaysia Industrial Training Intake and Garduate Students by Year 2000-2006. [Online] Available: http://www.jtr.gov.my (Retrieved from 10/6/2006)

Khairul Rizal, R. (2004). Human Capital. Malaysia. Press News Publication.

Loose, G. and Abdul Halim, J. (2004). Experience-Based Training for Malaysia: Private-Sector's Involvement in Training K-Workers. Journal of Technical Education, Vol. 3, No.1, 14 - 22.

Meighan, M. (1995). How to Design and Deliver Induction Training Programmes (2nd ed). London:Kogan Page.

Miller, W.C. (1998). Fostering Intellectual Capital. HR Focus, 75 (1), January 1998, 9-10. [Online] Available: http://www.nelh.nhs.uk/knowledgemanagement/km3/knowledge_worker.asp (Retrieved from 12th September 2004)

Moy, J. (1999). The Impact of Generic Competencies on Workplace Performance. Australia: NCVER.

Nasta, T. (1994). How To Design a Vocational Curriculum. London: Kogan Page Limited. 
Storm, B.T. (1966). The Role of Philosophy in Education - for Work. Journal of Industrial Teacher Education, Vol. 33, No. 2, 77-82.

UNESCO (2002). Technical and vocational education and training: A vision for the twenty-first century Recommendations. Paris: Section for Technical and Vocational Education, UNESCO. 1-68.

Wan Najib, W, D. and Nurul Huda, H. (2007). United State dominant investment in Penang, Malaysia. Kuala Lumpur, Malaysia: Press Malaysia News Publication.

Wexley, K. N., and Latham, P. G. (2002). Developing and Training Human Resources in Organisation ( ${ }^{\text {rd }}$ ed.). New Jersey: Pearson Education Inc.

Zalina, Z., Raziah, M. T. and Rizaudin, S. (2001). Knowledge Based Industries: Contribution to Malaysian Economy. Paper presented in Socio Economy and Information Technology Seminar on 2-4 November 2001, at Holiday Villa Hotel , organized by University of Northern Malaysia.

Table 1. Scale Level of Readiness To Be K-worker

\begin{tabular}{cccccc}
\hline & lower & Low & Moderate & High & Higher \\
\hline Scale & 1 & 2 & 3 & 4 & 5 \\
\hline
\end{tabular}

Table 2. Interpretation Level of Readiness To Be-K-worker Hayat dan dd

\begin{tabular}{|c|c|c|}
\hline \multicolumn{3}{|c|}{ Level interpretation } \\
\hline$>4.5$ to $\leq 5$ & Higher & \\
\hline$>3.5$ to $\leq 4.5$ & High & \\
\hline$>2.5$ to $\leq 3.5$ & Moderate & \\
\hline$>1.5$ to $\leq 2.5$ & Low & \\
\hline 1 to $\leq 1.5$ & Lower & \\
\hline K-worker attribute & Mean & Std. Deviation \\
\hline Willing to learn new knowledge related to work & 4.462 & .586 \\
\hline Must learn new technology due to rapid changes in technology & 4.403 & .653 \\
\hline Willing to learn new technology related to work & 4.381 & .627 \\
\hline Always prioritize the safety aspects while working & 4.328 & .640 \\
\hline Willing to accept comment/advise when making mistake & 4.296 & .640 \\
\hline Can work in a team to achieve organizational goal & 4.288 & .592 \\
\hline Can dress neatly & 4.277 & 668 \\
\hline $\begin{array}{c}\begin{array}{c}\text { Knowing the mechanism to save own self secure when there is any accident at } \\
\text { workplace }\end{array}\end{array}$ & 4.273 & .640 \\
\hline Ready to help co-workers who is having work problem & 4.268 & .600 \\
\hline Willing to ask in order to improve quality of working & 4.268 & .635 \\
\hline Can suit in workplace & 4.234 & .577 \\
\hline Confident to fulfill the rules and regulations at workplace & 4.218 & .669 \\
\hline Can communicate with top management harmoniously and effectively & 4.218 & .630 \\
\hline
\end{tabular}


Table 4. Moderate Level of Engineering Education Students Readiness Attributes to Be K-worker

\begin{tabular}{|c|c|c|}
\hline K-worker attribute & Mean & Std. Deviation \\
\hline Able to use English to increase work quality & 3.393 & .874 \\
\hline Ever learn the thinking skill theory & 3.384 & .987 \\
\hline Able to use English to get information related to work & 3.362 & .868 \\
\hline Able to use English to get information related to work & 3.348 & .909 \\
\hline Experience deliver any information using English & 3.326 & .990 \\
\hline Capable to deliver work related information using English as a medium & 3.304 & .892 \\
\hline Able to use the right English to write work report & 3.238 & 919 \\
\hline Experience writing report using English & 3.230 & .963 \\
\hline K-worker attribute & Mean & Std. Deviation \\
\hline Know how to use internet to gather information related to work & 3.690 & .948 \\
\hline Capable to do work without supervision & 3.687 & .847 \\
\hline Have learned problem solving theory & 3.677 & .846 \\
\hline Know about the work place environment & 3.672 & .742 \\
\hline Have experienced practicing thinking theory while working & 3.663 & .845 \\
\hline Know the best technique to guarantee the quality assurance & 3.643 & .705 \\
\hline Have practiced the job problem solving theory & 3.621 & .869 \\
\hline Know how to use the tools to do the work effectively & 3.614 & .708 \\
\hline Can determine the other job scope & 3.582 & .815 \\
\hline Experience in solving work problems & 3.581 & .864 \\
\hline Can determine the difficult part of work to do & 3.498 & .838 \\
\hline Know the types of industries to work after finished studying & 3.428 & .967 \\
\hline Able to use English to increase work quality & 3.393 & .874 \\
\hline Ever learn the thinking skill theory & 3.384 & .987 \\
\hline Able to use English to get information related to work & 3.362 & .868 \\
\hline
\end{tabular}




\title{
The Relationship among Knowledge Management, Organizational Learning, and Organizational Performance
}

\author{
Shu-hsien Liao \\ Graduate School of Management Sciences, Tamkang University \\ No. 151, Yingjuan Road, Danshuei Jen, Taipei 251, Taiwan, ROC \\ Tel: 886 - 2- 2621-5656\#3396 Fax: 886 - 2- 26223204 E-mail: Michael@mail.tku.edu.tw \\ Chi-chuan $\mathrm{Wu}$ (Corresponding author) \\ Graduate School of Management Sciences, Tamkang University \\ No. 151, Yingjuan Road, Danshuei Jen, Taipei 251, Taiwan, ROC \\ Tel: 886 - 2- 2264-1069 Fax: 886 - 2- 2265-6806 E-mail: ccwu@ttu.edu.tw
}

\begin{abstract}
Knowledge management (KM) and organizational performance are believed to be essential of the success in business. The different results in literatures which declare KM affects organizational performance positively. But there are still some confusing relations between KM and organizational learning (OL). Accordingly, we propose some hypotheses to verify relationships among KM, organizational performance, and organizational learning (OL). Base on a sample of Taiwan knowledge-intensive firms engaged in manufacturing, and financial sectors, data are collected using a mail survey, and hypotheses are tested using structural equation modeling. This paper presents OL as a coordinating mechanism, and the results support it in these samples. Empirical evidence also supports the perspective that KM affects organizational performance through OL. This paper is one of the empirical supports for the role of OL as a mediator between KM and organizational performance. Therefore, the positioning of OL as a mediator is also an important contribution to our thinking on this topic.
\end{abstract}

Keywords: Knowledge management, Organizational performance, Organizational learning, Structural equation modeling

\section{Introduction}

According to the resource-based view (RBV), firms gain and sustain competitive advantage by deploying valuable resources (Barney, 1991; Grant, 1996). Undoubtedly, resources accumulation is crucial in influencing business success. However, the straightforward application of the RBV in predicting firm success is too simplistic. In knowledge economy, $\mathrm{KM}$ is an important element as well as land, labor, and entrepreneurship. Knowledge management capabilities (i.e., knowledge acquisition, knowledge conversion, and knowledge application) are rooted in the operation of a firm and are derived from configurations of organizational structure and culture (Grant 1996; Moorman 1995).

Knowledge management (KM) and organizational performance are essential of the success in business. The different results in literatures that declare KM affects organizational performance positively. In Darroch (2005) research, the results support some KM process positively affects performance. She claims that knowledge acquisition doesn't positively affect performance directly, and knowledge dissemination doesn't positively affect performance, either. Accordingly, the first objective of this paper is to re-examine the relationship between KM and organizational performance.

Even though recent studies have examined the relationship between KM and organizational performance, this research continues to be hampered by the lack of organizational learning. As Tippins and Ravipreet (2003) mention the relationship between IT competency and firm performance is mediated by organizational learning. Also, KM and OL are two similar concepts, and always confuse by managers. Accordingly, the second objective of this paper is to re-examine the relationship between KM and OL, and propose a mediating conceptualization of OL.

The knowledge-intensive sectors are selected because of having large amount of knowledge input, short product life 
cycles, high demand for customized products, and great quantity of production value (Liao et al., 2007). Thus, the results of surveys involving Taiwan knowledge-intensive firms provide a rich data set of information regarding KM behaviors in unstable business environments.

In the sections that follow, we begin with a discussion on the relationship between KM, organizational performance, and OL. Following this, we develop hypotheses representing the relationships between independent variables and dependent ones. We test our hypotheses with the structural equation modeling technique, using data collected from employees in manufacturing and financial firms. Finally, we conclude with a discussion of the results and implications.

\section{Literature review and hypotheses}

\subsection{Knowledge management}

Information is becoming ever more important in our economy now, and most business take that knowledge can confer competitive advantage. But most business has been flooded with information, and most of us have more of it than we can handle. Knowledge management (KM) tries to resolve the troublesome paradox for us (Anthes, 1998).

Gold, Malhotra, and Segars (2001) examine that the issue of effective knowledge management from the perspective of organizational capabilities. This perspective suggests that a knowledge infrastructure consisting of technology, structure, and culture along with a knowledge process architecture of acquisition, conversion, application, and protection are essential organizational capabilities or "preconditions" for effective knowledge management. The results provide a basis for understanding the competitive predisposition of a firm as it enters a program of knowledge management.

Researchers have identified many aspects to this knowledge management process: capture, transfer, and use(Delong, 1997); acquire, collaborate, integrate, experiment (Leonard, 1995); create, transfer, assemble, integrate, and exploit (Teece, 1998); create, transfer use (Skyrme, 1998, Spender, 1996); and create, process (Ivers,1998). An examination of these various characteristics enables us to group them into four broad dimensions of process capability-Acquisition Process, Conversion Process, Application Processes, and Protection Process (Gold et al., 2001).

Cui et al. (2005) also mention that knowledge management capabilities consist of three interrelated processes: knowledge acquisition, knowledge conversion, and knowledge application (Gold, Malhotra, \& Segars, 2001). Knowledge is not only an important resource for a firm, but also it serves as a basic source of competitive advantage (Conner and Prahalad 1996; Gold, Malhotra, and Segars 2001; Grant 1996; Jaworski and Kohli 1993). Therefore, knowledge management capabilities refer to the knowledge management processes in an organization that develop and use knowledge within the firm (Gold, Malhotra, and Segars 2001).

With effective and efficient KM process, most companies claims it will be helpful to organizational performance. Accordingly, KM is taken for granted an important antecedent of organization performance or innovation (Darroch, 2005). But there are still some different results in KM sub-processes, or sub-dimensions, and organizational performance. It needs to verify very carefully.

And, literatures in KM discuss different influence on OL. Some authors find these two focuses are cause and effect simultaneously, and some authors take OL is a cause, KM is an effect; or opposite. In these studies, researchers implicitly assume a perspective of $\mathrm{OL}->\mathrm{KM}$ effect in which the causal direction runs primarily from $\mathrm{OL}$ to $\mathrm{KM}$. And a KM -> OL effect could also account for the associations between KM and OL (Su and Hsieh, 2003, 2004). In this perspective, $\mathrm{OL}$ is viewed as a reaction to KM rather than an action that contributes to KM. So, from the RBV, this study adopt $\mathrm{KM}->$ OL effect which view OL is a reaction to $\mathrm{KM}$.

\subsection{Organizational performance}

Performance is a recurrent theme in most branches of management, and it is of interest to both academic scholars and practicing managers. Although the importance of the performance concept (and the broader area, organizational effectiveness) is widely recognized, the treatment of performance in research setting is perhaps one of the thorniest issues confronting the academic researcher today. With the volume of literature on this topic continually increasing, there appears to be little hope of reaching any agreement on basic terminology and definitions. Some have expressed considerable frustration with this concept. Therefore, financial performance, operational performance, and organizational effectiveness should involve in performance (Venkatrman \& Ramanujam, 1986).

From a traditional perspective, organizational performance is commonly referred to as financial performance where considerations of budgets, assets, operations, products, services, markets and human resources are crucial in influencing the over-all bottom-line of an organization(Dixon, 1999; Thurbin, 1994; Smith, 1999). As such, the financial benefits of organizational performance are often associated with organizational success (Thurbin, 1994). However, the notion of performance embraces a far wider dimension of interpretations. With the focus on organizational learning, the performance outcomes associated with it need to be more carefully dealt with. The importance of performance measurement system is manifold. Not only does it demonstrate how an organization does, how well it does it and how much progress it makes over time in archiving its goals, most importantly, it helps to manage organizational change 
(Yeo, 2003). Hence, qualitative measures are more appropriate in investigating these key objectives that dominate and direct decision-making and action-taking levels (Thurbin, 1994; Herdges, 1998).

In Darroch (2005) research, she uses comparative and internally reflective performance measures, for example" Compared with the industry average, our company is more profitable" and internally reflective performance measures, for example, "We are more profitable than we were five years ago". These performance measures capture both financial measures and non-financial measures (e.g. market share and sale growth.)

However, similar to any organizational resource, effective knowledge management through the development of capabilities should contribute to key aspects of organizational performance (Andrew, 2001). Also, when firms develop greater knowledge management capabilities, they can more effectively develop marketing offerings to meet customer needs (Hunt 2000). With greater knowledge management capabilities, firms can obtain and use knowledge more effectively and efficiently, which results in above-normal performance. Thus, this study propose,

H1: Knowledge management affects organizational performance positively.

\subsection{Organizational learning}

In this rapid change economics volatility and uncertainty, many organizations are striving to survive and remain competitive. In order to develop and perform, organizational learning (OL) has been regarded as one of the strategic means of archiving long-term organizational success (Senge, 1990; Harung, 1996; Cunningham and Gerrard, 2000). Therefore, the analysis of organizational learning has become an increasingly important area recently. Various works have dealt with the analysis of this construct from differing viewpoints.

Jerez-Góomez et al.(2005) mention that there are many studies that focus on this construct using a psychological approach (Cyert and March, 1963; Daft and Weick, 1984), a sociological approach (Nelson and Winter, 1982; Levitt and March, 1988), or from the point of view of Organizational Theory (Cangelosi and Dill, 1965; Senge, 1990; Huber, 1991). More recently, organizational learning has been considered, from a strategic perspective, as a source of heterogeneity among organizations, as well as a basis for a possible competitive advantage (Grant, 1996; Lei et al., 1996, 1999).

One of the traditional ways to measure learning has been to use so-called "learning curves" (Yelle, 1979; Lieberman, 1987) and "experience curves" (Boston Consulting Group, 1968). However, these curves are "incomplete measuring tools" (Garvin, 1993, p. 89). Organizational learning is a complex multidimensional construct . . . encompassing multiple sub processes" (Slater and Narver, 1994, p. 2). So, Pilar et al. (2005) consider organizational learning to be a latent multidimensional construct including managerial commitment, systems perspective, openness and experimentation, and knowledge transfer and integration.

Facing the current uncertainty environment, business must keep learning to maintain its competitiveness. And, organizational learning will develop well base on well structured knowledge in organizations. In other words, business could have organizational learning capabilities underlying well individual learning (Nonaka and Takeuchi, 1995).

The experimental experience of English enterprises, Garratt (1990) finds that a learning organization is the application of organizational development and learning. In order to satisfy consumers' capricious demands, organization should develop personal or group learning abilities. In order to develop learning abilities, organization should complete well knowledge management process. Without knowledge management, one organization can't develop personal or group learning abilities (Garratt, 1990, Su, Huang, and Hsieh, 2004).

Pilar et al. (2005) also argue that knowledge and, more specifically, its acquisition or creation, along with its dissemination and integration within the organizations; become a key strategic resource to organizational learning. Organizational learning is seen as a dynamic process based on knowledge, which implies moving among the different levels of action, going from the individual to the group level, and then to the organizational level and back again (Huber, 1991; Crossan et al., 1999).

As a viewpoint of system, WeiLing Ke and Kwok Kee Wei (2006) discuss and identified knowledge is the antecedent and the base of organizational learning. Thus, this study propose,

$\mathrm{H} 2$ : Knowledge management affects organizational learning positively.

Various researches have long acknowledged the importance of organizational learning to overall performance. An organization with a strong organizational learning is not simply a collector or storehouse of knowledge but a processor of it. Feedback from customers, channels, and competitors must be used to develop core competence. The strategic literature suggests that good strategy will allow businesses to earn long-run supernormal profits. Therefore, this study propose,

H3: Organizational learning affects organizational performance positively.

As Tippins and Ravipreet (2003) mention the relationship between IT competency and firm performance is mediated by 
organizational learning. From literature review, knowledge management affects organizational learning positively (Garratt, 1990, Su, Huang, and Hsieh, 2004). In Su, Huang, and Hsieh (2004), OL mediates the relationship between KM flow factors and KM flows. Darroch (2005) also finds that knowledge acquisition had more indirect than direct influence on organizational performance. Therefore, this study propose,

H4: Organizational learning will be a mediator between knowledge management and organizational performance.

\section{Method}

\subsection{Sampling and data collection}

According to the OECD's definition in 2001, there are two types of knowledge-intensive industries: The first type is high-tech industrial companies in the manufacturing sector, which include the electronic, aerospace, and biotechnology industries. The second type is the knowledge-intensive services, which include education, communications, and information services industries.

The knowledge-intensive sectors are selected because of having large knowledge input, short product life cycles, high demand for customized products, and great quantity of production value (Liao et al., 2006). Thus, the results of surveys involving Taiwan knowledge-intensive firms provide a rich data set of information regarding KM behaviors in unstable business environments. In Taiwan Economic Forum, knowledge-intensive industry to real GDP is 36.7\% in 2004. According to Ministry of Economic Affairs reports, the percentage of value-added, this created by Taiwan's domestic knowledge-intensive services to the GDP increase from 37.7 percent in 1991 to 43 percent in 2001. Therefore, Taiwan's domestic industry structure is rapidly shifting towards a more knowledge-intensive approach. The firms selected for empirical study were chosen from the companies listed in Common Wealth Magazine's Top 1000 manufacturers and Top 100 financial firms in 2007.

A total of 600 questionnaires were mailed between Jun. 2007 and Sep. 2007, with 327 valid and complete responses used for subsequent quantitative analysis. Of the 342 in our effective sample, 15 are not avail for analysis. After accounting for respondent refusal and unusable surveys due to substantial missing data, a total of 327 questionnaires responded to our survey. The final response rate, defined as the number of usable responses received from the final sampling frame, is $54.5 \%(327 / 600)$.

Table 1 lists the study's sample distribution according to industry, gender, education, and departments.

\subsection{Measures}

To adequately build the constructs for testing our hypotheses, we perform a comprehensive review of the literature. From this review, we borrow and adapt valid multiple-scale items. In this study, 5-point Likert scale (1 totally disagree to 5 totally agree) is used. The questionnaire is refined base on a pilot study conducted with managers, and pre-tested conduct with those different from pilot. The format and content of the questionnaire items are initially developed from thorough literature review, and all items are listed in appendix.

We define knowledge management as the process of knowledge acquisition, knowledge conversion, and knowledge application. Knowledge acquisition is defined as the process to seek and acquire new knowledge, or create new knowledge out of existing knowledge through collaboration between individuals and business partners. Knowledge conversion is defined as the ability to make knowledge useful. Knowledge application is defined as the process oriented toward the use of knowledge. We adapted the scale for knowledge management from Gold, Malhotra, and Segars (2001).

Organizational learning is defined as the activities which organizations do in transformation of learning capability including individuals and competitors (Jerez-Gomez et al., 2003). It is considered to be four dimensions: management commitment, system perspective, openness and experimentation, and knowledge transfer and integration. Management commitment is to recognize the relevance of learning, and to develop a culture that promotes the acquisition, creation, and transfer of knowledge as fundamental values. System perspective entails bringing the organization's members together around a common identity. Openness and experimentation is a climate that welcomes the arrival of new ideas and points of view, both internal and external, allowing individual knowledge to be constantly renewed, widened, and improved. Knowledge transfer and integration refers to two closely linked processes, which occur simultaneously rather than successively internal transfer and integration of knowledge.

All the performance dimensions are measured from the perspective of the focal firm. We adapted the scale for organizational performance from Emden, Yaprak, and Cavusgil (2005). Both financial and market performance are measured relative to the focal firm's competitors. Financial performance relates to the success of the business programs in relation to the resources employed in implementing them. We use the specific components which are profitability, ROI, cash-flow, and cost control. Market performance is the success of a business' products and programs in existing businesses and in those related to the future positioning of the firm. The specific components of this measure are market share, market development, and product development. Partnership performance relates to the achievement of 
organizational objectives concerning the firm's partners, in terms of the strength, stability, and sustainability of their relationships.

\subsection{Analytical approach}

This study applies the item-to-total correlation and Cronbach's alpha to establish the adequacy of the measurement model. This study then performs path analysis in LISREL for hypotheses testing (Hair et al., 2006; Nunnally, 1978). The path analysis procedure is common in studies in which a small sample size restricts the use of full structural equation models (Li and Calantone, 1998; Chaudhuri and Holbrook, 2001).

\section{Results}

The study adopts a multi-step approach for data analysis. The analyses include testing the measurement model by subjecting our measures to a series of confirmatory factor analyses (CFA) by using SPSS12.0 and LISREL 8.51. LISREL's 8.51 maximum likelihood program (Joreskog and Sorbom, 1996) is implemented to test the theoretical model proposed. This method is characterized by its flexible interplay between theory and data, as well as its bridging of theoretical and empirical knowledge for a better understanding of the real world (Fornell, 1981). Such analysis allows for modeling based on both latent variables and manifest variables, which is a property well suited for the hypothesized model, where most of the represented constructs are abstractions of unobservable phenomena.

Table 2 displays the means, standard deviations of variables and their correlations. As can be seen, the following relationships exist between the research variables.

(1) Relationship between knowledge management and organizational performance: Knowledge management is positively related to organizational performance, meaning that business with more knowledge management show higher capability in enhancing organizational performance.

(2) Relationship between knowledge management and organizational learning: Knowledge management is positively related to organizational learning, meaning that business with more knowledge management show higher capability in enhancing organizational learning.

(3) Relationship between organizational learning and organizational performance: organizational learning is positively related to organizational performance, meaning that business with more organizational learning show higher capability in enhancing organizational performance.

Correlations can only reveal the degree of relationship between constructs. To further understand the direct and indirect effects, as well as mediating effects among the constructs, further analysis by structural equation model is required.

\subsection{Measure Reliability and Validity}

We first use a CFA analysis on our data, using SPSS12.0 and LISREL 8.51, to analyze all measures for validity and reliability, following the guidelines offered by Anderson and Gerbing (1988), and Bollen (1989). The reliabilities of indicators are assessed through their Cronbach's alpha scores (Cronbach, 1951) and composite reliability measures (Fornell and Larker, 1981). The reliabilities for all the measures are above the recommended limits of .536 and .823. These are displayed in Table 2. And final measurement model shows sufficient fit indices (Table 3) for the interpretation of our findings. Composite reliability is provided as $0.89,0.884$, and 0.838 showing in table 4 .

To ensure construct validity, we verify the convergent and discriminate validity of our constructs following the suggestions of Bollen (1989) and Churchill (1979): All of the measurement loadings in the measurement model are significant at the .01 level (convergent validity). Table 3 indicates the fitting index of measurement of each construct. Convergent validity can be judged by considering both the significance of the factor loading and t-values. All the multi-items constructs fit this criterion, and the loading is significantly related to its underlying factor (t-values greater than 1.96) in support of convergent validity (see Table 4).

A series of difference tests on the factor correlations among all the constructs to assess discriminate validity (Anderson and Gerbing, 1988). This is done for one pair of variables at a time by constraining the estimated correlation parameter between them to 1.0 and then performing a difference test on the values obtained for the constrained and unconstrained models (Anderson and Gerbing, 1988). Therefore, we get the results of convergent validity and discriminate validity. Based on Table 4 and Table 5, all t-values show well convergent validity, and the differences of chi-square $(\Delta \chi 2)$ are greater than 3.84, where this is a good evidence for the dimensions' discriminate validity.

\subsection{Hypothesis testing}

To best capture the theoretical interdependencies between KM, organizational performance, and OL, this study analyzes the data using structural equation modeling (LISREL 8.52 statistical package). This procedure allows for a fine analysis of the hypothesized relationships within the context of the entire model. Structural equation modeling is an especially attractive choice when testing mediating variables since all of the relevant paths are directly tested and complications, such as measurement error and feedback, are incorporated directly into the model (Edelman et al., 2005; Venkataraman, 
1989). We test the full structural equation model using the maximum likelihood method and raw data as input. The fit indices show an adequate fit. All of the hypothesized paths are found to be significant at the $\mathrm{P}<0.05$ level, except for the path between organizational learning and organizational performance. Consequently, path analysis in LISREL is performed for hypotheses testing.

Table 6 presents the overall model fit and the test of each hypothesis. As shown, the results of path analysis indicate an adequate fit: $\mathrm{GFI}=0.96, \mathrm{AGFI}=0.93$, RMSEA $=0.059, \mathrm{NFI}=0.97$ and $\mathrm{CFI}=0.99$. All four hypotheses are shown in Table 6 for details. The influence of the firm's knowledge management to organizational performance (H1) is significant, as same as we hypothesize in $\mathrm{H1}(\beta=0.34$, t-value $=2.74)$. The positive influence of knowledge management to organizational learning $(\mathrm{H} 2)$ is also supported by our findings $(\beta=0.78$, t-value $=11.79)$.

While we have expected to find a positive relationship between the firm's organizational learning and its organizational performance $(\mathrm{H} 3)$, our findings yield a non-significant relationship between these two constructs $(\beta=0.23$, $t$-value $=1.88)$. In our model, financial performance, marketing performance, and partnership performance are consisted in organizational performance. This study tries to find the reason why H3 is non-significant supported by our data. We test the path between OL and three dimensions of organizational performance each. We get the details from table 7 below. The path between OL and partnership performance is significant positive $(\beta=0.35$, $t$-value $=2.66)$. But the path between OL and financial performance and marketing performance are non-significant positive $(\beta=0.16$, t-value $=1.30 ; \beta=0.17$, $\mathrm{t}$-value $=1.36$ ). Therefore, the findings partially support the relationship between the firm's OL and its organizational performance (H3).

Under this path analysis, we test the mediation effect of OL. The results of path analysis indicate an adequate fit: GFI $=0.98, \mathrm{AGFI}=0.96, \mathrm{RMSEA}=0.017, \mathrm{NFI}=0.98$ and $\mathrm{CFI}=0.99$. OL plays a complete mediation role between $\mathrm{OL}$ and partnership performance in our model.

\section{Discussion}

After analysis, we got some results different from the past. Considering that knowledge management between partners with different business backgrounds often involves coordination challenges, exploring the potential role of organizational learning in such business. The underlying motivation of the current research is to discover and explain the significance of knowledge management and organizational learning behavior in these challenges, such as organizational performance.

We hypothesize three capabilities of knowledge management to drive behavioral routines of organizational performance: acquiring, conversion, and application. We use RBV as the foundation for our theoretical reasoning. Barney (1991) referring to Daft says: "...firm resources include all assets, capabilities, organizational processes, firm attributes, information, knowledge, etc; controlled by a firm that enable the firm to conceive of all implement strategies that improve its efficiency and effectiveness (Daft,1983)." Therefore, KM as a resource is to improve organizational performance which is supported by our H1.

As a perspective of RBV, we contribute that KM is an important elements in business. In this study, OL is viewed as a reaction to $\mathrm{KM}$ rather than an action that contributes to $\mathrm{KM}$. We hypothesize three processes of knowledge management to drive organizational learning. After statistical analysis, KM capabilities are the base to increase OL which is supported by H2. Therefore, this study verifies the KM -> OL effect which views OL is a reaction to KM. This result is also confirmed by the research of Jerez-Gomez at al. (2005), and Ke and Wei (2006).

In past, the relationship between organizational learning and performance will be positively (Hult et al., 2003; Calantone et al., 2002). But in Emden, Yaprak, Cavusgil (2005), the results say that they are unable to confirm a direct relationship between learning and the firm's financial performance is yet contrary to the findings of Anand and Khanna (2000). In our model, financial performance, market performance, and partnership performance are consisted in organizational performance. This study tries to find the reasons why H3 is non-significant supported by our data. We test the path between OL and three dimensions of organizational performance each. We get the details in table7.

Interestingly, the relationship between the firm's OL and its organizational performance is confirmed by the findings in Emden, Yaprak, Cavusgil (2005). We find the path between OL and partnership performance is significant positive. But the path between OL and financial performance and market performance are non-significant positive. In 2005, Emden, Yaprak, Cavusgil find that there is a path between the firms's marketing performance and its financial performance. Therefore, this relationship may explain why our data fail to show a positive relationship between organizational learning and organizational performance.

Although we are not initially interested in how the three performance measures are interrelated, following the results of the structural equation tests, we test this path respectively (see table 7). We find that OL only has positive influence on partnership performance. Therefore, we can't conclude OL has negative influence on performance. On the contrary, there are some important points to do for researchers and managers. Since OL mediate the relationship between KM and partnership performance, it is more important to take some measures to strengthen OL in organizations. 
We hypothesize that OL is a mediator in our research. This study contributes the second finding that we hypothesize that OL mediated the relationship between KM and partnership performance. Therefore, KM will affect partnership performance through OL.

For researchers, we hypothesize that KM is an antecedent affecting OL and organizational performance. This study contributes the finding that KM is an antecedent of OL, and the more KM capability will cause the more OL capability. Accordingly, KM is one of a key fundamental resource of organizations, which is confirmed by RBV.

This study contributes the third finding is knowledge map. Like other maps, it directs this study and provides other research in the future from literature review. We can find the directions precisely and easily from the knowledge map.

For managers, firstly, since KM is an important antecedent, organizations should implement KM thoroughly. In practices, KM implementation almost means the construction KM system. This study suggests that KM implementation is the ability of organization to acquire, converse, and apply their knowledge. After all, system implementation won't equal to the ability to implement. So, managers should consider does one firm set up system only? Or does one firm have the capability to set up and exercise it well?

Secondly, OL mediates the relationship between KM and partnership performance. Managers should take some measures to develop OL in order to link KM and partnership performance, for example: team work, managerial commitment, learning orientation, openness to new ideas...

Thirdly, OL will influence organizational performance under some circumstances. Therefore, managers should not enlarge the perspectives of performance. OL won't influence financial and marketing performance directly. Managers will take other ways to increase them, and this is not the focus of this study.

There are some methodological limitations to this study-notably, single sourcing, and self-reporting. We check this potential problem with the Harman one-factor test (Podsakoff \& Organ, 1986). An un-rotated factor analysis of ten focal variables result in a ten-factor solution, as expected, which account for $59.35 \%$ of the total variance; and Factor 1 account for $28.75 \%$ of the variance. Because a single factor does not emerge and Factor 1 does not explain most of the variance, common method bias is unlikely to be a concern in our data. In addition, the problem of common method bias when dealing with self-report, perceptual data is overstated in the literature and may be fictitious according to several researchers (Spector, 2006).

Utilizing a cross-sectional design with questionnaires is also one of the limitations of this study. A future research strategy that may overcome this limitation is one that involves longitudinal studies in which flow of knowledge and performance can be followed over time. In addition, using objective measures, archival data for some variables, such as organizational performance, may give results that are more objective.

In addition to the nature of data, the generalizability of sampling is another limitation of this study. The study conducts in a specific national context. It is important to note that readers should be cautious when generalizing the results to different cultural contexts. Further, the sample size is relatively small, requiring the increased sample size.

\section{Conclusion}

This study provides attention to the relationship among KM, organizational performance, and OL. We hope it intrigues researchers to clarify the important relationship among capability behavior patterns, and measures of organizational performance, and leads to more comprehensive investigations.

\section{Acknowledgement}

This research was funded by the National Science Council, Taiwan, Republic of China, under contract No. NSC 96-2416-H-032-003-MY2. We are deeply indebted to NSC. Special thanks also go to referee for helpful comments and suggestions.

\section{References}

Akgun, A.E., Keskina, H., Byrne, J.C., Aren, S. (2007). Emotional and Learning Capability and Their Impact on Product Innovativeness and Firm Performance. Technovation, Vol. 27, No. 9, pp. 501-513.

Anand, B.N., Khanna, T. (2000). Do Firms Learn to Create Value? The Case of Alliances. Strategic Management Journal, Vol. 21, No. 3, pp. 295-315.

Anderson, J.C., Gerbing, D.W. (1998). Structural Equation Modeling in Practice: A Review and Recommended Two-Step Approach. Psychological Bulletin, Vol. 103, No. 3, pp. 411-423.

Anderson, J.C, Gerbing, D.W. (1998). Some Methods for Re-specifying Measurements Models to Obtain Unidimensional Construct Measurement. Journal of Marketing Research, Vol. 19, No 4, pp. 453- 460.

Anthes, G.H. (1998). Learning How to Share. Computerworld, Vol. 32, No. 8, pp. 75-77.

Argyris, C, Schön, D. (1978). Organizational Learning: A Theory of Action Perspective, Reading, Mass: Addison 
Wesley Publishing.

Bagozzi, R.P., Yi, Y. (1988). On the Evaluation of Structural Equation Models. Journal of the Academy of Marketing Science, Vol. 16, No. 1, pp. 74-94.

Barney, J.B. (1991). Firm Resources and Sustained Competitive Advantage. Journal of Management, Vol. 17, No. 1, pp. 99-120.

Bollen, A.K. (1989). Structural Equations with Latent Variables. New York: Wiley Publishing.

Calantone, R.J., Cavusgil, S.T., Zhao, Y. (2002). Learning Orientation, Firm Innovation Capability, and Firm Performance. Industrial Marketing Management, Vol. 31, No. 6, pp. 515-524.

Chaudhuri, Arjun, Holbrook, Morris B. (2001). The Chain of Effects from Brand Trust and Brand Affect to Brand Performance: The Role of Brand Loyalty, Journal of Marketing, Vol. 65, No. 2, pp. 81-93.

Cronbach, L.J. (1951). Coefficient Alpha and the Internal Structure of Tests, Psychometrika, Vol. 16, No. 3, pp. 297-334.

Cui, A.S., Griffith, D.A., Cavusgil, S.T. (2005). The Influence of Competitive Intensity and Market Dynamism on Knowledge Management Capabilities of MNC Subsidiaries. Journal of International Marketing, Vol. 13, No. 3, pp. 32-53.

Darroch, J., MaNaughton, R. (2001). Examining the Link between Knowledge Management Practices and Types of Innovation. Journal of Intellectual Capital, Vol. 3, No. 3, pp. 210-222.

Darroch, J. (2003). Developing a Measure of Knowledge Management Behaviors and Practices. Journal of Knowledge Management, Vol. 7, No. 5, pp. 41-54.

Darroch, J. (2005). Knowledge Management, Innovation, and Firm Performance, Journal of Knowledge Management, Vol. 9, No. 3, pp. 101-115.

Davenport, T.H., Prusak, L. (1998). Working Knowledge: How Organizations Manage What They Know, Harvard Business School Press, Boston.

Dixon, N. M. (1999). The Organizational Learning Cycle: How We Can Learn Collectively, $2^{\text {nd }}$ ed., New York: McGraw-Hill, pp. 70-75.

Drucker, P. (1994). The theory of business. Harvard Business Review, September-October, pp. 95-104.

Emden, Z., Yaprak, A., Cavusgil, S.T. (2005). Learning from Experience in International Alliances: Antecedents and Firm Performance Implications, Journal of Business Research, Vol. 58, No. 7, pp. 883-892.

Fornell, C., Larcker, D.F. (1981). Evaluating Structural Equations Models with Unobservable Variables and Measurement Error. Journal of Marketing Research, Vol. 18, No. 1, pp. 39-50.

Garratt, B. (1990). Creating a Learning Organization: A Guide to Leadership, Learning, and Development. New York: Simon \& Schuster.

Goh, A.S. (2005). Harnessing Knowledge for Innovation: An Integrated Management Framework. Journal of Knowledge Management, Vol. 9, No. 4, pp. 6-18.

Goh, A.S., Richards, G. (1997). Benchmarking the Learning Capability of Organizations. European Management Journal, Vol. 15, No. 5, pp. 575-583.

Gold, A.H., Malhortra, A., Segars, A.H. (2001). Knowledge Management: An Organizational Capabilities Perspective. Journal of Management Information Systems, Vol. 18, No. 1, pp. 185-214.

Grant, R.M. (1996). Toward a Knowledge-Based Theory of the Firm. Strategic Management Journal, Vol. 17, Winter Special Issue, pp. 109-122.

Hult, G.T.M., Ferrell, O.C. (1997). Global Organizational Learning Capacity in Purchasing: Construct and Measurement. Journal of Business Research, Vol. 40, No. 2, pp. 97-111.

Jaworski, B.J., Kohli, Ajay K. (1993). Market Orientation: Antecedents and Consequences. Journal of Marketing, Vol. 57, No. 3, pp. 53-70.

Jerez-Góomez, Pilar, Céspedes-Lorente, José, Valle-Cabrera, Ramón. (2005). Organizational Learning Capability: a proposal of measurement. Journal of Business Research, Vol. 58, No. 6, pp. 715-725.

Joreskog, K.G., Sorbom, D. (1993). LISREL 8 User's Reference Guide. Chicago: SSI.

Ke, W.L., Wei, K.K. (2006). Organizational Learning Process: Its Antecedents and Consequences in Enterprise System Implementation. Journal of Global Information Management, Vol. 14, No. 1, pp. 1-22. 
Li,T., Calantone, R.J. (1998). The Impact of Market Knowledge Competence on New Product Advantage: Conceptualization and Empirical Examination. Journal of Marketing, Vol. 62, No. 4, pp. 13-29.

Liao, S.H. (2003). Knowledge Management Technologies and Applications-Literature Review from 1995 to 2002. Expert Systems with Applications, Vol. 25, No. 2, pp. 155-164.

Liao, S.H., Fei, W.C., Chen, C.C. (2007). Knowledge Sharing, Absorptive Capacity and Innovation Capability: An Empirical Study on Taiwan's Knowledge Intensive Industries. Journal of Information Science, Vol. 33, No. 3, pp. 340-359.

Liao, S.H., Fei, W.C., Liu, C.T. (2008). Relationship between Knowledge Inertia, Organizational Learning, and Organizational Innovation. Technovation, Vol. 28, No. 4, pp. 183-195.

Lin, H.F., Lee, G.G. (2004). Impact of Organizational Learning and Knowledge Management Factors on E-Business Adoption. Management Decision, Vol. 43, No. 2, pp. 171-188.

Montes, F.J.L., Moreno, A.R., Morales, V.G. (2005). Influence of Support Leadership and Teamwork Cohesion on Organizational Learning, Innovation and Performance: An Empirical Examination. Technovation, Vol. 25, No. 10, pp. 1159-1172.

Nunnally, J. C. (1978). Psychometric theory, 2nd ed., New York: McGraw-Hall.

Oswald, S.L., Mossholder, K.W., Harris, S.G. (1994). Vision Salience and Strategic Involvement: Implications for Psychological Attachment to Organization and Job. Strategic Management Journal, Vol. 15, No. 1, pp. 477-89.

Quinn, J.B., Anderson, P., Finkelstein, S. (1996). Managing Professional Intellect: Making the Most of the Best. Harvard Business Review, Vol. 74, No. 2, pp. 71-80.

Rademakers, M. (2005). Corporate Universities: Driving Force of Knowledge Innovation. Journal of workplace Learning, Vol. 17, No. 1, pp. 130-136.

Senge, P. (1990). The Fifth Discipline: The Art and Practice of the Learning Organization. Doubleday, New York.

Spector, P.E. (2006). Method Variance in Organizational Research: Truth or Urban Legend. Organizational Research Methods, Vol. 9, No. 2, pp. 221-232.

Su, K.J., Hsieh, H.L., Liu, K.A. (2003). Application of the Learning Organization Paradigm in Engineering Education: An Empirical Research of Universities in Taiwan. World Transactions on Engineering and Technology Education, Vol. 2, No. 2, pp. 285-290.

Su, K.J., Huang, L.C., Hsieh, H.L. (2004). The Development of a Knowledge Flow Paradigm in Engineering Education: Empirical Research in Taiwanese Universities. World Transactions on Engineering and Technology Education, Vol. 3, No. 1, pp. 125-128.

Tippins, M.J.S., Ravipreet, S. (2003). IT Competency and Firm Performance: Is Organizational Learning a Missing Link? Strategic Management Journal, Vol. 24, No. 8, pp. 745-761.

Venkatraman, N., Ramanujam, V. (1986). Measurement of Business Performance in Strategy Research: A Comparison of Approaches. The Academy of Management Review, Vol. 11, No. 4, pp. 801-814.

Yeo, R. (2003). Linking Organizational Learning to Organizational Performance and Success: Singapore Case Study. Leadership \& Organization Development Journal, Vol. 24, No. 1/2, pp. 70-84. 
Table 1. Demographic profile of respondents

\begin{tabular}{|c|c|c|c|}
\hline Demographic variable & Classification & Samples & Percentage \\
\hline \multirow{2}{*}{ Industry } & Manufacturing & 164 & $50.2 \%$ \\
\cline { 2 - 4 } & Financial & 163 & $49.8 \%$ \\
\hline \multirow{2}{*}{ Gender } & Male & 163 & $50.2 \%$ \\
\hline Education & Female & 164 & $0.6 \%$ \\
\hline & High School & 2 & $13.8 \%$ \\
\hline & Associate Degree & 203 & $62.1 \%$ \\
\hline Departments & Bachelor Degree & 77 & $23.5 \%$ \\
\hline & Master Degree & 9 & $2.8 \%$ \\
\hline & Manufacturing & 128 & $39.1 \%$ \\
\hline
\end{tabular}

Table 2. Table of descriptive statistics

\begin{tabular}{|c|c|c|c|c|c|c|c|c|c|c|}
\hline Variables & 1 & 2 & 3 & 4 & 5 & 6 & 7 & 8 & 9 & 10 \\
\hline $\mathrm{KAC}$ & 0.761 & & & & & & & & & \\
\hline $\mathrm{KCO}$ & $.730(* *)$ & 0.700 & & & & & & & & \\
\hline KAP & $.689(* *)$ & $.760(* *)$ & 0.807 & & & & & & & \\
\hline $\mathrm{MC}$ & $.576(* *)$ & $.532(* *)$ & $.577(* *)$ & 0.676 & & & & & & \\
\hline SP & $.553(* *)$ & $.507(* *)$ & $.575(* *)$ & $.675(* *)$ & 0.702 & & & & & \\
\hline EX & $.599(* *)$ & $.569(* *)$ & $.639(* *)$ & $.732(* *)$ & $.605(* *)$ & 0.656 & & & & \\
\hline TR & $.561(* *)$ & $.500(* *)$ & $.610(* *)$ & $.670(* *)$ & $.596(* *)$ & $.675(* *)$ & 0.536 & & & \\
\hline FP & $.374(* *)$ & $.353(* *)$ & $.368(* *)$ & $.323(* *)$ & $.404(* *)$ & $.324(* *)$ & $.288(* *)$ & 0.823 & & \\
\hline $\mathrm{MP}$ & $.398(* *)$ & $.353(* *)$ & $.429(* *)$ & $.346(* *)$ & $.425(* *)$ & $.326(* *)$ & $.335(* *)$ & $.829(* *)$ & 0.797 & \\
\hline $\mathrm{PP}$ & $.378(* *)$ & $.334(* *)$ & $.404(* *)$ & $.383(* *)$ & $.395(* *)$ & $.344(* *)$ & $.360(* *)$ & $.530(* *)$ & $.527(* *)$ & 0.733 \\
\hline Mean & 3.73 & 3.68 & 3.78 & 3.43 & 3.48 & 3.56 & 3.53 & 3.44 & 3.44 & 3.67 \\
\hline SD & .454 & .450 & .452 & .565 & .600 & .542 & .527 & .680 & .700 & .536 \\
\hline
\end{tabular}

Note1: Diagonal number represents reliabilities alpha.

Note 2: **Significant at $\mathrm{P}<0.01$.

Table 3. Fitting Index of Confirmatory Factor Analysis

\begin{tabular}{|c|c|c|c|}
\hline Index & Knowledge management & Organizational learning & $\begin{array}{c}\text { Organizational } \\
\text { performance }\end{array}$ \\
\hline GFI & 0.86 & 0.92 & 0.94 \\
\hline SRMR & 0.06 & 0.049 & 0.044 \\
\hline RMSEA & 0.077 & 0.063 & 0.081 \\
\hline NNFI & 0.94 & 0.97 & 0.97 \\
\hline CFI & 0.95 & 0.97 & 100.7 \\
\hline DF & 546.3 & 225.11 & 32 \\
\hline Normed chi-square & 186 & 98 & 3.15 \\
\hline
\end{tabular}


Table 4. Reliability and Convergent validity

\begin{tabular}{|c|c|c|c|c|}
\hline Variables & Composite Reliability & $\lambda$ & $\varepsilon$ & T-value \\
\hline \multirow{3}{*}{ Knowledge management } & \multirow{3}{*}{0.890} & 0.75 & 0.44 & $14.69 * * *$ \\
\hline & & 0.73 & 0.46 & $14.27 * * *$ \\
\hline & & 0.76 & 0.42 & $15.04 * * *$ \\
\hline \multirow{4}{*}{ Organizational learning } & \multirow{4}{*}{0.884} & 0.79 & 0.38 & $16.09 * * *$ \\
\hline & & 0.71 & 0.49 & $14.06 * * *$ \\
\hline & & 0.73 & 0.46 & $14.52 * * *$ \\
\hline & & 0.70 & 0.51 & $13.60 * * *$ \\
\hline \multirow{3}{*}{$\begin{array}{l}\text { Organizational } \\
\text { performance }\end{array}$} & \multirow{3}{*}{0.838} & 0.82 & 0.33 & $16.51 * * *$ \\
\hline & & 0.91 & 0.17 & $18.98 * * *$ \\
\hline & & 0.52 & 0.73 & $9.57 * * *$ \\
\hline
\end{tabular}

Table 5. Discriminate validity

\begin{tabular}{|c|c|c|c|}
\hline Model & $\chi^{2}$ & DF & $\Delta \chi^{2}$ \\
\hline-- & 67.82 & 32 & -- \\
\hline $\begin{array}{c}\text { Knowledge management-Organizational } \\
\text { learning }\end{array}$ & 140.00 & 33 & $72.18^{*}$ \\
\hline $\begin{array}{c}\text { Knowledge management-Organizational } \\
\text { performance }\end{array}$ & 306.42 & 33 & $238.6^{*}$ \\
\hline $\begin{array}{c}\text { Organizational learning-Organizational } \\
\text { performance }\end{array}$ & 292.88 & 33 & $225.06^{*}$ \\
\hline
\end{tabular}

Table 6. Testing result

\begin{tabular}{|c|c|c|c|c|}
\hline Causal path & Hypothesis & $\begin{array}{c}\text { Expected } \\
\text { sign }\end{array}$ & $\begin{array}{c}\text { Path } \\
\text { coefficient }\end{array}$ & t-value \\
\hline $\begin{array}{c}\text { Knowledge management-Organizational } \\
\text { learning }\end{array}$ & $\mathrm{H} 1$ & $0.34^{*}$ & 2.74 & Support \\
\hline $\begin{array}{c}\text { Knowledge management-Organizational } \\
\text { performance }\end{array}$ & $\mathrm{H} 2$ & $0.78^{*}$ & 11.79 & Support \\
\hline $\begin{array}{c}\text { Organizational learning-Organizational } \\
\text { performance }\end{array}$ & $\mathrm{H} 3$ & 0.23 & 1.88 & $\begin{array}{c}\text { Partial } \\
\text { Support }\end{array}$ \\
\hline
\end{tabular}


Table 7. Paths between OL and Organizational performance

\begin{tabular}{|c|c|c|c|}
\hline Paths & Expected sign & Path coefficient & t-value \\
\hline Knowledge management-Organizational learning & + & 0.16 & 1.30 \\
\hline $\begin{array}{c}\text { Knowledge management-Organizational } \\
\text { performance }\end{array}$ & + & 0.17 & 1.38 \\
\hline $\begin{array}{c}\text { Organizational learning-Organizational } \\
\text { performance }\end{array}$ & + & $0.35^{*}$ & 2.66 \\
\hline
\end{tabular}

Appendix

\begin{tabular}{|c|c|c|}
\hline Variable & & Items \\
\hline \multirow[t]{8}{*}{ Knowledge acquisition } & 1 & Has processes for acquiring knowledge about our customers. \\
\hline & 2 & Has processes for acquiring knowledge about our suppliers. \\
\hline & 3 & Use feedback from projects to improve subsequent projects. \\
\hline & 4 & Has processes for exchanging knowledge with our business partners. \\
\hline & 5 & Has process for acquiring knowledge about new product/services within our industry. \\
\hline & 6 & Has process for acquiring knowledge about competitors within our industry \\
\hline & 7 & Has process for benchmarking performance. \\
\hline & 8 & Has teams devoted to identifying best practice. \\
\hline \multirow[t]{6}{*}{ Knowledge conversion } & 1 & Has processes for converting knowledge into the design of new product/service. \\
\hline & 2 & Has processes for transferring organizational knowledge to individuals. \\
\hline & 3 & Has processes for absorbing knowledge form individuals into the organization \\
\hline & 4 & Has processes for absorbing knowledge from business partners into the organization. \\
\hline & 5 & Has processes for integrating different sources and types of knowledge. \\
\hline & 6 & Has processes for replacing outdated knowledge. \\
\hline \multirow[t]{7}{*}{ Knowledge application } & 1 & Has processes for applying knowledge learned from mistakes or experiences. \\
\hline & 2 & Has processes for using knowledge in development of new products/services. \\
\hline & 3 & Has processes for using knowledge to solve new problems. \\
\hline & 4 & Use knowledge to improve efficiency \\
\hline & 5 & Is able to locate and apply knowledge to changing competitive conditions. \\
\hline & 6 & Makes knowledge accessible to those who need it. \\
\hline & 7 & Quickly links sources of knowledge in solving problems. \\
\hline \multirow[t]{5}{*}{ Management commitment } & 1 & The managers frequently involve their staff in important decision making processes. \\
\hline & 2 & Employee learning is considered more of an expense than an investment. \\
\hline & 3 & $\begin{array}{l}\text { The firm's management looks favorably on carrying out changes in any area to adapt to } \\
\text { and/or keep ahead of new environmental situations. }\end{array}$ \\
\hline & 4 & Employee learning capability is considered a key factor in this firm. \\
\hline & 5 & In this firm, innovative ideas that work are rewarded. \\
\hline \multirow[t]{3}{*}{ System perspective } & 1 & All employees have generalized knowledge regarding this firm's objectives. \\
\hline & 2 & $\begin{array}{l}\text { All parts that make up this firm (departments, sections, work teams, and individuals) are } \\
\text { well aware of how they contribute to achieving the overall objectives. }\end{array}$ \\
\hline & 3 & All parts that make up this firm are interconnected, working together in a coordinated \\
\hline
\end{tabular}


fashion.

Openness \& experimentation
1 This firm promotes experimentation and innovation as a way of improving the work processes.

2 This firm follows up what other firms in the sector are doing; adopting those practices and techniques it believes to be useful and interesting.

3 Experiences and ideas provided by external sources (advisors, customers, training firms, etc.) are considered a useful instrument for this firm's learning.

4 Part of this firm's culture is that employees can express their opinions and make suggestions regarding the procedures and methods in place for carrying out tasks.

Knowledge transfer \& $\quad 1 \quad$ Errors and failures are always discussed and analyzed in this firm, on all levels. integration

2 Employees have the chance to talk among themselves about new ideas, programs, and activities that might be of use to the firm.

3

In this firm, teamwork is not the usual way to work.

4 The firm has instruments (manuals, databases, files, organizational routines, etc.) that allow what has been learnt in past situations to remain valid, although the employees are no longer the same.

1 Please rate your organization's performance, relative to your competitors, on each of

Financial performance the following dimensions:

Profitability

2

Return on investment

3

Cash flow from operations

Cost control.

\begin{tabular}{ccc}
\hline Marketing performance & 1 & Market development. \\
& 2 & Market share. \\
& 3 & Sales growth. \\
\hline
\end{tabular}

Partnership performance

1 Please rate your alliances performance on each of the alliance-related objectives: Strength of your relationship with key alliance partners

Stability of your alliances 


\title{
A Research on the Influences of Transnational Merger and Acquisition on China's Industry Security
}

\author{
Jianhong Huang \\ Tourism College, Hainan University \\ Haikou 570228, China \\ Tel: 86-898-6625-0179 E-mail: yanhuang3721@yahoo.com.cn
}

\begin{abstract}
With the rapid development of China's economy, foreign investment in China's industry has got strengthened in both breadth and depth. Transnational corporations, one of the sources of foreign investment, have done frequent M\&A, hence having some actual and potential influences on China's industry or even economy security. This article begins with the current situation and characteristics of transnational corporations' M\&A, then moves on to the positive and negative influences transnational corporations' M\&A in the recent time have on China's industry security and puts forward some relevant strategies and suggestions for China about how to cope with M\&A from the aspect of making reasonable use of foreign capital.
\end{abstract}

Keywords: Transnational corporation, M\&A, Industry security, Influence

In the recent years, large-scale transnational M\&A has drawn much attention from a large number of scholars to China's industry security. Seen from the existing documents, the present theoretical researches on industry security in China are mainly focused on defining this term (Fu, 2007; He, 2006) and the policies of maintaining industry security ( $\mathrm{Li}, 2006$; Zhao, 2007). In addition, some experts attach their attention to analyzing the factors influencing industry security (Liu, 2005; Xu, 2004), conducting quantitative analyses and researches on china's industry security by constructing an index system to assess it $(\mathrm{He}, 2002)$. Generally speaking, however, China still lies in the fundamental stage in terms of the research on industry security, and therefore, some relevant theories are being discussed, constructed and formed. (He, 2006). Besides, the present analyses are mainly focused on the negative influences, hence neglecting the positive ones. Based on the current situation in China, this article explores the influences M\&A has on China's industry security objectively and comes to some strategies and suggestions to cope with the current situation from the perspective of how to make reasonable use of foreign investment.

\section{Current Situation of Transnational M\&A in China}

With the rapid development of China's economy, the constant optimization of industrial structure and the appearance of some new consumption demands such as automobiles, telecommunication, travelling, housing and so on, China has become a highlight at the global M\&A market. In the recent years, the M\&A by foreign capital has stepped into a brand-new development platform and has displayed the following characteristics: one after another record of the transaction scale of M\&A by foreign capital has been created; M\&A mainly happens in banking, manufacturing and Internet industries; the M\&A pattern has been renewed over and again; overseas buy-out funds have opened China's door. (Jing, 2005)

\subsection{Constantly Expanded M\&A Scale}

Recently, quite a few M\&A transactions involving a large sum of money have taken place in China's market, setting one record after another in both the sum of money and the number of transactions. For instance, in June 2005, U.S. Bank first invested \$ 2.5 billion in buying 9\% of China Construction Bank's shares held by China Huijin Investment Corporation Ltd. and then subscribed for \$ 0.5 billion's shares at CCB's overseas IPO. This has got the largest sum of single investment of foreign corporations in China's inland banks so far and has broken the record of $\$ 1.747$ billion set by Hong Kong and Shanghai Banking Corporation when buying the shares of Communications Bank of China. In addition, Yahoo also set the largest sum on Internet when buying Alibaba.com. China has become a focus attracting various kinds of industrial capital and financial capital all around the world. 


\subsection{Focusing on Banking Industry}

In terms of industry, M\&A mainly takes place in the industries related to banking, manufacturing and Internet, in which banking industry has become a focus. For example, Temasek invested $\$ 3$ billion in the shares of Bank of China; Pangaea Capital Manage bought $6.88 \%$ of Huaxia Bank's shares with 1 billion yuan; ING Group in Holland invested $€$ 0.196 billion in $19.9 \%$ of Beijing Bank's shares. In addition, most of M\&A transactions are conducted in the leading enterprises of different industries.

\subsection{Constantly Renewed M\&A Patterns}

There are mainly four M\&A patterns including rescue M\&A, cooperative M\&A, scrambling M\&A and hostile M\&A. With all the four patterns existing in China now, we should welcome the former two patterns while be on alert for the latter two.

\subsection{Investment of Foreign Funds}

China has become a hot spot for buy-out funds (Jing, 2005). In May 2004, Shenzhen Development Bank announced that they had sold $17.89 \%$ of its shares to foreign funds at the price of 1.253 billion yuan. In July 2005, Harbin Pharmaceutical Group was changed into a corporation Ltd controlled by the state from a former state-owned one. $34.76 \%$ of its shares flew from the state to the legal person. This is the first merger transaction in which a Chinese large-scale state-owned enterprise was bought by global buy-out funds. In addition, Carlyle Funds bought Xuzhou Construction Machinery Group in October 2006.

\section{The Influences of Transnational M\&A on China's Industry Security}

According to the definition of industry security (Fu, 2007; He, 2006; Zhao, 2007), the following standards can be employed to assess whether transnational M\&A influences industry security: whether closely related to national security; whether closely related to the fundamental needs in people's life; the technological level of certain industry; correlation degree among different industries ( impacts on other industries and influences on employment as well as economic growth; ecological environment factors (such as paper-making industry which is not quite significant in national economy but plays an important role in ecological environment); whether characterized as natural monopoly industry, whether an important strategic resource and so on.

\subsection{Positive Influences}

\subsubsection{Improving Employees' Quality}

Foreign corporations usually emphasize employees' quality training, hence contributing to the improvement of Chinese employees' quality. Foreign investment will provides better wages, treatment, working conditions as well as social welfare compared with that of Chinese enterprises to attract more excellent employees to their corporations. In addition, many transnational enterprises have set training bases in China to give their employees necessary training and further education, improving their overall quality to a large degree.

\subsubsection{Increasing Industrial Capital}

As one of the important channels of direct foreign investment, transnational M\&A plays an active part in the increase of China's industrial capital. According to the statistics provided by the Ministry of Commerce, there has been a stable growth in the number of newly-established projects (enterprises), the sum of contracted foreign investment and the actually-utilized sum in the eastern, middle and western parts of China since 2000. In 2005, 44001 foreign-invested enterprises were approved to be newly built, involving \$ 189.06454 billion worth of contracted foreign capital and $\$ 60.32469$ billion worth of actually-utilized sum, providing a solid foundation for China's economic development.

\section{Insert Table 1 here}

\subsubsection{Improving Overall Industrial Management Level}

After many years' operation, foreign enterprises have formed an orderly management system. Therefore, when an enterprise is merged by a foreign enterprise with high management level, its old system will give way to a new one, hence having its management efficiency improved. With great efforts, the management of both the merged enterprise but the merging one will be improved a lot.

\subsubsection{Optimizing Industrial structure}

Transnational M\&A is of significance in facilitating the paces of state-owned enterprises' reform and recombination, promoting the adjustment of national economy strategies, improving China's industrial structure and regulating and developing China's capital market ( Wang, 2006). In the past, due to China's planned economy, many units formed their fully-equipped but isolated system, resulting in a large amount of over-duplicated projects as well as the destruction of reasonable economic system and coordination. In addition, because of the small and dispersed scale, their centralization was not advanced enough. For instance, in 2003, China ranked first in beer output in the world with the record of 25.4 
million tons while only 3 beer manufacturers had an annual output of over 1 million tons. M\&A can help to promote the centralization of production and capital, strengthen enterprises' competitiveness at market, form a complementing and coordinating relationship among large, middle and small enterprises as well as a reasonable labor-division pattern.

Objectively speaking, on one hand, the entry of transnational corporations will do a lot to improve an industry's overall capacity. On the other hand, it will also have great impacts on Chinese enterprises.

\subsection{Negative Influences}

\subsubsection{Endangering National Security and People's Livelihood}

Some industries involved in transnational M\&A are related to national security or the fundamental needs in people's life. In October 2006, Carlyle Funds bought 50\% of the shares of Xuzhou Construction Machinery Group at the price of 1.8 billion yuan. Taking the previous large number of machinery enterprises bought by foreign capital into consideration, we can draw the conclusion that the control of foreign capital in machinery industry has gone to a dangerous edge because the production of many militarily machinery parts will be dominated by it. In the recent years, foreign capital has frequently merged China's manufacturing industry, banking industry, circulation industry as well as high-tech industry. Once these industries closely related to national economy and people's livelihood are controlled by foreign investment, China's base of independence in economy as well as politics will be destroyed totally.

\subsubsection{The Loss of Intellectual Property Rights}

If Chinese enterprises are merged by foreign capital, we will lose not only our national brands which were established with great efforts but our capacity in independent research and development. A nation's well-known brands are the soul of its national enterprises as well as the foundation of its industrial development. By M\&A, foreign capital has succeeded in weakening the foundation of China's industrial development as well as getting rid of its competitors. Of course, this will influence China's industrial development and security. As is well known, technology is not only the result of industry but the core power determining the development of industrial competitiveness. After M\&A, foreign capital will gain the core technologies of the merged enterprises as well as restrict their R\&D activities.

\subsubsection{Influencing Industrial Control}

When investing in China, transnational corporations usually adopt a pattern of "joint venture--pushing out Chinese enterprises-- foreign-owned--oligarchy monopoly". Although at the beginning of joint ventures and M\&A negotiations, Chinese enterprises have dominant shares, transnational corporations will take advantage of their strengths in capital, technology and management to increase their investment and expand their shares and finally ask for the ownership of the whole enterprise. After absorbing the leading enterprise in a certain industry, transnational corporations will employ the strategy of "the big fish eats fingerling" to merge or acquire other middle or small-scaled enterprises of this industry, hence controlling China's market and monopolize the whole industry. As a result, China's industry security will be endangered.

\subsubsection{Strengthening the Imbalance of Regional Economy}

The regional imbalance of China' economic development influences the distribution of target Chinese enterprises for transnational M\&A, and then, the obvious disparity in spatial distribution of transnational M\&A also influences the development of China's regional economy. Let's take GDP for example, the disparity in GDP of East China, Middle China and West China is getting wider. Compared with East China, the GDP total of Middle and West China was respectively $59 \%$ and $40 \%$ of that of East China in 1980 while dropped to $31 \%$ and $27 \%$ in 2004 . This shows the increasingly wider disparity among the three areas in China.

\section{Insert Table 2 here}

\section{Current Measures in Replying to Transnational M\&A in China}

Transnational M\&A has certainly had influences on China in many ways. However, it is totally wrong to be terrified of M\&A and put the clock back to the isolation age. The tide of global M\&A has brought about both challenges and opportunities. Therefore, Chinese enterprises are expected to face up to, study carefully and then solve difficulties. Only with the right methods and measures can we change difficulties into motivation, challenges into opportunities.

\subsection{Establishing Right Security Concept}

Now, with the weakening of national industry concept, the idea of national industrial security is changing. As is shown in practice, one may not control an enterprise by controlling its shares. Therefore, it is impractical for most Chinese enterprises to pursue the control of shares when negotiating with transnational corporations. However, it doesn't mean giving up other controls to give up the control of shares. No matter in developed countries or developing countries, it has been an effective method for the government to control those large-scale transnational corporations by issuing regulations. So a government regulation control system is in bad need in China, in which the idea emphasizing the general international practice should be established. It has been shown in many countries' opening practice that all of 
them will be safer only by interacting with each other in all industries. In future, in addition to the introduction of foreign capital and technology, the portion of export should be increased, hence maintaining a proper ratio between the two.

\subsection{Guiding he Direction of $M \& A$}

Due to the profit-oriented purpose of transnational M\&A in China, their investment will be in conflict with the development strategy of Chinese economy. Chinese government should encourage transnational corporations to extend to Middle and West China from East in order to promote the balanced development of China's regional economy; government should also guide the M\&A pattern to encourage rescue and cooperative M\&A instead of hostile one such as that happened to Wahaha; government should put restrictions on the range of M\&A, in which some industries closely related to national economy and people's livelihood, such as oil industry, manufacturing industry, banking industry, should be restricted in foreign investment while those high-exhaustion, high-pollution, poor-technology industries should welcome foreign investment. A reasonable guidance of M\&A will promote China to develop towards industrial advance.

\subsection{Improving Independent Innovation Capacity}

For a long term, although China has introduced a large amount of advanced technologies and facilities from foreign countries, many enterprises still fall into a situation of "introduction-lagging-repeated introduction-repeated lagging" due to their failure in absorbing what they have introduced. It is shown in Haier and Huawei's success stories that independent innovation is the source and motivation for an enterprise to exist and develop. Therefore, national enterprises should put much importance on staff training, improving their independent $R \& D$ capacity and promoting their own brands. In addition, government should issue some policies and measures to encourage independent innovation in order to increase enterprises' input in technological research and development.

\subsection{Establishing M\&A Examination and Approval Institution and System}

Measures for Strategic Investment by Foreign Investors upon Listed Companies, Stock Law and Regulations of Acquisition of a Listed Company have set a law framework for foreign capital's acquisition of listed companies. However, law itself is not enough. An institution in charge of the examination and approval of transnational M\&A should be established to have an overall examination of some potential influences caused by M\&A on employment, technological level, correlation degree among different industries, ecosystem, strategic resources and national security. In addition, a set of examination and approval systems should be established to have careful property definition and asset assessment in order to prevent state-owned asset from flowing out. Some state-regulated strategic industries, key enterprises, key products and key technologies should also be established to regulate foreign M\&A.

\subsection{Establishing Industry Security Early Warning System}

Such a system should be able to assess the security state of all industries firstly, to predict the future security tendency secondly and finally to deliver the information to government and enterprises. In addition, the security state of key industries should be paid special attention to in order to prevent transnational corporations from monopolizing the whole industry. Some industries involving insufficient or excessive competitions should be regulated in tome to keep a healthy, orderly and fair competition order.

\section{References}

Fu, Min. (2007). An Overview of Industry Security. Economic Theory and Business Management, (2).

He, Weida \& He, Chang. (2002). Rudimentary Assessment of Main Three Industries Safety Nowadays in China. China Industrial Economy, (2).

He, Weida \& Li, Dongmei. (2006). An Overview of Theoretical Research on China's Industry Security. Economic Review, (8).

Jing, Yuqin. (2005). A Research on China's Industry Security.

Li, Bingyan, \& Wang, Xiaogang. (2006). The Threat and Countermeasures of Massive Introduction Foreign Capital to Our Country Economic Security. (2).

Liu, Yong, Li, Qiaojing \& Sun, Xiao. (2005). On Multinational Direct Investment's Influence on China's Economy. Special Zone Economy, (5).

Wang, Wei. (2006). China's M\&A Report. Post \& Telecom Press.

Wang, Xinong. (2004). Enterprises and Government in Transnational M\&A. Chine Economy Publishing House.

$\mathrm{Xu}$, Bo. (2004). A Research on the $5^{\text {th }} M \& A$ Tide and Its Influence on China's Economy. China Commerce and Trade Press.

Zhao, Ying \& Li, Haijian et. al. (2007). An Overall Report of National Economy Security in the Open Environment. 
Table 1. Direct foreign investment in China by the end of 2005 (in 100 million US dollars)

\begin{tabular}{|c|c|c|c|}
\hline Year/Type & Number of projects & $\begin{array}{l}\text { Contracted foreign } \\
\text { capital }\end{array}$ & $\begin{array}{l}\text { Actually-utilized foreign } \\
\text { capital }\end{array}$ \\
\hline 2000 & 22347 & 623.80 & 407.15 \\
\hline 2001 & 26140 & 691.95 & 468.78 \\
\hline 2002 & 34171 & 827.68 & 527.43 \\
\hline 2003 & 41081 & 1150.70 & 535.05 \\
\hline 2004 & 43664 & 1534.79 & 606.30 \\
\hline 2005 & 44001 & 1890.65 & 603.24 \\
\hline
\end{tabular}

Data source: statistics of the Ministry of Commerce

Table 2. The utilization of direct foreign capital in Middle and West China by the end of 2005 (in 100 million US dollars)

\begin{tabular}{|l|l|l|l|l|l|l|}
\hline \multirow{2}{*}{ Name of areas } & \multicolumn{2}{|l|}{ Number of projects } & \multicolumn{2}{l|}{ Contracted foreign capital } & \multicolumn{2}{l|}{ Actually-utilized foreign capital } \\
\cline { 2 - 7 } & Number & $\begin{array}{l}\text { Percentage } \\
(\%)\end{array}$ & Sum & $\begin{array}{l}\text { Percentage } \\
(\%)\end{array}$ & Sum & Percentage (\%) \\
\hline Total & 552942 & 100 & 12856.7299 & 100 & 6224.2531 & 100 \\
\hline East China & 457944 & 82.82 & 11174.7601 & 86.92 & 5383.7139 & 86.5 \\
\hline Middle China & 59947 & 10.84 & 1003.0724 & 7.8 & 562.9589 & 9.04 \\
\hline West China & 35051 & 6.34 & 678.8974 & 5.28 & 277.5803 & 4.46 \\
\hline
\end{tabular}

Data source: statistics of the Ministry of Commerce 


\title{
Inevitability and Necessity to Develop SWFs in China
}

\author{
Jing Xiang, Susheng Wang, Zhaokun Kong \& Wenhu Li \\ Economic and Management Department, Harbin Institute of Technology Shenzhen Graduate School \\ Shenzhen 518055, China \\ E-mail: carol.hsiang@163.com
}

\begin{abstract}
Sovereign Wealth Funds (SWFs) refer to the funds set up by government to manage and operate sovereign wealth. It has important significances for China and global financial system and it also restricts American financial hegemony, which is analyzed in details in this essay. In China, there are huge foreign exchange reserves whose return should be increased in the manner of SWFs. Therefore, it's obviously both inevitable and necessary for China to develop SWFs.

Keywords: SWFs, Foreign exchange reserves, Inevitability, Necessity

Sovereign Wealth is the public assets accumulated by ways of certain tax and budget policy, revenue from natural resources and surplus of balance of payments, controlled and administrated in the form of foreign currencies by government. Sovereign Wealth Funds (SWFs) refer to the funds set up by government to manage and operate sovereign wealth. These years, China's foreign exchange reserve is far beyond normal needs for liquidity and foreign exchange management, and therefore the surplus is invested into multiple assets, even into some securities and financial derivatives. The central bank is bound in duty to make more fortunes for China.
\end{abstract}

\section{Inevitability for SWFs to grow up in China}

(1) American growing deficit in current account is the fundamental cause of SWFs birth and quick expansion. U.S. is the biggest supplier for foreign exchange reserves and SWFs. Its current account deficit drives SWFs to grow up rapidly while providing liquidity for global capital market. Due to the quick expanding deficit, U.S. and other developed countries are compelled to maintain equilibrium of balance of payments through capital surplus, and therefore it is a good chance for China's SWFs to enter America.

\section{Insert Table 1 here}

(2) U.S. dollar continuing depreciation throws rather pressure in maintenance and increment of foreign exchange reserves in countries with large trade surplus, which also speeds SWFs foundation from foreign reserves in some extent. The rate of U.S. dollar to Euro decreases from 1.12 to 0.65 between the year 2002 and 2008, reaching $42 \%$ low. Too much foreign reserves will bring efficiency loss, exchange rate risk, liquidity excess and asset price bubble. It is an urgent task to lower growing speed of foreign reserves and increase their return. What China can do is to adjust policy to protect its foreign reserves. It is an important way to maintain and increase value of foreign exchange reserves by expanding equity investment through SWFs.

(3) China holds huge foreign exchange reserves and should increase their return in the manner of SWFs. By the end of 2007, foreign exchange reserves of China reach 1.53 trillion U.S. dollars and rank first in the world. They are mainly in form of U.S. dollar, for example $70 \%$ of them are invested into U.S. treasury bonds. However, U.S. treasury bonds have no superiority in return except for safety and certain liquidity. From 2001 to 2006, inflation in U.S. is $2.67 \%$ and exchange rate for dollar depreciates $1.53 \%$ in average, making the sum of $4.2 \%$ for both. Only its average nominal rate over $4.2 \%$ can U.S. treasury bonds give investor positive return. In fact, average rate is $2.73 \%$ and $3.46 \%$ for 1 year and 3 year U.S. treasury bonds at the same time, which is smaller than $4.2 \%$. Average rate for 10 year U.S. treasury bonds is $4.49 \%$, higher than $4.2 \%$. However, average return obtained by FDI in China is $22 \%$ (Yu, 2007, pp.11-16). That's to say, China imports obligatory rights with lower return as $4.49 \%$ and exports equity with higher return as $20 \%$ above. The longer this condition continues, the larger damage to China's welfare, so it's necessary to increase return of foreign exchange investments.

\section{Insert Table 2 here}

(4) It is a need to charge off huge foreign exchange reserves by SWFs. Surging of foreign exchange reserves is the fundamental reason for liquidity surplus and capital bubble in China. Base money flows into financial system in the process of open market operation by China central bank. Charge-off, in the ways of lifting deposit reserve rate, issuing 
central bank notes and directional notes, buy-back with special bonds, currency-exchange with commercial banks and so on, is being done, but it's hard to continue for the increasing cost. Capital bubble is becoming clear, and if breaks, it will beat real economy, financial system and household welfare heavily. SWFs help transfer foreign exchange reserves from central bank's balance sheet and release charge-off pressure and liquidity surplus.

(5) Financial globalization creates various channels for SWFs global operation. Firstly, financial globalization makes financial markets much more open and thus it is favorable to capital flow. The smoother the capital flow, the closer the financial co-operation among countries and the more blooming the financial innovation. Also, many countries increase financial market openness, which makes trans-national balance-off possible. There are sound technical instruments and policy foundations for financial capital's massive assembling and flow. Secondly, it enriches categories of financial products and SWFs investments. Various financial derivatives enlarge liquidity; provide various investment choices and hedge means for SWFS. Lastly, it guarantees the orderliness of transnational investment (SWFs) with countries experienced at international investment, which is standardized by global organizations with series of rules etc.

\section{Significances of SWFs for home country}

(1) Risk diversification. Nations relying on export for foreign exchange surplus need to set up SWFs, invest in various ways, increase long-term return, smooth multi-term income, decrease influence brought to economy and fiscal budget by unexpected income fluctuations. Investment diversification disperses risks in consideration of export fluctuations and exchange risk etc. SWFs helps a nation to share global economic rise and decreases reliance on some economy or investment instruments by investing widely in many industries, financial products and various kinds of countries.

(2) Charge-off of liquidity surplus and ease of appreciation pressure from foreign exchange reserves explosion. According to IMF, SWFs is government foreign investment and should be recorded in HP not BOP, which means that foreign exchange assets for mid-and-long term investment by SWFs does not belong to foreign exchange reserves. SWFs, in the form of Investment Companies, issues foreign exchange bonds to domestic market parties to absorb liquidity surplus and then buy foreign exchange reserves from central bank. From standpoint of central bank, this process is able to increase usage of foreign exchange assets, ease appreciation and charge off pressure from continuous explosion of foreign exchange reserves at the same time.

(3) Pursuance for higher investment return of foreign exchange reserves. It's important to use more active investment methods and optimize combinations of risky assets to obtain higher return than traditional management methods. Central banks lay out foreign exchange reserves to high grade government bonds, low-risk currency instruments and so on in old days, whereas SWFs can make multi-investments to get higher revenues.

(4) Support for national development strategy, optimization of resource allocation all over the world, cultivation of world top companies and representation of national benefits in international economic activities. SWFs contributes to the restructure and furtherance of certain national industry. On the one hand, it is national asset arrangement for SWFs. On the other hand, it is about to win some control on global strategic resources, ensuring safety and sustaining development for national economy. Offshore merger and acquisition by SWFs benefit industry upgrade. It's been the mainstream to purchase American equities in international market. Since recent secondary credit crisis and economic depression, it is a good chance to invest in American equities at a lower price. SWFs should be a major force in consideration of need of large money for emerging and acquisition.

(5) Enhancing the capacity in reconstruction of international financial system. Active participation in economic globalization is needed to promote national comprehensive strength and improve economic quality along with China's economic development. By using SWFs as its change of investment policy to participate in international financial market, china will increase discourse rights, remedy unfair international economic and financial order and protect national economic interests.

(6) Prevention of economic crisis and promotion of stable development for economy and society. China holds huge foreign exchange reserves as same as personal preventive saves to cope with economic crisis and development uncertainty. Take Kuwait for example, SWFs managed by investment bureau made important contribution in its reconstruction after Iraqi war.

(7) To guarantee welfare for our offspring by smoothing national assets. There exists a possibility that one day national resources are run out. Therefore, it's farsighted to build up funds with present incomes and leave them to our offspring when the uncertain days come.

\section{SWFs' promotion for international finance situation}

(1) Help stabilize global financial market. SWFs are characterized by long-term investment and low leverage and can stabilize global financial market for following reasons. At first, long-term investment is idle capital not debts, so there is low possibility to liquidate temporarily. Secondly, SWFs is large and usually focuses on gradualness of capital portfolio, which restricts the price reversion. Thirdly, SWFs can increase the depth, width and effectiveness of market and 
decrease the fluctuation of market as well. Further, SWFs adopts buy-and-hold policy as a long-term investor. There are no pressures such as dividend, redemption, investors' dump. So it is not possible to change strategic portfolio under short-term market fluctuation. At last, SWFs is able to allot revenues from primary commodities among countries and enhance market liquidity. SWFs from the world supplied 40 billion U.S. dollars in total to European and American banks in Secondary credit crisis, which makes positive sense in market stabilization.

(2) Change international capital flow direction and market portion. China accumulates large foreign exchange reserves and makes SWFs investment to financial market in developed countries. Developed countries such as U.S. integrate these capitals and invest them into emerging economies. Therefore, SWFs investment in developed countries helps maintain relative equilibrium of global capital flow. But global capital flow will be changed by SWFs when its diversified investment matures.

(3)Drive forward structure adjustment of global financial interests. The rise of China' SWFs will bring a shift in the balance of forces between the east and the west, which has profound impact on global economic geography. By obtaining equities from developed countries with its part of foreign exchange reserves, China is under transition from creditor to equity owner of the developed countries. SWFs are a strong weapon for trade negotiation, technology obtaining and intellectual property rights protecting. Due to its broad investment, not just centralizing in dollar assets, SWFs help to increase other currencies' (especially Euro's) portion in international market, Decrease international economy's dependence on dollar, stabilize the order of international economy. Further, this is promotion for the transfer from monopole (U.S.) to multi-pole (Europe, Asia and Petro-export countries).

\section{Why U.S. worries about SWFs growing-up}

(1) The hegemonic status of dollar is weakened. SWF's explosion is a symbol of emerging countries gaining the world economic status. Assets shift from dollars by SWFs will influence its exchange rate and shake its importance as international currency, and also compel U.S. to implement cautious fiscal policy and deal with trade unbalance. The status of Yean, Euro and Pound will increase at the same time.

(2) Purchase for U.S. government bonds is decreased. Purchasing U.S. government bonds is the main channel for leading countries to deal with their huge foreign exchange reserves and these countries were also primary buyers of U.S. government bonds before the boom of SWFs. In this way, endless foreign exchange flows to American bonds market, which is very important for sustained development of U.S. economy, most important for supply of essential capital to U.S. Both fiscal and trade deficits are the largest factors threatening stability of U.S. macro-economy in recent 30 years. U.S. had to issue bonds continuously to offset the gap of capital. However, SWFs set up by other countries is aiming at diversified foreign exchange investments and a higher return, which means that it will not buy more, even decrease, U.S. government bonds. Then, it will disturb American regular borrowing pattern, even no money for America to borrow.

(3) Financial freedom defined by U.S. is disobeyed. American finance industry is undoubtedly the largest beneficiary of global financial freedom, which is critical reason to promote American financial hegemony. Therefore, U.S. government always drums for financial freedom in both global multilateral trade negotiation and regional bi-lateral trade negotiation. Financial freedom contains many aspects, such as openness of financial market, allowing entrance for foreign countries and openness of capital account and so on, the most critical among which is to eliminate government interference. Obviously, SWFs is against financial freedom. What are U.S. worries is that SWFs controlled by government will not only be pure business, but also political and strategic decisions, thus threatens American benefit.

(4) If SWFs cuts down dollar capital and adds to global equity indices for the need of diversified investment, capital inflow to U.S. will decrease and cause real rate margin increase and dollar depreciation. Moreover, when other countries and private investment institutions learn about this model, it will be a big obstacle for American global financial strategy.

(5) U.S. control on international financial system is shaken. IMF, World Bank, Bank for International Settlements and WTO form international financial system. They usually attend to the need of America and act as agent for American hegemony in global financial system. Presently, international financial organizations such as IMF play a role mainly in exchange rate policy supervision and supply of conditional loans on global financial system and its membership countries. The growing up of SWFs will cut down these two functions and also the control on global financial system by international financial organizations such as IMF etc. Overall, the growing up of SWFs will not only influence international financial condition, but also restricts American financial hegemony for three effects above.

\section{References}

Cai, W. Q. (2007). China SWF's sailing. China Market, 46, 38-39.

Kristian, F. (2007). The Trend and Challenge of Foreign Exchange Reserves Management. Washington: IMF. pp. 2-4.

Li, Y., Yu, W. B., and Zeng, G. (2007). Reformation of China Foreign Exchange Management System under Economy Globalization. Studies of International Finance, 4, 11-16. 
Song, G. Y. (2007). The Rise of Sovereign Wealth Funds and U.S. Financial Hegemony. CONTEMPORARY INTERNAL RELATIONS, 9, 31-33.

Zheng, L. Y. (2008). SWFs' Foreign Investment: Review and Outlook. Studies of International Finance, 6, $14-19$.

Zhong, W. (2007). The Orientation of China National Foreign Exchange Investment Company from Standpoint of SWF. China Development Observation, 9, 39-40.

Zhou, X. H. (2008). The Growing-up and Debate of SWF. International Forum, 1, 17-19.

Table 1. U.S. Current Account Deficit and Analysis of SWFs Source (1987-2007.09) (Unit: 100million U.S. dollar)

\begin{tabular}{|c|c|c|c|c|c|c|}
\hline \multirow[t]{2}{*}{ Year } & \multirow{2}{*}{$\begin{array}{l}\text { Current } \\
\text { Account } \\
\text { Deficit }\end{array}$} & \multirow{2}{*}{$\begin{array}{c}\text { Oil } \\
\text { Commodity } \\
\text { Deficit }\end{array}$} & \multicolumn{4}{|c|}{ Non-oil Commodity Deficit (several east Asian countries) } \\
\hline & & & Japan & China & South Korean & Singapore \\
\hline 1987-1991 & 4714 & 1718 & 2147 & 352 & 296 & 89 \\
\hline 1992-1996 & 4035 & 2142 & 2812 & 1400 & 82 & 120 \\
\hline $1997-2001$ & 12544 & 5060 & 3411 & 3422 & 380 & 57 \\
\hline $2002-2006$ & 30056 & 7006 & 3827 & 8232 & 481 & -190 \\
\hline $\begin{array}{c}2007 \text { (first } 3 \\
\text { quarters) }\end{array}$ & 5615 & 2314 & 762 & 2141 & 80 & -147 \\
\hline total & 57344 & 10270 & 12004 & 15506 & 1004 & -78 \\
\hline
\end{tabular}

Source: relation statistics from Department of Commerce, U.S.

Table 2. The Comparative Analysis of Capital Return Invested in U.S. (2001-2006) （unit: \%)

\begin{tabular}{|c|c|c|c|c|c|c|c|c|}
\hline year & $\begin{array}{c}\text { U.S. } \\
\text { CPI }\end{array}$ & $\begin{array}{c}\text { Exchange } \\
\text { rate of } \\
\text { dollar } \\
\text { of direct } \\
\text { investment in } \\
\text { U.S. }\end{array}$ & $\begin{array}{c}\text { Return rate } \\
\text { Company } \\
\text { bonds }\end{array}$ & $\begin{array}{c}\text { Rate of 1 } \\
\text { year } \\
\text { government } \\
\text { bonds }\end{array}$ & $\begin{array}{c}\text { Rate of 3 } \\
\text { years } \\
\text { government } \\
\text { bonds }\end{array}$ & $\begin{array}{c}\text { Rate of 10 } \\
\text { years } \\
\text { government } \\
\text { bonds }\end{array}$ & $\begin{array}{c}\text { Rate of 20 } \\
\text { years } \\
\text { government } \\
\text { bonds }\end{array}$ \\
\hline 2001 & 2.8 & 5.4 & 0.9 & 7.08 & 3.45 & 4.09 & 5.02 & 5.63 \\
\hline 2002 & 1.6 & 0.6 & 2.9 & 6.49 & 1.72 & 3.10 & 4.61 & 5.43 \\
\hline 2003 & 2.3 & -6.0 & 4.3 & 5.66 & 1.68 & 2.10 & 4.01 & 4.96 \\
\hline 2004 & 2.7 & -4.6 & 6.2 & 5.63 & 1.61 & 2.72 & 4.24 & 5.04 \\
\hline 2005 & 3.4 & -2.6 & 6.5 & 5.13 & 3.50 & 3.93 & 4.29 & 4.61 \\
\hline 2006 & 3.2 & -2.0 & -- & 5.91 & 3.60 & 4.27 & 4.8 & 5.00 \\
\hline average & 2.67 & -1.53 & 4.26 & 5.95 & 2.73 & 3.46 & 4.49 & 5.11 \\
\hline
\end{tabular}

Source: Song Guoyou. (2007). The Rise of Sovereign Wealth Funds and U.S. Financial Hegemony. CONTEMPORARY INTERNAL RELATIONS. 


\title{
Performance Evaluation of Selected Private Commercial Banks in Bangladesh
}

\author{
Tanbir Ahmed Chowdhury \\ Department of Business Administration, East West University \\ 43 Mohakhali C/A, Dhaka -1212, Bangladesh \\ Tel: 880-2-9882-308 Ext-244 E-mail: tanbir@ewubd.edu
}

Kashfia Ahmed

Department of Business Administration, East West University

43 Mohakhali C/A, Dhaka -1212, Bangladesh

Tel: 880-2-9882-308 Ext - 186 E-mail: kashfia_ahmed@hotmail.com

\begin{abstract}
In a developing country like Bangladesh the banking system as a whole play a vital role in the progress of economic development. In this paper we have tried to analyze the development and growth of Selected Private Commercial Banks of Bangladesh. It is observed that all the selected private commercial banks are able to achieve a stable growth of branches, employees, deposits, loans and advances, net income, earnings per share during the period of 2002-2006. Seven trend equations have been tested for different activities of the private commercial banks. Among them the trend value of branches, employees, deposits and net income are positive incase of all the selected banks. Square of correlation coefficient $\left(\mathrm{r}^{2}\right)$ has also been tested for all trend equations. The $\mathrm{r}^{2}$ of branches, deposits and net income is more than 0.5. It indicates the prospect of private commercial banks in Bangladesh is very bright.
\end{abstract}

Keywords: Bank, Commercial Bank, Loans, Deposit, Net Income

\section{Introduction}

\subsection{Banking Scenario in Bangladesh}

Banking system plays a very important role in the economic life of the nation. The health of the economy is closely related to the soundness of its banking system. In a developing country like Bangladesh the banking system as a whole play a vital role in the progress of economic development. A bank as a matter of fact is just like a heart in the economic structure and the Capital provided by it is like blood in it. As long as blood is in circulation the organs will remain sound and healthy. If the blood is not supplied to any organ then that part would become useless. So if the finance is not provided to agriculture sector or industrial sector, it will be destroyed. Loan facility provided by banks works as an incentive to the producer to increase the production. (http://www.blurtit.com/q197532.html)

Banking is now an essential part of our economic system. Modern trade and commerce would almost be impossible without the availability of suitable banking services. First of all, banking promotes savings. All manner of people, from the ordinary laborers and workers to the rich land owners and businessmen, can keep their money safely in banks and saving centers.

Secondly, banking promotes investments. Banks easily invest the money they get in industry, agriculture and trade. They either invest it directly or advance loans to other investors.

Thirdly, it is most through banks that foreign trade is carried on. Whether we export or import, it is through banks that money is transferred from one country to another. For example, bills of exchange and letters of credit are the regular ways banks use to transfer money.

A number of recent studies, however, indicate that the banking sector plays a more important role than it was believed earlier (World Bank, 1996; Almeyda)

In Bangladesh Sonali Bank is the largest among the Nationalized Commercial Banks (NCBs) while Pubali is leading in the private ones. Among the 12 foreign banks, Standard Chartered has become the largest in the country. Besides the 
scheduled banks, Samabai (Cooperative) Bank, Ansar-VDP Bank, Karmasansthan (Employment) Bank and Grameen bank are functioning in the financial sector. In Bangladesh the number of total branches of all scheduled banks is 6,038 as of June 2000. Of the branches, 39.95 per cent $(2,412)$ are located in the urban areas and 60.05 per cent $(3,626)$ in the rural areas. Of the branches NCBs hold 3,616, private commercial banks 1,214, foreign banks 31 and specialized banks 1,177 .

\subsection{Bangladesh Bank}

Bangladesh Bank (BB) has been working as the central bank since the country's independence. Its prime jobs include issuing of currency, maintaining foreign exchange reserve and providing transaction facilities of all public monetary matters. Bangladesh Bank (BB) regulates and supervises the activities of all banks. BB is also responsible for planning the government's monetary policy and implementing it thereby.

The BB has a governing body comprising of nine members with the Governor as its chief. Apart from the head office in Dhaka, it has nine more branches, of which two in Dhaka and one each in Chittagong, Rajshahi, Khulna, Bogra, Sylhet, Rangpur and Barisal.

\section{Category of Banks in Bangladesh}

\begin{tabular}{|c|c|c|}
\hline Category & Number of Banks & Number of Branches \\
\hline NCBs & 4 & 1214 \\
\hline Private Banks & 28 & 31 \\
\hline Foreign Banks & 12 & 1177 \\
\hline Development Banks & 5 & 1280 \\
\hline Other & 4 & 3616 \\
\hline
\end{tabular}

\section{Review of Literature}

With respect to the Performances of Bangladeshi Commercial Banking sector, foreign and national experts undertook number of studies. Some of the notable ones are; Bhattacharya (2007), Chowdhury and Islam (2007), Jahangir, Shill and Haque (2007), Chowdhury (2002), Siddique and Islam (2001), Al-Shamrnari and Salirni (1998), Avkiran (1997), Bhatt \& Ghosh (1992), Hossain \& Bhuiyan (1990), Swamy \& Vasudevan (1985), Ahmed \& Jamsheduzzaman (1985)

Bhattacharya (2007) pointed out that six major recent policy measures include: reduction of bank rate and lending rate, linking classified loans to large loan sanctioning; rationalization and merger of bank branches, measures for loan recovery, and demarcation of responsibilities between the management and the board and decision on cash reserve ratio.

Chowdhury and Islam (2007) stated that deposits and loan advances of Nationalized Commercial Banks (NCBs) are less sensitive to interest changes than those of Specialized Banks (SBs). So SBs should not make abrupt change in lending or deposit rates by following the NCBs. If NCBs change their lending or deposit rates, their deposits or loans and advances will be affected less than those of SBs. Moreover, deposits of NCBs have higher volume and higher volatility than those of SBs. On the other hand, loans advances of NCBs show a higher volume and higher volatility than those of SBs. However, SBs offer higher deposit rates and charge higher lending rates than NCBs. That is why the interest rate spread of SBs was higher than that of NCBs.

Jahangir, Shill and Haque (2007) stated that the traditional measure of profitability through stockholder's equity is quite different in banking industry from any other sector of business, where loan-to-deposit ratio works as a very good indicator of banks' profitability as it depicts the status of asset-liability management of banks. But banks' risk is not only associated with this asset liability management but also related to growth opportunity. Smooth growth ensures higher future returns to holders and there lies the profitability which means not only current profits but future returns as well. So, market size and market concentration index along with return to equity and loan-to-deposit ratio grab the attention of analyzing the banks' profitability.

Chowdhury (2002) observed that the banking industry of Bangladesh is a mixed one comprising nationalized, private and foreign commercial banks. Many efforts have been made to explain the performance of these banks. Understanding the performance of banks requires knowledge about the profitability and the relationships between variables like market size, bank's risk and bank's market size with profitability. Indeed, the performance evaluation of commercial banks is especially important today because of the fierce competition. The banking industry is experiencing major transition for the last two decades. It is becoming imperative for banks to endure the pressure arising from both internal and external factors and prove to be profitable.

Siddique and Islam (2001) pointed out that the Commercial Banks, as a whole, are performing well and contributing to the economic development of the country. The average profitability of all Bangladeshi banks collectively was $0.09 \%$ during 1980 to 1995 which means that a profit of TK 0.09 was earned by utilizing assets of TK 100 . In every aspect of 
profit, banking sector contributes the national economy as well as to the individual organization. Despite overall growth of the banking sector being positive, the performances of different categories of banks were not equally attractive.

According to Al-Shamrnari and Salirni (1998) profitability ratio especially return on equity (ROE) signals the earning capability of the organization. They also suggest that higher return on equity (ROE) ratio is appreciable as it is the primary indicator of bank's profitability and functional efficiency.

Avkiran (1997) stated that the details the process whereby multivariate interdisciplinary measures of potential to perform are integrated with performance measures to develop models of retail performance for bank branches. The predictive models use the key business drivers of a major trading bank as dependent variables. Independent variables explaining business drivers are the theorized potential variables that measure the capacity to generate retail business. The models allow a comparison between the predicted and actual levels of key business diverts, thus measuring unrealized performance. Findings can assist decision making during restructuring, branch closures or downsizing. The variables presented should be regarded as examples rather than universally accepted measures of branch performance.

Bhatt \& Ghosh (1992), observed that the profitability of commercial banks depend on several factors some of them are endogenous and some exogenous. The endogenous factors represent control of expenditure, expansion of banking business, timely recovery of loans and productivity. The exogenous factors consist of direct investments such as SLR (Statutory Liquidity Ratio), CRR (Cash Reserve Ratio) and directed credit programs such as region wise, population wise guidelines on lending to priority sectors. The regulated and restricted regime in the operation of banking system in terms of investment, credit allocation, branch expansion, interest rate determination and internal management eroded the productivity and profitability of commercial banks.

Hossain and Bhuiyan (1990) stated that there is no universally accepted operational definition of performance measures. In broad sense performance level of an enterprise can be measured by the extent of its organizational effectiveness. In the context of services rendered towards public the performance of an organization can be 2 viewed as 'the extent to which its work is carried out within established specifications for goods and services produced, to the general satisfaction of the clientele served, within given cost and time constraints, and in such a manner as to support or contribute to the achievement of the organization objectives.

In measuring performance level of a bank Swamy and Vasudevan (1985) used per employee, deposits, advances, profits, etc.

\section{Objectives of the Study}

The specific objectives of the study are as follows;

1) To present an overview of Private Commercial Banks of Bangladesh.

2) To appraise the performance of selected Private Commercial Banks of Bangladesh

3) To recommend remedial measures for the development of selected Private Commercial Banks of Bangladesh

\section{Scope \& Methodology of the study}

The present study has been carried out to evaluate the performance of selected private commercial banks of Bangladesh. The selected banks are Dutch Bangla Bank (DBBL), Dhaka Bank Ltd. (DBL), National Bank Ltd. (NBL), Prime Bank and Islami Bank Bangladesh Limited (IBBL). This study has been based mainly on data from secondary sources. The relevant data and information were collected from Stock Exchanges, Annual Reports of different commercial banks of Bangladesh, Bangladesh Bank, Securities and Exchange Commission and web sites of relevant commercial banks of Bangladesh etc. Relevant articles and literature in this context have also been consulted. In this article we analyzed last five years data of selected private commercial banks of Bangladesh. For evaluating the performance of selected private commercial banks of Bangladesh data has been analyzed through the various statistical measures like growth percentage, trend equation, square of correlation coefficient, correlation matrix etc.

Among the various straight line Trend Methods of Time Series Analysis the method of Least Square is most popular and widely used in practice. The method of least square can be used either to fit a straight-line trend or a parabolic trend. The straight line trend is represented by the equation $Y c=a+b$. Where, Yc denotes the trend values to distinguish them from the actual $\mathrm{Y}$ values. ' $\mathrm{a}$ ' is the $\mathrm{Y}$ intercept or the value of the $\mathrm{Y}$ variable when $\mathrm{X}=0$. ' $b$ ' represents the slope of the line of the amount of change in $\mathrm{Y}$ variable that if associated with a change of one unit in $\mathrm{X}$ variable. ' $\mathrm{X}$ ' variable in time series analysis represents time. The square of correlation coefficient $\left(r^{2}\right)$ is called the multiple determinations or squared multiple correlation coefficients. The coefficient of correlation is denoted by $r$. The value of $r$ lies between 0 and 1. The higher the $r^{2}$ the greater the percentage of the variation of $Y$ explained by the regression model, that is, the better the "goodness of fit" of the regression model to the sample observations. $r^{2}$ closer to zero, the worse the fit. 


\section{An overview of the Selected Private Commercial Banks of Bangladesh}

\subsection{DUTCH BANGLA BANK}

Dutch-Bangla Bank Limited (the Bank) is a scheduled commercial bank. The Bank was established under the Bank Companies Act 1991 and incorporated as a public limited company under the Companies Act 1994 in Bangladesh with the primary objective to carry on all kinds of banking business in Bangladesh. The Bank is listed with Dhaka Stock Exchange Limited and Chittagong Stock Exchange Limited. DBBL- a Bangladesh European private joint venture scheduled commercial bank commenced formal operation from June 3, 1996.

\subsection{Dhaka Bank Ltd. (DBL)}

A group of highly acclaimed businessmen of the country grouped together to responded to this need and established Dhaka Bank Ltd. in the year 1995. The bank was incorporated as a public limited company under the companies Act.1994. The bank started its commercial operation on July 05, 1995 with an authorized capital of TK. 1,000 million and paid up capital of the Bank stood at TK. 1,289,501,900 as on June 30, 2006. The total equity (capital and reserves) of the bank as on June 30, 2006 stood at TK. 2,188,529,224.

The Bank has 37 branches across the country and a wide network of correspondents all over the world. The bank offers the full range of banking and investment services for personal and corporate customers, backed by latest technology and a team of highly motivated officers and staff. In the effort to provide Excellence in Banking Services, the bank has launched Online Banking Service, Joined a countrywide shared ATM network and has introduced a co-branded credit card. A process is also underway to provide e-business facility to the bank's clientele through Online and home banking solutions.

\subsection{National Bank Ltd. (NBL)}

National bank has born as the first hundred percent Bangladeshi owned bank in Private sector. The then President of the People's Republic of Bangladesh Justice Ahsanuddin Chowdhury inaugurated the bank formally on March $28,1983$. NBL was first domestic bank to establish agency arrangement with the world famous Western Union in order to facilitate quick and safe remittance of the valuable foreign exchanges earned by the expatriate Bangladeshi nationals. NBL was also the first among domestic banks to introduce Master Card in Bangladesh. Since the very beginning, the bank exerted much emphasis on overseas operation and handled a sizeable quantum of homebound foreign remittances. The Bank established extensive drawing arrangement network with banks and exchange companies located in important countries of the world.

\subsection{Prime Bank}

Prime Bank Ltd. was created and commencement of business started on 17th April 1995. The sponsors are reputed personalities in the field of trade and commerce and their stake ranges from shipping to textile and finance to energy etc. Prime Bank Ltd. has already made significant progress within a very short period of its existence. The bank has been graded as a top class bank in the country through internationally accepted Capital adequacy, asset quality, management, earnings, liquidity, and sensitivity to market risk (CAMELS) rating. The bank has already occupied an enviable position among its competitors after achieving success in all areas of business operation. Prime Bank Ltd. offers all kinds of Commercial Corporate and Personal Banking services covering all segments of society within the framework of Banking Company Act and rules and regulations laid down by our central bank. Diversification of products and services include Corporate Banking, Retail Banking and Consumer Banking right from industry to agriculture, and real state to software. Prime Bank Ltd., since its beginning has attached more importance in technology integration. In order to retain competitive edge, investment in technology is always a top agenda and under constant focus. Keeping the network within a reasonable limit, our strategy is to serve the customers through capacity building across multi delivery channels. Our past performance gives an indication of our strength. We are better placed and poised to take our customers through fast changing times and enable them compete more effectively in the market they operate.

\subsection{Islami Bank Bangladesh Limited (IBBL)}

Bangladesh is one of the largest Muslim countries in the world. The people of this country are deeply committed to Islamic way of life as enshrined in the Holy Qur'an and the Sunnah. Naturally, it remains a deep cry in their hearts to fashion and design their economic lives in accordance with the precepts of Islam. The establishment of Islami Bank Bangladesh Limited on March 13, 1983, is the true reflection of this inner urge of its people, which started functioning with effect from March 30, 1983. This Bank is the first of its kind in Southeast Asia. It is committed to conduct all banking and investment activities on the basis of interest-free profit-loss sharing system. In doing so, it has unveiled a new horizon and ushered in a new silver lining of hope towards materializing a long cherished dream of the people of Bangladesh for doing their banking transactions in line with what is prescribed by Islam. With the active co-operation and participation of Islamic Development Bank (IDB) and some other Islamic banks, financial institutions, government 
bodies and eminent personalities of the Middle East and the Gulf countries, Islami Bank Bangladesh Limited has by now earned the unique position of a leading private commercial bank in Bangladesh.

\section{Performance Evaluation of Selected Private Commercial Banks of Bangladesh}

\subsection{Growth of Branches of Selected Private Commercial Banks}

Table: 1 shows the growth pattern of number of branches of selected banks. The growth of branches is highest in DBBL. But IBBL has highest number of branches i.e. 176. The lower growth percentage is in Prime Bank. Till 2005 Prime Bank had 50 branches but in 2006 Prime Bank had closed 9 of its branches.

\subsection{Growth of Employee of Selected Private Commercial Banks}

No of employees of selected banks have been shown in table: 2. The highest no of employees are working in IBBL i.e. 7459 and lowest in DBBL. The growth percentage is higher in DBBL and lowest in Prime Bank.

\subsection{Growth of Deposit of Selected Private Commercial Banks}

Table 3 shows growth pattern of deposits of selected commercial banks. It is observed from the table that the deposit is highest in IBBL that is TK 132,419,403,524 in 2006. The growth percentage of Prime Bank is highest that is $51.92 \%$ in 2006. In 2006 Growth percentage of Dutch Bangla Bank and Dhaka Bank is $47.25 \%$ and $46.12 \%$ in year 2006 respectively. The lowest growth percentage of deposit is in National Bank Ltd. that is $22.33 \%$ in 2006. During 2002 to 2006 every year deposit of Dhaka Bank, DBBL, NBL, Prime Bank and IBBL has increased from the previous year except 2005. So it is reflected from the table that the deposit of all the sele2cted banks have showed an increasing trend during the period of 2002-2006.

\subsection{Growth of Total Loans \& Advances of Selected Private Commercial Banks}

The growth pattern of total loan and advances of selected private commercial banks of Bangladesh are reflected from Table-4. It is reflected from the table that almost every year's loan and advances of selected private commercial banks of Bangladesh has increased from the previous year. The growth of loan and advances is more than $30 \%$ in Prime Bank, Dutch Bangla Bank and Dhaka Bank. The lowest growth observed in National Bank.

\subsection{Classified Loans of Selected Private Commercial Banks}

It is observed from table: 5 that the classified loan of DBBL, DBL and PBL is very low i.e. about $2 \%$. It seems that DBBL, DBL and PBL is able to manage credit efficiently as a result recovery is quite good. The percentage of classified loan in NBL and IBBL is above 5\%. It indicates percentage of classified loan is more in PBL and IBBL.

\subsection{Growth of Net Income of Selected Private Commercial Banks}

It is observed from the table: 6 that the net income of DBL, DBBL, NBL and IBBL has almost increased from the previous year during 2003 to 2006. It is also reflected that all the selected banks has earned net income in all the year during 2002 to 2006. Prime Bank has earned net income in every year but has failed to increase the net income from the previous year in 2003 and 2005. The growth rate of net income is stable and very high in NBL and DBL.

\subsection{EPS of Selected Private Commercial Banks}

It is reflected from the table: 7 that the EPS of all the selected commercial banks are very high during 2002 to 2006. It is observed that the average EPS of DBBL is more than $100 \%$. It is also reflected that average EPS of PB, DBL and NBL is more than $40 \%$. We have also observed that the EPS of IBBL is more than $400 \%$ during 2004 to 2006 . It is indicates the selected private commercial banks are earning very high profit. Highest growth of EPS in 2006 is IBBL and lowest is in Dhaka Bank. During 2004 IBBL have the highest growth of EPS and in 2003 NBL had lowest growth of EPS.

\subsection{Trend Equations of Selected Private Commercial Banks}

Table: 8 shows the summary of trend equation and $r^{2}$ of Branch expansion of selected private commercial banks. It is reflected from the table that trend equation of all the selected banks are positive and goodness of fit of all the equations are high i.e. more than 0.50. Incase of Islami Bank and Dhaka bank its very high i.e. more than 0.90.

Table: 9 shows the summary of trend equation and $r^{2}$ of employees of selected private commercial banks. It is reflected from the table that the trend equation of all the selected banks are positive. Goodness of fit of all the selected banks are high i.e. more than 0.80 except National Bank Ltd.

Table: 10 shows the summary trend equation and $\mathrm{r}^{2}$ of net income of selected private commercial banks. It is reflected from the table that the trend equation of all the selected banks are positive and goodness of fit of all the selected private commercial banks are very high i.e. more than 0.70 .

Table: 11 shows the summary trend equation and $\mathrm{r}^{2}$ of EPS of selected private commercial banks. It is reflected from the table that the trend equation of Dutch Bangla bank and National bank are positive and goodness of fit of Dutch Bangla Bank is very high i.e. more than 0.60 . 
Table: 12 shows the summary of the trend equation and $r^{2}$ of deposits of selected private commercial banks. It is reflected from the table that the trend equation of all the selected banks are positive and goodness of fit of all the equations are very high i.e. more than 0.85 .

Tabl2e: 13 shows the summary of the trend equation and $r^{2}$ of dividends of selected private commercial banks. It is reflected from the table that the trend equation of Dutch Bangla bank and National bank are positive and goodness of fit of Dutch Bangla Bank is very high i.e. more than 0.70 .

Table: 14 shows the summary of the trend equation and $r^{2}$ of Net Asset Value per Share of selected private commercial banks. It is reflected from the table that the trend equation of Dutch Bangla bank and National bank are positive and goodness of fit of Dutch Bangla Bank is very high i.e. more than 0.70.

\subsection{Correlation Matrix of Net Profit of Selected Private Commercial Banks}

Table2: 15 shows the correlation matrix for estimating interrelationships between chosen parameters of all the selected private commercial banks. From the correlation matrix we have observed the followings;

- $\quad$ Net Income has strong correlation with deposit, loans, branches and employees.

- $\quad$ Deposit has strong correlation with net income, loans, branches and employees.

- $\quad$ Loans have strong correlation with net income, deposit, branches and employees.

- $\quad$ Branches have strong correlation with net income, loans, deposits and employees.

- $\quad$ Employees have strong correlation with net income, loans, branches and deposits.

\section{Findings and Conclusion}

The journey of Private commercial banks has started in Bangladesh in the year 1982-1983. After commencement the private commercial play a vital role in the economic development of the country. The selected private commercial banks create employment opportunities for more than twelve thousand people. It has been observed that the net income of the selected private commercial banks have increased from the previous year during 2003 to 2006 . It is also reflected from the analysis that the EPS of all the selected commercial banks are very high during 2002 to 2006. It indicates the profitability of all the selected banks is quite satisfactory. Loans recovery rate indicated that the banks are able to manage their credit efficiently. Every year these banks open new branches and the IBBL has highest number of branches i.e. 176. It is observed that the classified loan of DBBL, DBL and PBL is very low i.e. about $2 \%$. It seems that DBBL, DBL and PBL is able to manage credit efficiently as a result recovery is quite good.

Seven trend equations have been tested for different activities of the private commercial banks. Among them the trend value of branches, employees, deposits and net income are positive incase of all the selected banks. Square of correlation coefficient $\left(r^{2}\right)$ has also been tested for all trend equations. The $r^{2}$ of branches deposits and net income is more than 0.5. It indicates the prospect of private commercial banks in Bangladesh is very bright.

Till 2005 the growth percentage of branches in case of National bank was zero. In 2006 Prime bank has closed 9 branches. In order to increase the activities and income these banks need to expand its new branches.

From the sequence of our analysis it is reflected that although the deposit of all the selected banks have showed an increasing trend during the period of 2002 to 2006, the total deposits of DBL, DBBL, NBL are not satisfactory in comparison to IBBL. So these banks need to increase their deposits.

It has been identified that although almost every year's loans and advances of selected private commercial banks have increased from the previous year, the growth rate of loans and advances is not satisfactory for NBL. So it should try to increase the growth rate.

DBBL need to increase its net income by increasing deposits, decreasing cost and expanding more branches. As the net income of Prime Bank is fluctuating, the bank should try to keep it at a stable point.

We are quite optimistic that if the given suggestions of this paper are implemented then the Banking sector may be able to overcome its present problems and may contribute in the rapid development of the economy of Bangladesh.

\section{References}

Al Shammari, M., and Salimi, M. (1998). Modeling the operating efficiency of banks, A parametric methodology. Journal of Logistic Information Management, Vol. 11.

Avkiran, N. K. (1997). Models of retail performance for bank branches: predicting the level of key business drivers. International Journal of Bank Marketing, Vol. 15, No. 6.

Bhatt, P. R., and Ghosh, R. (1992). Profitability of Commercial Banks in India. Indian Journal of Economics, India.

Chowdhury, A., (2002). Politics, Society and Financial Sector Reform in Bangladesh. International Journal of Social Economies, 29(12), $963-988$. 
Chowdhury, H. A., and Islam, M. S. (2007). Interest Rate Sensitivity of Loans and Advances: A Comparative Study between Nationalized Commercial Banks (NCBs) and specialized Banks (SBs). ASA University Review, Vol.1, No.1.

CPD Dialogue Report 49, (2002). Financial Sector Reforms in Bangladesh: The Next Round. Center for Policy Dialogue, Dhaka.

Hossain, M. K., and Bhuiyan, R. H. (1990). Performance Dynamics of Nationalized Commercial Banks in Bangladesh - The Case of Sonali Bank. Journal of Business Studies, University of Dhaka, Vol. XI, No. 1.

Jahangir, N., Shill, S., and Haque, M. A. J. (2007). Examination of Profitability in the Context of Bangladesh Banking Industry. ABAC Journal, Vol. 27, No. 2.

Siddique, S. H., and Islam, A. F. M. M. (2001). Banking Sector in Bangladesh: Its Contribution and Performance. Journal of Business Research, Jahangirnagar University, Vol. 3.

Swamy, M. R., and Vashudevan, S. V. (1985). A Text Book of Banking. S. Chand \& Company, New Delhi.

Table1. Number of Branches of Selected Private Commercial Banks

\begin{tabular}{|c|c|c|c|c|c|c|}
\hline \multirow{2}{*}{ SL } & Name of Banks & \multicolumn{5}{|c|}{ Number of Branches } \\
\hline & & 2002 & 2003 & 2004 & 2005 & 2006 \\
\hline 1 & Dhaka Bank Ltd. & 18 & 20 & 23 & 29 & 37 \\
\hline & Growth & & $11.11 \%$ & $15.00 \%$ & $26.09 \%$ & $27.59 \%$ \\
\hline 2 & Dutch Bangla Bank Ltd. & 17 & 17 & 19 & 28 & 39 \\
\hline 3 & Growth & & $0.00 \%$ & $11.76 \%$ & $47.37 \%$ & $39.29 \%$ \\
\hline 4 & National Bank Ltd. & 76 & 76 & 76 & 76 & 91 \\
\hline & Growth & & $0.00 \%$ & $0.00 \%$ & $0.00 \%$ & $19.74 \%$ \\
\hline 5 & Prime Bank Ltd. & 27 & 30 & 36 & 50 & 41 \\
\hline & Growth & & $11.11 \%$ & $20.00 \%$ & $38.89 \%$ & $-18.00 \%$ \\
\hline
\end{tabular}

Source: Compiled from different issues of Annual Report of Dhaka Bank Ltd., Dutch Bangla Bank Ltd., National Bank Ltd., Prime Bank Ltd. and Islami Bank Bangladesh Ltd.

Table 2. Employees of Selected Private Commercial Banks

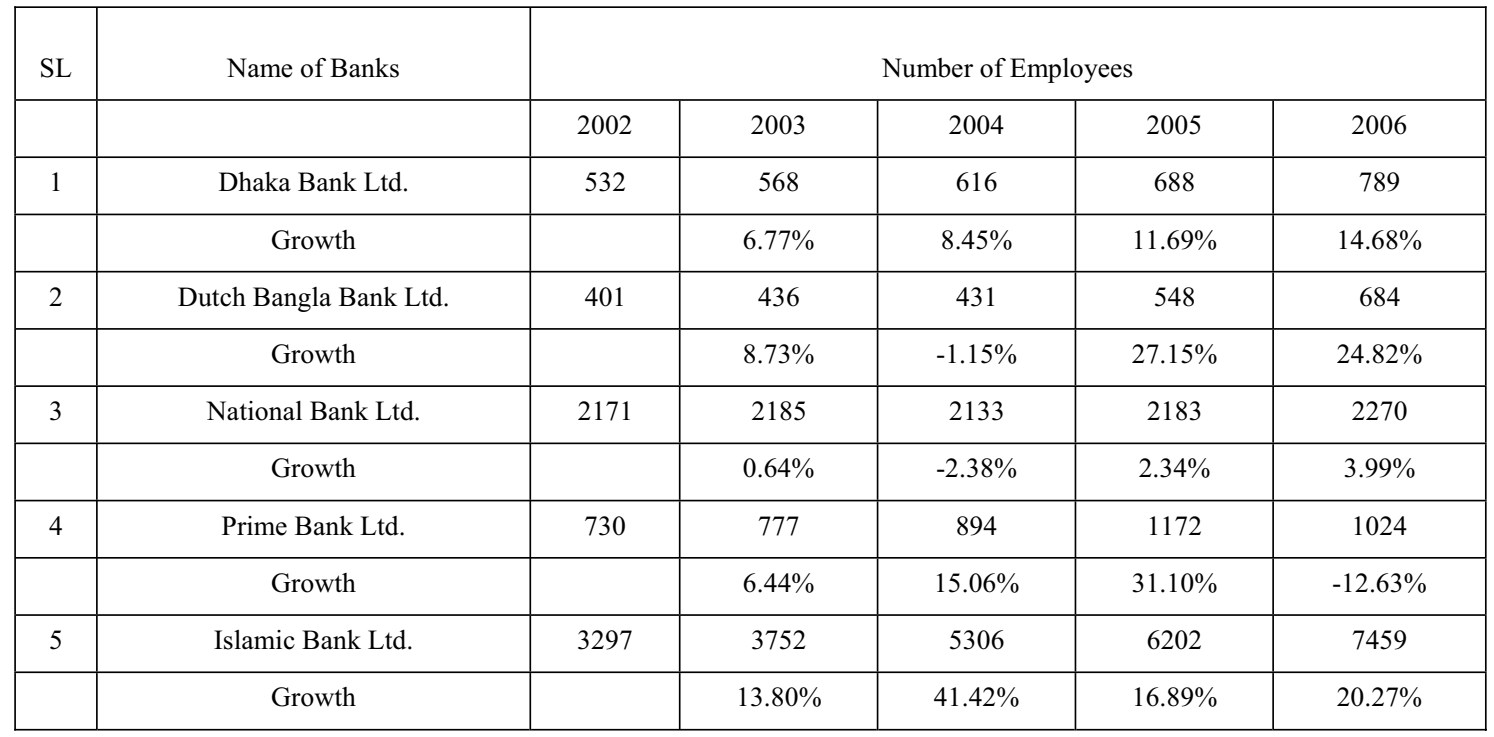

Source: Compiled from different issues of Annual Report of Dhaka Bank Ltd., Dutch Bangla Bank Ltd., National Bank Ltd., Prime Bank Ltd. and Islami Bank Bangladesh Ltd. 
Table 3. Deposits of Selected Private Commercial Banks

\begin{tabular}{|c|c|c|c|c|c|c|}
\hline \multirow[t]{2}{*}{ SL } & \multirow[t]{2}{*}{ Name of Banks } & \multicolumn{5}{|c|}{ Total Deposits (BDT) } \\
\hline & & 2002 & 2003 & 2004 & 2005 & 2006 \\
\hline \multirow[t]{2}{*}{1} & Dhaka Bank Ltd. & 14809967557 & 16850833278 & 22575365660 & 28438792427 & 41553551972 \\
\hline & Growth & & $13.78 \%$ & $33.97 \%$ & $25.97 \%$ & $46.12 \%$ \\
\hline \multirow[t]{2}{*}{2} & Dutch Bangla Bank Ltd. & 15975446123 & 17133812704 & 21067558418 & 27241107393 & 40111536968 \\
\hline & Growth & & $7.25 \%$ & $22.96 \%$ & $29.30 \%$ & $47.25 \%$ \\
\hline \multirow[t]{2}{*}{3} & National Bank Ltd. & 26276237646 & 27762117033 & 28973387115 & 32984053891 & 40350868324 \\
\hline & Growth & & $5.65 \%$ & $4.36 \%$ & $13.84 \%$ & $22.33 \%$ \\
\hline \multirow[t]{2}{*}{4} & Prime Bank Ltd. & 16172287880 & 20483225521 & 28069242650 & 36022455081 & 54724080584 \\
\hline & Growth & & $26.66 \%$ & $37.04 \%$ & $28.33 \%$ & $51.92 \%$ \\
\hline \multirow[t]{2}{*}{5} & Islamic Bank Ltd. & 55461621964 & 69941790927 & 87841013143 & 107779418134 & 132419403524 \\
\hline & Growth & & $26.11 \%$ & $25.59 \%$ & $22.70 \%$ & $22.86 \%$ \\
\hline
\end{tabular}

Source: Compiled from different issues of Annual Report of Dhaka Bank Ltd., Dutch Bangla Bank Ltd., National Bank Ltd., Prime Bank Ltd. and Islami Bank Bangladesh Ltd.

Note: $\quad$ US \$1 = BDT 69.35

Table 4. Total Loans \& Advances of Selected Private Commercial Banks

\begin{tabular}{|c|c|c|c|c|c|c|}
\hline \multirow{2}{*}{ SL } & Name of Banks & \multicolumn{5}{|c|}{ Total Loans \& Advances (BDT) } \\
\hline & & 2002 & 2003 & 2004 & 2005 \\
\hline 1 & Dhaka Bank Ltd. & 10761348979 & 12886688559 & 16538805141 & 23372450372 & 34048820675 \\
\hline & Growth & & $19.75 \%$ & $28.34 \%$ & $41.32 \%$ & $45.68 \%$ \\
\hline 2 & Dutch Bangla Bank Ltd. & 9391643291 & 11431318979 & 14976056619 & 20349422855 & 28325339997 \\
\hline & Growth & & $21.72 \%$ & $31.01 \%$ & $35.88 \%$ & $39.19 \%$ \\
\hline 3 & National Bank Ltd. & 21677960687 & 22257153235 & 22840436542 & 27020205114 & 32709675950 \\
\hline & Growth & & $2.67 \%$ & $2.62 \%$ & $18.30 \%$ & $21.06 \%$ \\
\hline 4 & Prime Bank Ltd. & 12686845330 & 16492224405 & 23219673305 & 31916112508 & 45010218048 \\
\hline & Growth & & $29.99 \%$ & $40.79 \%$ & $37.45 \%$ & $41.03 \%$ \\
\hline 5 & Islamic Bank Ltd. & 46280613393 & 59007490255 & 75858562224 & 93644154974 & 113575071129 \\
\hline & Growth & & $27.50 \%$ & $28.56 \%$ & $23.45 \%$ & $21.28 \%$ \\
\hline
\end{tabular}

Source: Compiled from different issues of Annual Report of Dhaka Bank Ltd., Dutch Bangla Bank Ltd., National Bank Ltd., Prime Bank Ltd. and Islami Bank Bangladesh Ltd.

Note: $\quad$ US \$1 = BDT 69.35 
Table 5. Classified Loan of Selected Private Commercial Banks

\begin{tabular}{|c|c|c|c|c|c|c|}
\hline \multirow[t]{2}{*}{ SL } & \multirow[t]{2}{*}{ Name of Banks } & \multicolumn{5}{|c|}{ Classified Loan } \\
\hline & & 2002 & 2003 & 2004 & 2005 & 2006 \\
\hline 1 & $\begin{array}{c}\text { Dhaka Bank Ltd } \\
.\end{array}$ & $2.48 \%$ & $3.26 \%$ & N/A & $1.51 \%$ & $1.64 \%$ \\
\hline 2 & Dutch Bangla Bank Ltd. & $0.60 \%$ & $0.36 \%$ & $0.16 \%$ & $1.76 \%$ & $2.88 \%$ \\
\hline 3 & National Bank Ltd. & N/A & N/A & $\mathrm{N} / \mathrm{A}$ & $5.58 \%$ & $6.01 \%$ \\
\hline 4 & Prime Bank Ltd. & $1.48 \%$ & $1.98 \%$ & $1.52 \%$ & $0.96 \%$ & $0.82 \%$ \\
\hline 5 & Islami Bank Bangladesh Ltd. & $6 \%$ & $6.8 \%$ & $6 \%$ & $3.25 \%$ & $3.43 \%$ \\
\hline
\end{tabular}

Source: Compiled from different issues of Annual Report of Dhaka Bank Ltd., Dutch Bangla Bank Ltd., National Bank Ltd., Prime Bank Ltd. and Islami Bank Bangladesh Ltd.

Note: N/A - Data not available

Table 6. Net Income of Selected Private Commercial Banks

\begin{tabular}{|c|c|c|c|c|c|}
\hline & \multicolumn{5}{|c|}{ Net Income (BDT) } \\
\hline & 2002 & 2003 & 2004 & 2005 & 2006 \\
\hline Dhaka Bank Ltd. & 234310726 & 269007381 & 357572894 & 462558947 & 580494670 \\
\hline Growth \% & & 14.81 & 32.92 & 29.36 & 25.50 \\
\hline Dutch Bangla Bank Ltd. & 177599990 & 210157591 & 236350352 & 367816801 & 362183665 \\
\hline Growth \% & & 18.33 & 12.46 & 55.62 & -1.53 \\
\hline National Bank Ltd. & 146191756 & 88122765 & 170017097 & 271667990 & 507492348 \\
\hline Growth \% & & -39.72 & 92.93 & 59.79 & 86.81 \\
\hline Prime Bank Ltd. & 418144625 & 375455447 & 611938344 & 568196286 & 1051890526 \\
\hline Growth \% & & -10.21 & 62.99 & -7.15 & 85.13 \\
\hline Islamic Bank Ltd. & 596430550 & 391405599 & 1013647225 & 1125821683 & 1400591591 \\
\hline Growth \% & & -34.38 & 158.98 & 11.07 & 24.41 \\
\hline
\end{tabular}

Source: Compiled from different issues of Annual Report of Dhaka Bank Ltd., Dutch Bangla Bank Ltd., National Bank Ltd., Prime Bank Ltd. and Islami Bank Bangladesh Ltd.

Note: US \$1 = BDT 69.35

Table 7. Earning Per Share of Selected Private Commercial Banks

\begin{tabular}{|c|c|c|c|c|c|}
\hline \multirow{2}{*}{ Name of Banks } & \multicolumn{5}{|c|}{ Earning Per Share (EPS) } \\
\hline & 2002 & 2003 & 2004 & 2005 & 2006 \\
\hline Dhaka Bank Ltd. & 61.77 & 50.65 & 53.86 & 37.66 & 45.02 \\
\hline Dutch Bangla Bank Ltd. & 87.86 & 103.97 & 116.93 & 181.97 & 179.18 \\
\hline National Bank Ltd. & 33.98 & 20.48 & 32.93 & 43.85 & 63.01 \\
\hline Prime Bank Ltd. & 69.69 & 53.64 & 61.19 & 32.47 & 60.11 \\
\hline Islamic Bank Ltd. & 0.93 & 203.86 & 439.95 & 407.20 & 405.26 \\
\hline
\end{tabular}

Source: Compiled from different issues of Annual Report of Dhaka Bank Ltd., Dutch Bangla Bank Ltd., National Bank Ltd., Prime Bank Ltd. and Islami Bank Bangladesh Ltd. 
Table 8 . Trend equation and $r^{2}$ of Branches

\begin{tabular}{|c|c|c|}
\hline Bank & Yc=a+bx & $\mathrm{r}^{2}$ \\
\hline Dhaka Bank Ltd. & $25.4+4.7 \mathrm{x}$ & .93 \\
\hline Dutch Bangla Bank Ltd. & $24+5.5 \mathrm{x}$ & .5 \\
\hline National Bank Ltd. & & $79+3 \mathrm{x}$ \\
\hline Prime Bank Ltd. & & .68 \\
\hline Islami Bank Bangladesh Ltd. & $36.8+4.8 \mathrm{x}$ & .99 \\
\hline
\end{tabular}

Table 9. Trend equation and $\mathrm{r}^{2}$ of no. of Employees

\begin{tabular}{|c|c|c|}
\hline Bank & Yc $=\mathrm{a}+\mathrm{bx}$ & $\mathrm{r}^{2}$ \\
\hline Dhaka Bank Ltd. & $638.6+63.4 \mathrm{x}$ & .96 \\
\hline Dutch Bangla Bank Ltd. & $500+67.8 \mathrm{x}$ & .84 \\
\hline National Bank Ltd. & $2188.4+19.6 \mathrm{x}$ & .38 \\
\hline Prime Bank Ltd. & $919.4+98.3 \mathrm{x}$ & .73 \\
\hline Islami Bank Bangladesh Ltd. & & .98 \\
\hline
\end{tabular}

Table 10. Trend equation and $\mathrm{r}^{2}$ of Net Income

\begin{tabular}{|c|c|c|}
\hline Bank & Yc $=\mathrm{a}+\mathrm{bx}$ & $\mathrm{r}^{2}$ \\
\hline Dhaka Bank Ltd. & $380.8+88.9 \mathrm{x}$ & .97 \\
\hline Dutch Bangla Bank Ltd. & $270.8+52.68 \mathrm{x}$ & .88 \\
\hline National Bank Ltd. & $236.7+90.61 \mathrm{x}$ & .73 \\
\hline Prime Bank Ltd. & $605.12+146.02 \mathrm{x}$ & .82 \\
\hline
\end{tabular}


Table 11. Trend equation and $r^{2}$ of EPS

\begin{tabular}{|c|c|c|}
\hline Bank & Yc=a+bx & \multicolumn{2}{|c|}{$\mathrm{r}^{2}$} \\
\hline Dhaka Bank Ltd. & $49.79-4.65 \mathrm{x}$ & .88 \\
\hline Dutch Bangla Bank Ltd. & $134+26.06 \mathrm{x}$ \\
\hline National Bank Ltd. & & .66 \\
\hline Prime Bank Ltd. & $38.85+8.14 \mathrm{x}$ & .20 \\
\hline Islami Bank Bangladesh Ltd. & $55.42-4.03 \mathrm{x}$ & .25 \\
\hline
\end{tabular}

Table 12. Trend equation and $\mathrm{r}^{2}$ of Deposits

\begin{tabular}{|c|c|c|}
\hline Bank & $\mathrm{Yc}=\mathrm{a}+\mathrm{bx}$ & $\mathrm{r}^{2}$ \\
\hline Dhaka Bank Ltd. & $\mathrm{Y}=24845.7+6507.51(\mathrm{x})$ & .91 \\
\hline Dutch Bangla Bank Ltd. & $\mathrm{Y}=24305.89+5837.94(\mathrm{x})$ & .87 \\
\hline National Bank Ltd. & $\mathrm{Y}=31269.33+3337.11(\mathrm{x})$ & .87 \\
\hline Prime Bank Ltd. & $\mathrm{Y}=31094.26+9264.28(\mathrm{x})$ & .93 \\
\hline Islami Bank Bangladesh Ltd. & $\mathrm{Y}=90688.64+19175.32(\mathrm{x})$ & .99 \\
\hline
\end{tabular}

Table 13. Trend equation and $\mathrm{r}^{2}$ of Dividend

\begin{tabular}{|c|c|c|}
\hline Bank & $\mathrm{Yc}=\mathrm{a}+\mathrm{bx}$ & $\mathrm{r}^{2}$ \\
\hline Dhaka Bank Ltd. & $\mathrm{Y}=15-1.5(\mathrm{x})$ & .22 \\
\hline Dutch Bangla Bank Ltd. & & .89 \\
\hline National Bank Ltd. & $\mathrm{Y}=22.4+1.5(\mathrm{x})$ & .72 \\
\hline Prime Bank Ltd. & $\mathrm{Y}=28+7(\mathrm{x})$ & .48 \\
\hline Islami Bank Bangladesh Ltd. & $\mathrm{Y}=23+6.5(\mathrm{x})$ & .41 \\
\hline
\end{tabular}


Table 14. Trend equation and $\mathrm{r}^{2}$ of Net Asset Value per Share

\begin{tabular}{|c|c|c|}
\hline Bank & $\mathrm{Yc}=\mathrm{a}+\mathrm{bx}$ & $\mathrm{r}^{2}$ \\
\hline Dhaka Bank Ltd. & $\mathrm{Y}=222.5-2.62(\mathrm{x})$ & .016 \\
\hline Dutch Bangla Bank Ltd. & $\mathrm{Y}=524.9+122.3(\mathrm{x})$ & .97 \\
\hline National Bank Ltd. & & .73 \\
\hline Prime Bank Ltd. & $\mathrm{Y}=447.9+48.58(\mathrm{x})$ & .55 \\
\hline Islami Bank Bangladesh Ltd. & $\mathrm{Y}=186.5+49.37(\mathrm{x})$ & .53 \\
\hline
\end{tabular}

Table 15. Inter- Parameter Correlation Matrix

\begin{tabular}{|c|c|c|c|c|c|}
\hline Variables & Net income & Deposit & Loans & Branches & Employees \\
\hline Net income & 1.000 & .869 & .873 & .630 & .708 \\
\hline Deposit & .869 & 1.000 & .999 & .891 & .934 \\
\hline Loans & .873 & .999 & 1.000 & 1.000 & .940 \\
\hline Branches & .630 & .891 & .897 & .970 & 1.000 \\
\hline Employees & .708 & .934 & .940 & & .970 \\
\hline
\end{tabular}

The covariance matrix is calculated and used in the analysis. 


\title{
A Case for Performance Management in the Public Sector in Nigeria
}

\author{
Bassey B. Esu (Corresponding author) \\ Department of Marketing, University of Calabar \\ PMB 1115 Calabar, Nigeria \\ Tel: 234-8034-740-556Ｅ-mail: esubenjamin@yahoo.com \\ Benjamin J. Inyang \\ Department of Business Management, University of Calabar \\ PMB 1115 Calabar, Nigeria
}

Tel: 234- 8033-773-403Ｅ-mail: benji1955.unical@yahoo.co.uk

\begin{abstract}
The public sector in Nigeria has suffered setbacks which are largely attributed to ineffective and inefficient management. Performance management is a tool which focuses on managing the individual and work environment in such a manner that an individual/team can achieve set organizational goals. It is a relatively new concept in human resource management. The paper gives a perspective of the public sector in Nigeria and presents the performance management system as one such tool that can enhance the performance of the public executing agencies.
\end{abstract}

Keywords: Performance management, Motivation, Organization, Individual, Human resource, Nigerian public service

\section{Introduction}

Businesses exist to meet the needs and wants of a society. A business is any activity that seeks to make profit by providing goods and services to others (Nickels, McHugh and McHugh, 1999). Businesses used inputs from the environment and transformed them into outputs such as food, clothing, housing, medical care, transportation as well as other things that add meaning to human existence (leisure and recreation). There are different types of business organizations - the profit and the not-for-profit organizations. The former is interested in making monetary gains for its owners, while the latter do not seek monetary gains for its owners.

The performance of these businesses is predicated on several factors. Many businesses have failed to meet the objective or purpose of its formation. This has been the experience in all economies. It is more worrisome in the developing economics of the world where managers lack the requisite managerial skills in management. It is one thing to formulate individual and organizational objectives, and another thing is to achieve the set targets, sustain task-level and later improve on performance. The fact that most of the businesses (both large and small scale business) that we saw in our communities, states and country are no more in existence, means that something is wrong somewhere.

Although there is a plethora of studies on the reasons why businesses failed (Esu, 2003; Abram, 1981), this paper argues that most public sector businesses failed because of ineffective and inefficient performance management system. Drawing from the above, we opine that the reasons for the failure of most of the public sector enterprises in Nigeria are not because of its public or government ownership status. The Wall Street Journal (2003) quoted Michael Klein, the World Bank's Vice President for private sector development as saying that, 'now it doesn't matter so much whether infrastructure is in public or private hands'. The inference from Klein's statement is that what matters in business is not the ownership status, but the quality of management. It is on this premise that the authors argue for the implementation or adoption of performance management system as a tool for increase efficiency of the Nigerian public sector executing agencies.

Performance management is a new concept in human resource management. In Nigeria the performance of staff of executing agencies or public enterprises is limited to budget monitoring and annual performance evaluation. However, experts are of the view that there is no linked between employee performance and financial data (Pollitt and Bouckaert, 2004). 
This paper therefore seeks to elaborate on the meaning, purpose, design, development and implementation of performance management system. It is our hope that it will position today's Nigerian public sector managers to efficiently set performance management systems that will offer the citizenry all the deliverables for individuals, organizations and the society at large.

The information used for this paper was based on an extensive literature review of local and international materials available to the authors. This paper has five main objectives:

1) To explore the historical antecedents of the public service in Nigeria;

2) To identify the theoretical under-pinning of performance management;

3) To capture the taxonomy of performance;

4) To highlight the benefits to be derived from the implementation of a performance management system; and

5) To propose a model for the implementation of performance management system in Nigeria.

\section{Public Service in Nigeria}

The Nigerian public service "is a product of colonialism, established as an instrument of the British colonialist, from the late $19^{\text {th }}$ century" (Inyang, 2008a: 52). According to Tokunboh (1990), the system of state enterprises begun in 1898 when the British colonial administration undertook the railway transport project from Iddo in the capital city of Lagos to the hinterland. This was followed by coal mining, electricity and marine ports. All these enterprises were established primarily as administrative organs for facilitating trade and commercial activities of the colonial government. In 1949, The Fitzegerald Commission into the colliery trouble articulated the idea of public corporation. This concept was borrowed from the British Labour Party rationalization of British Coal in 1947, electricity in 1949 (Tokunboh, 1990). Subsequently, in 1950s, the following public corporations were established in Nigeria: Nigerian Coal Corporation; Electricity Corporation; Nigerian Cement Company, Nkalagu; Nigerian Railway Corporation, and Nigerian Ports Authority. All the corporations were managed by Boards. Since then more corporations have been established based on national interest. Some state governments have also established public corporations to actualize their developmental interests.

There is a general opinion that most of the public enterprises have failed to deliver on the purposes for which they were established. Management ineffectiveness and inefficiency have been advanced by practitioners and researchers of public enterprises as the bane of the Nigerian public sector (Tokunboh, 1990). The former president of Nigeria, Olusegun Obasanjo (2003) observes that: "Nigerians have too long been feeling short-changed by the quality of public service. Our public offices have too long been showcases for combined evils of inefficiency and corruption, whilst being impediments for effective implementation of government policies. Nigerians deserve better. And will ensure they get what is better". Agagu (2008: 243) asserts that "the public service which was seen as the custodian of rules and regulations and the engine of the development had lost its prestige and confidence. The aftermath of this is the invention of series of reforms which, have led to privatization, downsizing and right-sizing of the public service and even minimizing the role of the public sector in the national life"

In Nigeria, we are living witnesses of the fate of commercial banks in the 1990s, the inability of the re-branded National Electric Power Authority (now called Power Holding Company of Nigeria) to meet the power requirements of the country, the inability of Nigerian National Petroleum Company and other parastatals in the oil and gas sector to provide quality and regular supplies of petroleum products, the failure of our national shipping lines and airlines to provide quality services and remain competitive globally, to mention but a few.

The concept of privatization is old fashion. It was based on the notion of superior private sector efficiency. Evidence from studies done by the International Monetary Fund (IMF) (2004) shows that there is a consistent stream of empirical evidence consistently and repeatedly showing that there are no systematic significant differences between public and private operations in terms of efficiency or other performance measures. The theory behind the assumption of private sector superiority is also being shown to have serious flaws.

\section{Theoretical framework}

The concept of performance management is theoretically under-pinned on the theory of motivation. There are several motivational theories in the literature: Maslow's needs hierarchy theory, Herzberg's two-factors theory, expectancy theory, goal setting theory, McClelland's needs achievement theory, etc. (Bateman and Zeithaml, 1993; Inyang, 2008b; Kreitner, 1998). Of all these theories the goal setting theory fits the performance management concept best. This is because performance standards are antecedent situations in the employee's work environment. Goals are performance levels which individuals and organizations have agreed upon as performance standards.

Philosophically, the goal setting theory is based on the assumption that people have conscious goals that energized them and direct their thought and behavior toward one end (Bateman and Zeithaml, 1993). People obtained the positions they 
are today (whether in profession, politics, athletics or community service) because they were goal-oriented. Many organizations have been turned into empires and conglomerates because they are/or were goal-oriented. Lessons from researchers in goal setting theory show that properly conceived goals trigger a motivational process that improves performance (Locke, 1981). A general goal setting model has four components: goal, motivation, improved performance and feedback on performance.

Goals motivate by directing employee's attention, encouraging effort, encouraging persistence and fostering goal attainment strategies and action plan. For there to be a performance measurement, there must first be a goal setting.

\section{Case studies on the implementation of performance management system in public sector management}

Barry (1997), reports that Mecklenburg County Performance Management System individualized each component of the work task to suit the particular needs of the department. It involves three steps: performance planning, performance coaching and performance summary.

Hall (2002), also reports that most American counties have institutionalised approaches for improving organisational performance. Performance management is one tool that provides idea for implementing Government Performance and Results Act (GPRA). GPRA is a law that focuses on interpreting strategies and resources to get the outcomes needed for unique missions. The focus of the GPRA through the President's Management Agenda (PMA) is a citizen-centred government that is accountable for results.

Reports from an Australian organization revealed that Performance Management System (PMS) had a more positive impact on performance than it did on employees. The work groups that were already performing well benefited from PMS, whereas those that were not, had a more negative attitude to PMS and was less positive about its impact on performance (Harper and Vilkinas, 2005).

\section{Expected benefit of Performance Management System (PMS) implementation}

A survey from literature indicates the following benefits of PMS:

1) Performance management facilitates the implementation of business strategy by indicating what to measure, determining appropriate means of measuring, setting targets and linking the measure with organisational performance (Scheiner, Shaw \& Beatty, 1991).

2) Performance management improves the organisational performance (McDonald \& Smith, 1995).

3) Improves processes within the organisation (Rummler \& Brache, 1995).

4) Improves employee performance (Egan, 1995; Longenecker \& Fink, 1999)

5) Improves team performance (Kenett et al., 1994; Lawler, 1994)

6) Eases implementation of change in the organisational culture (Wellins \& Schultz Murphy, 1995)

7) Improves customer satisfaction (Bilgin, 207)

8) A competitive advantage is obtained (Bilgin 2007)

9) Improves quality of supervision (Bilgin, 2007)

\section{Meaning and scope of performance management}

The concept of performance management was first used by Beer and Ruh (1978). The concept was popularized in the mid 1980s (Akata, 2003). Armstrong and Baron (1998) and Armstrong (2004: 477) describe performance management "as a strategic and integrated approach to delivering sustained success to organisations by improving the performance of the people who work in them and by developing the capability of teams and individual contributors." Akata (2003:14) considers it as "a systematic and holistic (all-embracing) process of work planning, monitoring and measurement aimed at continuously improving the teams and individual employee's contribution to achievement of organizational goals". Oladimeji (1999:51) defines performance management as "a means of getting better results from the organization, teams and individuals by understanding and managing performance within agreed framework of planned goals, objectives and standards".

The three definitions show that performance management has the following characteristics; strategic (concerned with the broader issues facing the business), systemic, systematic and holistic. It is integrated in four ways: vertically aligning business teams and individual objectives; functionally integrated; human resource integration and integration of individual needs.

To increase our understanding of performance management, we draw from the definition of the word performance by Brumbach (1988) that: performance means both behavior and results. Behavior emanates from the performer and transforms performance from abstraction to action. As instruments for result, behaviors are also outcomes in their own right - the product of mental and physical efforts applied to tasks - and can be judged apart from results. The scope of 
performance is broader than performance appraisal. Performance appraisal according to Fajana (2002:283) "focuses on the extent to which an individual is carrying out assigned duties, as well as joint actions that can be taken by both the supervisor and the subordinate to manage observed variances between set standards and actual performance", while performance management deals with the processes and activities of the organization that enhance the design, development, implementation of performance technologies. It embraces all formal and informal methods adopted by an organization and its managers to increase commitment and individual and corporate effectiveness. Performance appraisal is reactive while performance management is proactive.

\section{Establishing performance management system}

A performance management system enables individuals and organization to achieve strategic ambitions through processes that are both systemic and systematic (Watkins, 2007b). Performance improvement management systems in the public and private sectors have no differences between them. This is because they both seek to achieve goals - micro or macro. Performance management focuses on future performance planning and improvement rather than on retrospective performance appraisal (Armstrong, 2004). There are several studies that deal with performance management process. Watkins (2007b) offers us the most comprehensive model of performance management system that could be used in the public sector. The system has seven components (see figure 1).

\subsection{Identify desired performance}

Performance refers to the results to be achieved, while the process of achieving this performance is performing. This is achieved by defining the role profile of the role holder - what is the main output area of the role holder. Performance is a multi-dimensional construct, the measurement of which varies depending on a variety of factors. The desired performance is closely related to the organisation's vision: social responsibility, customer orientation, profitability, corporate image, etc. The desired performance of each employee should begin from the pre-recruitment stage. It should be clearly stated in the medium advertising the position for recruitment. This will help prospective recruits and employees of the organization easily identify with the aspirations of the organization at the point of entry. In the public sector, the vision and purpose of public enterprises are set by legislative instruments. It is the responsibility of the management of the executing agencies or the supervising department or ministry to highlight the desire performance areas of each position in the organization.

\subsection{Define performance objectives}

Performance objectives of each position are a joint responsibility of both the employee or role holder and the top management. Establishing standards of performance is not a new concept or process. Standards exist whether they are discussed or put in writing. The philosophy behind establishing performance standards is whether to accept or reflect the task/job performed by an employee. Armstrong (2004:488) defines objectives or goals (the terms are interchangeable) as "what organizations, functions, departments and individuals are expected to achieve over a period of time". Objectives could be in the form of targets (quantifiable result to be attained: return on investment, output, throughput, sales, service quality, customer satisfaction) and/or tasks/projects (to be completed by specified dates in the form of completion dates), etc. Objectives should be integrative. Good objectives have the following attributes: specificity/stretching, measurable, achievable, relevant and time framed (SMART).

\subsection{Performance assessment}

Performance measures are agreed when setting objectives. The crux of the matter is in knowing what to measure and how to measure it. Armstrong (2004) gives five guidelines and classification of performance measurement. These guidelines include:

1) Relating measurement to results and not effort.

2) The results must be within the job holder's control.

3) The measure should be objective and observable.

4) The data relating to the matter should be available.

5) Adopt existing measure where possible.

The following performance indicators are commonly used for performance assessment:

1) Finance (income, shareholder, economic value added etc).

2) Output (units produced or processed).

3) Impact (attainment of a standard, quality, level of service, etc).

4) Reaction (judgment by others, colleagues, internal and external customers).

5) Time (speed of respond or turn-around, achievements compare with time tables, amount of backlog, time to market, delivery time, etc.). 
According to Hedge et al., (2007) task level performance standards can be identity through scientific methods that involve administering a job/task analysis questionnaire to representative members of the organization.

Performance is assessed at two levels - performance outcomes and behavior. It is the outcomes of individuals' or team's action or behavior.

\subsection{Identify a solution set}

Every organization, profit or not-for-profit is confronted with performance problems. These problems must be fixed in order to achieve performance goals or objectives. Problems can be identified using strength, weakness, opportunity and threat (SWOT) analysis. Ogden et al., (2007) develop a model that can help performance managers select solutions for complex problems. The model is called Solution Variable Analysis Tool (SVAT) and Decision Variable Analysis Tool (DVAT). SVAT is designed to assist in root cause analysis, identifying and narrowing possible solutions for root cause and also discriminating between root causes and solutions (Elliot, 1999; Robinson \& Robinson, 1999). The SVAT and DVAT produce a set of intervention activities, technically called performance technologies. Secondly, the Human Performance Technology (HPT) Maturity Model can also be used in developing solution sets in the public sector business.

HPT maturity model is a model that guides the progression of an organization. According to the International Society for Performance Improvement (ISPI, 2003), HPT refers to the systemic and systematic identification and removal of barriers to individual's commitment and organizational results. A maturity model is a structured collection of elements that describe the characteristics of effective processes at different stages of development.

The concept of HPT maturity concept is strategically important to the public and private sectors. Pullen (2007: 10) asserts that it is the place to start when considering future growth and identifies necessary events and predictable transition challenges.

HPT maturity model can be used at two levels of a public sector organization. First, lessons from the model can be useful for legislative or funding bodies, oversight agencies or high- level program managers. Secondly, the ideas can be used within an organization that has implemented HPT and wishes to understand more fully the decisions it will use in its performance improvement system. Pullen's HPT maturity model has a five-by-six grid with horizontal and vertical axes. The horizontal axis measures the progression of the organization along a scale of increasing levels of maturity that finally correspond to progression in development. They include: recognizing, understanding, managing, mastering and leading. The vertical axis has six vectors that comprehensively describe an organizational effort to implement HPT in the public sector. They include: accountability (policy, doctrine, and standards), directing (strategy, plans, and tactics), resources (organization, structure, and staff), method (methodology, process and gaps), relationship (culture, clients, and partners), and results (outputs, outcomes and values).

\subsection{Design and development performance solution.}

At this stage based on the SWOT analysis, the HPT professional could identify the performance management problem. The design of a performance management system serves as a performance intervention that will improve the performance of the employees in critical areas of the organization. What is required is to identify performance technologies (interventions) from the set of solutions in the preceding stage that will lead to better results. Some consideration must be made when selecting performance technologies. These include: 1. Verify alignment 2. Define the roles responsibilities and partnership.

Two commonly used designs or processes as given by Watkins (2007b) are the Electronic Performance Support System and Balanced Scorecard. Some of the performance technologies are monitoring recruitment program, learning, leadership retreats, coaching and work place design. The mix of performance technologies depend on the nature of the performance faced by your organization. It is the commonly used multiple performance technologies (Watkins, 2007b). The performance technologies are expected to improve the performance of the employees if properly designed and developed. Successful performance improvement initiatives rely on the support and commitment of key individuals within an organization as well as external partners. The various roles required in performance improvement process are: initiative leader, initiative advocates, intervention project manager and technical development team.

\subsection{Conduct formative evaluation}

Formative evaluations provide multiple opportunities for an intervention's deliverables to be examined (Watkins, 2007b) by future users, demonstrated for experts and post-tested in the performance environment. It is also reasonable if formative evaluation can also be done on each performance technology. It should be added to performance interventions prior to implementation. The key roles for formative evaluation in any performance initiative include, receiving feedback, documentation, recommendations, and changing and assessing performance. The best methodology of monitoring and evaluation is to ask those involved - managers, individuals and teams how it works. Armstrong (2004) suggests that evaluation can be carried out by members of the project team and/or by the personnel department, an 
independent consultant can be engaged. Formative evaluation is not the same thing as performance review. The latter reflects the past performance.

\subsection{Implementation and continual improvement}

Implementation refers to the execution or administering of the design of the performance technologies as agreed by team members using available data. The choice of performance technologies will affect the structure of the organization and may make new demands on the organization. No matter how wonderful a strategy or plan is, if it is not effectively implemented, it will lead to failure of performance of individuals, teams and organizations.

\section{Conclusion}

Performance management is a comprehensive approach for planning and sustaining improvements in the performance of employees and teams, so as to meet standards. In the public sector, annual budgets and annual performance evaluations are used in managing performance-outcomes and behavior. These two deal with the past and not futuristic. The absence of PMS has contributed to the high rate of business failures in the public sector. The adoption of PMS will make public business effective, efficient and sustainable. This will turnaround the Nigerian public sector and enables it to achieve the national goals and remain an influential institution as "an instrument of public service delivery and development" (Kauzya, 2001:3).

\section{References}

Abram, B. (1981). Despite mixed records, firms still pushing for new products. Wall Street Journal, November, 5.

Agagu, A. A. (2008). Re-inventing the Nigerian public service in an era of reforms. Pakistan Journal of Social Science, 5(3): 244-252.

Akata, G. O. (2003). Strategic performance management: your key to business success. Ibadan, Nigeria: Spectrum Books Limited.

Armstrong, M. (2004). Handbook of human resource management practice (9 ${ }^{\text {th }}$ ed.). London: Kogan Page.

Armstrong, M. \& Baron, A. (198). Performance management: the new realities. IPD: London .

Barry, J.M. (1997). Performnce management: a case study. Journal of Environmental Health, 10(4): 35. [Online] Available: http://www.questia.com/read/print (Retrieved from September 29, 2008).

Bateman, T.S., \& Zeithalm, C.P. (1993). Management: function and strategy. (2 ${ }^{\text {nd }}$ Edition). Illinois: IRWIN.

Beer, M. \& Ruh, R. A. (1976). Employee growth performance management. Harvard Business Review, July-August, 59-66.

Bilgin, K. U. (2007). Performance management for public personnel: multi-analysis approach toward personnel. Public Personnel Management, 36(2):93. [Online] Available: http://www.questia.com/read/print (Retrieved from September 23, 2008).

Brumbach, G. B. (1988). Some ideas, issues and predictions about performance management. Public Personnel Management, Winter: 387-402.

Egan, G. (1995). A clear path to peak performance. People Management, 18: 34-37.

Elliott, P.H (1999). Job Aids. In H. D. Stolovitch \& E. J. Keeps (Eds.), Handbook of human performance technology: improving individual and organisation performance worldwide. (2nd ed.) pp. 430-441. San Francisco: Jossey-Bass.

Esu, B. B. (2005). Introduction to marketing. Calabar, Nigeria: Jochrisam Publishers.

Fajana, S. (2002). Human resource management: an introduction, Ist. Edition. Lagos: Labofin and Company.

Inyang, B. J. (2008a). Human resource capacity building: an imperative for effective performance in the public service. MRL Journal, 1(2):50-64.

Inyang, B.J. (2008b). Creating an enabling environment for organizational goal attainment through employee motivation and job satisfaction, Nigerian Journal of Labour Law Review and Industrial Relations, 2(2): $92-109$. International Monetary Fund (March, 2004). Public private partnership, IMF. [Online] Available: http://www/imf.org/external/np/fed/2004/pitp/eng/031204htm (Retrieved from 25 September, 2008).

International Society for Performance Improvement (2003). What is HPT? [Online] Available: http://www.1spi:org/hpt-instite-hmtl (Retrieved from September 25, 2008).

Hall, M. (2000). Aligning the organisation to increase performance results. The Public Manager, 31(2):7. [Online] Available: http://www.questia.com./reader/print (Retrieved from September 29, 2008).

Harper, S. \& Vilkinas, T. (2005). Determining the impact of an organisation's performance management system. Asia Pacific Journal of Human Resources, 43(1): 76-97. 
Hedge, J. W., Borman, W.C., Kubisiak, N.G. \& Bourne, M.J. (2007). The development of a methodology for establishing task-level performance standards for apprentice, journeyman, and Master skill levels in the U.S. Navy. Performance Improvement, 46(4): 34-41.

Kauzya, J. (2001). A holistic model for managing ethnic diversity in the public service in Africa. Paper presented at UN expert group meeting on managing diversity in the civil service. New York: UN Headquarters. [Online] Available: http://www.UPAN.org.analytical-report.asp pp. 1-11 (Retrieved from September 22, 2008).

Kenett, R.S., Waldman, D. K. \& Graves, S. B. (1994). Process performances appraisal systems: a working substitute to individual performance appraisal (in Hebrew). Total Quality Management, 5: 267-250.

Kreitner, R. (1998). Management ( $7^{\text {th }}$ ed.) Boston: Houghton Mifflin Company.

Lawler, E. E. (19994). Performance management: the next generation. Compensation and Benefits Review, 26(3): 10 20.

Locke, E.A. (July, 1981). Goal Setting and Task Performance,1969-1980. Psychological Bulletin, 90, 125 -152.

Longenecker, C. \& Fink, C. (1999). Creating effective performance approach, Industrial Management, 41(5):18-25.

McDonald, K. S. \& Smith, A. (1995). A proven connection: performance management and business results. Compensation and Benefits Review, 27(1): 59-62.

Nichels, S. W., McHugh, J. M. \& McHugh, S. M. (1999). Understanding business. $5^{\text {th }}$ Edition. Boston: Irwin McGraw-Hill.

Obasanjo, O. (2003). On SERVICOM. [Online] Available: http://www.servenigeria.com (Retrieved from September 29, 2008).

Ogden, S. A. \& Williams, K. A. (2007). Selecting solutions for complex problems. Performance Improvement, 46(4): $16-24$.

Oladimeji, A. (1999). Human resource management in Nigeria. Lagos: Business and Institutional Support Associates Limited.

Pollit, C. \& Bouckaert, C. (2004). Public management reform: a comparative analysis. (2 ${ }^{\text {nd }}$ Edition). Oxford: Oxford University Press.

Pullen, W. (2007). A public sector HPT maturity model. Performance Improvement, 46 (4): 9-15.

Robinson J. C. \& Robinson, D.G. (1999). Performance consultant. In H. D. Stolovitch \& E. J.Keeps (Eds.), Handbook of human performance technology: improving individual and organization performance worldwide. (2nd edition) pp. 442-451. San Francisco; Jossey-Bass.

Rummler, G. A. \& Brache, A. P. (1995). Improving performance: how to manage the white space in the organization chart. San Francisco: Jossey-Bass.

Scheiner, C. E., Shaw, D. O. \& Beatty, R. W. (1991). Performance measurement and management: a tool for strategy execution. Human Resource Management, 30(3): 279-201.

Tokunboh, M. A. (1990). Public enterprise: the Nigeria experience, Lagos: Lantern Books.

Wall Street Journal (21 July, 2003). The World Bank as privatization agnostic.

Watkins, R. (2007a). Designing for performance: aligning your HPT decisions from top to bottom (part 1 of a 3-part series). Performance Improvement, 46(1): 7-13.

Watkins, R. (2007b). Designing for performance, part 3: design, development, and improve. Performance Improvement, 46(4): 42-48.

Wellins, R. S. \& Schultz Murphy, J. (1995). Reengineering: plug into the human factor. Training and Development, 49 (1): 33-37. 


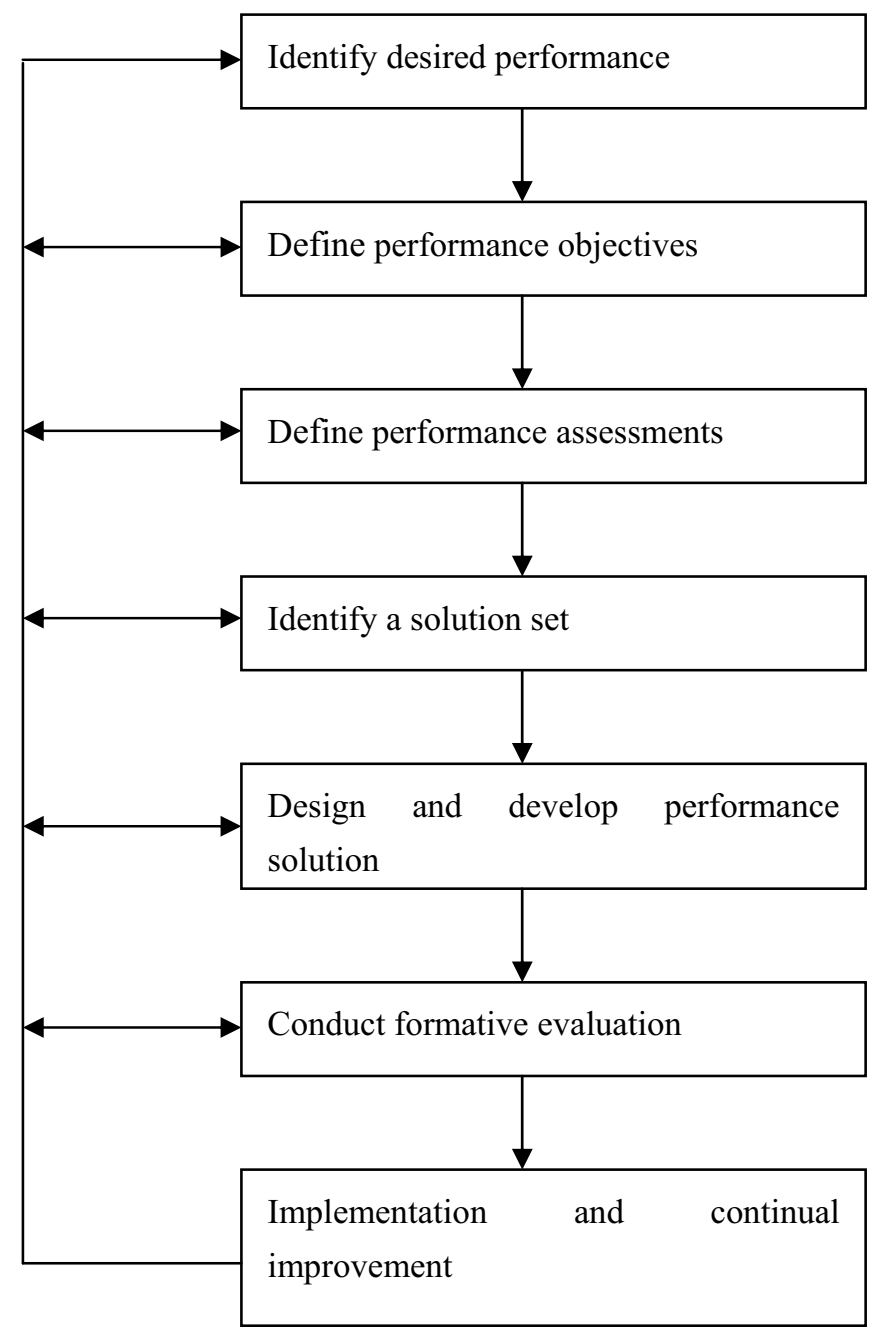

Figure 1. The Performance-by-design Framework

Source: Watkins, R. (2007a). Designing for performance: aligning your HPT decisions from top to bottom (part 1 of a 3-part series). Performance Improvement, 46(2):9-15. 


\title{
Innovation Fund: a Booster of Science
}

\author{
and Technology SME Development
}

\author{
Yurong Chen, Liuying Xu \& Weixing Wang \\ School of Economics and Management, Jiangsu Polytechnic University \\ Changzhou 213164, Jiangsu, China \\ E-mail: cyrpzh@126.com
}

\begin{abstract}
Innovation Fund, the leading special funds supported by the government, is playing a positive role in the development of the enterprises. In order to better support the science and technology SMEs rapid and healthy development, we should further promote the development of technological innovation fund of science and technology SMEs.

Keywords: Science and Technology, SME, Innovation fund, Venture capital

1. The significance of scientific and technological SMEs development

In recent years, science and technology SMEs have maintained a strong momentum of growth. They have become important forces in promoting the national economic development, constructing the subject of the market economy and promoting social stability, and they have become dynamic new economic growth points in regional economic development in China. At present, there are about 0.12 million sciences and technology SMEs and 9.6 million employees or so in China. Although accounting for only 3.3\% of the total enterprises, about $66 \%$ of the patented invention, over $74 \%$ of technological innovation and $82 \%$ of new product development have been created by science and technology SMEs, which have become major forces in technological innovation in China. There are four reasons. First, generally, the founders are the senior technical staff of research institutions or universities, having technological achievements and relatively strong technological base; Second, being no advantages of economies of scale and financial resources and the weaken strength, the enterprises have to constantly innovate and change innovation achievements into practical productive forces timely to maintain its survival in the market of fierce competition; Third, their external and internal unique characteristics can better meet the needs of technical innovation; Finally, although short of funds, they can meet market better with the advantages of the flexible mechanism and being good at innovation.
\end{abstract}

\section{The bottlenecks of science and technology SMEs development}

Science and technology SMEs are the enterprises in which the high-tech technology and products have been developed and produced and sold as the main business. Capital is an integral part of production factors in the process of its development. Presently, the most prominent problem of technology-based SMEs is the lack of capital and the financing channels are poor. The main reasons can be listed as follows:

\subsection{The nature of the science and technology SMEs}

Science and technology SME'S growth has its own unique characteristics, which can be summed up as "three-highs": (1) high-risk nature. With small-scale enterprises and uncertain operation, it is difficult to predict whether the innovation is successful or not and often has a higher mortality rate. (2) high-growth. Once the venture is successful, the revenue will increase in geometrically, maybe 10 times or 20 times a year. (3) high degree of asymmetry of information. They are the asymmetry of necessary knowledge to understand innovation achievements and the asymmetry of requirement information of innovation commercialization. Internal people have significant advantages on information than external people. The growth rule of science and technology SMEs determine its financing uniqueness. For the specific performance:(1)high input: whether in the earlier stage of research and development, or in the trial period ,or in the producing period ,or in the market development period, capital support is necessary for the enterprises.(2) external financial difficulties :enterprises often only have the technology ,or even just the concept and model of the innovation and creativity, and without collateral assets, it is impossible for them to borrow capital from the bank and it is difficulty for them to get secured financing from the security company.

\subsection{The defects of the current financing system of science and technology SMEs}

(1)Capital market imperfections. At present, in order to promote the reform of state-owned enterprises as the purpose 
and major support the large and medium-sized state-owned enterprises listed on stock market, the direct financing market for science and technology SMEs are lack in the stock market. Although the SME board has been launched, the market is still very high threshold, emerged as by-products of the main board for minor amendments to the rules of the game of the main board. As its limited capacity for a large number of science and technology SMEs still fall short of demand , will not solve the problem.(2)"Fearless credit" of commercial banks. Science and technology SMEs generally can not get credit loan from commercial banks because of its small scale, high-risk and uncertainty. Being fear of loan risk, banks often carefully issue collateral loans other than credit loans. Most of science and technology SMEs are lack of collateral and difficult to find security. With the bank's commercial and marketability deepening, the status of equal market transaction subject between the banks and the enterprises have been enhanced. Since banks have strengthened the mechanism of prevention, they will not provide loans for them for the prevention of the risk. (3)Smaller scale of investment risk and unsound mechanism. Risk investment plays a lifeline role in the start-up and growing period. Absorbing high-tech venture investment is an important financing channel for science and technology SMEs in foreign countries. But in China, as venture capital has just started, the overall size tends to be small, and risk investment mechanism is not yet perfect, so it is far from meeting the "incubator" demand of science and technology SMEs. (4)Lack of sound financial service intermediaries. Financial market can be regarded as surplus and shortage of capital co-exist. On the one hand, financial institutions and investment companies have large amounts of funds and have not invested direction. On the other hand, science and technology SMEs can not access to finance. As many science and technology SMEs do not have enough equity to mortgages, but can only rely on secured loans, which also need to establish the appropriate intermediary service institutions to "balance" the two sides of supply and demand. However, at present, there are few organizations specifically serving science and technology SMEs. Even if such institutions have been established in some regions, they have difficulties operating them effectively because of such problems as inadequate source of funds and with no evasion risk of the enterprises of their own.

\section{The role of innovation fund for the development of science and technology SMEs}

The technology innovation fund of science and technology SMEs is approved by the State Council. The special fund is set up to support technological innovation to promote the transformation of scientific and technological achievements and foster a number of science and technology SMEs with Chinese characteristics and speed up the process of high-tech industries by means of funding, loan discount and capital investment. This will make overall optimization of industrial structure and product mix to stimulate and promote the national economy to healthy, stable and rapid development. Enterprises survey results show that 91 percent of enterprises believe that the innovation fund has increased the company's sense of innovation; 89 percent of enterprises believe that the innovation fund has raised innovation capability of enterprises; 84 percent of enterprises believe that the innovation fund has improved the competitiveness of enterprises; 64 percent of the enterprises believe that the innovation fund has played a significant role in increasing employment.

\subsection{Promoting the cultivation of high-tech achievements and transformation}

The enterprises that are in seeds or start-up phases would get support to enhanced technical innovation capacity by using innovation fund, resulting in more innovation fund to be changed into products. With the establishment of innovation fund, favorable conditions have been provided to change the scientific research results that are large number of high-tech technology, innovation, good market prospects upper reaches goods into products rapidly.

\subsection{Creating encouraging innovation and entrepreneur atmosphere}

This is the most important model role for setting up innovation fund.

Government's initiatives often have a significant impact on society. The establishment of innovation fund by Central Government creates an atmosphere to entire society to support innovation and encourage entrepreneur and take a very important guidance for the local government to take part in. The formation of such atmosphere can not be replaced by other actors.

\subsection{Broadening the financing channels of science and technology SMEs}

With innovative fund guiding risk investment, financial institutions and other social funds to financing for the science and technology SMEs, the investment and financing mechanism, meeting the market economy development in the high technology industrialization, should be built to achieve independent innovation, industrial structure optimization and upgrading and promote the national economy healthy, stable and rapid development.

\subsection{Strengthening the financing capacity of science and technology SMES}

With innovative fund supporting and enhancing business's technological innovation capacity, the values of their own enterprises have been increased. Enterprises can set a good social image and attract other investors to invest and result in strength the financial capacity of science and technology SMEs. 


\section{Thinking of promoting the development of innovation fund of science and technology SMEs}

\subsection{Further clarifying the objectives and position of innovation fund}

In order to match other technology plan ,innovation fund should be highlighted its own characteristics and located in the technical support of laboratory results to the market, in particular ,to promote the technological achievements formed by science and technology plan of government to the market. Commercialization technology should be targeted for innovation fund. At the same time of supporting technology incubation projects, enterprises are nurtured. Therefore, we should focus on financing the projects in test, development pilot phases, reducing production projects, outstanding common technology and high universality of technology transformation.

\subsection{Constructing multi-level innovation fund system}

At present, the investment is limited by government and investment theme of the relative is single in China, which mainly rely on central government finances. Fund-scale can not meet the capital requirements of technological innovation of science and technology SMEs. In order to better support the technology innovation of science and technology SMEs, first of all, the fund pattern should be formed, which is integration of central government finances, local government finances and social donation. Central government should continue to increase financial input to the innovation fund and give full play local advantages and enthusiasm. Investment for science and technology SMEs should be increased and local science and technology innovation fund for science and technology SMEs should be established in conditional region to absorb community funds and expand the sources of fund in various ways and promote the development of science and technology SMEs in local region. Second, with increasing loan guarantees and note endorsed, investing and setting up professional security companies for science and technology innovation, the fund and the policy, commercial finance and venture capital should be combined to further enhance the function of supporting and guiding of innovation fund. In addition, we should advocate the benefit enterprises nurturing fund when they entered the mature stage, forming a virtuous circle between fund and enterprises to support the development of science and technology SMEs.

\subsection{Optimizing the environment of science and technology SMEs to make it become the main innovation subject in} society

The priority project supported by innovation fund is the large projects with relatively clear technological property rights and good market potential. Special work should be conducted in technology innovation, technical property rights declaration, and fund declaration as well after getting independent property rights so as to raise the possibility of winning bidding. In order to promote science and technology enterprises in technological innovation activities, the state issued the "Contract Law" and "Patent Law" directly related to innovation and technology and a series of national laws and a variety of local technology markets laws and regulations and implementation so that the technological innovation of enterprises activities can be protected through legal means. We should encourage and support institutions of higher learning, scientific research institutes-oriented enterprises providing reliable technical support for the technological innovation of enterprises and be able to make full use of market mechanisms, co-operation with enterprises in a wide range, and expand effective way of joint production and research to promote enterprises to become the main subject of innovation and technology. All these will provide a good social environment for technology innovation of science and technology SMEs.

\subsection{Structures the service system platform of science and technology SMEs}

In order to promote the healthy growth of science and technology SMEs and enhance the utilization efficiency of innovation fund, the project management of innovation fund is not only supervised and inspected, but also advisory services for financing project should be strengthened. Because the regional distribution of innovation fund projects is uneven, and there exist great regional differences. The supervision and advisory services of the innovation fund projects should be implemented and special attention should be paid to management with the combination of point and face management and integration of centralized and decentralized management, the unified planning of fund management in planning, decision-making, guidance and supervision to play the role of professional intermediaries and provide quality services. Since some regional projects are more concentrated, we should set up special professional management and service agencies that learn from the experience of incubator management. For some regions with fewer projects, special institutions are not needed; the commissioned management approach should be taken, that is to say, commissioned by the relevant local government departments or agencies to act as intermediary functions of supervision and recommendation.

\subsection{Strengthening intellectual property management}

Innovation fund management approach should be added to the relevant intellectual property protection and management of contents. At the same time, the protection of the benefit of innovator, usage and proliferation of technology should be promoted. 
4.6 Strengthening the project evaluation of the social benefits

In order to improve the social benefits of government-funded projects, we should establish specific assessment indicators of the social benefit and strengthen the project evaluation of the social benefits. The social benefits of innovation fund projects are mainly in increasing employment, the proliferation of technology (including patent, combining production and research), the leading role of the relevant industries and consumption, enhancing their credibility, and so on.

\section{References}

Cao, Jianlin. (2008). Establish the direct financing system suitable for Science and technology SMEs. China Venture Capital, (2).

Fang, Hanting. (2007). National Innovation Fund: its mission and vision. Science \& Technology Industry Parks, (1).

Ni, Jie. (2007). Science and technology SMEs financing: the practice of developed countries and the Enlightenment based on the government level. HI-TECH, (4).

$\mathrm{Hu}$, Lan. (2006). Research on the hope projects of Innovation Fund fostering scientific and technological SMEs. HI-TECH, (3).

Sun, Linjie. (2007). The evaluation studies of financing capacity of science and technology SMEs. Science of science and management of $S . \& T .,(5)$.

Wang, Yuchun. (2005). The study on capital protection strategy of High-tech industry. Hefei University of Technology Press.

$\mathrm{Xu}$, Hua. (2008). The study on supervision and Management Model of Science and technology SMEs Fund Project. Science of science and management of $S . \& T,(2)$.

Yue, Hongbao. (2008). The performance evaluation of SMEs Innovation Fund. Science of science and management of S. $\& T,(2)$. 


\title{
The Application of Control Chart
}

\section{in the Measurement System Analysis}

\author{
Yueyi Zhang \& Zhijun Han \\ School of Economics and Management, Nanjing University of Science and Technology \\ Nanjing 210094, China \\ Tel: 86- 571-8569-0073 E-mail: zyysh@163.com
}

\begin{abstract}
The effectiveness of the quality improvement depends on the capability of the measurement system to a great extent. Based on the researches of the stability and bias analysis of the measurement system, we analyzed the application of the control chart in the stability and bias analysis of the measurement system, and gave the applied example.
\end{abstract}

Keywords: Measurement system analysis (MSA), Control chart, Stability, Bias

\section{Introduction}

In the statistical quality control, the usages of data are very frequent, and the effectiveness and the benefit of the quality control statistical method are decided by the quality of the used data to a great extent. To acquire the data with high quality, we should fully understand and deeply analyze the measurement system which produces the data. The quality of the measurement data is relative with the statistical characters of the measurement results from the measurement system. The reason which induces the low quality of the measurement data is that the variation rate of the measurement data is too big. And there are many reasons such as measurement equipments, and measurement employees, measurement environment and measurement methods which can make the measurement data become bad.

The researches of the measurement system begun by Eagle A.R. (Eagle A.R., 1954, P.10-14) and Grubbs F.E. (Grubbs F.E., 1973, P.53-56), and they studied and analyzed the measurement errors from the mathematical statistics. Since 1990s, the industry community has broad researched and applied the measurement system, and QS9000 pushed by the US three largest auto companies listed MSA as one of important contents of the quality control system auditing. ISO/TS16949 also took MSA as one necessary part, and it compiled and issued the manuals of MSA. The Six Sigma Way is one of the most popular control methods, and the second stage " $\mathrm{M}$ " in its improvement mode "DMAIC" is the measurement, which very emphasizes the importance of MSA.

MSA mainly analyzes 5 statistical variation rates such as the bias, the linearity, the stability, the repetition and the reappearance of the measurement system, and evaluates the ability of the measurement system. In this article, we first discuss the application of the control chart in the stability analysis of the measurement system, and evaluate the bias of the measurement system according to the applications, and give the applied example.

\section{Stability and bias of the measurement system}

The stability of the measurement system means the variation range of the measurement value which the measurement system acquires when measuring the single character with same benchmark or accessory in certain durative time (seen in Figure 1).

The analysis of the stability is related with the cognition of the measurement system. For example, the long-term stability means the ability of the measurement system keeps the original performance in quite long time, which is generally denoted by the difference between the output of the measurement system and the output when denoting after stated time under certain condition, and the short-term stability is mainly represented as the repetition of the measurement value. The stability of the measurement system is also related with the exterior conditions of the measurement system, for example, some measurement systems needs being preheated for certain time to enter into the stable work state, and we should confirm how much time that the measurement system preheats to work.

The bias is also called as the bias of the measurement, and it is the difference between the expectation value and the real value of the measurement result. We can compute the bias by many differences between the observation values and the reference values. As seen in Figure 2, the bias is generated by one sort of or several sorts of system errors, and when the bias is not acceptable, we can eliminate or reduce the bias through the adjustment or examination. 


\section{The application of the control chart in MSA}

\subsection{The application of the control chart in the stability analysis of the measurement system}

If the measurement system is regarded as a data production process, various process control charts which are used to judge the stability of the process can be used to evaluate the stability of the measurement system. The average and extreme difference control chart and the average and standard deviation control chart are generally used in practice, and because their principles and application process are basically consistent, so we only analyze the application of the average and standard deviation control chart in the stability analysis of the measurement system.

(1) Select the standard component or the standard sample, and at the appointed time points, the application measurement system implement repetitive measurements, and every time point should be measured for three or five times, and above 25 time points at least should be selected, and we can obtain above 25 groups of data, and confirm the center line and the control limitation of the control chart, and use it as the analyzed control chart, and for the concrete process, we can refer the control reference materials of the statistical process.

(2) Judge whether the control chart of the measurement system is in the state of the statistical control. After analysis, if the process is in the non-statistical control state, we should look for the reason of the abnormity, and eliminate the abnormal data point, and recomputed the center line and the control limitation, and if the proportion of the abnormal data point is too large, we should improve the measurement system, recollect the data and compute the center line and the control limitation.

(3) Evaluate the ability of the measurement process which means the ability that the measurement quality fulfills the acquirement of the measurement technology. The computation formula is $C_{p}=T / 6 \sigma$, and T is the tolerance of the measurement error, and $\sigma$ is the standard deviation of the measurement error. $C_{p}$ is bigger, and the measurement quality is higher, and for the concrete measurement standards, we can refer relative literatures about process ability analysis.

(4) If the measurement system can fulfill the measurement requirements, we can translate the analysis-control chart into the control-control chart, and confirm the sample capability and the data acquirement interval of the measurement system control chart. The data acquirement interval can be confirmed by the time, or by the batch of the test. For the confirmation of the interval, we should consider following factors such as the risk induced by the error, the measurement charge, the importance degree of the test item, the mature of the test method, and the fluctuation of the process input.

(5) Compute the average and extreme difference of several measurement data, and denote them on the corresponding control chart.

(6) Analyze whether the abnormities occur on the control-control chart, and when the measurement system is in the statistical process control, we should stop measuring, analyze reasons and implement the correction measures.

The researches of the stability of the measurement system should be a durative process, and we should not only study it in short term, but also supervise it in the long term. In the using life period of the measurement system, the control chart should still follow the measurement system, found and eliminate many abnormalities such as component aging and user replacing.

\subsection{The application of the control chart in the bias analysis of the measurement system}

The researches of the bias for the measurement system can be completed by measuring the production components for the samples of the benchmark values. The bias research of the measurement system by the control chart is based on the stability research of the measurement system, and only the control chart displays that the measurement system is in the stable state, its data can be used to evaluate the bias.

(1) Confirm the benchmark value $\mu$ of the sample component. We can select one component in the operation range of the measurement system, and measure it many times by the measurement personnel, and confirm its benchmark value $\mu$.

(2) Confirm the average $\overline{\bar{X}}$ of the measurement data. According to the control chart of the stability analysis, we can acquire the average $\overline{\bar{X}}$.

(3) Compute the bias average. $\overline{\text { Bias }}=\overline{\bar{X}}-\mu$.

(4) Compute the competitive standard deviation $\sigma_{s}$. The $\sigma_{s}$ can be evaluated by $\hat{\sigma}_{s}=\bar{s} / c_{4}$, and $c_{4}$ can be obtained by the coefficient table of the control chart. $\delta_{b}=\delta_{s} / \sqrt{\text { totalmeasurmenttimes }}$. 
(5) Compute the $\mathrm{t}$ statistics of the bias which can be computed by $t=\overline{\operatorname{Bias}} / \sigma_{b}$, and the freedom degree of the $\mathrm{t}$ distribution is that the total measurement times detract the amount of the subgroup. The value of $\mathrm{P}$ can be computed by the $t$ distribution, and when the value of $\mathrm{P}$ exceeds the comprehensive significance level $\alpha$, the bias is significant, and its value is 0 , and the bias can be accepted.

(6) Compute the confidence interval of the bias. The confidence interval of the bias is $\overline{\operatorname{Bias}} \pm t_{\alpha / 2}(f) \cdot \sigma_{b}$, and $t_{\alpha / 2}(f)$ can be found in the table of $t$ distribution. If 0 is in the confidence interval, the bias can be accepted under the significance level $\alpha$. Under general situation, we can select the significance level, $\alpha=0.05$.

\section{Applied example}

In the factory which produces the reservoirs, the engineer needs to measure the size of the reservoir component model. The model size standard is limited in $10 \pm 0.02 \mathrm{~mm}$. The factor uses the three-coordinate measurement machine to measure the model size of the reservoir, and to ensure the stability of the measurement system, the engineer selects one component and three time points every day, and at every time point, he measures the component three times, and the measurement result is seen in Table 1 .

According to the data in Table 1, we can make the average and standard deviation control chart by the Minitab software (seen in Table 3).

For the average and standard deviation control chart of the model size, we can that both the average and the standard deviation control chart don't exceed the control limitation, and the arrangement of the points in the limitation is random, so we can adjudge that the measurement system is in the stable state. For the bias error analysis, suppose that the engineer measured the component many times, and the bias value is $10.00017 \mathrm{~mm}$. From above control chart, we can obtain $\overline{\bar{X}}=10.00047$, and the bias average is $\overline{\text { Bias }}=\overline{\bar{X}}-\mu=10.00047-10.00017=0.0003 \mathrm{~mm}$.

From above control chart, we can obtain $\bar{s}=0.00357$, and $c_{4}(3)=0.8862$ from the control chart coefficient table, so the evaluation value of the repetitive standard deviation $\sigma_{s}$ is $\hat{\sigma}_{s}=\bar{s} / c_{4}=0.004$, $\sigma_{b}=\sigma_{s} / \sqrt{90}=0.004 / 9.487=0.00042$. The t statistics is $t=\overline{\text { Bias }} / \sigma_{b}=0.71$ the $\mathrm{t}$ distribution. From the $\mathrm{t}$ distribution table, we can obtain the confidence interval $(-0.00033,0.00093)$ by the computation and list above computation results in Table 2.

From the analysis results in Table 2, the value of $\mathrm{P}(0.483)$ exceeds the significance level 0.05 , and 0 is in the confidence interval of $95 \%$ bias, so the bias can be accepted.

\section{Conclusions}

The measurement system is the "machining" system of the data, and the quality of the data depends on the quality of the measurement system. The control chart is the effective method for the stability analysis, bias analysis and continual supervision for the measurement system. In this article, we introduce the analysis method for the stability error and the bias error of the measurement system, and give the concrete applied example.

\section{References}

Dong, Shuangcai. (2006). Measurement System Analysis: Theory, Method and Application. Beijing: Chinese Measurement Press.

Eagle A.R. (1954). A method for handling errors in testing and measuring. Industrial Quality Control, No. 3, P. 10-14.

Grubbs F.E. (1973). Error of measurement precision, accuracy and the statistical comparison of measuring instruments. Technometrics, No. 15(2), P. 53-56.

He, Zhen \& Liu, Bao. (2002). Study on application of CUSUM control chart in controlling measurement system stability. Journal of Systems Engineering, No. 6, P. 547-550.

Mao, Shisong. (1999). Measurement System Analysis (Two). Shanghai Quality, No. 5, P. 16-19.

Wang, Yu, Fan, Baoming \& Zhu, Lisheng. (2005). The Application of SMA and Process Control Technology in Enterprises. Industrial Measurement, No. 5, P. 47-49. 
Table 1. Measurement data statistics

\begin{tabular}{|c|c|c|c|c|c|c|c|}
\hline No. & $\mathrm{X}_{1}$ & $\mathrm{X}_{2}$ & $\mathrm{X}_{3}$ & No. & $\mathrm{X}_{1}$ & $\mathrm{X}_{2}$ & 10.004 \\
\hline 1 & 10.003 & 9.995 & 9.997 & 16 & 10.003 & 10.001 \\
\hline 2 & 9.998 & 9.999 & 10.009 & 17 & 9.991 & 10.003 & 9.996 \\
\hline 3 & 10.002 & 10.001 & 10.007 & 18 & 9.999 & 10.001 & 10.003 \\
\hline 4 & 9.990 & 10.001 & 10.002 & 19 & 10.006 & 10.008 & 9.996 \\
\hline 5 & 10.004 & 9.999 & 10.001 & 20 & 9.996 & 10.001 & 9.996 \\
\hline 6 & 9.998 & 9.999 & 10.002 & 21 & 10.006 & 10.002 & 10.001 \\
\hline 7 & 10.003 & 9.998 & 10.004 & 22 & 9.997 & 10.003 & 10.001 \\
\hline 8 & 10.002 & 10.006 & 10.002 & 23 & 10.003 & 9.996 & 9.994 \\
\hline 9 & 9.999 & 10.001 & 9.991 & 24 & 9.999 & 10.002 & 10.001 \\
\hline 10 & 10.006 & 10.002 & 10.001 & 25 & 9.996 & 10.001 & 9.991 \\
\hline 11 & 9.999 & 10.007 & 10.001 & 26 & 10.002 & 9.999 & 10.001 \\
\hline 12 & 10.005 & 9.997 & 10.004 & 27 & 10.010 & 9.996 & 9.998 \\
\hline 13 & 9.999 & 10.001 & 10.005 & 28 & 9.995 & 10.001 & 10.002 \\
\hline 14 & 10.003 & 10.000 & 10.003 & 29 & 9.994 & 10.001 & 10.003 \\
\hline 15 & 9.997 & 9.998 & 9.999 & 30 & 9.998 & 10.001 & 10.004 \\
\hline
\end{tabular}

Table 2. Bias error analysis results

\begin{tabular}{|c|c|c|c|c|c|}
\hline Bias average & $\sigma_{s}$ & $\sigma_{b}$ & $95 \%$ bias confidence interval & t Stat. & $\mathrm{p}$ \\
\hline 0.0003 & 0.004 & 0.00042 & $(-0.00033,0.00093)$ & 0.71 & 0.483 \\
\hline
\end{tabular}

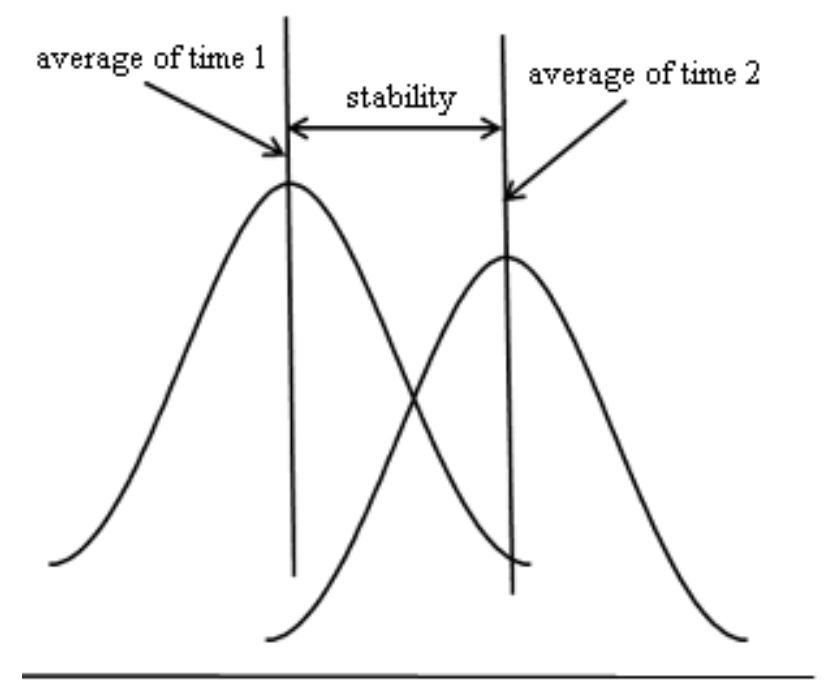

Figure 1. Sketch Map of the Stability 


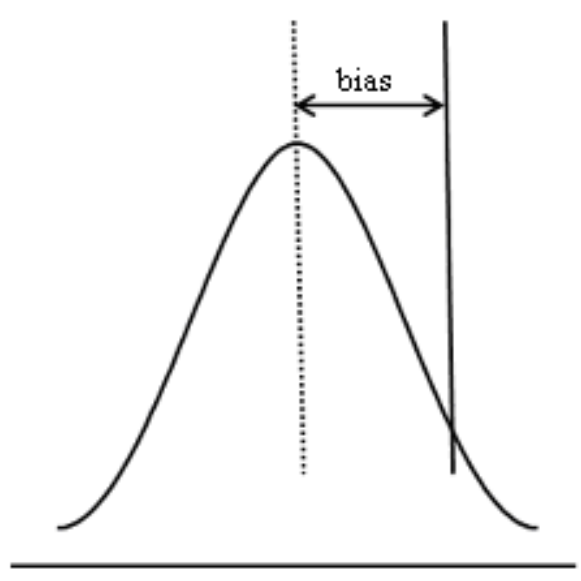

Figure 2. Sketch Map of the Bias

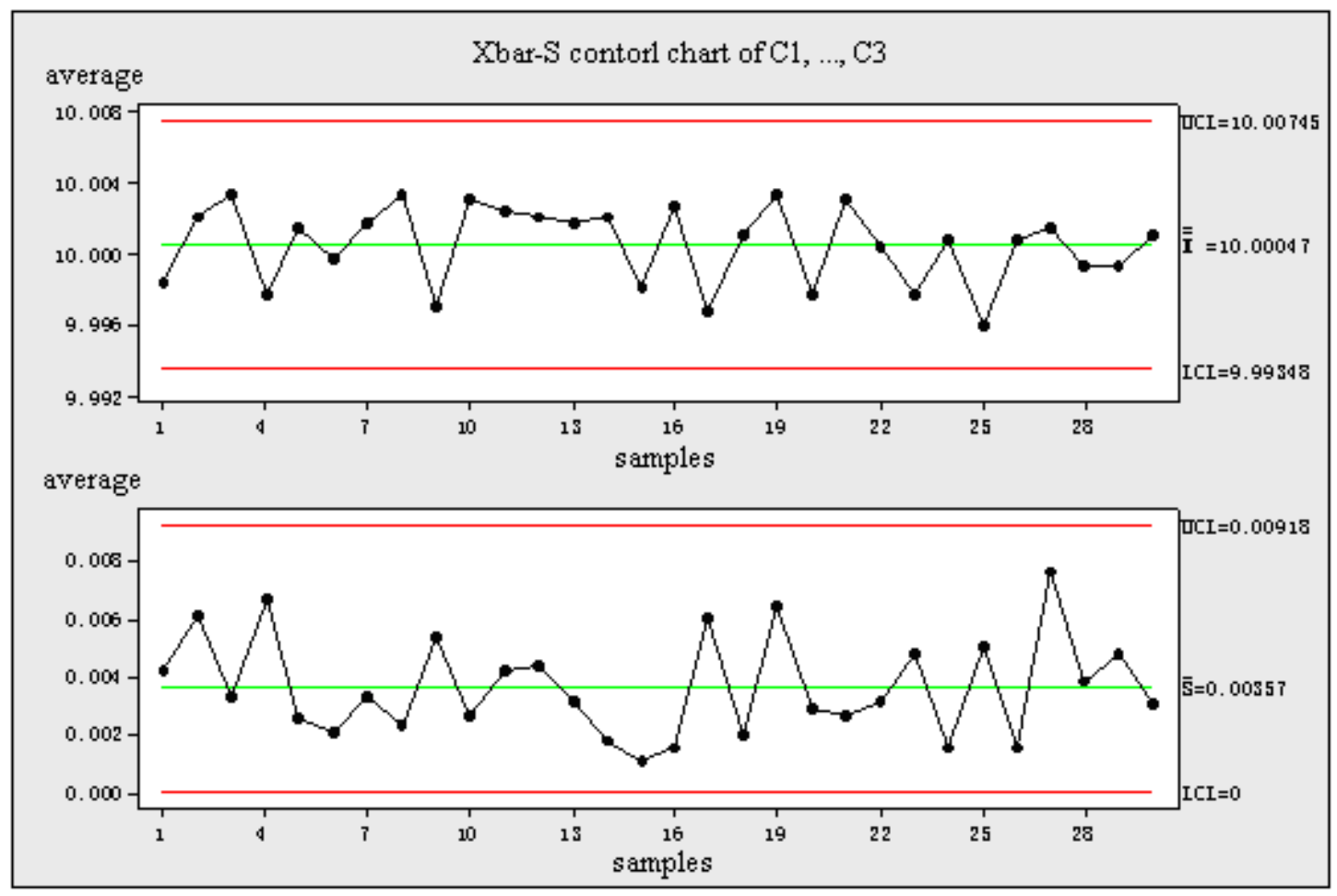

Figure 3. Model Size Average and Standard Deviation Control Chart 


\title{
Knowledge Sharing in a Knowledge Intensive
}

\section{Organisation: Identifying the Enablers}

\author{
Hazman Shah Abdullah (Corresponding author) \\ Faculty of Administrative Science \& Policy Studies, Universiti Teknologi MARA \\ Tel: 60-3-5544-4157_E-mail: hazman@salam.uitm.edu.my
}

Aliza Abu Hassim

Faculty of Administrative Science \& Policy Studies, Universiti Teknologi MARA

Tel: 60-3-5543-5943 E-mail: aliza770@salam.uitm.edu.my

Razmi Chik

Faculty of Mechanical Engineering, Universiti Teknologi MARA

Tel: 60-3-5544-6231 E-mail: razmichik@yahoo.co.uk

\begin{abstract}
The importance of organizational learning and knowledge to the competitive strength of organisation has become common wisdom. The challenge is in generating new knowledge via active learning and the sharing of the knowledge to ensure optimum exploitation. The identification and creation of the context, the policies, the structures and the mechanisms to facilitate learning, retention, sharing/transfer, and exploitation of knowledge are the real issues on the road to becoming a learning organisation. A total 118 executives of a knowledge intensive firm were surveyed to examine the role of these enablers on their knowledge sharing behavior. The commitment to training and development, access to learning resources, retention of learning, incentives for and feedback on learning were examined as key enablers of knowledge sharing. Correlation analysis suggests that the enablers posited are moderately to highly inter-related. Regression analysis shows that model accounts for $68 \%$ of the variance in knowledge sharing. Of the 5 enablers examined, feedback on learning and access to learning resources were significant and point toward a strong role in knowledge sharing. The study provides strong support for the synergistic use of internally coherent set of practices with feedback on learning behavior and access to learning resources playing the principal role in stimulating knowledge sharing. The findings generally resonate with the positions taken by Nonaka and Takuechi (1998), Krogh et al. (2002), Snowden (2003) and Gilmour (2003) who call for "atmospheric management" in knowledge intensive firms.
\end{abstract}

Keywords: Organizational Learning, Sharing of knowledge, Knowledge management

\section{Introduction}

The capacity of an organisation to learn and to exploit the outcome of learning - the knowledge, more effectively than the rest is viewed as a core competence that can assure competitive advantage in today's uncertain business environment (Hsu, 2008: Lim \& Chan, 2004; Senge, 2003). Evidence shows that organisations with superior performance relative to their counterparts engage actively and systematically in organisational learning and sharing activities (Accenture, 2004; Breene \& Thomas, 2004; Hsu, 2006; Stewart, 2001). Although the organisational learning (OL) stream of study has somewhat been overshadowed by the arrival of knowledge management (KM), intensifying learning and maximizing exploitation of knowledge is still the key challenge (Magalhaes, 1996:23; Senge, 2003). The main challenge faced by knowledge intensive firms (KIF) is to facilitate the learning and sharing of knowledge among and between members of an organisation (Alvesson \& Karreman, 2001; Currie \& Kerrin, 2003). The extent of knowledge sharing transforms individual learning into potentially OL and becomes a more stable component of the organisational store of knowledge to be readily exploited by all whenever the occasion arises. Hence, sharing of knowledge occupies a central role in KM (Bartell, 2001; Hsu, 2006). Knowledge intensive organisations (i.e. professional firms, consultancies, advertising agencies, software etc.) rely on the knowledge factor more than other firms and hence, the strategic importance of knowledge sharing within the organisation (Lee \& Ahn, 2007; Bechina \& 
Bommen, 2006; Karreman, Sveningsson \& Alvesson, 2003; Alvesson, 1995). This study examines the factors that influence the extent of sharing of knowledge in a knowledge intensive organisation - a systems integrator.

\section{Literature review}

Ever since Nonaka dan Takuechi (1995) popularized OL/KM as the new key arsenal in competitive strength, the management of the learning process and product has taken centre stage in organizational analysis. OL calls for not only more intensive attention to learning at all levels, it also requires that the learning be transferred from individuals to the collective to become accepted and later embedded as organizational learning (Crossan, Lane \& White, 1999). Nonaka \& Takuechi's (1996) Socialization, Externalization, Combination and Internalization (SECI) model placed sharing or exchange as the mechanism of transforming the knowledge types. The two key challenges for KM and OL are to intensify learning (and knowledge acquisition) and also to share (and to exploit) the resultant knowledge across the organisation (Bechina \& Bommen, 2006)

\subsection{Training and Development}

To intensify knowledge sharing, organisations must continue or redouble structured learning via effective training and development of its staff (Beer, 2003; Bartell, 2000). This helps in transferring explicit and tacit competencies to the employees to ensure talent regeneration. This also provides formal and organized occasion for people to learn from each other (Liebowitz, 1999). As Hsu (2008) indicated, investment in people signals to the employees the management's values and commitment to their skills and knowledge development. A recent Accenture study showed that, contrary to popular fear, investing in the development of the executives engenders stronger commitment to the organization's values and intentions to stay on (Craig, Pham \& Bobulsky, 2008:13).

\subsection{Access to Resources}

The intermittent training programmes are inadequate in the world of rapid change. Given the rapid development and flux in knowledge in all disciplines and practices, the traditional methods, though necessary, are inadequate (Accenture, 2004). Employees must be motivated to learn continually on their own. Mere exhortations are not substantive evidence of top management commitment to self-learning (Breene and Thomas, 2004). The management must provide the access to resources to enable learning to take place. Hsu (2006) provided idiographic evidence of e-learning systems which facilitated continual learning as an antecedent of knowledge sharing. These facilities can take place in form of professional memberships, subscription to professional journals, attendance at forums, conferences and exhibitions, sabbaticals etc.

\subsection{Incentives and Rewards}

Making available the resources does not mean staff will avail themselves of these opportunities (Grover \& Davenport, 2001). Ghosh (2004) asserted that knowledge sharing is time consuming and potentially dilutes personal power. In fact, knowledge hoarding is viewed as compatible with the nature of many workplaces - individualistic, political and competitive. Cormican and Dooley's (2007) survey of Knowledge Management Officers (KMO) noted that motivating employees to share is the primary challenge and KMOs expressed frustration at the lack of practical models to engender such motivation (p.109). All theories of human motivation call for the staff to be adequately incentivized to respond to or engage in the learning activities. (APQC, 2001; Zhang, 2005; Ghosh, 2004:12). Altruism is not sufficient or reliable driver of human behavior. Needs fulfillment must be addressed to drive employee behavior towards continual self-learning. However, to be effective Gammelgaard, (2007) found that the incentive system must be customized to, among others, the level of employees and also the type of knowledge sharing sought. Lee and Ahn (2007) showed that the optimality of the rewards systems in producing knowledge sharing among employees is dependent on the KM strategies pursued i.e. codification or personalization. Hsu (2006) noted that high performing Taiwanese firms only used extrinsic rewards sparingly and relied more on intrinsic rewards to engender knowledge sharing among its employees. Some studies, however, did not find rewards a significant factor in sharing and attitudes and intentions and have cautioned against its use (Kankanhalli, Tan \& Wei, 2005; Lin, 2007). In the main, the literature calls for a calibrated and judicious use of rewards to move people to share or transfer their knowledge.

\subsection{Performance Evaluation and Feedback}

While managers may expect knowledge sharing among their staff, the communication of this imperative is fraught with lack of clarity and uncertainties (Cormican \& Dooley, 2007:109). Regular evaluation and also feedback on the state of knowledge sharing within the organisation and between groups to the staff, communicates the management's meaning and priorities effectively. Empirically, Hsu (2006) found that higher performing firms in Taiwan provided feedback on knowledge sharing much more actively; and formally than did the less performing ones (p.330). To effectively manage the learning and sharing behavior of the staff, managers must provide periodic feedback on the learning performance of every staff. The feedback communicates to the staff the seriousness of the management and the importance of this attribute. Evaluations and feedback which are developmental in orientation was a common practice found among successful Taiwanese firms (Hsu, 2007:332). 


\subsection{Knowledge Retention}

The tools-based approach to knowledge sharing essentially focused on creating the platforms and repositories for employees to transfer their knowledge i.e. their learning to enable easier sharing within the organisation (Swan, Newell, Scarborough, \& Hislop, 1999). As active learning by individuals enhances the capacity of individual staff, the management must also establish practices to encourage the retention of this learning within the organisation by explicit practices of reporting, reflections, review and insight papers and regular open sharing with associates. Through these practices the individual learning has the potential of becoming organizational - shared and embedded in organizational routines. Most importantly, the feedback should also focus on the efforts to share the knowledge with the relevant others in the organisation. McManus, Wilson and Snyder (2004) and Gilmour (2003) cautioned that knowledge retention projects have yet to show convincing returns on investment. The tool-based KM changes that created bloated repositories of so-called knowledge have since been questioned (Gilmour, 2003).

\subsection{Knowledge Sharing}

Knowledge sharing involves the transfer of knowledge from one person, group or firm to another (Garvin, 1993). Knowledge sharing as a central pillar of KM is critical to the realization of its full value. Indeed, knowledge sharing is recognised as the most intractable problem facing KM (Chow \& Chan, 2008; Bechina \& Bommen, 2006). Hsu (2008) found support for the innovation strategy and management values as antecedents of knowledge sharing. The nature of knowledge is also a key factor in effective knowledge sharing. Explicit knowledge can be shared more easily through many formal methods of training and development. It is the tacit knowledge that is difficult to share but more important that it is shared. Since, knowledge hoarding is common human attitude, it must be reversed through greater trust (Cormican \& Dooley, 2007), effective management communication (Hsu, 2008), better evaluation and feedback (Hsu, 2006; MacManus et al., 2004) and appropriately tailored reward schemes (Hsu, 2006; Lee \& Ahn, 2007). An HRM system that explicitly calls for knowledge sharing and systematically reinforces this attribute is evident is high performing firms (Hsu, 2006). He opined that a more integrative approach via the HRM system has a greater chance of success than piecemeal approaches.

\section{Conceptual Framework}

Most studies in information science have focused on the technical perspective of sharing i.e. knowledge management systems but there is greater appreciation now of the psychology and sociology of sharing (Choi, Kang \& Lee, 2008:743). This study adopts a social and humanistic perspective in looking at the enablers of knowledge sharing in organisations as enjoined by (Hsu, 2006:336; Cormican \& Dooley, 2007:111). Knowledge sharing is posited as being shaped by the learning value that is articulated by and manifested in the five learning practices (see Fig. 1). Strong top management commitment is a sine quo non for all changes in the organisation (Kotter, 1996) and holds the same with knowledge sharing (Hsu, 2008). Without management commitment, the training and development activities lack importance in the scheme of things in an organisation (Beer, 2003; Hsu, 2006; Lipshitz, et al., 2002). Visible involvement and budget support are necessary to transmit the interest and attention of the management to the rest (Cormican \& Dooley, 2007). Specifically in the context of KIFs, the knowledge of the present and impending technologies, market needs etc. are critical elements in winning new projects, contracts and clients. Therefore, the KIFs must make available effective access to learning resources. These resources may be subscription to relevant professional journals, attendance at conferences and seminars, exhibitions and trade shows, networking time and etc. These resources enable continuous and life-long learning which is necessary to keep up with the industry.

Exhortations alone will not do the job. The employees look at the signaling system to 'understand' what is important and what is merely rhetorical. Incentives, when systematically and systemically designed and delivered, will incentivize required attitudes and behaviors among the employees (Beer, 2003; Lee \& Ahn, 2007). It is widely acknowledged that much of the training and development expenditure is wasted because there is no transfer to the work or to others (Bartell, 2001; Macaulay \& Cree, 1999). There is a strong and obvious self-interest in hoarding knowledge. The organization must reverse this adverse habit by giving suitable incentives to share and help others. It is not enough to set goals for employees but appropriate feedback must be given to encourage the employees and also to counsel those who are less productive in the sharing function. The feedback helps to transmit the importance of the value of sharing of what is learned or acquired.

\section{Method}

A total 118 structured questionnaires were distributed to the executives in the Techco (not the real name of the knowledge intensive firm). All questionnaires were returned providing a $100 \%$ response rate. For the study, we utilised Ellis and Shpielberg's (2003) Organizational Learning Mechanism Questionnaire. The instrument used 48 Likert type items to assess various facets of the learning processes. Five items in the original measure were rephrased for greater clarity after the pilot test. The factor analysis showed that 6 items did not converge on the factors as expected and these items were dropped from further analysis. The Cronbach Alpha for the Likert type multi-item measures are displayed 
in the diagonals in Table 2. The instruments demonstrated acceptable level of reliability beyond Cronbach Alpha level of .70 to proceed with the analysis (Hair et al., 2006; Nunnally, 1978).

\section{Results}

The company is a Malay-owned company and as such the employee racial distribution is not unexpected. The average age of the executives is 31 and have about 3 years of working experience.

\subsection{Profile of Respondents}

The employee profile is shown in Table 1. A majority of the executives are female and this gender distribution is no surprise given that about the same distribution is evident in graduate output of universities in Malaysia (Hazman, 2005). Besides, in KIFs, female entrants face fewer difficulties in securing employment. A great majority of the executives have degree or diploma and are engaged in research and development work - the heart of the technology company (Alvesson, 1995). The educational profile of the executives supports the KIF classification of the firm. As a medium sized privately held Malay owned company, the clear dominance of Malays in the workforce is not unusual.

\subsection{Inter-variable Correlation}

The organizational learning variables display strong positive correlations between and among the variables. The lowest correlation is .427 and highest is .773 . The moderate to high inter-correlation shows that there is some degree of coherence in the overall effort to share learning among and between employees (see Table 2).

Knowledge sharing was regressed on 5 predictor variables (see Table 3). The regression model is significant with an $\mathrm{F}$ value of $48.229(\mathrm{p}<.000)$ and model has fairly high explanatory power. The Tolerance and VIF values were examined for evidence of collinearity. As a rule of thumb TOL values less than .3 (or VIF values $\geq 4.0$ ) is indicative of multi-collinearity problems (Hair et al., 2006). The TOL values for all the independent variables were above this cut-off criterion. About $68, \%$ of the variance in sharing of knowledge was explained by the 5 predictor variables. Unsurprisingly, only Access to Resources and Feedback emerged as significant predictors of sharing of knowledge.

The results provide strong support for the belief that sharing of knowledge is influenced or affected by the quality of feedback and also the extent of access to learning resources. These relationships are not hard to fathom in a practical sense. More sharing can takes place if more means to acquire knowledge exists in the first place. Similarly, feedback on how one is performing in so far as sharing of learning is concern signals the importance of the conduct organizationally. Importance of a value is a perceptually and socially constructed property in organisational life. It also indicates to the focal individual that the conduct is being observed and will be appropriately rewarded when it reaches a noticeable threshold. All KM proponents suggest incentives to encourage sharing behaviour among the employees and to undermine the natural propensity to hoard knowledge.

\section{Discussion}

The study posited that commitment to training and development, access to learning resources, retention arrangements, incentives for and feedback on learning behavior facilitate knowledge sharing in knowledge intensive firms based on the review of literature. Evidence from this study indicates that knowledge sharing is positively correlated with all the learning enablers examined. Most notably, the correlation of knowledge sharing with feedback on learning $(\mathrm{r}=.773$, $\mathrm{p}<.001)$ and access to resources $(\mathrm{r}=.668, \mathrm{p}<.01)$ is much stronger than the rest. The significant and relatively high correlation between the learning variables provide further evidence that sharing of the product of learning - i.e. knowledge must be actively and systematically nurtured (Hsu, 2008; Hayes \& Walsham, 2000). A variety of practices as posited in this study must be synergistically implemented to give knowledge sharing the necessary collective impetus. Given the differentiated nature of most organizations, management policy and practice often lacks optimal integration and unity of purpose (Lawrence and Lorsch, 1967). Ideally, the many practices must be aligned to achieve maximal impact in furthering the knowledge sharing goal (Kaplan \& Norton, 1996).

The regression analysis singled out access to learning resources $(b=.458, \mathrm{p}=.000)$ and feedback on learning $(b=.230$, $\mathrm{p}=.007$ ) as the key influence on knowledge sharing. The two predictors accounted for about $68 \%$ of variance in knowledge sharing which, by Cohen's (1992) reckoning is a large effect size. Learning is not a costless activity. Organisation must be willing to invest in the learning resources and activities of their employees. Providing access to learning resources for the employees especially when it involves significant costs is a mark of faith in the employees to learn, share and contribute. The trust that the employer places in their employees, strengthens the psychological contract between the two (Craig, Pham \& Bobulsky, 2008). This reciprocity is a necessary element of the social capital that is a precondition to effective sharing of learning within organisations. This relational dimension is critical to transfer of knowledge - the Achilles heel of knowledge management (Nahapiet \& Ghoshal, 1998). As social exchange theorists propounded, it is the mutuality of benefit that facilitates the exchange and reduces the transaction cost of the exchange process (Blau, 1998; Homans, 1961; Thibaut and Kelly, 1959). Rhetorical commitment to knowledge sharing cannot 
actively undermine the natural instinct to hoard knowledge which, according to Alvesson \& Karremen (2001) and Kamoche \& Mueller (1998), is quite a rampant behavior.

The feedback to the employees on their performance or behaviour is a cardinal rule in human performance management (Breene \& Thomas, 2004). Feedback on learning behavior indicates to employees that their performance is being observed. It also transmits the importance of the value of sharing beyond the usual exhortations and rhetoric (Hsu, 2006). Peter Drucker's (1954) dictum that "what gets measured, gets done" is highly instructive here. When the feedback is provided by important others i.e. managers and is perceived to be frank, fair and developmental, commitment will be strengthened. Hence, the empirical results points to the twin policy of investment in learning and feedback to engender greater sharing of learning or knowledge to maximise the potential to exploit knowledge for business success.

\section{Conclusion}

In conclusion, the study provides further evidence of, and adds weight to the importance of access to learning resources of all kinds and feedback on learning as means to stimulate greater sharing of knowledge in knowledge intensive organisations. Unless knowledge can be diffused into the organisation, the learning must remain individual or group-based. Little organisational learning can be said to take place. In this regard, this study provides yet another test to tease out the enablers of knowledge sharing. However, this is a single organisation study and as such the observed relationships could be context dependent. It is a knowledge intensive firm and therefore, the awareness of sharing is probably a lot more heightened than that in ordinary organisations. Despite the strength of the relationships observed in this study, the usual caveat in generalisation to other settings applies.

\section{References}

Accenture. (2004). The rise of the high performance learning organisation: Results from the Accenture Learning 2004 Survey of Learning Executives. [Online] Available: www.accenture.com (Retrieved on November 20).

Alvesson, M. and Karreman, D. (2001). Odd couple: Making sense of the curious concept of knowledge management. Journal of Management, 38(7), 995-1018.

Alvesson, M. (1995). Management of Knowledge Intensive Companies. Berlin. Walter DeGruyter.

Argyris, C, and Schon, D.A. (1996). Organizational learning II. Theory, methods and practice. Reading MA: Addison-Weslley..

Bartell, S.M. (2001). Training's new role in learning organisations. Innovations in Education and Teaching International. [Online] Available: http://www.tandf.co.uk/journals(Retrieved on Nov. 12, 2002).

Bartol, K.E. \& Srivastava, A. (2002). Encouraging knowledge sharing: The role of organizational reward system. Journal of Leadership \& Organizational Studies, 9(1), 64-76

Bechina, A. A. \& Bommen, T. (2006). Knowledge sharing practices: Analysis of a global Scandinavian consulting company. The Electronic Journal of Knowledge Management, 4(2), 109-116

Beer, M. (2003). Why total quality management programs do not persist?: The role of management quality and implementation for leading a TQM transformation. Decision Science, 34(4), 623-642.

Bell, S.J., Whitwell, G.J. and Lukas, B.A. (2002). Schools of thought in organizational learning. Journal of Academy of Marketing Science, 30(1), 70-86.

Blau, P.M. (1998). Exchange and Power in Social Life. New Brunswick: Transaction Publisher:

Breene, T. and Thomas, R.J. (2004). In search of performance anatomy. [Online] Available: www.accenture.com (Retrieved on Nov. 20, 2004).

Choi , S.Y., Kang, Y.S. \& Lee, H. (2008). The effects of socio-technical enablers on knowledge sharing: an exploratory examination. Journal of Information Science. 34(5), 742-754.

Chow, W.S. \& Chan, L.S. (2008). Social network, social trust and shared goals in organizational knowledge. Information and Management, 45, 458-465.

Cohen, J. (1992). Quantitative methods in psychology. A power primer. Psychological Bulletin, 112(1), 155-159.

Cormican, K. \& Dooley, L. (2007). Knowledge Sharing in a Collaborative Networked Environment. Journal of Information \& Knowledge Management, 6(2), 105-114.

Craig, E., Pham, C.T \& Bobulsky, S. (2008). Rethinking Retention: If you want your best executives to stay, equip them to leave. Research Report. [Online] Available: www.accenture.com/Accenture (Retrieved on October 4, 2008)

Crossan, M., Lane, H.W \& White, R.E. (1999). An Organizational Learning Framework: From Intuition to Institution. Academy of Management Review, 24(3), 522-537. 
Currie, G. and Kerrin, M. (2003). Human resource management and knowledge management: Enhancing knowledge sharing in a pharmaceutical company. International Journal of Human Resource Management, 14(6), 1027-1045.

Cyert, R.M. and March, J.C. (1963). A Behavioral Theory of the Firm. New Jersey: Prentice-Hall.

Ellis, S and Shpielberg, N. (2003). Organisational learning mechanisms and managers' perceived uncertainty. Human Relations, 56(10), 1233-1254.

Drucker, P.F.(1954). The Practice of Management. New York: Harper \& Row.

Gammelgaard, J. (2007). Why Not Use Incentives To Encourage Knowledge Sharing? Journal of Knowledge Management Practice, 8(1), p. NA. [Online] Available: www.tlainc.com/articl127. htm (Retrieved on Dec. 15, 2008)

Garvin, D.A. (1993). Building a learning organization. Harvard Business Review, 71(4), 78-91.

Ghosh, M. (2004). Creating Incentives for Knowledge Sharing. [Online] Available: www.ocw.mit.edu/NR/rdonlyres (Retrieved from September 27, 2008)

Gilmour, D. (2003). How to fix knowledge management? Harvard Business Review, Oct. 16-17.

Grover, V. \& Davenport, T.H. (2001). General perspectives on knowledge management: Fostering a research agenda. Journal of Management Information Systems, 18(1), 5-21.

Hair, J.F., Tatham, R. R., Anderson, R.E. \& Black, R.E. W. (2006). Multivariate Data Analysis. (6th Edition). New York: Pearson Publication.

Hamel, G. (2000). Leading the revolution. Boston, MA: Harvard Business School Press.

Hayes, N. and Walsham, G. (2000). Safe enclaves, political enclaves and knowledge working In Pritchard C., Hull, R., Chumer, H. and Willmott, H. (Eds). Managing knowledge: Critical investigations of work and learning. London. Macmillan.

Hazman, S.A. (2005). Unemployed Graduates in Malaysia: Seeing through the Smog. Proceedings of the Seminar in Unemployment of Graduates, Faculty of Administrative Science \& Policy Studies, Universiti Teknologi MARA, Shah Alam, Malaysia, $12^{\text {th }}$ March.

Hazman, S.A. and Razmi, C. (2004). Managing knowledge organisations: The case of a medium size company. Proceedings of the $4^{\text {th }}$ International Conference on Knowledge, Culture and Change, University of Greenwich, London, UK. $3^{\text {rd }}-6^{\text {th }}$ August 2004.

Homans, G.C. (1961). Social behavior. New York: Harcourt, Brace and World.

Hsu, I. (2006). Enhancing employee tendencies to share knowledge - Case studies of nine companies in Taiwan. International Journal of Information Management, 26, 326-338.

Hsu, I. (2008). Knowledge sharing practices as facilitating factor for improving organizational performance through human capital: A preliminary study. Experts Systems with Applications, 35, 1316-1326.

Kamoche, K and Mueller, F. (1998). Human resource management and the appropriation strategies. Human Relations, 51(8), 1033-1060.

Kaplan, R.S. and Norton, D.P. (1996). Translating Strategy into Action, The Balanced Scorecard. Boston, MA: Harvard Business School Press.

Kankanhalli,, A, Tan, B.C.Y. \& Wei, K.K. (2005). Contributing knowledge to electronic repositories: an empirical investigation. MIS Quarterly, 29(1), 113-143.knowledge sharing intentions.

Karreman, Sveningsson, S. \& Alvesson, M. (2003). The Return of Machine Bureaucracy? Management Control in the Work Settings of Professionals. International Studies of management \& Organisation, 32(2), 70-92.

Kotter, J.P. (1996). Leading Change. Boston, MA: Harvard Business School Press.

Krogh, G. V., Ichojo, K and Nonaka, I. (2002) Enabling Knowledge Creation: How to unlock the mystery of tacit knowledge and releasing the power of innovation. Oxford: Oxford University Press.

Lawrence, P and Lorsch, J. (1967). Organization and Environment. Cambridge, MA: Harvard University Press.

Lee, D.J. \& Ahn, J. H. (2007). Rewards Systems for Intra-Organizational Knowledge Sharing. European Journal of Operations Research, 180, 938-956.sharing.

Lim, L.L.N and Chan, C.C.A. (2004). The development and application of an organisational learning matrix. International Journal of Management, $21(1), 100-107$.

Lin, H.F. (2007). Effects of intrinsic and extrinsic motivation on employee. Journal of Information Science, 33(2), 135-149. 
Liebowitz, J. (1999). The Knowledge Management Handbook, Boca Raton, FL: CRC Press.

Lipsitz, R, Popper, M. and Friedman, V. J (2002). A multifaceted model of organizational learning. The Journal of Applied Behavioral Science, 39(1), 78-98.

Macaulay, C. and Cree, V. (1999). Transfer of learning: concept and process. Social Work Education, $18(2), 183-194$.

Magalhaes, R. (1996). Organizational Learning, Organisational Knowledge and organisational memory: New proposals towards a unified view. Working Paper Series No 60. Department of Information Systems, London School of Economics and Political Science.

McManus, D. J., Wilson, L.T. \& Snyder, C.A. (2004). Assessing the business value of the knowledge retention projects: Results from four case studies. IFIP International conference on Decision Support Systems (DSS2004) [Online] Available: http://www.knowledgeharvesting.org/papers.htm(Retrieved on Nov.1, 2008).

Mueller, F. and Dyerson, R. (1999). Expert human or Expert Organisation? Organisation Studies, $20(2), 225-256$.

Nahapiet, J. and Ghoshal, S. (1998). Social capital, intellectual capital and organisational advantage. Academy of Management Review, 23(2), 242-266.

Nonaka, I. and Takuechi, H. (1998). The knowledge creating company In Mabey, C., Salaman, G. and Storey, J. (Eds). Strategic Human Resource Management. A Reader. London. Sage Publication.

Nunnally, J.C. (1978). Psychometric Theory. $2^{\text {nd }}$ ed. New York: McGraw-Hill.

Pedler, M. (1995). A guide to learning organisation. Industrial and Commercial Training, 27(4), 21-25.

Pedler, M., Burguyne, J. Boydell, T. (1996). The Learning Company: A Strategy for Sustainable Development. $2^{\text {nd }}$ ed. Maidenhead: McGraw-Hill.

Penrose, E.T. (1959). The Theory of the Growth of the Firm. Oxford, UK: Basil Blackwel.

Senge, P (1992). The Fifth Discipline. Boston. MA. MIT Press.

Senge, P. (2003). Taking personal change seriously: The impact of Organizational Learning on management Practice. An executive commentary. Academy of Management Executive, 17(3), 47-50.

Sikula, J.M., Baker, W.E. and Noordeweir, T. (1997). A Framework for Market Based Organisational Learning. Linking values, knowledge, and behaviour. Journal of Academy of Marketing Science, 25(2): 305-318.

Simon, G. (2002). The "reality" of rhetoric and the learning organisation in the UK. Human Resource Development International. 155-174 Accessed on 12 . [Online] Available: http://www.tandf.co.uk/journals (Retrieved on Nov. 2004).

Simon, H. (1945). Administrative Behaviour. New York: MacMillan.

Snowden , D. (2003). KM in Perspective, Keynote speech at the Management Conference, 11-14 August, Penang.

Stewart, T. (2001). The Wealth of Knowledge. Intellectual Capital and the twenty First Century Organization. New York. Currency.

Swan, J., Newell, S. Scarborough, H. \& Hislop, D. (1999). Knowledge management and innovation. Networks and networking. Journal of Knowledge Management, 3(4), 262-275.

Teece, D. J., Pisano, G. and Schuen, A. (1997). Dynamic Capabilities and Strategic Management. Strategic Management Journal, 18(7), 509-533.

Thibaut, J.W. and Kelley, H.H. (1959). The Social Psychology of Groups. Wiley: New York.

Vince, R., Sutcliffe, K. and Olivera, F. (2002). Organisational learning: New directions. British Journal of Management, $13,1-6$.

Zhang, Z. (2005). Managing knowledge assets in organizations: Role of incentives and information systems. DAI-A 66/. [Online] Available: http://kmvirtual.com/2008/06/23/are-incentives-in-knowledge-management-important/ (Retrieved on Dec. 15, 2008). 
Table 1. Profile of Respondents

\begin{tabular}{|c|c|c|c|}
\hline & Profile & No & $\%$ \\
\hline \multirow[t]{4}{*}{1} & Gender & & \\
\hline & Male & 46 & 39 \\
\hline & Female & 67 & 56.8 \\
\hline & NA & 5 & 4.2 \\
\hline \multirow[t]{6}{*}{2} & Race & & \\
\hline & Malay & 76 & 64.4 \\
\hline & Chinese & 24 & 21.3 \\
\hline & Indian & 5 & 4.2 \\
\hline & Others & 2 & 1.7 \\
\hline & NA & 11 & 9.3 \\
\hline \multirow[t]{7}{*}{3} & Department & & \\
\hline & Marketing & 7 & 5.9 \\
\hline & Research \& Development & 65 & 55.1 \\
\hline & Technical Support & 18 & 15.3 \\
\hline & Operational Support & 13 & 11 \\
\hline & Retailing & 3 & 2.5 \\
\hline & NA & 12 & 10.2 \\
\hline \multirow[t]{6}{*}{4} & Qualification & & \\
\hline & SPM & 1 & .8 \\
\hline & Diploma & 20 & 16.9 \\
\hline & Degree & 89 & 75.4 \\
\hline & Masters & 4 & 3.4 \\
\hline & NA & 4 & 3.4 \\
\hline 5 & Experience & $2.36^{*}$ & $1.776^{* *}$ \\
\hline 6 & Age & $31.6^{*}$ & $18.8^{* *}$ \\
\hline
\end{tabular}

* Mean, ** Standard deviation

Table 2. Pearson Inter-Variable Correlations

\begin{tabular}{|c|c|c|c|c|c|c|c|c|c|}
\hline & Variables & M & SD & 1 & 2 & 3 & 4 & 5 & 6 \\
\hline 1 & $\begin{array}{l}\text { Commitment to } \\
\text { Training. }\end{array}$ & 3.3462 & .63610 & (.89) & & & & & \\
\hline 2 & $\begin{array}{l}\text { Access to } \\
\text { Learning } \\
\text { Resources }\end{array}$ & 3.2665 & .50564 & $.616^{* *}$ & $(.82)$ & & & & \\
\hline 3 & $\begin{array}{l}\text { Retention of } \\
\text { Learning }\end{array}$ & 3.4110 & .54765 & $.510^{* *}$ & $.649 * *$ & $(.74)$ & & & \\
\hline 4 & $\begin{array}{l}\text { Knowledge } \\
\text { Sharing }\end{array}$ & 3.3320 & .42723 & $.597 * *$ & $.773 * *$ & $.659 * *$ & $(.87)$ & & \\
\hline 5 & $\begin{array}{l}\text { Incentive for } \\
\text { Learning }\end{array}$ & 3.4421 & .54635 & $.417 * *$ & $.561 * *$ & $.591 * *$ & $.566^{* *}$ & $(.70)$ & \\
\hline 6 & $\begin{array}{l}\text { Feedback on } \\
\text { Learning }\end{array}$ & 3.3085 & .51217 & $.536 * *$ & $.627 * *$ & $.729 * *$ & $.688 * *$ & $.585^{* *}$ & $(.80)$ \\
\hline
\end{tabular}

** Correlation is significant at the 0.01 level (2-tailed). The Cronbach Alphas are in the diagonals 
Table 3. Predictors of Knowledge Sharing

\begin{tabular}{|c|c|c|c|c|c|}
\hline Predictors & $\mathrm{b}$ & Std Err & Std b & $\mathrm{t}$ & Sig. \\
\hline Constant & .735 & .174 & & 4.224 & .000 \\
\hline Commitment to Training \& Development & .076 & .047 & .113 & 1.618 & .109 \\
\hline Access to Learning Resources & .387 & .068 & .458 & 5.657 & .000 \\
\hline Incentives for Learning & .056 & .055 & .071 & 1.007 & .316 \\
\hline Feedback on Learning & .192 & .070 & .230 & 2.724 & .007 \\
\hline Retention of Learning & .074 & .067 & .094 & 1.107 & .271 \\
\hline \multicolumn{6}{|l|}{ Model Summary } \\
\hline $\mathrm{R}^{2}$ & & & .683 & & \\
\hline Adj. $R^{2}$ & & & .669 & & \\
\hline F value & & & 48.229 & & \\
\hline
\end{tabular}

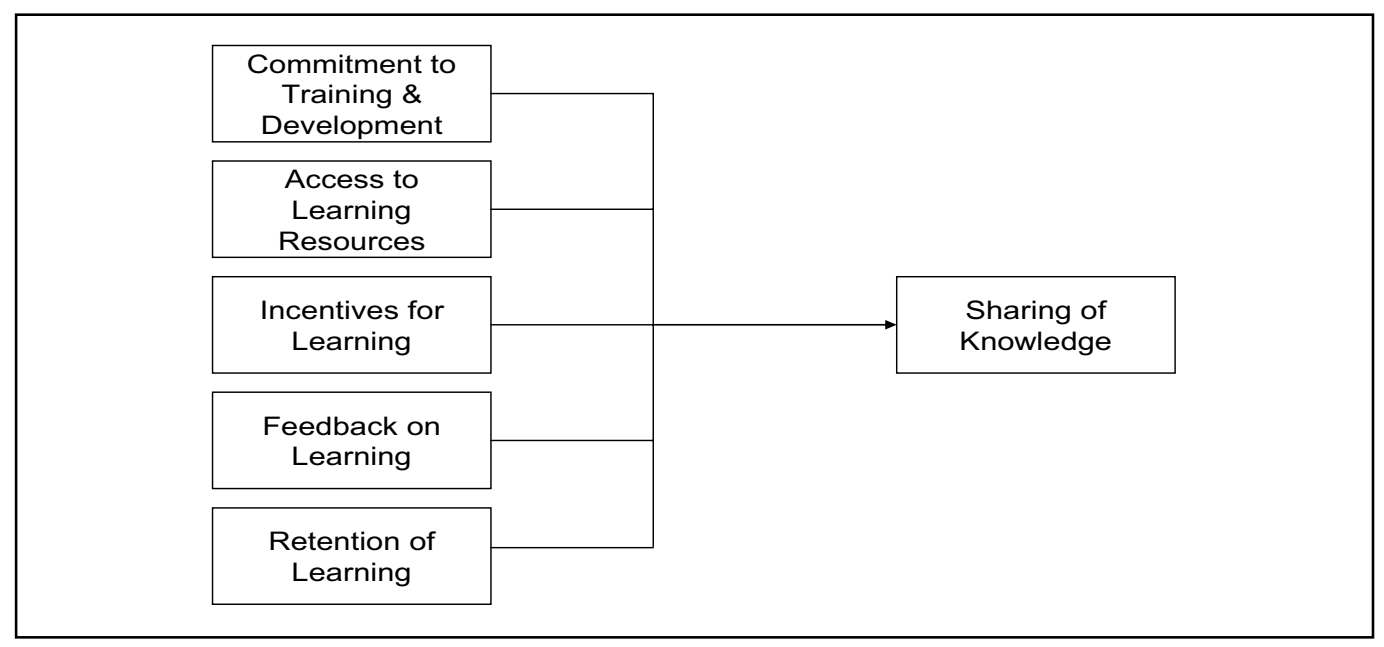

Figure 1. Conceptual Framework 


\title{
Analysis on Local Government Support
}

\author{
in Agricultural Industriazation-Based on the Reflection \\ of Dumping Milk in Zhaodong City of Heilongjiang Province
}

\author{
Yukun Zhang \\ School of Economic \&Trade, Shihezi University \\ Shihezi 832003, China \\ Tel: 86-993-2595-859_E-mail: zyk00505@sina.com
}

\begin{abstract}
During the developing process of agricultural industrialization, the peasant,the Facilitating agency, the Leading enterprise are carrying on gambling in every way. And the Local government 's unreasonable support behaviors, will certainly speed up the gambling being out of balance. This article carries on the analysis of Pours the milk event of Zhaodong cattle-raising household in Heilongjiang Province, to discover the unfairness of Local government's support behaviors in agricultural industrialization. It aslo analyzes the main cause of Local government's support behaviors, as well as the negative influence produced by such kind of unreasonable support behaviors. And finally the paper points out that the Local government needs to set up scientific and reasonable support behaviors to promote the regional economic development and to escort for the healthy development of agricultural industrialization.
\end{abstract}

Keywords: Agricultural industrialization, Local government, Support behaviors, Region economy

\section{Review of Pours the milk event of Zhaodong city cattle-raising household in Heilongjiang Province}

At the inquire deeply Heilongjiang Province Zhaodong city pour milk event, we discovered but actually Zhaodong raised the cow to have a section of historical development, already formed the development scale, has had certain region superiority, promoted the local economy to develop fast. in 2007 the second half of the year, because the international market powdered milk rise in price influence, the Heilongjiang Province various fresh milks Processing industry milk source is been anxious, causes each dairy product Processing industry to fight for the fresh milk. But the Zhaodong municipal government is precisely surges upward in the international domestic milk price, in the milk source intense situation, by "the standard milk source market, prevents the milk price fluctuation wound agriculture" the name, prevents the local milk source outflow, protects the local dairying enterprise development. Nearly presented but actually the milk event.

On September 27, 2007 the Heilongjiang Province Zhaodong Xuanhua township raiseing cattle household concurrently receives the milk to stand stationmaster the generation of cloud peak, because the discontented Local government supposes the card in the road to seize and hold in custody the milk vehicle, to prevent the milk source foreign shipment forcefully the behavior, is in a rage pours into own 9 ton fresh milk the trench. Simultaneously the Xuanhua township and Songzhan Town's several other milks stand Stationmaster Huo Guiquan, Hong Quan, Zhang Xudong et al. also in abundance to reflect, the Zhaodong municipal government to protect a local enterprise milk source, does not let their toward the outside enterprise sell the milk, although the outside areas enterprise receives the milk price to be high, also does not permit to sell. Not only Zhaodong's milk source does not permit the outflow, transports the milk vehicle from the Zhaodong process also to have the phenomenon which is seized and held in custody by the locality. Some media track reported this event, has caused some disputes, this article is embarks from this event, analyzes the Local government to support the behavior in the agricultural industrialization the reason and the guidance analysis.

Zhaodong dairying development pattern mainly by "company + Intermediary organization + peasant household" primarily, what Facilitating agency here figure receives the milk station. Receives the milk station function is the collection disperses peasant household's fresh milk, then the enterprise receives the milk station to carry on the unified purchase. Such movement pattern reduced some transaction cost, also strengthened has received the middle function which the milk stood. The milk station is shouldering the dual statuses, since enterprise's request representative, is also the raiseing cattle household benefit spokesman, is the milk agriculture and the enterprise linked link. But in the 
Zhaodong milk event, the milk stands with the milk agriculture is event's victim similarly but actually, the milk stands the intermediary function submerges completely under government's compulsion control. But the place dairying enterprise's fast development makes the very big contribution for the provincial economy development, solved the employment, the tax revenue for the Local government and so on some questions, the place dairying enterprise has a stronger influence to the Local government policy decision-making. The peasant household is at the dispersion production state, has the weak negotiated price words power, not with enterprise coordinated negotiations status, what are more accepts the price which the enterprise proposed, draws up in the enterprise under the contract carries on the production, is weak to Local government's influence.

\section{Pours in the milk event the Local government to support the influence which the behavior produces}

\subsection{Strong administrative interference, harm government image}

Local government's role should be in the jurisdiction district economical event's pacificator originally, but is not the economical event's participant, the localization should be serves the broad masses. But in the Zhaodong milk event we discovered but actually starts from September 25, 2007, Zhaodong departments and so on public security traffic police, raising livestock, sanitation and antiepidemics unite the starting off interception, to detain the dairying company to transport the milk vehicle, even if transports the milk vehicle from the Zhaodong process not to let off. Obviously, this behavior has the strong administrative interference color, has the very strong benefit tendentiousness obviously. The Local government takes the economic subject participation economic activity, has disturbed the normal market economy, the display function is not the economical event's pacificator obviously. Zhaodong municipal government's behavior serious violation raiseing cattle household and dairying company's legitimate rights and interests, also serious damage Local government's image.

\subsection{Violates the fair competition principle, the destruction reasonable environment of competition}

From the milk event, we discovered but actually the Zhaodong municipal government actually forcefully prevents the local milk source outflow, its goal nothing but is wants to protect the local dairying enterprise development. Although the Local government has protected the place individual dairying enterprise, actually has poured into the very strong jamming to the normal dairying development, violates the fair competition principle. Along with the people living standard's enhancement, will certainly to increase to the milk product demand. The milk product enterprise development irregular "Dominoes" the dominoes will be advanced, the milk product expense level promotion, will make the cow dairy industry competition to intensify gradually, the dairy industry market will be experiencing is mixing the cards "the Warring States dispute". In the market had disorderly, the distortion competition behavior, causes the dairy industry production confusion, government's role to be this dispute's pacificator, for enterprise between fair and principle competition cultivation health beneficial environment. But should not for the place benefit, protect the Local enterprises, artificial breaks the reasonable environment of competition.

\subsection{Breaks the enterprise and peasant household's gambling is balanced, affects the region economy healthy development}

In the international or domestic milk price surges upward in the situation, the Heilongjiang Province various fresh milks Processing industry milk source is anxious, each dairy product Processing industry fights for the fresh milk in abundance. By rights, the market appears competes for the milk source competition, should be the best opportunity which the milk agriculture profits, should create the condition maintenance milk agriculture benefit positively as the local government department. But the government strengthened firmly to the fresh milk mobile control, the milk agriculture only could sell to the fresh milk the place the dairying enterprise, but produced the fresh milk the cost to increase, the enterprise purchased the milk price actually to continue somewhat low. Under this kind of environment, dampens the milk agriculture inevitably the production enthusiasm, only then makes is willing to fall over the fresh milk extreme behavior. According to the market rule management's Local government's support behavior, artificial has not broken the dairying market supply and demand balanced relations, has harassed the market order, has limited the market economy free development. Looking from the region economic development's long-term angle, has hindered the milk source unrestricted flow, did not favor improves the milk source quality, has broken market economy own adjustment, deep harm locality and nearby regions dairying production healthy development

Under the Local government control, the milk agriculture will have the possibility to make the withdrawal to raise cow's profession, will change to other professions to carry on the production. But fresh milk insufficient supply under the background, will affect the dairying enterprise's normal production inevitably, has enlarged the cost which the enterprise will produce, will create the milk source artificial reduction, will have the negative influence to the region dairying development, near and will also be having the negative effect to the region economic development. 


\section{The Local government supports the question which and the reason analysis in the agricultural industrialization the behavior displays}

\subsection{Between the Central authorities and the Local government exist cooperate gambling}

Our country is the centralization sole system country, the Local government is Central authorities' at place business representative. The Local government should carry out Central authorities' decision-making. But in high degree of concentration planned economy system to market economy system switch process, corresponding centralization pattern gradually to decentralization pattern development. Local government's benefit main body status protrudes day after day, its government also suddenly inflated, has had ability which bargained back and forth with the Central authorities, thus in with in Central authorities' relations, presented in some kind of degree not to cooperate gambling.

The decentralization may cause the Local government to display its information dominance well, also provided a better economy for the Local government to drive, caused the Local government to be more positive joins in the provincial economy development, strengthened Local government's in region economy words power and the leading power. But while is promoting region economic development positively, also cultivated the Local government to become a special benefit main body, aggravated in the jurisdiction district the place protection color. The Central authorities to the Local government hit product, actually lack the powerful supervising mechanism and the restraint mechanism, causes the Local government jurisdiction restraint to weaken, like this sought oneself benefit for the Local government to lay down the foreshadowing.

\subsection{The Local government benefit urges the regional protectionism to be in vogue}

The Local government takes one "the economic man" the role, must maintain own benefit surely, in aspects and so on resources, businessmen are invited to open companies will carry on the keen competition. Under Local government competition dual effectiveness influence, both the positive promotion locality economic development function, simultaneously and will multiply the regional protectionism, will initiate between the Local government not, when will compete. Between Local government not, when will compete the chain-like response to affect the market disposition resources, artificial will take the measure to harm the region economic development, the harm general participation economic subject benefit. Looks over our country near for 20 year economic development practice to look that between the Local government is the competitor mutually, take competes high quality may flow the element of production as the key point, adopts "yields profit excessively" or "competes excessively" policy, achieves the enhancement resources right to control the goal, its result is inevitably affects the market to the resources disposition.

\subsection{The latter taxes and fees time presses to send the Local government "to seek" the behavior}

Since16th National Congress of the Communist Party of China, Central authorities several years appear about the agricultural aspect "the first of the document", the implementation to adjust the national income assignment pattern reasonably continuously, implement the industry to return nurturing to parents the agriculture, the city to support the countryside under the policy background. in 2006, our country global phasing-out agricultural tax, has finished the farmer turns in more than 2000 years "the imperial grain national tax" the history, after our country countryside has welcomed ", the taxes and fees time".

Under the central policy's background, strengthened the peasant household to farm the livestock-raising the enthusiasm, has enlarged to the agricultural production investment dynamics. But is opposite in the Local government says, the agricultural tax revenue has been the local finance income main part, now the local finance receives the central policy the influence, but the sharp decline, Local enterprises' tax revenue becomes local the financial revenue main point of growth. Is to local finance's consideration, the Local government and the Central authorities is different to peasant household's policy tendency degree, in 17 big reports the Central authorities bright pointed out that must solve the farmer question and the support Leading enterprise develops pays equal attention. But in the place administration stratification plane, Local government's policy motive more encourages the development enterprise, enlarges to the enterprise development support dynamics, increases the Local government financial revenue through the enterprise tax revenue. This will cause the Local government to be insufficient to peasant household's attention degree, more tendency in the enterprise, nearly have neglected peasant household's benefit, will be receives in exchange for the Local enterprises with peasant household's benefit to develop.

\subsection{The enterprise has the stronger about Local government decision-making ability compared to the peasant household}

In the barrio scope, benefit representative who the Leading enterprise takes a collective, easier to have the collective action color, has the stronger collective action ability, easier to take the measure to strengthen to Local government's influence. But disperses the milk agriculture, likely disperses sand, very difficult to unify, forms the collective action to exert own influence to the Local government. Therefore the enterprise is more advantageous than the milk agriculture in affects the Local government, about Local government's support behavior elects. But the Local government itself also has own benefit trend, when the Local government benefit is consistent with the peasant household benefit, the Local government behavior will enlarge to the peasant household protection dynamics, otherwise, when the Local government 
benefit even may say will work as place certain official own benefit and is by chance inconsistent with the peasant household benefit, peasant household's benefit's outflow was unavoidable.

\subsection{The narrow achievements view induces local government's unreasonable behavior}

Local government's main officials will be about the Local government decision-making main strength, the achievements view which the local governments will twist must make Local government's unreasonable behavior. Now, takes the local government, what are more is pursues the economical the fast development, what because are more in government official's inspection system is the economic indicator weight, but is not the social efficiency weight. When one-sided pursue economic efficiency, will neglect the social efficiency. Sometimes at the serious deficient social surveillance and in the restraint situation, local government's blind pursue economic development, is by harms the peasant household benefit to receive in exchange, even is harming the local resources and the environment serious pollution obtains for price receiving in exchange.

\section{The Local government the positive role which should display in the agricultural industrialization}

Must set up the Local government in the agricultural industrialization the correct support behavior, overcomes some negative factors to the Local government behavior influence, escorts for the peasant household benefit, cultivates the just environment of competition for the enterprise, makes the contribution for the agricultural industrialization healthy development, displays the Local government fully the guidance role which plays in the region economic development process.

\subsection{The Local government must carry on the reasonable industrial layout, stimulates the region economy}

The Local government wants to carry on the characteristic industry layout reasonably. Must act as circumstances permit in the superiority characteristic industry's choice, the key development has the region characteristic and on the latent competitive power product. If the Heilongjiang Zhaodong, is situated at south Heilongjiang, is the dairying develops one of earliest local, local cow raising has become the scale. Therefore the Local government should positive display oneself command the superiority, the prioritize and cultivates the region superiority characteristic industry, serves in the broad masses, guides the people to become rich, stimulates the region economy.

4.2 Display government leading role, supplement and consummation agriculture industrial production operational mechanism

Plays Local government's leading role, "operates independently, the voluntary contract, the benefit linkage, the risk share, the communal development" the orientation according to the market main body, instructs from the benefit assignment mechanism and the revolution restraint mechanism two aspects to its market main body's behavior. The benefit assignment mechanism had decided industrial production movement's tightness, the revolution restraint mechanism has guaranteed the industrial production smooth development. As the Local government not only as the agricultural industrialization's in economic activities' system decision maker, has the problem to the agricultural industrialization prompt well distributed. The government most intermediate, the function is very big, government's support guidance, can definitely control the benefit the assignment, nearly affects the benefit main body.

\subsection{The enhancement government supports dynamics, perfect agricultural product market distribution system}

In the advancement agriculture industrial production management's process, must the develop market network, establish the perfect circulation services structure vigorously, forms one take to wholesale the big market frame, by all levels of synthesis agricultural market fair as the support, from to construct the business city primarily take each region as the network, take the farmer production and marketing organization as the supplement four big market distribution system. At the same time, must the market network system, the circulation services structure's construction and the small cities construction organically unifies, must emphasize will concern the project, the enterprise, the market, the processing region and so on unify with the town construction, cause its relative centralism. Both may promote the small cities development, and is helpful in courses the agricultural industrialization management a higher stage.

\subsection{Sets up the Local government correct achievements view, serves for the agricultural industrialization}

Sets up the correct achievements view, accepts the society to supervise, displays the Local government to serve the function truly. Guides the region economy healthy development positively, is coordinated in the good agricultural industrialization various main bodies interest relations, during pursue economic development, also pays attention to the ecological environment, the science harmonious development, constructs has the Chinese characteristic socialist market economy, escorts for the agricultural industrialization's healthy development.

\section{Conclusion}

Correct Local government role localization. The Local government is in this region the economic activity pacificator, but is not the economic activity participant, is the contradictory coordinator, but is not the aggravating contradictory pusher. Must understand Nourse correctly the paradox, breaks through bottleneck which in the region development 
meets, gives full play to the Local government to guide the function positively.

In "companies plus households" in the benefit gambling model, increased the peasant household and the enterprise transaction cost, even more has underlined the cooperation instability, must form the Facilitating agency, is enterprise's spokesman, is the general peasant household's benefit spokesmen, is the Leading enterprise and peasant household's contradictory intermediate area, effective strengthened the peasant household and Leading enterprise's cooperation stability. Simultaneously must establish the profession association, strengthens the Uygur power dynamics, practical completes the milk agriculture benefit spokesman.

Strengthens the supervision of public opinion, displays the news the guidance function, the enhancement milk agriculture strives for the reasonable right dynamics. The public opinion inspector general can admonish in the agricultural industrialization all quarters behavior, protects the weak one benefit. The Local government is in the region the policy leader, in the reform developing process, is playing the very major positive role, but magistrate's pursue achievements constantly, pursue in the region the economic efficiency, actually to a great extent has neglected government's social efficiency. Should strengthen the public opinion the surveillance, urges on the Local government in the administration process, true carries out Central authorities' wish, practical maintenance good milk agriculture benefit.

\section{References}

Guo, Qian Qi. (2008). By Local government's in marketability advancement Nourse paradox behavior . Academic circle, February. 160-165.

Lei, Junzhong, Chen, Wenkuan \& Tan, jing. (2003). In agricultural industrialization management government role and function. Agricultural economy question, July, 41-44.

Li, Xiuhong. (2008). West latter taxes and fees time farmer additionally receiving mechanism discussion. Ningxia college newspaper (person literary society branch version), May, 149-152.

Lu, Xianxiang. (2004). Western new system economic. Beijing: Chinese Development Publishing house.

Niu, Ruofeng. (2002). A contemporary agriculture industrialization body management. Nanchang: Jiangxi People's Publishing Agency.

Ren, Weide. (2005). Between Local government's competition and competitive power promotion. Inner Mongolia college newspaper (person literary society branch version), March, 3-9. 


\title{
An Attitude Approach to the Prediction of Entrepreneurship on Students at Institution of Higher Learning in Malaysia
}

\author{
Mohd Noor Mohd Shariff (Corresponding author) \\ College of Business, Universiti Utara Malaysia \\ 06010 Sintok, Kedah, Malaysia \\ E-mail: mdnoor@uum.edu.my \\ Mohammad Basir Saud \\ College of Business, Universiti Utara Malaysia \\ 06010 Sintok, Kedah, Malaysia \\ E-mail: basir372@uum.edu.my
}

\begin{abstract}
An attitude approach to the prediction of entrepreneurship has been the subject of extensive research in the developed world. However, this approach especially entrepreneurship attitude among students in the institutions of higher learning has not been conducted extensively in Malaysia and is ripe for research. This paper reports the findings on the entrepreneurship attitude perspective of the final year business management undergraduate students in one of the Institutions of Higher Learning in Malaysia. Fifty-eight undergraduates minored in entrepreneurship courses and sixty-five non-minored undergraduates from the Faculty of Business Management were tested and validated using the Entrepreneurial Attitude Orientation (EAO) scale instrument. Discriminant validity was used to test the known groups. There was a significance difference between known groups for two of the four EAO subscales (self-esteem and personal control); all subscales were entered into a stepwise discriminant function. The classification results showed that the overall number of cases classified correctly was 104 or 84.6 percent of the sample.
\end{abstract}

Keywords: Entrepreneurship, Undergraduates, Institution of Higher Learning, Entrepreneurial attitude orientation scale

\section{Introduction}

Previous research has shown a potential to create aspiring entrepreneurs in various fields such as academicians and fishermen (Louis, Blumenthal, Gluck \& Stoto, 1989; Roberts, 1991; Hatten \& Ruhland, 1995; Barcelona \& Valida, 1992; Mohd Noor, Ooi \& Mohd Zin, 2004; Mohd Noor \& Jamal, 2005). The studies conducted by these researchers were based on several perspectives, using the personality/character, demographics and attitudinal approaches.

The personality theories frequently loss its effectiveness in measuring entrepreneurial attitudes which according to Ajzen \& Fishbein (1977), the loss of its effectiveness in measuring entrepreneurial attitudes was due to the presence of increased margins of error related to all the situations that these instruments were used and not linking to the research concept. However, Robinson, Stimpson, Huefner \& Hunt (1991) stated that, the problems with the personality/traits approach when measuring entrepreneurship attitudes were regards to:

1) research methodologies that were not developed specifically to be used in measuring entrepreneurship;

2) different instruments that purport to measure the same concept actually correlate poorly;

3) personality theories are intended for use across a broad spectrum of situation, measuring general tendencies; and

4) the need for theoretical model that both influence and are influenced by activities in the environment that are interactive.

The demographic approach had also its own problems in measuring entrepreneurial attitudes because the approach was prone to generalizing individual groups within the population. Rychlak (1981) stated that future action was not influenced by demographic characteristics but more so by specific reactions to certain situations. In other words, entrepreneurial attitudes were determined by specific reaction to a situation and not by a set of common individual demographic characteristics. 
The structure of this article is as follows. The following section offers essential background information on the characteristics and entrepreneurial attitudes based on several perspectives propagated by previous literatures. The third section reviews the methodology employed that set out the hypotheses. The fourth and final section of the paper highlights the findings and discussions and conclusion respectively.

\section{Review of literature}

\subsection{Characteristics and entrepreneurial attitudes}

The attitude of individual to get involve in the field of entrepreneurship is driven by a number of factors that can be categorized as a Push Factors and Pull Factors. The Push Factors incorporate frustration that inherited entrepreneurial culture. Frustration result from limited opportunities, economic downturn and dissatisfaction. Pull Factors incorporate psychology and profit. Individuals will be pushed into entering business as a result of the frustration faced due to limited job opportunities and social mobility. Economic downturn also causes individuals to be influenced in becoming entrepreneurs because of the lack of job opportunities in both the public and private sectors.

Another reason is for individuals who do not have job satisfaction in his/her present jobs either because of the job itself, unsatisfactory remuneration, conflicting with leadership or organization culture. This is thought to be inappropriate which may lead to entrepreneurial attitudes. For some individuals who are already in the group with rich entrepreneurship culture, continual socialization process with the support and help in the form of material and moral will directly or indirectly encourage that individual to enter business.

Psychological encouragement also makes individuals to become influenced by entrepreneurship. The individual ego to carry out something that is self-created and being an own boss may also lead to entrepreneurial attitudes. Apart from this, the drive to make a profit is a strong motivator for aspiring entrepreneur. The profit derived from business is seen by many to be much more than being a mere wage earner.

Crant (1996) found that entrepreneurial attitudes could be linked to an individual consideration of owning a business. The research was conducted in a university in the United States and highlighted that gender; educational level and parents who own businesses contribute towards influencing entrepreneurial attitudes. Caird (1988a) stated that entrepreneurial attitudes could also be referred to individual levels of entrepreneurial attitudes to establish and run projects. Caird (1988b) also concluded that entrepreneurial attitudes tended to rely on the need for autonomy, internal locust of control, creativity, risk taking and self-believe.

A research analysis conducted by Mazzarol, Doss and Thein (1999) on the sampling of 93 respondents among entrepreneurs in Western Australia, found out that environmental factors (such as social factor, economics, politics and infrastructure development) and personality factors (such as individual character and the background of the respondents) influenced the drive to establish self-owned businesses

Entrepreneurial character and nature owned by some individuals together with demographic factors have also been proven to have close relationships towards the attitude to become an entrepreneur by establishing new businesses. Past research had shown that the interest of various demographic variables such as personality, human capital, ethnicity, marital status, educational level, family size, work status and experience, age, gender, socio-economics status, religion and nature of personality contribute towards establishing a business (Mazzarol, Doss \& Thein, 1999).

Entrepreneur characteristics inherent in someone may be linked with the attitude to establish a business as presented by researchers such as McClelland (1961) (need for achievement), Brockhous (1982) (attitude to take self internal control and risk), Schere (1982) (compromising with uncertainty), Greenberger and Sexton (1998) (need for personal control). However there are also background factors, which relate to individual personality such as previous employment (Ronstadts, 1985), family background (Matthews \& Moser, 1996), gender (Buttner \& Rosen, (1989), education (Storey, 1982) and ethnicity (Aldrich, 1980) which is also linked to the attitude to establish a business. Geographical factors and outside assistance also play a role in influencing the formation of new business by those who posses entrepreneurial characteristics (Chrisman, 1999).

Entrepreneurial attitudes can be associated with five main factors such as personal elements/traits factor (need for achievement, internal control, taking risk), personal environmental factor (family status, gender and having business-owning family), personal objective factor (being the owner of business, financial guarantee and vision), business environment factor (competition, societal attitudes towards new businesses and the accessibility of loan) and business idea factor (Naffziger, Hornby \& Kuratko, 1994). Research conducted by Mazzarol, Doss \& Thein (1999) found an attitude to set up an own business by a group of West Australian entrepreneurs based on demographic factors such as age, educational level, ethnicity, gender, previous work experience, jobless rate, residing location, family business experience and self-employment. Meanwhile, Crant (1996) studied on a group of first year undergraduates (91) and degree holders (90) found that entrepreneurship attitude among the respondents had significantly higher relationships with gender, education, family with business interest and a personal proactive attitude. 
In a comparative study conducted by Cromie and O’Donoghue (1992) on 194 managers and 661 first year degree undergraduate students with a group of entrepreneurs; they found that managers had high entrepreneurial attitudes by exhibiting characteristics and the nature for achievement, internal self control, need for autonomy, creativity, risk taking as well as higher self confidence as compared with the first year undergraduate students. Matthews and Moser (1996) study on 89 ex-business administration students, found that gender and families which own businesses, influenced entrepreneurial attitudes among the respondents. This finding supported the finding by Scherer and Brodzinski (1990), which found gender influenced the choice of entrepreneurship career among the respondents. The responsibility factor also influenced individuals when indulging in the field of entrepreneurship. This was proven by a research conducted by Buttner and Moore (1997) on 129 professional women and executives who have left their careers in major firms to become entrepreneurs by establishing their own companies. This course of action was taken to fulfil the movement factors (motivation) such as challenge, personal needs as well as balancing family and social responsibilities.

Other than the factors stated above, the factor of actually going through a relevant programme also influenced an individual to become an entrepreneur. This was further substantiated by the research conducted by Hatten and Ruhland (1995) on 220 college students who were following a programme sponsored by the Small Business Institute in USA. The research found that students which incline to become entrepreneurs was higher after competing the programme and it could be linked to high internal self control as well as age. Research conducted by Barcelona and Valida (1992) on 800 final year students at Universiti Utara Malaysia also found significant correlative existence between the respondents' personality and the characteristics of entrepreneurial attitudes. For technical entrepreneurs who have worked as university lecturers and researchers the elements such as family background, objective orientation, motivation and personality, work experience, education and age could be linked to the decision in becoming technical entrepreneurs (Roberts, 1991). Research by Louis et al. (1989) on lecturers at the Life Sciences Faculty at various universities in the United States also found that age and gender are factors that can influence lecturers into becoming academic entrepreneurs.

Researchers such as Ajzen (1982), Rosenberg and Hovland (1960) and Shaver (1987) defined attitude as the predisposition to respond in a generally favourable or unfavourable manner with respect to the object of the attitude. Allport (1935), Breckler (1983 and 1984), Carlson (1985), Kothandapani (1970) and others categorised attitude as the tripartite model consisting of three types of reaction to everything: affect, cognition, and conation. Robinson et al. (1991) defined:

The cognitive component consists of the beliefs and thought about an attitude object. The affective component consists of positive or negative feelings toward the object. The conative or behavioural component consists of behavioural intentions and predisposition to behave in a given way toward the object.

Robinson et al. (1991) concluded that the attitude theory has been used in many studies and benefited in terms of theoretical and practical approach on entrepreneurial attitudes. To substantiate the statement, Robinson et al. (1991) carried out a study to test the reliability of the "Entrepreneurial Attitude Orientation" (EAO) scale instrument on 63 undergraduate students while 54 entrepreneurs and 57 non-entrepreneurs were taken as a group to form discriminant validity for the EAO test. The result of the study indicated that the reliability of the EAO test was within the acceptable standard; entrepreneurs and non-entrepreneurs were significantly different for each of the four subscales and when submitted to discriminant analysis, three of the four subscales contributed significantly to the discriminant function. The findings of Robinson et al. (1991) has actually been supported by the study done earlier by Carlson (1985) which stated that the attitudes by individual to entrepreneurship can be measured by his/her attitude (consisting of the effective, cognitive and conative components) on the innovation, achievement, self-esteem, and personal control.

\section{Research hypotheses}

Based on findings of past researches and theoretical frameworks, the hypothesis presented in this analysis is:

$\mathrm{H}_{\mathrm{o}} 1$ : There is no significant difference between undergraduates minored in entrepreneurship and non-entrepreneur undergraduates in terms of the subscales (i.e. self-esteem, personal control, innovation and achievement).

\section{Methodology}

This research-design applied the method of cross sectional survey using questionnaires, which were distributed to the final year business management undergraduate students of Universiti Utara Malaysia. The questionnaires are divided into two (2) parts. Part A consisted of questions that relate to the respondent's background and his/her job experience and entrepreneurial courses or seminar that he/she has attended. While Part B consisted of 75 questions from the Entrepreneur Attitude Orientation (EAO) instrument, which include the main component of attitudes i.e. affective, cognitive, and conative and the sub-scales that are linked to the entrepreneurial attitudes which are the needs for achievement, self-esteem, personal control and innovation. A sample size of 274 respondents using the figure generated by Krejcie and Morgan (1970) was selected from the total population of 960 final year undergraduate business management students based on the stratified random sampling method. This is to ensure adequate representation of 
undergraduates minored in entrepreneurship and non-entrepreneur undergraduates. A total of 130 respondents returned their questionnaires but only $123(44.9 \%)$ of the questionnaires consisting of fifty-eight students minored in entrepreneurship and sixty-five non-minored students are usable. The sample size is excellent, because of the participants viewed this study as a valuable exercise. [Robinson et al. (1991) based their findings on 54 respondents (18\%) out of the 300 questionnaires that being sent].

\subsection{Reliability test result}

To determine the reliability of the responses given by the respondents, a reliability test was conducted to the dependent variable. The result of the test for the Cronbach's alpha value of 0.858 was obtained (Figure 1). This shows that the responses given by the respondents were highly reliable as the Reliability Coefficient is closer to 1 (one).

\subsection{Hypothesis testing}

MANOVA was run to test whether undergraduates minored in entrepreneurship had higher attitude subscale values than business undergraduates who are not minored in entrepreneurship. The predictive value of the four subscales was tested by running a stepwise discriminant analysis using Wilks' lambda to predict entrepreneur graduates and non-entrepreneur graduates based on the four subscales.

\section{Findings and discussions}

A MANOVA test showed a significant overall difference between entrepreneur undergraduates and non-entrepreneur undergraduates for self-esteem subscale in hypothesis $\mathrm{H}_{0} 3\left(\mathrm{~F}_{1},{ }_{121}=97.817, \mathrm{p}<0.05\right)$. The results of the univariate $\mathrm{F}$ tests along with the group means for each of the subscales are shown in Table 1. The findings supported those found by Robinson et al. (1991), where the univariate tests show a highly significance difference between entrepreneur and non-entrepreneur undergraduates for self-esteem and personal control, with the mean for the entrepreneur undergraduates group being higher than that of the non-enterpreneur undergraduates group in personal control.

The predictive value of the four subscales was tested by running a stepwise discriminant analysis using Wilks lambda to predict entrepreneurs and non-entrepreneurs based on the four subscales. One of the four subscales contributed significantly to the discriminant function. Table 2 provides a summary table and classification function coefficients. The subscales that did not contribute significantly to the discriminant function were achievement and innovation. The discriminant function had a lambda $=0.491\left(\chi^{2}=84.597, \mathrm{df}=4, \mathrm{p}<0.05\right)$.

Table 3 shows the classification results. There was $84.6 \%$ accuracy in predicting group membership (entrepreneur undergraduates and non-entrepreneur undergraduates) using the classification function coefficients. It seems likely that self-esteem and personal control were the greatest contributors to the discriminant function because of the operationalization of entrepreneur graduates used in this study (individuals who had to attends entrepreneur courses and having self-esteem to start a businesses). Further research may indicate a need to combine the subscales as the correlations were high enough for the subscales could be combined.

As shown in table 4, kappa is .692. A kappa of .692 indicates a highly moderate accuracy in prediction of the predicted group (non-entrepreneur undergraduates' vs entrepreneur undergraduates'). Kappa ranges in value from -1 to +1 . A value of 1 for kappa indicates perfect prediction, while a value of 0 indicates chance-level prediction (Green \& Salkin, 2005).

\section{Conclusion}

This study showed that the attitude approach to the study of entrepreneurship among the undergraduates minored in entrepreneurship and the non-minor entrepreneurship undergraduates showed a significant difference between them for the four subscales; and when submitted to discriminant analysis, two of the four subscales contributed significantly to the discriminant function. It seems likely that

Further testing using classification function coefficients indicated 84.6 percent accuracy in predicting group membership (entrepreneur undergraduates and non-entrepreneur undergraduates) and 0.692 indicated better than chance-level prediction of the predicted group membership.

\section{References}

Ajzen, I. (1982). On behaving in accordance with one's attitudes. In M.P. Zanna, E.T. Higgins, \& C.P. Herman, (Eds.), Consistency in social behavior: The Ontario symposium (2, pp. 3-15). Hillsdale, NJ: Erlbaum.

Ajzen, I., \& Fishbein, M. (1977). Attitude-behaviour relations: A theoretical analysis and review of empirical research. Psychological Bulletin, 84, 888 - 918.

Aldrich, H. (1980). Asian Shopkeepers as a Middleman Minority: A Study of Small Business. In E. A. Wandsworth, \& D. Eversley, (Eds). The Inner City: Employment and Industry. (pp. 389-407). London: Heinemann. 
Allport, G.W. (1935). Attitudes. In C. Murchison (Ed.), Handbook of Social Psychology, (pp. 798-884). Worchester, MA: Clark University.

Barcelona, A.C., \& Valida, A.C. (1992). Interrelationship between personal variables and entrepreneurial potentials of senior students of Universiti Utara Malaysia. Malaysian Management Review, 29(4), 15-28.

Breckler, S.J. (1983). Validation of affect, behavior and cognition as distinct components of attitude, Dissertation Abstracts International, 44(11B), pp. 3569 (Microfilm No. DA8403491).

Breckler, S.J. (1984). Empirical validation of affect, behavior and cognition as distinct components of attitude. Journal of Personality and Social Psychology, 47, 1191-1205.

Brockhous, R.H. (1982). The Psychology of Entrepreneur, Encyclopedia of entrepreneurship. New Jersey: Prentice Hall.

Buttner, E.H., \& Moore, D.P. (1997). Women's organizational exodus to entrepreneurship: Self-report motivations and correlated with success. Journal of Small Business Management, 35(1), 34 - 46.

Buttner, E.H., \& Rosen, B. (1989). Funding new business ventures: Are decision makers biased against women entrepreneurs? Journal of Business Venturing, 4, 249-261.

Caird, S. (1988a). Review of Methods Of Measuring Enterprise Attributes. Unpublished Paper, Durham University Business School

Caird, S. (1988b). Report On The Development And Validation Of A Measure Of General Enterprising Attitude, Unpublished Paper, Durham University Business School.

Carlson, S.D. (1985). Consistency of attitude components: A new proposal for an old problem, Dissertation Abstract International, 46(09B), 3261 (Microfilm No. AAC8526328).

Chrisman, J.J. (1999). The influence of outsider-Generated knowledge resource on venture creation. Journal of Small Business Management, 37(4), 42 - 58.

Crant, J.M. (1996). The proactive personality scale as a predictor of entrepreneurship intention. Journal of Small Business Management, 34(3), 42 - 49.

Cromie, S., \& O Donoghue, J. (1992). Assessing entrepreneurial attitudes. International Small Business Journal, 10(2), $66-70$.

Green, S.B., \& Salkind, N.J. (2005). Using SPSS for windows and macintosh: Analyzing and understanding data (4th ed.). New Jersey: Pearson Prentice Hall.

Greenberger, D.B., Sexton, D.L. (1998). An interactive model for new venture creation. Journal of Small Business Management, 26 (3), 107-18.

Hatten, T.S., \& Ruhland. S.K. (1995). Student attitude toward entrepreneurship as affected by participation in an SBI program. Journal of Education For Business, 70(4), 224 - 227.

Kothandapani, V. (1971). Validation of feeling, belief and intention to act as three components of attitude and their contribution to prediction of contraceptive behaviour. Journal of Personality and Social Psychology, 19, 321-333.

Krejcie, R.V., \& Morgan, D.W. (1970). Determining sample size for research activities. Educational and Psychological Measurement, 30, 607-610.

Lankard, B.A. (1991). The vocational education / entrepreneurship, ERIC Clearing House On Adult Career and Vocational Education, Digest No. 118

Louis, K.S., Blumenthal, D., Gluck, M.E., \& Stoto, M.A. (1989). Entrepreneur in academe: An exploration of behaviours among life scientist. Administrative Science Quarterly, 34(1), $110-113$.

Mathews, C.H., \& Moser, S.B. (1996). A longitudinal investigation of the impact of family background and gender on interest in small firm ownership. Journal of Small Business Management, 34(2), 29 - 43.

Mazzarol, T., Doss, N., \& Thein, V. (1999). Factors influencing small business start-up. International Journal of Entrepreneur Behaviour and Research, 5(2), 48 - 63.

McClelland, D.C. (1961). The Achieving Society. Princeton NJ: Van Nostrand.

Mohd Noor, M.S., \& Jamal, A. (2005). A study of entrepreneurship inclinations among the board members of the fisher's associations. International Journal of Management \& Entrepreneurship, 1(2), 82-95.

Mohd Noor, M.S., Ooi, Y.K., \& Mohd. Zin, M. (2004). Kecenderungan keusahawanan: Satu kajian empirikal di kalangan tenaga akademik Politeknik-Politeknik Malaysia. International Journal of Management Studies 11 (2), 171-194. 
Naffziger, D.W., Hornby, J.S., \& Kuratko D.F. (1994). A proposed research model of entrepreneurial motivation. Entrepreneurship Theory and Practice, 17(1), 49 - 55.

Roberts, E.B. (1991). Entrepreneur in high technology: Lessons from MIT and beyond. New York: Oxford University Press.

Robinson, P.B., Stimpson, D.V., Huefner, J.C., \& Hunt, H.K. (1991). An attitude approach to the prediction of entrepreneurship. Entrepreneurship Theory \& Practice, Summer, 15(4), 13 - 30.

Ronstadts, R.C. (1985). The educated entrepreneur: A new era of entrepreneurial education beginning. American Journal of Small Business, 10 (1), 7 - 23.

Rosenberg, M.J., \& Hovland, C.I. (1960). Cognitive, affective, and behavioural components of attitudes. In M.J. Rosenberg, C.I. Hovland, W.J. McGuire, R.P. Abelson, \& J.W. Brehm, (Eds.), Attitude organisation and change: An analysis of consistency among attitude components. New Haven, CT: Yale University.

Rychlak, J.F. (1981). Introduction to Personality and Psychotherapy: A Theory-Construction Approach (2nd Ed.). Boston: Houghton Mifflin.

Schere, J. (1982). Tolerance of ambiguity as a discriminating variable between entrepreneurs and managers. Proceedings of the Academy of Management, 42, 404-408.

Scherer, R.F. \& Brodzinski, J.D. (1990). Entrepreneur career selection and gender. A socialization approach. Journal of Small Business Management, 15(4)), 37 - 44.

Shaver, K.G. (1987). Principles of social psychology (3rd ed.). Cambridge, MA: Winthrop.

Storey, D.J. (1982). Entrepreneurship and the New Firm. Beckenham: Kent. 
Table 1. MANOVA analysis of entrepreneur undergraduates and non-entrepreneur undergraduates using the EAO Subscales

\begin{tabular}{|c|c|c|c|c|c|}
\hline \multirow{2}{*}{$\begin{array}{c}\text { Univariate Tests of } \\
\text { Significance }\end{array}$} & \multirow[t]{2}{*}{$\mathbf{F}$} & \multirow[t]{2}{*}{ df } & \multirow[t]{2}{*}{ Sig } & \multicolumn{2}{|c|}{ Group Means } \\
\hline & & & & $\begin{array}{c}\text { Entrepreneur } \\
\text { Undergraduates }\end{array}$ & $\begin{array}{c}\text { Non-entrepreneur } \\
\text { Undergraduates }\end{array}$ \\
\hline Achievement & 0.270 & 1,121 & .604 & 185.91 & 184.01 \\
\hline Self-Esteem & 97.817 & 1,121 & .000 & 33.06 & 54.58 \\
\hline Personal Control & 4.536 & 1,121 & .035 & 58.51 & 55.87 \\
\hline Innovation & 0.300 & 1,121 & .585 & 153.00 & 154.50 \\
\hline
\end{tabular}

$* \mathrm{p}<.05$

Table 2. Stepwise discriminant analysis

\begin{tabular}{|c|c|c|c|c|c|}
\hline \multirow[b]{2}{*}{ Subscale } & \multirow[b]{2}{*}{$\begin{array}{c}\text { F to } \\
\text { remove }\end{array}$} & \multirow[b]{2}{*}{$\begin{array}{c}\text { Wilks' } \\
\text { Lambda }\end{array}$} & \multirow[b]{2}{*}{ Sig } & \multicolumn{2}{|c|}{ Classification Function Coefficient } \\
\hline & & & & $\begin{array}{c}\text { Non-entrepreneur } \\
\text { Undergraduates }\end{array}$ & $\begin{array}{c}\text { Entrepreneur } \\
\text { Undergraduates }\end{array}$ \\
\hline Step 1: Self-Esteem & 97.82 & .553 & .000 & .536 & .373 \\
\hline Step 2: Personal Control & 4.54 & .964 & .035 & -.101 & .102 \\
\hline Step 3: Achievement & .270 & .998 & .604 & .211 & .184 \\
\hline Step 4: Innovation & .300 & .998 & .585 & .549 & .486 \\
\hline (Constant) & & & & -74.259 & -64.072 \\
\hline
\end{tabular}

$* \mathrm{p}<.05$

Table 3. Classification results from discriminant analysis

\begin{tabular}{cccc}
\hline Actual Group & No. of Cases & $\begin{array}{c}\text { Pon-Entrepreneur } \\
\text { undergraduates }\end{array}$ & $\begin{array}{c}\text { Entrepreneur } \\
\text { undergraduates }\end{array}$ \\
\hline Non-Entrepreneur Graduate & 58 & $52(89.7 \%)$ & $6(10.3 \%)$ \\
\hline Entrepreneur Graduate & 65 & $13(20.0 \%)$ & $52(80.0 \%)$ \\
\hline
\end{tabular}

Percent of cases correctly classified: $84.6 \%$

Table 4. Results of kappa analysis

\begin{tabular}{cccccc}
\hline & & Value & $\begin{array}{c}\text { Asymp. } \\
\text { Std. Error }\end{array}$ & Approx. T & Approx. Sig \\
Measure of Agreement & Kappa & .692 & 0.065 & 7.725 & .000 \\
N of Valid Cases & 123 & & & \\
\hline
\end{tabular}

\begin{tabular}{|l|}
\hline Reliability Coefficients \\
$\mathrm{N}$ of Cases $=123$
\end{tabular}

Figure 1. Test result of the reliability analysis of the responses

Source: Adopted from Robinson et al. (1991), Table 1, and p. 22. 


\title{
The Change of Financial Environment and
}

\section{the Evolvement of Financial Goals}

\author{
Jianhui Jian \\ North China Electric Power University, Beijing 102206, China \\ Zhongnan University of Economics \& Law, Wuhan 430060, China \\ E-mail: jianjianhui4894@sina.com
}

\begin{abstract}
With the changing financial environment, financial goals are constantly changing. In the course of development of financial theory, there were numerous financial goals theories, which are mainly "profit maximization, shareholders' wealth maximization, and stakeholders' wealth maximization." These financial goals basically reflect the business requirements of the market environment, the adaptation to the changing financial environment, and also reflect the different preferences of the different periods of property rights.
\end{abstract}

Keywords: Financial goals, Profit maximum, Interests of shareholders

\section{Introduction}

The financial goal of enterprise is the aim that the enterprise should achieve in the capital movement and the process of dealing with the economic stakeholder relationship. For the financial environment, the main composing factors of the corporate financial environment include the political factor, economic factor, legal factor and science-technology education factor. For all enterprises, their exterior financial environments are different. As viewed from the enterprise financing, the economic factor is the most influencing factor, which directly or indirectly influence the financial management of the enterprise, and provide a perfect exterior market for the enterprise, i.e. the capital market. The management of the enterprise is influenced and restricted by the financial environment, and the financial goal of the enterprise will change with the change of the financial environment.

Because of the core status in the financial researches, the financial goal can connect with the theory and practice. And the bridge functions of the enterprise interior management and exterior management are largely concerned in the history of financial researches, and the researches about the financial management goal developed from simple goal to complex goal, from single goal to multiple goals, from emphasizing short-term profits of the enterprise to emphasizing long-term sustainable harmonious development, from emphasizing the owners' benefits to emphasizing the development with multiple benefits such as the enterprise, the society and various stakeholders. For the dispute of financial goal, there is not a uniform opinion, and many factors such as the cultural background, political and legal environment, the productivity level and the interior governance structure of the enterprise will induce the change of the financial goal of the enterprise, which is not only from the limitation of the financial goal in the original cognition process, but also from the change of property relations (Yang Ruilong, Nie Huihua, 2006). In the development process of financial theory, there were numerous theories about the financial goal, and these opinions mainly included "the profit maximization, the shareholder fortune maximization and the stakeholder fortune maximization". These financial goals basically reflect the requirements of the enterprise to the market environment, and for the adaptivity of the finical environment change, these financial goals also embody the different preferences or property interests in different terms.

The evolvement course of the financial goal of enterprise is not single, and it is complex and changeable. There is not one sort of financial goal in one term, but there are different interests to be intermixed. But of course, in one term, there will be one sort of current tendency, and with the development of the time and the social economy, the variance of financial environment, the interest direction of the financial goal will be on speaking terms, and both of them will influence and drive each other.

\section{The financial goal of the profit maximization}

The financial goal of the enterprise first occurred before the First World War, and according to Adam Smith, David Richard and Marshall's economic theories, the financial goal of the profit maximization was the traditional point of view in western economic academy, and the point of view thought that the enterprise was the economic organization which took the payoff as the aim, and the profit creation was the necessary condition for the survival and development 
of the enterprise.

The financial goal of maximum profit is scientific, because the profit presents the contribution of the enterprise, but this goal doesn't reflect the time to acquire the anticipated profit, the proportion between the profit and the investment capital, and it doesn't consider necessary risk factor, which will induce short-term enterprise behaviors. With the process of time and the continual development of the market, after the Second World War, the west financial theory gradually turned to pay attention to the reasonable distribution of enterprise capitals and the function under the condition of the effective capital market, and the distribution of resources among various sorts of assets. And the measurement of the profit was turned into the maximization of the present value, and the net present value of the various investment projects of one enterprise was most, the net profit of the enterprise would be most. Because the goal of net present value maximization considers the time value of the coin, it will better than the goal of profit maximization, and it still doesn't consider the risk factor and the deficiency of the investment capital. The above opinion about the present value maximization is another thinking mode of the enterprise profit, and there is not essential change. But it is obviously limited to take the profit maximization as the financial goal. First, to take the profit gross as the financial goal ignores the relation between the investment and the output. As the final management result of the enterprise, the profit is the net output in the process of production and management, and if it is not compared with the capital investment, we can not judge the investment benefits. Second, the financial goal of profit maximization doesn't consider the relation between income and risk. Generally speaking, the income is positively proportional with the risk. It is not reliable for the financial goal without risk consciousness, which will induce that the enterprise pursues unilaterally the maximum profit without considering the size of the risk. More importantly, it will easily ignore the social responsibility and induce the short-term enterprise behaviors. The profit maximization may make the enterprise scarify the social resources to exchange the payoff and induce the short-term enterprise behaviors (Zhang Maoyan, 2005).

\section{The financial goal of shareholder benefit first}

The Second Industrial Revolution in the later of the 19th century not only largely drove the course of human civilization, but also brought very important opportunity for the development of the corporate system. With the separation between the property and the management right, the profit maximization has not been the reasonable noun to describe the goal of the enterprise, and human eyes have gradually turned to the shareholders' benefits.

Through many forms such as stock and bond, the extension of the enterprise scale and the increase of the shareholder number make the ownership structure highly decentralized, and as the owner of the enterprise, the shareholders are gradually far from the management of the enterprise. Berle and Means found that the property and the control right begun to separate in these companies, and modern companies had been controlled from the "owners" to the "managers". Under this background, it is very necessary to emphasize the shareholders' benefits and realize the supervision to the managers, and the view of "shareholder benefit first" was formed in this term. Therefore, with the increasing perfection and maturation of the shareholder system, the respect of the financial goal is turned from the profit of the enterprise to the benefit of the shareholder, and the basic opinion of the shareholder value tropism is that the company is owned by the shareholders and the director is the assignee of the shareholder, and its first task and main responsibility are to create values for shareholders and ensure the benefit of the shareholder is the final respect of the company (Li Huaian, 2005). In 1930s, the emphasis of the US public policy is to protect the benefit of the shareholders. The "Stock Act" of 1993 and the "Securities Act" of 1934 were to take the protection of shareholder benefit as the final aim. In the first 30 years of the 20th century, the "shareholder benefit first" had been the standard cognized by the company theory, the legal system and the public policy together.

With the development of time, in the theory of "shareholder benefit first", the financial goal gradually develops to the stock price maximization which became into the financial goal recognized by western enterprises. The market value considers not only the risk character of the company, but also the present and potential EPS, bonus quantity and the anticipation of time. But the deficiency of the stock price maximization is that the stock price is the objective evaluation for the participators in the enterprise exterior capital market, and it is their opinions about the enterprise managers represent stockholders to finance and exert the operations, and it possesses large uncertainty especially under the premise of the imperfect capital market. In 1980s, many companies proposed the financial goal to make the shareholders' fortune maximum. It not only includes the maximization of the stock price, but also reflects the exterior objective evaluation of the enterprise, eliminates all risks and uncertain factors, which can promote the reasonable flow of the social resource. But the opinion still takes the shareholder as the core, and it can not fairly consider the objective need of other property bodies.

So far, the stockholder benefit oriented corporate value concept is still the mainstream concept for the economics, management science and corporate law, but in recent years, the critical opinions from various aspects are more and more. The main critical opinions include following aspects. First, many people thought that the concept of the stockholder value tropism was not responsible as viewed from the sociology and the economics, and it also doesn't accord with the principle of commercial morality, but it ignores the importance of the stakeholders, and these 
stakeholders include enterprise employees, clients, the community and the environment of the company, and even shareholders' long-term interests. Even in the extremely free market economy such as US market, many people thought it was too narrow and marble to simply pursue shareholder values (Jensen, 2001). Second, the corporate value view of shareholder orientation excludes other stakeholders' benefits except for the shareholders from the goal of the company, which not only runs in the opposite direction with the theory about strengthening the social responsibility of the company, but its theory can not justify itself (Liu Junhai, 1999). Finally, the corporate value view of the shareholder orientation has not adapted with the developments of the society and the economy, and the variance of the corporate management environment. The basic premise confirmed by the shareholder value orientation includes that the main responsibility of the directors is responsible for the shareholders, and the shareholders are the absolute managers for the corporate responsibility and control right. This opinion was first generated in the early capitalism society, and at that time, the individuals as the investors and the companies as the invested objects had direct relations, and human possessed the real senses as the shareholders of the company. But at present, the situation is different, the company influences the group which is bigger than the range of the shareholder, and it is also influenced by the group, and every core of the company is the relation net of stakeholders, and the every relation net is established on the mutual dependences.

\section{Fortune maximization for stakeholders}

The economic crisis from 1929 to 1933 was another turning point in the US and world economic history. The Great Depression brought serious social costs, and people begun to reevaluate the value of the company and the opinion of the shareholder benefit maximization. But with the continual extension of the company scale and the capital, a series of social conflicts such as polarization between the rich and the poor, the social impoverishment, the labor problem and the labor and capital conflict are generated. Some scholars begin to discuss the social responsibility of the company on the moral layer aiming at a serious of problem in the management of the company. So the concept of the stakeholder enters into the historical stage.

Aiming at the Berle's opinion about the shareholder benefit first, Dodd put forward that the social responsibility of the company was the base of the citizen status in 1995 . He thought that since the company is regarded as the independence "juridical person", it should assume citizen's responsibility, i.e. the corporate management layer should not only assume the "fiduciary responsibilities" for shareholders, but perform the citizen responsibility of the company as the assignee of the "company electorates", though that might induce the decrease of the shareholder value. In 1960s to 1970s, the concern to the stakeholders in the management had been a sort of popular opinion, and the consumer dominion movement, the environment protection and other social movements had produced large influences, and the company begun to care about the employees, the community and the public business, and the concept of "social responsibility" had been carried out. For the legislation system, US begun leaning to stakeholders from shareholders, and issued many acts to protect stakeholders. In this term, the concern and protection about stakeholders could largely relax the social conflicts intensified by the Great Depression and the Second World War, and it was also the necessary result of the evolvement of the corporate management concept. The protection for the employees, the consumers and the natural environment embodied the social advancement, and it was a sort of reasonable modification to simply emphasize shareholders' benefits, and it further influenced the opinion of the social responsibility of the company.

The stakeholder means various personnel and organizations in the management of the company which can become into the undertakers of the risks and the sharers of the benefits. This shows that the shareholders, the creditors, the employees, the suppliers, the consumers, the communities, relative groups, social organizations and the government all can be regarded as the stakeholders of the company, and obviously, the range of the stakeholder is broad. US scholar Clarkson thought that "stakeholders are natural persons or social groups which take or claim the property, the right or the benefits in the past, present or future activities of the company", and Clarkson further classified the stakeholders of the company into two sorts, i.e. the primary stakeholder and the secondary stakeholder. The primary stakeholder means the indispensable persons for the survival of the company, and it includes the owners, the clients, the employees, the communities, the government, and even the suppliers and the creditors. The secondary stakeholder includes other organizations and individuals which have little relations with the survival of the company, but the management of the company will influence their benefits. The secondary stakeholders include relative environment activists, media, scholars, critics, trade organizations, and even competitors. The so-called "stakeholders" means "the property subjects which can create fortunes for the enterprise through special assets investment". The governance of "stakeholder" makes all property subjects which have created fortunes for the company through the investments of the special assets to participate in the organizational mechanism, the decision control mechanism and the benefit distribution mechanism for the company. US economist Coase put forward the "enterprise contract theory", and defined the enterprise as "the business of the production agents, i.e. the long-term authorized contract relation between the labor and the capitals", so more scholars begun to understand the company as the combination of a series of contracts among the material capital owners, the human capital owners, creditors and other stakeholders, i.e. the individuals and organizations with different capitals could distribute their own responsibilities, rights and benefits through the negotiation, and the result of the 
negotiation was the promissory enterprise contract. So the company is not the benefit subject belonging to one shareholder, and the creditors and shareholders invest material capitals. The managers and employees are the investors of the human capitals, and the consumers and communities invest social capitals (reputation assets). As the contractor, the enterprise participators all possess the benefit claim rights for the enterprise factors invested by them, and this sort of benefit can be presented by the economic form or the non-economic form (Li Xinhe, 2004).

Under modern market economic conditions, the goal of the enterprise is not only to pursue the benefit maximization of the capital for owners, and the enterprise is the sum of multilateral contract relations, or the "contract network" composed by the human capital and material capital, and the equality and the independence of the contract contained in the benefit subjects require that the subjects of the corporate management structure should be equal and independent. These subjects associated each other include shareholders, creditors, managers, producers, consumers, suppliers and other relative benefit subjects, which compose the stakeholders, but the efficiency of the enterprise should be established on the equality of stakeholders. Under this new corporate governance logic, the enterprise should emphasize not only shareholders' benefits, but also other stakeholders' actual participations. Concretely speaking, there should be stakeholder representatives except for the shareholders in the directorate and the board of supervisors (such as the employee representative, the creditor representative) to exert the function of stakeholders. The shareholders' benefit should not be regarded as the most important thing, and it should be one party in the stakeholder network. The company is a benefit relation network, and various factors in every relation network should base on interaction, and the managers of the company in the company governance should not only try to realize shareholders' benefits, but also consider other stakeholders' benefits. After 1980s, many countries begun to regulate that the manager take charge for stakeholders except for shareholders in the company law, i.e. they wanted to establish a sort of corporate governance mode about "stakeholders".

\section{References}

Dodd. (1995). A Stakeholder Framework for Analyzing and evaluating Corporate Social Performance. Academy of Management Review.

Li, Huaian. (2005). Corporate Social Responsibility: From Concept to Practice. Nankai Management Review (in Chinese), 10: 73-74.

Li, Xinhe. (2004). The Choices of Company Values and its Evolution Trend. Accounting Research (in Chinese), 10:132-142.

Liu, Junhai. (2002). Corporate Social Responsibility. Law Press, pp. 30-31.

Michael C. Jensen. (2001). Value Maximization, Stakeholder Theory, and the Corporate Objective Function. The Monitor Group and Harvard Business School, 10.

Yang, Ruilong \& Nei, Huihua. (2006). Incomplete Contract Theory: A Summary. Economic Research (in Chinese), 2: 55-59.

Zhang, Maoyan. (2005). The Choice of the Best Financial Targets from the Evolution of Corporate Financial Goals. Business Management, 10:103-107. 


\title{
An Investigation of Consumer Decision-Making Styles of Young-Adults in Malaysia
}

\author{
Safiek Mokhlis \\ Faculty of Management and Economics, Universiti Malaysia Terengganu \\ 21030 Kuala Terengganu, Malaysia \\ Tel: 60-9-6683-164 E-mail: safiek@umt.edu.my
}

\begin{abstract}
The purpose of this exploratory study was to investigate the consumer decision-making styles of young-adults in Malaysia. Exploratory factor analysis was conducted to determine the dimensions considered by young-adults in their transactions in the market. Seven reliable factors and their corresponding decision-making styles were identified: Novelty, Brand Conscious Consumer; Perfectionistic, High-Quality Conscious Consumer; Confused by Overchoice; Recreational, Hedonistic Consumer; Impulsive, Careless Consumer; Variety-Seeking and Habitual, Brand-Loyal. Comparison was made with other studies to identify differences and similarities of consumer style factor structures across different countries.
\end{abstract}

Keywords: Consumer decision-making styles, Young-adults, Malaysia

\section{Introduction}

Young-adult consumers provide an interesting topic for the consumer research for at least four reasons (Grant and Waite, 2003). First, at the period of transition from adolescence to early adulthood, the young people seek to establish their own individual personas and form behaviour patterns, attitudes, and values, hence their own consumption patterns. They make purchases to define themselves and to create an identity of their own making (Holbrook and Schindler, 1989). Many of these patterns are carried well into individual's lifetimes (Moschis, 1987). Secondly, young people are able to influence the purchase and decision-making of others (Grant and Waite, 2003). Thirdly, they act as a change agent by influencing society and culture (Leslie et al. 2001). And finally, from a marketing perspective, young adults are recognised as a specialised market segment that forms a powerful consumer spending group in their own way (Moschis, 1987; Grant and Waite, 2003).

One specific group of young-adult population in Malaysia that represents the most lucrative market segment is college students. Despite the fact that the majority of college students are unemployed and their 'earning' comes mainly from educational loans and parental contributions, college students represent an extremely large and important market segment for many products and services. They are seen as a lucrative market since they have higher than average lifetime earnings and are just beginning a major transition period which is a key time to change previous behaviours (Warwick and Mansfield, 2000). Marketers are keen to target this group because they perceive them as potential loyal customers both currently and in the future (Feldman, 1999; Speer, 1998).

The rapid growth of college student population in Malaysia over the past two decades has been largely attributable to the government policy of expanding the tertiary education facilities through public as well as private institutions (Government of Malaysia, 2006). With the expansion of tertiary educational services, which resulted in the establishment of 20 public universities and many more private colleges, the number of students in further and higher education has been increasing steadily over the years. Recent statistics showed that the number of students entering local public universities for undergraduate studies rose dramatically from 29,962 in 2001 to 58,304 in 2006 - a 95 per cent increase within a five year period (Ministry of Higher Education, 2007). The government policy to have at least $35 \%$ of the labor force with tertiary education should see this growth continue in the future (Government of Malaysia, 2001).

While this segment is a potentially lucrative target for many marketers, it is also complex and must be examined carefully. One aspect of consumer behaviour of college students that deserve investigation is their decision-making styles. In this context, the Consumer Style Inventory (CSI) developed by Sproles and Kendall (1986) provides a potentially useful instrument to assist marketers in examining consumer decision-making styles. According to Sproles 
and Kendall (1986, p. 267), identification of decision-making styles among consumers "helps to profile an individual consumer style, educate consumers about their specific decision-making characteristics, and counsel families on financial management."

Since its introduction, the CSI has been tested using various nationalities - Americans (Sproles and Kendall, 1986; Lysonski et al. 1996), Koreans (Hafstrom et al. 1992), Chinese (Fan et al. 1997; Fan and Xiao, 1998; Hiu et al. 2001; Siu et al. 2001), New Zealanders (Durvasula et al. 1993; Lysonski et al. 1996), Greek (Lysonski et al. 1996), Indians (Lysonski et al. 1996; Canabal, 2001; Patel, 2008), Germans (Walsh et al. 2001; Walsh and Vincent, 2001), British (Mitchell and Bates, 1998), South African (Radder et al. 2006) and Turkish (Gonen and Ozmete, 2006; Kavas and Yesilada, 2007). Although these studies have shown that the CSI has a potential utility across international populations, there is not much known about the decision-making styles of young consumers in other Asian countries such as Malaysia. It is not clear yet if young Malaysian consumers follow the same behavioural patterns identified for other consumers in Asia and the United States or if they exhibit unique characteristics when confronting choices in the market. Therefore, this study takes a pioneering role in applying the scale to young-adult consumers in Malaysia.

This study has attempted to serve three purposes: (1) to examine the cross-cultural applicability of the CSI in Malaysia; (2) to identify the decision-making styles of the college students in Malaysia and (3) to compare the identified styles with the results of previous studies.

The remainder of this paper is divided into five sections. The next section provides an overview of Malaysia, the context of the study. This is followed by a brief review of past studies, research methodology, empirical results and concluding remarks.

\section{The Malaysian Context}

The landscape of the global economy has changed dramatically as Southeast Asia and other regions have taken an expanded role. Recent widespread economic in stability sparked by concerns about the purchasing power of Southeast Asian consumers illustrates the extent to which some of these once-small markets such as Malaysia have now become important players. Described as "Asia'a Tiger with a Vision" (Selvarajah, 1993), Malaysia is presently classified as an upper-middle income county and considered as one of the most developed of the developing countries.

Despite the challenging external environment, particularly during Asian financial crisis from 1997 to 1998, Malaysia generated an average Gross Domestic Product (GDP) growth of 6.2 per cent per annum from 1991 to 2005 . This growth more than doubled average household income from MYR1.169 per month in 1990 to MYR3,249 a month in 2004 (Government of Malaysia, 2006).

The retailing industry represents a significant part of the domestic economy. The rise of consumerism, increased urbanisation, higher disposable incomes, a rapidly rising population, a growth in consumption credit, a reduction in import duties and an influx of foreign investment and retailers have led to a dramatic expansion of the Malaysian retail industry. The sector recorded an average annual growth rate of 5.2 per cent in total sales from MYR159.6 billion in 2000 to MYR205.6 billion in 2005. By the end of 2005, the contribution of trade distributive sector to GDP increased from MYR26.8 billion in 2000 to MYR33.1 billion (Government of Malaysia, 2006). By this standard, the retail industry in Malaysia is expected to grow at an average rate of 6.8 annually and is anticipated to continue to be a prominent economic activity in the country.

In tune with the Government's aim to establish Malaysia as a prime regional shopping destination, many new shopping areas have been designated and many shopping campaigns and carnivals were launched to attract shoppers from local and abroad. The number of shopping complexes increased from 392 in 2000 to 550 in 2005. The number of shop units, being an integral feature of most housing developments as well as new and established townships, expanded at an average annual rate of 4.2 per cent (Government of Malaysia, 2006). Among the notable impacts of this development is that Malaysian consumers are increasingly exposed to and are selecting from a wider range of products, brands, quality and prices than ever before, thus increasing their confusion and need for consumer education. With the emergence of e-commerce, the complexity of decision making intensifies further. The business to consumer (B2C) e-commerce spending registered an increase from RM3.4 billion in 2000 to RM7.4 billion in 2005, as more companies and businesses offered their services direct to consumers through online transactions (Government of Malaysia, 2006).

Considering the scenario discussed above, consumer decision-making is of great interest for marketers and consumer educators interested in serving the consumer (Canabal, 2002). In order to develop the appropriate marketing strategies, the decision-making styles of consumers should be investigated thoroughly, keeping in mind the unique characteristics of the target consumers. The present study attempts to identify the decision making styles of young-adults in Malaysia, with an explicit focus on one homogeneous population - college students.

\section{Consumer decision-making styles}

A consumer decision-making style is defined as "a patterned, mental, cognitive orientation towards shopping and 
purchasing, which constantly dominates the consumer's choices. [... ] these traits are ever-present, predictable, central driving forces in decision-making. In essence we are speaking of a relatively enduring consumer personality, analogous to the more general concept of human personality in psychology" (Sproles, 1985, p. 79).

The examination on decision-making construct can be categorised into three major approaches: the psychographic/lifestyle approach (e.g., Wells, 1974), the consumer typology approach (e.g., Kenson, 1999; Ownbey and Horridge, 1997; Shim and Kotsiopulos, 1993) and the consumer characteristics approach (Sproles and Sproles, 1990; Walsh et al. 2001). Among these three approaches, the consumer characteristics approach has been widely acknowledged by consumer researchers as the most explanatory and powerful construct because it focuses on a cognitive and affective aspect of consumer behaviour. This approach deals with consumer's general predisposition toward the act of shopping and describing mental orientation of consumers in their decision-making process (Lysonski et al., 1996).

Based on examination of types of consumer decision-making styles in the previous literature, Sproles (1985) has identified 50 items related to consumers' cognitive and affective orientation towards shopping and buying. The author believes that measuring consumers' general orientations toward shopping and buying can identify their decision-making styles. The underlying assumption is that all consumers are thought to approach the market with certain fundamental decision-making orientations.

Sproles and Kendall (1986) have refined this inventory and accordingly developed a more parsimonious scale consisting of 40 items. The Consumer Style Inventory (CSI) that they have developed consists of eight mental characteristics of consumer decision-making styles namely: 1) perfectionistic and high-quality conscious; 2) brand conscious and price equals quality; 3 ) novelty and fashion-conscious; 4) recreational and hedonistic; 5) price conscious and value for money; 6) impulsive and careless; 7) confused by overchoice and 8) habitual and brand-loyal.

In an attempt to get a better understanding of consumer decision-making processes across different cultures, the CSI has been tested and validated in several countries. Hafstrom et al. (1992) examined the cross-cultural applicability of the CSI developed by Sproles and Kendall (1986) using a sample of Korean students. They found that five of the styles, Brand Consciousness, Quality Consciousness, Recreational Shopping Consciousness, Impulsiveness, and Confused-by-Overchoice, are common in both Korean and U.S. cultures. An additional factor of Time/Energy Conserving was suggested.

Durvasula et al. (1993) confirmed a high level of reliability and validity of the scale via the use of a sample of 210 undergraduate students in New Zealand. Lysonski et al. (1996) further investigated the cross-cultural applicability of the CSI using multi-country samples from India, Greece, U.S and New Zealand. While the CSI inventory received some support from these four different samples, the researchers noticed that the inventory appears to be more applicable to the economically developed countries (U.S. and New Zealand) than to the economically developing countries (India and Greece). More recently, some researchers attempted to adopt the CSI to profiles decision-making styles of consumers in China (Fan and Xio, 1998; Fan et al. 1997; Hiu et al. 2001; Siu et al. 2001), India (Canabal, 2002; Patel, 2008), United Kingdom (Mitchell and Bates, 1998), Germany (Walsh et al. 2001; Walsh and Vincent, 2001), South Africa (Radder et al. 2006) and Turkey (Gonen and Ozmete, 2006; Kavas and Yesilada, 2007).

There is a general consensus among researchers that decision-making styles can vary across cultures. Thus, CSI in its original form cannot be generalised to different countries without some modification. Rosenthal and Rosnow (quoted in Walsh et al. 2001) suggest that a study needs to be replicated at least fifteen times before results can be generalised, indicating that additional work on the CSI is necessary. Sproles and Kendall (1986) recommended using the inventory with different population groups to determine the generality of its applicability. The study reported in this article responds to these calls and extends the research stream into Malaysia. This study has attempted to serve three purposes: (1) to examine the cross-cultural applicability of the CSI in Malaysia; (2) to identify the decision-making styles of the college students in Malaysia and (3) to compare the identified styles with the results of previous studies.

\section{Methodology}

\subsection{The questionnaire}

A structured questionnaire was prepared for use in the survey based on literature review and objectives of the study. Consumer decision-making orientations were measured using the 40-items of Consumer Style Inventory (CSI), developed by Sproles and Kendall (1986). All scales were measured on a 5-point Likert-type scales ranging from strongly disagree to strongly agree. The reliabilities of the CSI Scale, according to Sproles and Kendall (1986), ranged from 0.48 to 0.76 . Scale items were translated into Malay language with minor changes in wording to clarify the meaning. Demographic items were related to (a) gender, (b) age, (c) residence and (d) state of origin.

To determine the potential effectiveness of the questionnaire, the researcher distributed the questionnaire to 20 undergraduate students. The test found no serious problems and minor amendments were made to the survey questions based on the verbal feedback received. The final result of the pilot test finally indicated that the questions had face validity. 


\subsection{Sampling and data collection}

The sample for the study comprised of traditional undergraduate students from one public university at the northeast of Malaysia, majoring in management and economics studies. Given the nature of the study, a non-probability (convenience) sampling was chosen. To provide an adequate level of confidence in this study, 450 respondents were selected for the survey.

The survey was taken in a controlled classroom environment; allowing for a stronger research design. Specifically, the researcher read a standard set of instructions to the class, informing them of the survey purpose and conditions and encouraged their participation in the study. Students were assured of the confidentiality of their responses and their names were not solicited. No inducements were offered to encourage the students to participate, although virtually all of the students who were asked did cooperate in the study. Students were given approximately 20 minutes to complete the questionnaire. Students were prevented from communicating with each other while the survey was in progress.

Of 442 returned questionnaires, a total of 419 responses deemed valid for data analysis, yielding a response rate of 94.8 percent. Such a response rate was considered sufficient for statistical reliability and generalisability (Tabachnick and Fidell, 2001) and most satisfactory especially when compared with previous research works on consumer decision making styles (e.g. Hafstrom et al. 1992; Durvasula et al. 1993; Lysonski et al. 1996; Canabal, 2001). This relatively high response rate was attributed to the self-administered approach undertaken in distributing the questionnaires.

The sample had a mean age of 21.9 years and consisted of 29.8 percent male and 70.2 percent female. The students were from different regions with diverse backgrounds ranging from urban to rural which also reflect their differences in socioeconomic status.

\subsection{Analysis}

The data were entered into the computer for statistical analysis with the application of the SPSS computer program. The first step in analyzing the data was to identify the salient items that explain the correlations among a set of variables. For this purpose, factor analysis with principal component method was conducted on decision-making style scale items. Factoring ceased when all eigenvalues of greater than one were obtained and when a set of factors explained a large percentage of the total variance was achieved. Bartlett test of sphericity was run to test the assumption that the variables are uncorrelated in the population. To test the appropriateness of factor analysis, Keiser-Meyer-Olkin (KMO) measure of sampling adequacy was assessed while the factor analysis was run. An accepted method of interpretation of factor loadings is to regard as significant any variable with a loading of 0.5 or greater as associated with the appropriate factor.

To assess the internal consistency of each factor group obtained, a reliability analysis was carried out. The assumption behind this approach is that the items of a measure work together as a set and should be capable of independently measuring the same construct. The items should be consistent in what they indicate about the concept being measured. The Cronbach alpha was used to measure internal reliability by unit weighting items with salient loadings in a factor where Cronbach's alpha coefficient at 0.4 or higher was considered acceptable (Sproles and Kendall, 1986).

\section{Results and interpretation}

The purpose of factor analyzing the 40-item inventory was to determine if the factors identified by previous researchers were common to the Malaysian sample. As a result of factor analysis, 28 items were retained in this study. Table 1 presents the results of an eight-factor solution for consumer decision-making style items. Factors are named in line with Sproles and Kendall (1986) when they reflect similar decision-making styles between U.S. and Malaysian consumers. Each factor consists of at least two items, indicating that the scales are multidimensional scales as opposed to unidimensional scale where all items would be loaded on just one factor.

The factor analysis shows that the items included in the questionnaire can be grouped in eight factors with eigenvalues ranging from 1.2 to 6.54 (see Table 1). Bartlett's test of sphericity is significant and the value of KMO statistic $(0.831)$ is also large $(\mathrm{p}<0.0001)$. Thus, factor analysis can be considered appropriate. However, the reliability analysis shows that factor 8 cannot be considered a reliable factor in the identification of decision-making styles of young Malaysian consumers (Alpha $<0.4$ ). The seven factor model explained $44.4 \%$ of the variance in the correlation matrix compared to $35 \%$ in Canabal (2002) and Fan and Xiao (1998), 47\% in Hafstrom et al. (1992), and 46\% in Sproles and Kendall (1986) for Indian, Chinese, Korean, and United States young consumers respectively.

\subsection{Interpretation of the factors}

Factor 1: With a combination of brand name, fashion and price as the important purchasing criteria, this factor can be conceptually named as Novelty, Brand Conscious consumer. Item loading on this factor indicates that consumers who score high on this factor are likely to buy best-selling and well-known brands that are the latest in style and expensive at nice department and specialty stores. They are also feels that highly advertised brands are very good choices. They believe that a product sold at a higher price means better quality. A Cronbach's alpha of 0.83 for this factor is considered as highly reliable. 
Factor 2: This factor depicts the characteristics of a consumer as Perfectionistic, High-Quality Conscious. Characteristics identified in this factor are a consumer who particularly concern in seeking high-quality products, to get the best value for money, tends to watch his/her spending and set a high standard of expectation for products. This factor is considered reliable with an alpha coefficient of 0.67 .

Factor 3: This factor implies a Confused by Overchoice consumer characteristic. High scorers on this characteristic perceive many brands and stores from which to choose from and the amount of information available to them about different products adds to confusion. As they experience information overload, they always get into trouble when making choices. This factor is considered reliable with an alpha of 0.59 .

Factor 4: This measure describes the consumer as Recreational, Hedonistic Conscious. Those scoring high on this dimension found shopping as an enjoyable and pleasant activity as they do not feel shopping wastes their time. In addition, they are gain excitement from shopping task by buying something new. This factor is accepted to be reliable with an alpha value of 0.65 .

Factor 5: This factor appears to measure a consumer style labeled as Impulsive, Careless Consumer. Consumers who score high on this factor tend to buy on the spur of the moment and later regret their impulsive behaviour. They are also unconcerned about getting best products by shopping quickly as they could. An alpha of 0.65 indicates that this factor is reliable.

Factor 6: This is a description of a consumer consciousness in seeking variation when making choice decision. Consumers with this characteristic tend to shop at different stores and change brands they buy regularly. This factor identifies a Variety-Seeking Consumer characteristic and is marginally reliable (0.42).

Factor 7: This factor measures Habitual, Brand-Loyal Consumer style. High scorers on this factor can be characterized as consumers who have favourite brands and stores and have formed habits by choosing them repetitively. Those scoring high identified themselves as consumers with strong feelings of loyalty by sticking to a favourite brand. This factor is considered reliable with an alpha of 0.52 .

\subsection{Comparison with other studies}

In this section, the results of this study are compared with the results of four selected previous studies: Sproles and Kendall (1986), Hafstrom et al. (1992), Canabal (2001) and Fan and Xio (1998). The "Brand Conscious" style is number one in the list of factors for the present study, the Korean, the Chinese and the Indian samples and second for the U.S. sample (see Table 2). The "Perfectionists" or "High-Quality Conscious" consumer is also identified among the top three factors for all four samples. However, a factor such as "Confused by Overchoice" is relatively more common among the Malaysian and Indian samples than it is for the Korean, the Chinese or the U.S. samples. It should be noted that for the Chinese sample (Fan and Xiao, 1998), the components of the "Confused by Overchoice" are similar to what the authors identified as "Information Utilization" style. Furthermore, it seems that the "Price-Value Conscious" style is more important for U.S. and Chinese samples than for Indians and Koreans as a factor. This factor however was not found in the present study.

The "Fashion Conscious" style, reported for U.S. consumers by Sproles and Kendall (1986) and not found by Hafstrom et al. (1992) for the Korean students and by Fan and Xio (1998) for the Chinese students, loaded some of the items in the "Novelty, Brand Conscious" style for the Malaysian sample. It could be interpreted that young Malaysian consumers who are fashion conscious derive pleasure from buying well-known brands that are the latest in style and expensive at nice department and specialty stores. Also identified for the Malaysian sample was a style labeled "Time-Energy Conserving" similar to the one found in Korean consumers but with different item loadings. However, as with the Korean sample, this factor was not considered a reliable scale. Clearly, additional research is needed on the interrelation of these styles.

\section{Concluding remarks}

This study investigates the applicability of the CSI to the Malaysian culture by examining its factor structure, validity and reliability. Seven reliable factors of consumer decision-making styles were identified in this study: Novelty, Brand Conscious Consumer; Perfectionistic, High-Quality Conscious Consumer; Confused by Overchoice; Recreational, Hedonistic Conscious Consumer; Impulsive, Careless Consumer; Variety-Seeking and Habitual, Brand-Loyal. Overall results of this study compare favourably to those of the Sproles and Kendall's (1986) original study and have provided a general support to the inventory. The most important finding is that there is an indication of the generality of several consumer decision-making styles of young U.S. and Malaysian consumers. Given this finding, there is reason for cautious optimism that the CSI has elements of construct validity and has potential use across international populations. The implication is that the inventory is a suitable device to be used in understanding the behaviour of young consumers in Malaysia.

Comparing decision-making styles of consumers from different countries contributes to the understanding of the effect 
of the market environment as well as cultural factors impacting on consumer decision-making styles (Fan and Xiao, 1997). This study has made the first attempt to apply the CSI to the college students in Malaysia. The cross-cultural examination reinforces the inventory as a universal theory in the area of decision-making style. Moreover, it provides information to marketers interested in the decision-making profile of young-adult consumers in Malaysia so that they may gear their efforts accordingly.

\section{References}

Canabal, M. E. (2001). Decision Making Styles of Young South Indian Consumers: An Exploratory Study. College Student Journal, 36 (1), 12-19.

Durvasula, S., Lysonski, S. \& Andrews, J. C. (1993). Cross-Cultural Generalizability of a Scale for Profiling Consumers' Decision-Making Styles. Journal of Consumer Affairs, 27 (1), 55-65.

Fan, J. X. \& Xio, J. J. (1998). Consumer Decision-Making Styles of Young-Adult Chinese, Journal of Consumer Affairs, 32 (2), 275-294.

Fan, J. X., Xio, J. J. \& Xu, Y. (1997). Decision-Making Styles of Young-Adult Chinese Consumers: An International Comparison. Consumer Interests Annual, 43, 76-82.

Feldman, J. (1999). Back-to-school buying guide. Money, 28 (9), 165-168.

Gonen, E. \& Osemete, E. (2006). Decision-Making Styles of Young Turkish Consumers, Journal of the Home Economics Institute of Australia, 13 (1), 26-33.

Government of Malaysia. (2001). The Third Outline Perspective Plan 2001-2010. Kuala Lumpur: Percetakan Nasional Malaysia.

Government of Malaysia. (2006). Ninth Malaysia Plan 2006-2010. Putrajaya: Percetakan Nasional Malaysia.

Grant, I. C. \& Waite, K. (2003). Following the Yellow Brick Road - Young Adults' Experiences of the Information Super-Highway. Qualitative Market Research: An International Journal, 6 (1), 48-57.

Hafstrom, J. L., Chae, L. S. \& Chung, Y. S. (1992). Consumer Decision-Making Styles: Comparison between United States and Korean Young Consumers. Journal of Consumer Affairs, 26 (1), 146-158.

Hiu, A. S. Y., Siu, N. Y. M., Wang, C. C. L. \& Chang, L. M. K. (2001). An Investigation of Decision-Making Styles of Consumers in China. Journal of Consumer Affairs, 35 (2), 326-345.

Holbrook, M. \& Schindler, R. M. (1989). Some Explanatory Findings on the Development of Musical Tastes. Journal of Consumer Research, 16 (1), 119-124.

Kavas, A. \& Yesilada, F. (2007). Decision Making Styles of Young Turkish Consumers. European Journal of Economics, Finance and Administrative Sciences, 9, 73-85.

Kenson, K. M. (1999). A Profile of Apparel Shopping Orientation Segments among Male Consumers. Unpublished MA thesis, California State University Long Beach.

Leslie, E., Sparling, P. B. \& Owen, N. (2001). University Campus Settings and the Promotion of Physical Activity in Young Adults: Lessons from Research in Australia and the USA. Health and Education, 101 (3), 116-125.

Lysonski, S., Durvasula, S. \& Zotos, Y. (1996). Consumer Decision-Making Styles: A Multi-Country Investigation. European Journal of Marketing, 30 (12), 10-21.

Ministry of Higher Education Malaysia (2007). http://www.mohe.gov.my/web_statistik

Mitchell, V. W. \& Bates, L. (1998). UK Consumer Decision-Making Styles. Journal of Marketing Management, 14, 199-225.

Moschis, G. P. (1987). Consumer Socialization: A Life Cycle Perspective, Lexington, MA: Lexington Books.

Ownbey, S. F. \& Horridge, P. E. (1997). Acculturation Levels and Shopping Orientations of Asian-American Consumers. Psychology \& Marketing, 14 (1), 1-18.

Patel, V. (2008). Consumer Decision Making Styles in Shopping Malls: An Empirical Study. In U. Dhar et al. (Eds.), New Age Marketing: An Emerging Realities (pp. 627-637). New Delhi: Excel Books.

Radder, L., Li, Y. \& Pietersen, J. J. (2006). Decision-Making Styles of Young Chinese, Motswana and Caucasian Consumers in South Africa: An Exploratory Study. Journal of Family Ecology and Consumer Science, 34, 20 -31.

Selvarajah, C. T. (1993). The opening strategic windows for Australia and New Zealand in the Asia-Pacific: focus on Malaysia: the tiger with a vision, in Chin Tiong Tan et al. (eds.), Emerging International Strategic Frontiers Proceedings of the American Marketing Association International Marketing Conference in Singapore, American Marketing Association, pp. 48-52. 
Shim, S. \& Kotsiopulos, A. (1993). A Typology of Apparel Shopping Orientation Segments among Female Consumers. Clothing and Textiles Research Journal, 12, 73-85.

Siu, N. Y. M., Wang, C. C. M., Chang, L. M. K. \& Hui, A. S. Y. (2001). Adapting Consumer Style Inventory to Chinese Consumers: A Confirmatory Factor Analysis Approach. Journal of International Consumer Marketing, 13 (2), $29-47$.

Speer, T. (1998). College Come-Ons. American Demographics, 20 (3), 41-45.

Sproles G. B. \& Kendall, E. L. (1986). A Methodology for Profiling Consumers' Decision-Making Styles. Journal of Consumer Affairs, 20 (2), 267-279.

Sproles, E. K. \& Sproles, G. B. (1990). Consumer Decision-Making Styles as a Function of Individual Learning Styles. Journal of Consumer Affairs, 24 (1), 134-147.

Sproles, G. B. (1985). From Perfectionism to Fadism: Measuring Consumers' Decision-Making Styles. Proceedings, American Council on Consumer Interests, 79-85.

Tabachnick, B. G. \& Fidell, L. S. (2001). Using Multivariate Statistics, 4th ed. HarperCollins, New York.

Walsh, G., \& Vincent, W. (2001). German Market Mavens’ Decision-Making Styles. Journal of Euro-Marketing, 10 (4), 83-108.

Walsh, G., Mitchell, V. W. \& Thurau, T. H. (2001). German Consumer Decision-Making Styles. Journal of Consumer Affairs, 35 (1), 73-95.

Warwick, J. \& Mansfield, P. (2000). Credit Card Consumers: College Students' Knowledge and Attitude. Journal of Consumer Marketing, 17 (7), 617-626.

Wells, W. D. (1974). Life Style and Psychographics, Chicago: American Marketing Association. 
Table 1. Factor analysis of consumer decision making styles

\begin{tabular}{|c|c|c|c|}
\hline Items & Loadings & Eigenvalue & Variance \\
\hline \multicolumn{4}{|l|}{ Factor 1: Novelty, Brand Conscious Consumer } \\
\hline The well-known national brands are best for me & 0.75 & 6.54 & $11.33 \%$ \\
\hline The more expensive brands are usually my choice & 0.74 & & \\
\hline I prefer buying the best-selling brands. & 0.73 & & \\
\hline The most advertised brands are usually good choices. & 0.65 & & \\
\hline The higher the price of a product, the better its quality & 0.65 & & \\
\hline I keep my wardrobe up-to-date with the changing fashion & 0.58 & & \\
\hline Fashionable, attractive styling is very important to me & 0.55 & & \\
\hline \multicolumn{4}{|l|}{ Factor 2: Perfectionistic, High-Quality Conscious } \\
\hline When it comes to purchase products, I try to get the best. & 0.67 & 3.45 & $8.08 \%$ \\
\hline I look carefully to find the best value for the money. & 0.65 & & \\
\hline In general, I usually try to buy the best overall quality. & 0.55 & & \\
\hline I carefully watch how much I spend. & 0.60 & & \\
\hline I should plan my shopping more carefully than I do. & 0.52 & & \\
\hline I take the time to shop carefully for the best buys. & 0.52 & & \\
\hline \multicolumn{4}{|l|}{ Factor 3: Confused by Overchoice Consumer } \\
\hline There are many brands to choose that often I feel confused. & 0.63 & 2.32 & $5.77 \%$ \\
\hline All the information I get on different products confuses me. & 0.52 & & \\
\hline The more I learn about products, the harder to choose the best. & 0.69 & & \\
\hline \multicolumn{4}{|l|}{ Factor 4: Recreational, Hedonistic Conscious } \\
\hline Shopping is not a pleasant activity to me. & 0.75 & 1.84 & $5.47 \%$ \\
\hline Shopping the stores wastes my time. & 0.68 & & \\
\hline Shopping is one of the enjoyable activities of my life. & 0.54 & & \\
\hline \multicolumn{4}{|l|}{ Factor 5: Impulsive, Careless Consumer } \\
\hline I am impulsive when purchasing. & 0.62 & 1.39 & $5.04 \%$ \\
\hline I shop quickly, buying the first product or brand. & 0.63 & & \\
\hline Often I make careless purchases I later wish I had not. & 0.53 & & \\
\hline \multicolumn{4}{|l|}{ Factor 6: Variety-Seeking Consumer } \\
\hline To get variety, I shop different stores and brands. & 0.62 & 1.35 & $4.43 \%$ \\
\hline Fashionable, attractive styling is important for me. & 0.52 & & \\
\hline \multicolumn{4}{|l|}{ Factor 7: Habitual, Brand-Loyal Consumer } \\
\hline I go to the same stores each time I shop. & 0.70 & 1.25 & $4.29 \%$ \\
\hline Once I find a product or brand I like, I stick with it. & 0.58 & & \\
\hline \multicolumn{4}{|l|}{ Factor 8: Financial, Time-Energy Conserving } \\
\hline I make my shopping trips fast. & 0.55 & 1.20 & $3.94 \%$ \\
\hline The lower price products are usually my choice. & 0.51 & & \\
\hline
\end{tabular}


Table 2. Comparison with other studies

\begin{tabular}{|c|c|c|c|c|}
\hline $\begin{array}{l}\text { Present study: } \\
\text { Malaysia }\end{array}$ & $\begin{array}{c}\text { Canabal (2002): } \\
\text { India }\end{array}$ & $\begin{array}{c}\text { Fan and Xio } \\
\text { (1998): } \\
\text { China }\end{array}$ & $\begin{array}{l}\text { Hafstrom et al. } \\
\qquad(1996): \\
\text { South Korea }\end{array}$ & $\begin{array}{l}\text { Sproles and Kendall } \\
\text { (1986): U.S. }\end{array}$ \\
\hline $\begin{array}{l}\text { Novelty, Brand } \\
\text { Conscious }\end{array}$ & Brand conscious & Brand Conscious & Perfectionistic & Perfectionistic \\
\hline $\begin{array}{l}\text { Perfectionist, } \\
\text { High-Quality } \\
\text { Conscious }\end{array}$ & $\begin{array}{c}\text { High-Quality } \\
\text { Conscious/Perfectionist }\end{array}$ & Time Conscious & $\begin{array}{c}\text { Recreational/ } \\
\text { Shopping Conscious }\end{array}$ & Brand Conscious \\
\hline $\begin{array}{l}\text { Confused by } \\
\text { Overchoice }\end{array}$ & Confused by Overchoice & Quality Conscious & $\begin{array}{l}\text { Confused by } \\
\text { Overchoice }\end{array}$ & $\begin{array}{l}\text { Novelty/Fashion } \\
\text { Conscious }\end{array}$ \\
\hline $\begin{array}{l}\text { Recreational, } \\
\text { Hedonistic } \\
\text { Conscious }\end{array}$ & $\begin{array}{l}\text { Impulsive/Brand } \\
\text { Indifferent }\end{array}$ & Price Conscious & $\begin{array}{l}\text { Time-Energy } \\
\text { Conserving* }\end{array}$ & $\begin{array}{c}\text { Recreational, } \\
\text { Shopping Conscious }\end{array}$ \\
\hline $\begin{array}{c}\text { Impulsive, Careless } \\
\text { Consumer }\end{array}$ & Time Conscious* & $\begin{array}{l}\text { Information } \\
\text { Utilization }\end{array}$ & Impulsive & $\begin{array}{l}\text { Price/Value } \\
\text { Conscious }\end{array}$ \\
\hline Variety-Seeking & Recreational Shopper & & $\begin{array}{c}\text { Habitual/ } \\
\text { Brand-Loyal* }\end{array}$ & Impulsive \\
\hline $\begin{array}{l}\text { Habitual, } \\
\text { Brand-Loyal }\end{array}$ & $\begin{array}{l}\text { Price/ } \\
\text { Value-Conscious* }\end{array}$ & & $\begin{array}{l}\text { Price/Value } \\
\text { Conscious* }\end{array}$ & $\begin{array}{l}\text { Confused by } \\
\text { Overchoice }\end{array}$ \\
\hline $\begin{array}{l}\text { Financial, } \\
\text { Time-Energy } \\
\text { Conserving* }\end{array}$ & Dissatisfied/Careless* & & & Habitual Brand-Loyal \\
\hline
\end{tabular}

*Factors with Cronbach alpha levels below 0.4

Factors appear in the order presented by the authors. 


\title{
Study on the Evaluation Criterions and Methods
}

\section{for the Supermarket Food Suppliers Based on IAHP}

\author{
Xiaoping Li \\ School of Economics and Management, Jiangsu University of Science and Technology \\ Zhenjiang 212003, China \\ E-mail: lixiaoping610@163.com
}

\begin{abstract}
By investigating classified management of suppliers of supermarkets, this paper establishes the evaluation index system of food suppliers of supermarkets, studies standards of evaluation index, and then implements the synthetical evaluation to 30 suppliers of Suguo supermarket by employing the Analytic Hierarchy Process with interval judgment and interval eigenvalue method, this paper makes some suggestions for Suguo supermarket to manage food suppliers.
\end{abstract}

Keywords: Supermarkets, Food, Evaluation of suppliers, Interval judgment Analytic hierarchy process, Index system

\section{Introduction}

Food is the source that human being depends on to survival, and the food safety is the base line of the consummation for people. Pawel Zukowski (2003) pointed out that in the early days of the 21 st century, it was more difficult to ensure the quality of the food than other products, and the task was more difficult, and more and more consumers hope not only the food can not bring negative influences for their health, but also the food can provide the nutrition values needed by the flesh such as the mineral composition and vitamins (Cythia M, 2002, P.105-112 \& Pawel Zukowski, 2003). At present, the circulation of Chinese food supply includes the supermarket, the farmer's market and some small-sized food retail stores. Since 1990s, the supermarket has been developed quickly, and it is gradually replacing the traditional trade market and becoming the important channel to stock the foods for Chinese residents. One report of All-China Commercial Information Center showed that the food sales in the supermarket will occupy above $90 \%$ of the social food sales amount till 2010. As the retail end, it is very important to effectively evaluate the food suppliers, manage the suppliers and form the long-term and stable strategic alliance with them, and provide safe foods for consumers.

According to the investigation, there are many problems existing in the food supplier management of Chinese supermarket, such as the lagged supplier management concept, the simple management measure, and the too subjective supplier evaluation and selection. So it is imperative under the situation to strengthen the supplier management in the supermarket chains. In this article, based on the analysis of the necessity of the supermarket chains supplier management, we studied the classification management mechanism, the evaluation criterion and the evaluation methods for the supermarket food suppliers.

\section{Supplier classification management}

Because the amount of the supermarket chains suppliers is numerous, we classify and manage the suppliers according to the type of the stocked products. The foods stocked by the supermarket are generally divided into two sorts. The one sort is the food with designed packaging, and we call it as the food type A, and this sort of food possesses the characters that the demand amount is large and the suppliers should form certain scale and be relatively stable, and these foods include milk, edible oil and so on. The other sort is the food without designed packaging, and we call it as the food type $\mathrm{B}$, and this sort of food possesses the characters that the demand amount of the single breed is small and the suppliers are dispersive and unstable, and these foods include vegetable and fruits. According to the characters of these two types of food, we classify and manage the suppliers of the supermarket, and the classification and evaluation program of the supermarket food suppliers is seen in Figure 1. For the suppliers of the food type A, we should strictly use the qualitative and quantitative qualification auditing and locale auditing method to select and evaluate them. First, qualitatively evaluate all suppliers, select the selectable supplier set, and confirm the final suppliers by the qualification auditing and locale auditing method. For the suppliers of the food type B, we can use the qualitative method to select and confirm the suppliers by the qualification auditing and locale auditing evaluation method. Then we input the information of qualified suppliers and the daily representations of suppliers into the supplier database, and audit the 
suppliers, which can be taken as the input information to evaluate the supermarket food safety quality management system.

\section{The method of IAHP evaluation}

\subsection{The generation background of IAHP}

As a sort of effective and practical decision method to deal with complex decision-making method, AHP (Analysis Hierarchy Process) has be broadly applied in many domains, and its problems existing in the theory and practical application have been improved and developed. When the decision-maker makes the decision by AHP and he can obtain complete information, he can compare the importance of two projects (or the sub-rule) in single rule, and give the exact judgment value under certain standard. But in actual social and economic system, because of the complexity of the system, it is very difficult or even impossible to directly obtain the evaluation of various projects under single rule or the weights of various sub-rules in the hierarchy structure. Therefore, under single rule, the deficiency of the information or the imperfection of the project will make the experts can not certainly judge the relative importance degree of the project, and the interval judgment AHP (IAHP) is generated. In IAHP, the paired comparison adopts the interval standard, and the corresponding judgment matrix can be obtained by the form of the interval judgment matrix.

\subsection{The algorithm of IAHP}

In 1987, Saaty and Vargas defined the interval judgment matrix, and put forward the simulated algorithm to seek the weight vector of the interval judgment matrix (Saaty, 1987, P.107-117), and E.S. Rosenbloom put forward the Monte-Carlo simulation method in 1996 (E.S. Rosenbloom, 1996, P.371-378), and David Hauser (1996) put forward the Cauchy distribution method (David Hauser, 1996, P.27-37), and many domestic experts and scholars extended the algorithm judging the weight vector of the dot judgment matrix to the domain of the interval judgment matrix, for example, Wei Cuiping et al (1996) put forward the interval gradient eigenvector method (IGEM) according to decision-makers' different grasps for the judgment interval in the interval judgment matrix (Wei, 1996, P.25-30), and Wei Yiqiang et al (1994) put forward the interval eigenvector method (IEM) (Wei, 1994, P.16-22).

According to the basic idea generated by the algorithm, we divide the interval judgment matrix compositor algorithm into the approximate algorithm and the optimization algorithm to study, and the approximate algorithm of the interval judgment compositor mainly includes the simulation algorithm, the interval eigenvector method, the interval number gradient character vector method, the improved interval number gradient character vector method, the coherence approach method, the optimal transfer matrix method and the Cauchy distribution method. And the optimization method of the interval judgment matrix compositor mainly includes the linear programming method, the convex cone model method, the interval number least square method, and the interval number generalized least warp method and the interval number $\chi^{2}$ method. Through studying the algorithms proposed by foreign and domestic scholars, we think IEM is sort of concise and practical algorithm ( $\mathrm{Li}, 2004)$.

For the coherence interval judgment matrix,

$$
A=\left(a_{i j}\right)_{n \times n}=\left[\begin{array}{cccc}
1 & {\left[a_{12}^{-}, a_{12}^{+}\right]} & \cdots & {\left[a_{1 n}^{-}, a_{1 n}^{+}\right]} \\
{\left[a_{21}^{-}, a_{21}^{+}\right]} & 1 & \cdots & {\left[a_{2 n}^{-}, a_{2 n}^{+}\right]} \\
\vdots & \vdots & \ddots & \vdots \\
{\left[a_{n 1}^{-}, a_{n 1}^{+}\right]} & {\left[a_{n 2}^{-}, a_{n 2}^{+}\right]} & \cdots & 1
\end{array}\right]=\left[A^{-}, A^{+}\right]
$$

Where, $a_{j i}^{-}=1 / a_{i j}^{+}, a_{j i}^{+}=1 / a_{i j}^{-}$and $A^{-}=\left(a_{i j}^{-}\right)_{n \times n}, A^{+}=\left(a_{i j}^{+}\right)_{n \times n}$.

The concrete computation approaches of IEM include three steps.

First, respectively compute the standardized character vectors $x^{-}, x^{+}$with the positive weight corresponded by the maximum character roots of $A^{-}, A^{+}$.

Second, by the formula $k=\sqrt{\sum_{j=1}^{n} \frac{1}{\sum_{i=1}^{n} a_{i j}^{+}}} m=\sqrt{\sum_{j=1}^{n} \frac{1}{\sum_{i=1}^{n} a_{i j}^{-}}}$to compute the values of $k, m$.

Third, seek the weight vector, $w=\left[k x^{-}, m x^{+}\right]$.

\section{The evaluation index system and evaluation criterions for food suppliers}

\subsection{The evaluation index system for food suppliers}

Comprehensively considering nine indexes such as qualified rate of the product, consumer withdrawal rate, price 
representation, delivery time, delivery quality, delivery safety, market share, service quality and mark traceability, we establish the supermarket food supplier evaluation index system from five aspects including the quality level, the price level, the delivery ability, the market competition ability and the service level (seen in Table 1).

According to the principles such as the science character, the maneuverability and the system character, we adopt the method combining the qualitative analysis with the quantitative analysis to constitute detailed evaluation standards aiming at various evaluation projects.

\subsection{The evaluation criterions for food suppliers}

\subsubsection{The quality level}

From Table 1, we can use the qualified rate of the product and the consumer withdrawal rate to evaluate the quality of the food supplied by the suppliers, and the product qualified rate means the spot check qualified rate of the stock test, and its score can be denoted by the formula.

$$
Q_{C_{1}}=\left(1-\frac{n}{N}\right) \times 100
$$

Where, $n$ is the disqualified batch and $N$ is the total batch of the stock.

The score of the consumer withdrawal rate $Q_{C_{2}}$ can be denoted by the following formula.

$Q_{C_{2}}=(1-r) \times 100$

Where, $r$ is the consumer withdrawal rate.

\subsubsection{The price level}

According to the price representations of the suppliers, we can evaluate the price level of supplier.

If the supplied product price is stable and drops little, the score of the price representation $Q_{C_{3}}$ is 90 points, and if the price is stable persistently, $Q_{C_{3}}$ is 80 points, and if the price is basically stable the price fluctuates little with the price of the farm products, $Q_{C_{3}}$ is 70 points, and if the price is not stable and it is largely influenced by the market price, $Q_{C_{3}}$ is 60 points, and the price is not stable and not reasonable, $Q_{C_{3}}$ is 0 points.

\subsubsection{The delivery ability}

The delivery ability is composed by three indexes such as the delivery time, the delivery quantity and the delivery safety, and the score of the delivery time $Q_{C_{4}}$ can be computed by the following formula.

$Q_{C_{4}}=\left(1-\frac{m_{1}}{M_{1}}\right) \times 100$

Where, $m_{1}$ is the delivery batch before or after the schedule, and $M_{1}$ is the total batch of the delivery.

The score of the delivery quantity $Q_{C_{5}}$ can be denoted by the following formula.

$Q_{C_{5}}=\left(1-\frac{m_{2}}{M_{2}}\right) \times 100$

Where, $m_{2}$ the quantity of the deficient goods, and $M_{2}$ is the total quantity of the delivery.

In the delivery process, it is the important measure to ensure the nutritious components and the safety of the foods by strictly defending the foods according to the characters of the foods and the requirement of the refrigeration chain, so the score of the delivery safety $Q_{C_{6}}$ can be divided into two sorts. One sort is to defend the foods strictly according to the contract, and $Q_{C_{6}}$ is 100 points, and the another sort is the necessary defense without the requirements of the contract, and $Q_{C_{6}}$ is 0 points.

\subsubsection{The market competition ability}

We use the market occupation rate to reflect the market competition ability of the product, and because the regional character exists in the food consumption, the market occupation rate means the market share of the product in the region, and the score $Q_{C_{7}}$ can be denoted as

$$
Q_{C_{7}}=\frac{p}{P} \times 100
$$

Where, $p$ is the market share of the product, and $P$ is the maximum market share of the same sort of product.

4.2.5 The service ability

Two indexes including the service quality and the mark traceability can be used to evaluate the suppliers' service ability, 
and the service quality is a comprehensive index which can be denoted by the hundred percent of the five-class conversion. The service quality is very good, the score of the service quality $Q_{C_{8}}$ is 100 points, and the service quality is better, $Q_{C_{8}}$ is 80 points, and the service quality is common, $Q_{C_{8}}$ is 60 points, and the service quality is bad, $Q_{C_{8}}$ is 40 points, and the service is very bad, $Q_{C_{8}}$ is 20 points.

The mark traceability is mainly used to measure the traceability of the foods supplied the suppliers, and whether the supplier system is perfect and possesses good traceability is related with the start of the food withdrawal program and consumers' safety and health when the unsafe goods or the potential unsafe goods enter into the sales and consumption stage. The score of this index of supplier can be divided into following sorts. First, the mark traceability in the good production process is very strong, and the good materials can be traced to the producing area, so the score $Q_{C_{9}}$ is 100 points. Second, the mark traceability in the good production process is strong, and the good materials can be traced to the upper supplier, so the score $Q_{C_{9}}$ is 80 points. Third, the mark traceability in the good production process is strong, so the score $Q_{C_{9}}$ is 60 points. Fourth, the mark traceability in the good production process is common, so the score $Q_{C_{9}}$ is 40 points. Fifth, the mark traceability in the good production process is bad, so the score $Q_{C_{9}}$ is 20 points. Sixth, the mark traceability in the good production process is very bad, so the score $Q_{C_{9}}$ is 0 point.

\section{The application of IAHP in the comprehensive evaluation of supermarket food suppliers}

\subsection{To establish the hierarchical structure}

According to the evaluation index system in Table 1 and the dominant and dominated relation among factors, the hierarchy structure is established (seen in Figure 2). From Figure 2, there are four layers, i.e. the objective layer, the rule layer, and sub-rule layer and the project layer.

\subsection{To establish the interval judgment matrix by paired comparison}

According to the 1 9 proportion scale proposed by Saaty (1980), we respectively compare the factors dominated by the total objective and various rules in pair, and establish the interval judgment matrix (seen in Table 2 to Table 5).

\subsection{To compute the weight interval of the interval judgment matrix}

We adopt the interval eigenvector method (IEM) to compute the weight intervals of the judgment matrix compositor in pair (seen in Table 2 to Table 5).

\subsection{To compute the combined weights among various factors}

In Table 2 to Table 5, the local compositor weight interval vectors of factors in various layers, we use the combined weight formula of various-layer factors in Wu Yuhua's article (Wu, 1995, P.700-705) to obtain the total weight interval vector (seen in Table 6).

\subsection{Case analysis and advices}

According to the evaluation criterions of various indexes for the suppliers, we evaluated 30 qualified food suppliers in SUGUO Supermarket, and obtained Table 7.

According the scores of various indexes and the weight of each index, we use the following formula to obtain the comprehensive evaluation of 30 suppliers (seen in Table 7).

$Q_{j}=\sum_{i=1}^{9} Q_{C_{i} j} \times w_{i}$

Where, $Q_{j}$ is the comprehensive score of the $j^{\prime}$ th supplier, $Q_{C_{i j}}$ is the score of the $i^{\prime}$ th index of the $j^{\prime}$ th supplier, and $w_{i}$ is the weight of the $i$ 'th index in the index system.

According to the comprehensive evaluation result of the suppliers, the supermarket should establish the long-term and stable cooperation relation with the suppliers with higher score, and supervise and urge the suppliers with lower score to improve the product quality and perfect the traceability system. According to the two-eight principle, the supermarket should further check the qualifications of those six suppliers with lower scores, and delete them from the qualified supplier index necessarily.

\section{References}

Cythia M. Stewart. (2002). Food safety: new concepts for the new millennium. Innovative Food Science \& Emerging Technologies, No. 3, P. 105-112.

David Hauser \& Pandu Tadikamalla. (1996). The analytic hierarchy process in an uncertain environment: A simulation approach. European Journal of Operational Research, No. 91, P. 27-37.

E.S. Rosenbloom. (1996). A probabilistic interpretation of the final rankings in AHP. European Journal of Operational Research, No. 96, P. 371-378. 
Li, Xiaoping. (2004). Study on the AHP Theory and Application Based on the Interval Judgment. Thesis of Nanjing University of Science and Technology, June of 2004.

Pawel Zukowski. (2003). Modeling of the Integrated System of Food Products' Quality Assurance in an Agricultural and Industrial Complex. Proceedings of the 5th IEEE International Symposium on Assembly and Task Planning. Besancon, France. July 10, 2003.

Saaty T.L. \& Vargas L.G. (1987). Uncertainty and rank order in the Analytic Hierarchy Process. European Journal of Operational Research, No. 32, P. 107-117.

Wei, Cuiping \& Hou, Chengjun. (1996). Several New Compositor Methods in Uncertain AHP and Their Comparisons. Journal of Qufu Normal University, No. 22(2), P. 25-30.

Wei, Yiqiang, Liu, Jinsheng, \& Wang, Xuzhu. (1994). The Coherence Concept and Weight of the Judgment Matrix in Uncertain AHP. Systems Engineering Theory \& Practice, No. 4, P. 16-22.

$\mathrm{Wu}$, Yuhua et al. (1995). Interval Analytic Hierarchy Process (IAHP). Journal of Tianjin University, No. 28(5), P. 700-705.

Table 1. The evaluation index system of supermarket supplier

\begin{tabular}{|c|c|c|}
\hline First class index & Second class index & Third class index \\
\hline \multirow{9}{*}{$\begin{array}{l}\text { Supplier comprehensive } \\
\text { performance level A }\end{array}$} & \multirow{2}{*}{ Quality level $B_{1}$} & Qualified rate of the product $\mathrm{C}_{1}$ \\
\hline & & Consumer withdrawal rate $\mathrm{C}_{2}$ \\
\hline & Price level $\mathrm{B}_{2}$ & Price representation $\mathrm{C}_{3}$ \\
\hline & \multirow{3}{*}{ Delivery level $\mathrm{B}_{3}$} & Delivery time $\mathrm{C}_{4}$ \\
\hline & & Delivery quality $\mathrm{C}_{5}$ \\
\hline & & Delivery safety $\mathrm{C}_{6}$ \\
\hline & Market competition ability $\mathrm{B}_{4}$ & Market share $C_{7}$ \\
\hline & \multirow{2}{*}{ Service ability $B_{5}$} & Service quality $\mathrm{C}_{8}$ \\
\hline & & Mark traceability $\mathrm{C}_{9}$ \\
\hline
\end{tabular}

Table 2. The interval judgment matrix and weight intervals under the total objective supplier comprehensive performance level

\begin{tabular}{|c|c|c|c|c|c|c|}
\hline A & B1 & B2 & B3 & B4 & B5 & Weight interval \\
\hline B1 & {$[1,1]$} & {$[2,4]$} & {$[1,2]$} & {$[2,3]$} & {$[1,2]$} & {$[0.2730,0.3538]$} \\
\hline B2 & {$[1 / 4,1 / 2]$} & {$[1,1]$} & {$[1 / 2,1]$} & {$[1,1]$} & {$[1 / 3,1 / 2]$} & {$[0.1122,0.1275]$} \\
\hline B3 & {$[1 / 2,1]$} & {$[1,2]$} & {$[1,1]$} & {$[1,2]$} & {$[1,2]$} & {$[0.1815,0.2523]$} \\
\hline B4 & {$[1 / 3,1 / 2]$} & {$[1,1]$} & {$[1 / 2,1]$} & {$[1,1]$} & {$[1 / 2,1]$} & {$[0.1254,0.1458]$} \\
\hline B5 & {$[1 / 2,1]$} & {$[2,3]$} & {$[1 / 2,1]$} & {$[1,2]$} & {$[1,1]$} & {$[0.1868,0.2356]$} \\
\hline
\end{tabular}

Table 3. The interval judgment matrix and weight intervals under the criterion of quality level

\begin{tabular}{|c|c|c|c|}
\hline B1 & C1 & C2 & Weight interval \\
\hline $\mathrm{C} 1$ & {$[1,1]$} & {$[3,4]$} & {$[0.7563,0.7952]$} \\
\hline $\mathrm{C} 2$ & {$[1 / 4,1 / 3]$} & {$[1,1]$} & {$[0.2183,0.2295]$} \\
\hline
\end{tabular}

Table 4. The interval judgment matrix and weight intervals under the criterion of delivery level

\begin{tabular}{|c|c|c|c|c|}
\hline B3 & C4 & C5 & C6 & Weight interval \\
\hline C4 & {$[1,1]$} & {$[1,2]$} & {$[1 / 3,1 / 2]$} & {$[0.2173,0.2657]$} \\
\hline C5 & {$[1 / 2,1]$} & {$[1,1]$} & {$[1 / 4,1 / 3]$} & {$[0.1572,0.1848]$} \\
\hline C6 & {$[2,3]$} & {$[3,4]$} & {$[1,1]$} & {$[0.5681,0.6066]$} \\
\hline
\end{tabular}


Table 5. The interval judgment matrix and weight intervals under the criterion of service level

\begin{tabular}{|c|c|c|c|}
\hline B5 & C8 & C9 & Weight interval \\
\hline C8 & {$[1,1]$} & {$[1,2]$} & {$[0.5347,0.6327]$} \\
\hline C9 & {$[1 / 2,1 / 1]$} & {$[1,1]$} & {$[0.3781,0.4474]$} \\
\hline
\end{tabular}

Table 6. The comprehensive compositor weight intervals, interval medians and adjusted interval medians of various factors

\begin{tabular}{|c|c|c|c|}
\hline Index & Weight interval & Interval median & Adjusted interval median \\
\hline C1 & {$[0.2065,0.2813]$} & 0.2439 & 0.2436 \\
\hline C2 & {$[0.0596,0.0812]$} & 0.0704 & 0.1198 \\
\hline C3 & {$[0.1122,0.1275]$} & 0.1199 & 0.0531 \\
\hline C4 & {$[0.0394,0.0670]$} & 0.0532 & 0.0376 \\
\hline C5 & {$[0.0285,0.0466]$} & 0.0376 & 0.1279 \\
\hline C6 & {$[0.1031,0.1530]$} & 0.1281 & 0.1354 \\
\hline C7 & {$[0.1254,0.1458]$} & 0.1356 & 0.0879 \\
\hline C8 & {$[0.0706,0.1054]$} & 0.0880 & 0.1244 \\
\hline C9 & {$[0.0999,0.1491]$} & 0.1245 & 1 \\
\hline Total & - & 1.0012 & \\
\hline
\end{tabular}


Table 7. Various index evaluation values for suppliers

\begin{tabular}{|c|c|c|c|c|c|c|c|c|c|c|c|}
\hline Supplier & $Q_{C_{1}}$ & $Q_{C_{2}}$ & $Q_{C_{3}}$ & $Q_{C_{4}}$ & $Q_{C_{5}}$ & $Q_{C_{6}}$ & $Q_{C_{7}}$ & $Q_{C_{8}}$ & $Q_{C_{9}}$ & Value & Ranking \\
\hline S1 & 95.66 & 99.43 & 71 & 87.94 & 94.47 & 95.14 & 78.51 & 86 & 85 & 87.9523 & 11 \\
\hline S2 & 95.34 & 98.49 & 78 & 96.85 & 91.83 & 98.67 & 61.38 & 81 & 74 & 85.3449 & 27 \\
\hline S3 & 95.35 & 99.54 & 74 & 97.83 & 93.15 & 96.03 & 66.72 & 79 & 73 & 85.1288 & 28 \\
\hline S4 & 95.73 & 99.49 & 76 & 96.42 & 96.42 & 98.46 & 67.86 & 82 & 77 & 86.7320 & 19 \\
\hline S5 & 95.11 & 99.83 & 79 & 97.25 & 90.45 & 98.63 & 75.02 & 84 & 79 & 88.1996 & 8 \\
\hline S6 & 97.22 & 99.69 & 76 & 97.97 & 93.60 & 96.99 & 65.39 & 96 & 77 & 87.7934 & 13 \\
\hline S7 & 96.85 & 99.74 & 70 & 91.99 & 97.54 & 96.89 & 80.06 & 87 & 70 & 87.1302 & 15 \\
\hline S8 & 95.82 & 97.38 & 77 & 98.55 & 94.93 & 98.02 & 80.43 & 86 & 72 & 88.1577 & 9 \\
\hline S9 & 94.89 & 99.26 & 75 & 95.24 & 93.10 & 99.09 & 72.42 & 81 & 72 & 86.1920 & 22 \\
\hline S10 & 95.79 & 99.69 & 74 & 92.87 & 97.68 & 100 & 71.30 & 88 & 71 & 86.8236 & 18 \\
\hline S11 & 96.13 & 98.41 & 70 & 91.87 & 92.24 & 95.51 & 64.95 & 90 & 73 & 85.0702 & 30 \\
\hline S12 & 96.64 & 99.41 & 77 & 97.77 & 99.98 & 98.88 & 69.43 & 80 & 73 & 86.8662 & 16 \\
\hline S13 & 94.92 & 99.59 & 77 & 97.17 & 89.12 & 96.42 & 81.01 & 82 & 78 & 88.0708 & 10 \\
\hline S14 & 94.34 & 99.51 & 74 & 98.91 & 86.30 & 97.86 & 68.83 & 87 & 72 & 85.7790 & 24 \\
\hline S15 & 94.28 & 99.46 & 77 & 92.68 & 94.33 & 98.95 & 74.66 & 85 & 70 & 86.5955 & 20 \\
\hline S16 & 96.58 & 97.19 & 80 & 95.01 & 90.69 & 99.1 & 85.37 & 84 & 71 & 88.8483 & 3 \\
\hline S17 & 98.36 & 99.10 & 78 & 98.70 & 94.38 & 97.13 & 67.11 & 83 & 66 & 86.077 & 23 \\
\hline S18 & 95.35 & 98.73 & 70 & 92.06 & 95.99 & 96.73 & 68.59 & 86 & 71 & 85.1022 & 29 \\
\hline S19 & 95.69 & 99.35 & 90 & 96.10 & 93.20 & 97.51 & 73.24 & 87 & 69 & 88.3027 & 7 \\
\hline S20 & 95.05 & 99.44 & 91 & 98.59 & 96.13 & 98.49 & 66.96 & 90 & 72 & 88.4273 & 6 \\
\hline S21 & 95.96 & 99.43 & 75 & 92.77 & 97.21 & 96.4 & 73.26 & 82 & 67 & 85.7235 & 26 \\
\hline S22 & 95.18 & 99.31 & 75 & 95.47 & 94.16 & 97.76 & 73.47 & 86 & 70 & 86.481 & 21 \\
\hline S23 & 96.58 & 99.55 & 70 & 95.43 & 95.98 & 99.31 & 75.58 & 80 & 66 & 85.7651 & 25 \\
\hline S24 & 95.54 & 99.45 & 72 & 95.50 & 100 & 96.79 & 66.98 & 85 & 82 & 86.8424 & 17 \\
\hline S25 & 94.56 & 99.37 & 81 & 90.54 & 97.02 & 98.71 & 78.82 & 83 & 70 & 87.4809 & 14 \\
\hline S26 & 96.43 & 99.57 & 73 & 96.89 & 93.93 & 96.65 & 84.77 & 84 & 79 & 88.9627 & 2 \\
\hline S27 & 94.71 & 99.51 & 87 & 93.17 & 97.48 & 95.84 & 71.31 & 80 & 79 & 87.875 & 12 \\
\hline S28 & 97.62 & 98.11 & 76 & 96.77 & 99.32 & 98.46 & 76.28 & 91 & 78 & 89.2785 & 1 \\
\hline S29 & 96.78 & 99.12 & 76 & 87.56 & 100 & 99.93 & 77.99 & 92 & 74 & 88.6913 & 5 \\
\hline S30 & 97.65 & 99.48 & 79 & 98.68 & 100 & 95.9 & 81.63 & 86 & 70 & 88.8308 & 4 \\
\hline
\end{tabular}




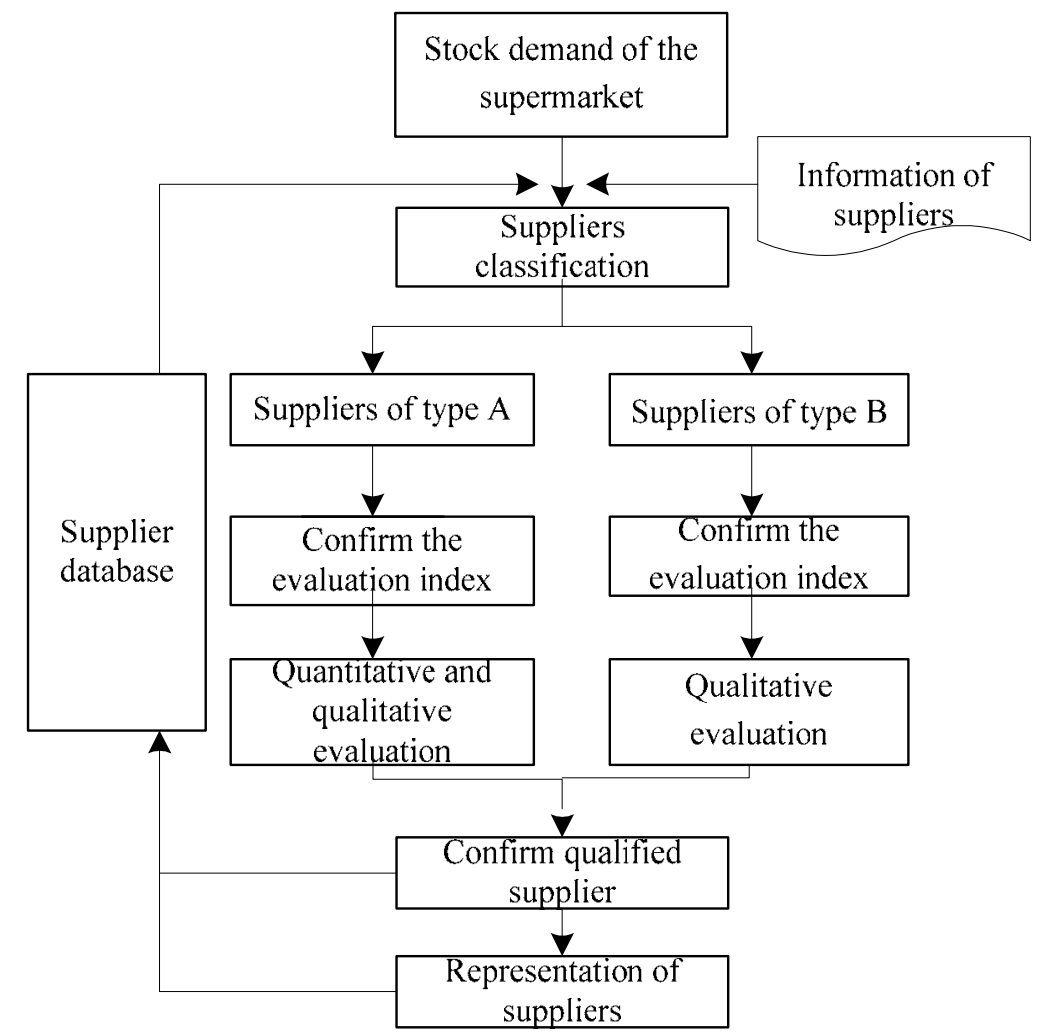

Figure 1. The Classification Evaluation Program of Supermarket Good Suppliers

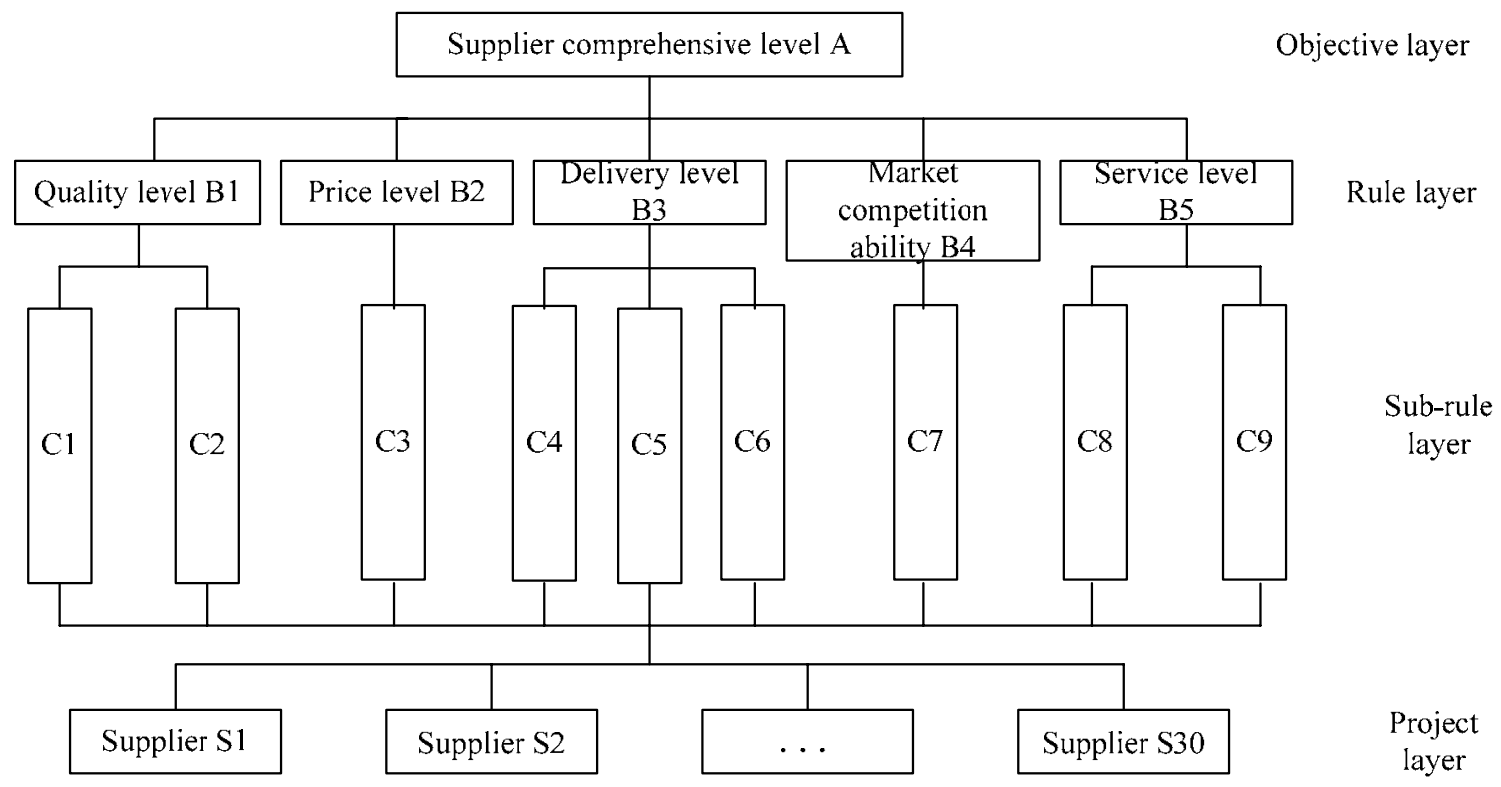

Figure 2. The Hierarchical Structure of the Supplier Comprehensive Evaluation $\left(\mathrm{C}_{1}\right.$ : Qualified rate of the product, $\mathrm{C}_{2}$ : Consumer withdrawal rate, $\mathrm{C}_{3}$ : Price representation, $\mathrm{C}_{4}$ : Delivery time, $\mathrm{C}_{5}$ : Delivery quality, $\mathrm{C}_{6}$ : Delivery safety, $\mathrm{C}_{7}$ : Market share, $\mathrm{C}_{8}$ : Service quality, $\mathrm{C}_{9}$ : Mark traceability) 


\title{
Study on the Countermeasures for Developing
}

\section{China's International Logistics Industry}

\author{
Dan Tan \\ Economic School, Central South University of Forestry and Technology \\ Changsha 410004, Hunan, China \\ E-mail: newtandan@gmail.com
}

\begin{abstract}
The continuous development of China's foreign trade in recent years brings forward new requirements on the efficiency, quality, cost and safety to our international logistics industry. Accelerating the development of our international logistics industry is an imperative choice to follow the trend of globalization. However, the international logistics industry in China is facing problems on the service capability, operation cost, infrastructure construction, professional concept, professional talents, administration system, legal system, and information network etc. This paper proposes some effective countermeasures to these problems.
\end{abstract}

Keywords: International logistics, International trade, Countermeasures

As the basic tache of international merchandise value chain, international logistics ensures the actualization of international business activity and brings added value to international trade, thus becoming "the Third Profit Source". Compared with domestic logistics, international logistics is geographically extended and enlarged. It is promoted by the development of international trade and transnational companies which require higher levels of international logistics support. The substance of international logistics is to actualize the movement and exchange of merchandize between different countries by using internationalized logistics network, facility and technology. The target of international logistics is to provide service for international trade and transnational operation, to promote the development of regional economy and the optimal allocation of worldwide resources.

\section{The necessity of developing China's international logistics industry}

In recent years, the international trade of the world develops with a high growth rate and a large scale. From year 2000 to year 2007, the average annual growth rate of world merchandize trade is $5.5 \%$. The total amount of international trade in 2007 reaches 28.3 trillion. It is reported (Zhang Guoqing, 2008) that the dependence degree on worldwide trade of all the countries gradually increased from $48.4 \%$ to $69.5 \%$, from year 2001 to year 2007 , respectively, which indicates that the economic connection between countries and areas is further enhanced and the international logistics activities around the world are greatly expedited. The foreign trade of our country has been rapidly developing in such circumstances. China has become the third largest trading nation and the second largest exporting country of the world. More and more multinationals transfer their manufacturing bases to China, which is becoming the manufacturing center of the world and its potential of international logistics is promptly released.

According to the research of Mr. Yang Changchun with the University of International Business and Economics, the Granger causality test proves that foreign trade and international logistics of China interact as both cause and effect. International trade promotes the development of international logistics, and accordingly, international trade brings forward new requirements on the efficiency, quality, cost and safety to our international logistics industry. Therefore, to accelerate the development of China's international logistics industry becomes essentially important for us to enhance the competitiveness of companies, optimize the allocation of resources, improve the trade environment, as well as realize the sustainable and healthy development of the Chinese economy.

\section{The existing problems of international logistics industry in China}

China's international logistics industry has made certain achievements in recent years; however, problems on various aspects still exist.

\subsection{The logistics enterprise lacks comprehensive service capability}

The fast development of economy requires that logistics enterprises not only provide transportation services and 
interrelated services, but also implement integrated logistics models and supply chain management models, constructing integrated service systems which extend from a raw material source through the production and distribution system to the point of consumption and the associated reverse logistics. The logistic activities comprise freight transport, storage, inventory management, materials handling as well as all of the related information processing. However, with their small scale and an extensive operation model, most of our logistics enterprises lack functional structure and comprehensive management capability and can only provide simple, non-value-added logistic services, which hardly meet the requirements of many modern enterprises, especially multinationals. Consequently, many manufacturing enterprises do not use these kind of international logistic services, but make the logistics arrangement by themselves.

\subsection{The low level of industrial systematization results in relatively high operation cost}

At present, the enterprise alliance of logistics industry in our country has not come into being. The communication and cooperation between logistics enterprises, and the connection between logistics enterprises and manufacturing enterprises, have not become a regular phenomenon. The low level of industrial systematization cannot reduce the logistics operation cost effectively. Therefore, facing the fierce competition from overseas logistics service providers, our logistics enterprises are not in the favorable position.

\subsection{The construction of logistics infrastructure is not well developed}

The overall scale of our transportation facilities is small. The quantity and function of established distribution and storage facilities cannot meet the increasing needs of international logistics. Due to the absence of reasonable programming and coordination, the compatibility of existing logistics infrastructure is low and the systematic function is weak. The progress of building logistics centers, logistics parks, comprehensive traffic hubs, which have important impact on the development of logistics industry, is slow.

\subsection{The administration system is not sound}

The logistics industry of our country is administrated by many government departments, including transportation, domestic trade, foreign trade, city management, taxation, public security, customs, inspection, and so on. There are big differences in terms of the management function, management mode, and management policy of these departments. Due to the barriers between different departments and regions, the layout of logistics organizations is scattered; the logistics resources are wasted; the logistics markets are cut apart.

\subsection{The legal system is not maturely established}

Compared with the long history of international logistics industry in developed countries, the international logistics industry in our country is just in the primitive stage. The legal system for this field has not been constructed. Many important matters are not strictly regulated, such as qualification, market entry, competition rules, industrial standards, and so on. In addition, different countries have different regulations in logistics fields. Our logistics enterprises have not clearly and completely understood the big differences and complexity of them, which might bring trouble to enterprises and cause the obstacle when exploring the international market.

\subsection{Professional talents are in great demand}

The education and training of logistics professionals are slowly developing. The market urgently needs large numbers of specialized talents, especially the high level talents who can provide effective logistics solutions to the companies. Liu Hanyun(2008,p6) said that the lack of qualified talents limits the growth of logistics industry.

\subsection{The advanced logistics concepts are not widely accepted and implemented}

Most of our logistics enterprises evolved from traditional material circulating companies. With the inherent weakness, these enterprises' understanding of logistics is confined to the transportation and warehousing. The advanced logistics concepts, such as green logistics and supply chain management, are not widely understood and accepted, and even seldom implemented in the management and operation.

\subsection{The informatization degree of the industry remains low}

Our logistics enterprises have not taken the importance of informatization into serious consideration. The informatization degree of the whole industry remains low. For example, logistics information software developed and applied by logistics enterprises is not compatible with the customer's information system; the internal logistics information system of logistics enterprises cannot be effectively connected with the third party's information system; the transportation information system, storage information system and operation information system are not organically synchronized. The operation efficiency of our logistics enterprises has been negatively influenced.

\section{The effective measures of promoting the development of our international logistics industry}

With the above problems in mind, we should ponder over from different aspects and take effective measures to improve the operation efficiency of logistics industry and increase the core competitiveness of logistics enterprises, so as to ensure the healthy development of our international logistics industry and sustainable growth of our foreign trade. 


\subsection{To make market segmentation and provide value-added, customer-oriented logistics service}

Based on the market needs, our logistics enterprises should make market segmentation and diversify the service modes, and provide value-added services, such as circulation processing, distribution, agency, logistics finance and payment collection, etc. They should also provide supply chain integration and integrated logistic services based on the modern information technology and supply chain management, and provide whole-process logistics services based on multi-modal transportation, making the services cover the whole process of material purchasing, manufacturing, storage, outer packaging, distribution, delivery, return of goods, repair and recycle.

\subsection{To promote the collaborative development of logistics enterprises and reduce the operation cost}

The integrated development could bring efficiency improvement, cost reduction and competitiveness enhancement. Therefore, on one hand, aiming at the establishment of strategic cooperation partnership, logistics enterprises should strengthen the connection with key customers and enhance the mutual dependence; on the other hand, works need to be done to facilitate the merger and acquisition of logistics enterprises. The service scope and service capability of logistics enterprises could be enlarged and enhanced accordingly.

Enterprises should also follow the trend toward the fourth party logistics, which make the integration of best logistics service providers and provide the best solution of supply chain management or logistics services. The 4PL is beneficial to the tight connection of every member of international logistics and the evident reduction of logistics cost. All of these are helpful to the external expansion of logistics enterprises.

\subsection{To improve the construction of logistics infrastructure and reasonably program the international logistics network}

We need to rationally integrate the layout, scale and function of existing logistics infrastructure, make full use of existing logistics parks, distribution centers and warehouses. At the same time, we should increase the investment on transportation facilities, such as highway, railway, waterway, aviation, and pipeline, etc. The international logistics network should be reasonably programmed, based on the merchandize transaction plan and the foreign trade master plan. But redundant construction and waste of land resources should be strictly prohibited. The comprehensive application of standardized logistics equipments will be helpful for logistics industry to meet the international requirements of continuous and prompt operation. During the process of construction and management of logistics facilities, we can actively introduce the capital, equipment and technology of foreign countries, promote the international cooperation of logistics and improve the status of domestic logistics system in the international frame.

\subsection{To reform the administration system}

The government should draw the blueprint of the industry development with foreseeable eyesight, and change the existing unsystematic and deficient management model. Government agencies at all levels should keep close cooperation, simplify the administrative procedures, and provide convenient services, so as to create a comfortable environment for international logistics industry. The barriers between departments and regions should be broken. The support from government will improve the operation efficiency of logistics enterprises and bring confidence to them for the international competition.

\subsection{To attach importance to the $3 R$ rule and expedite the construction of legal systems}

Due to the fact that different countries adopt different laws and regulations in the logistics fields, the complexity of international logistics is much higher than domestic logistics. The legal system of logistics we are going to build should be in line with the international standards. Learning from those developed countries, we need to attach the importance to the $3 \mathrm{R}$ (reduce, reuse and recycle) rule and apply it to the legislation, regulation and administration, which can facilitate the sustainable development of our international logistics industry.

Moreover, when providing services to foreign customers, our logistics enterprises need to make study on the logistics laws and regulations of foreign countries and international customs of logistics as well. It can help logistics enterprises to explore international market and protect themselves.

\subsection{To build and improve the educational and training system of logistics industry}

The employees of international logistics industry are required not only to master the knowledge of modern logistics services, supply chain management, customs declaration, inspection application, insurance, transportation, international settlement and electronic commerce, but also to be familiar with the practical operation process as well. Evidently, this target is hard to achieve merely by the elementary school education. Therefore, schools, enterprises, governments, industrial associations should work together to build and improve the E\&T system for international logistics industry. Besides degree education and on-job training, they can also take many other measures to enhance the comprehensive competency of professionals, such as popularizing professional qualification systems, establishing and popularizing industrial standards, and holding logistics exhibition and logistics seminar, etc. 


\subsection{To keep updating the advanced professional concepts and popularizing the green logistics}

The low efficiency, high energy consumption and high pollution of our current logistics operation system are the embodiment of the laggard concepts of our logistics enterprises, which is not in accordance with the international development trend. To achieve the sustainable development of our international logistics industry, the popularization of green logistics becomes an extremely urgent task. Green logistics advocates the control and elimination of the negative impacts caused by logistics activities on the environment, and the utility maximization of logistics resources as well. I would like to comment on two important points. Firstly, logistics plans with small negative impact on environment, for example, short-distance distribution, and night delivery should be given priority; Secondly, construction of the logistics system of waste disposal should be on the agenda. The essentials of green logistics are to apply the concepts of environment protection and sustainable development to the logistics management and operation. (Liu Zhixue, 2001, $\mathrm{p} 51)$

3.8 To accelerate the construction of logistics information system and popularize the application of advanced logistics technology

The construction of the comprehensive logistics information system including sorting of functional sub-systems and the information systems of production, wholesale, retail, financing and law, is the guarantee of healthy development of international logistics. (Yang Tailun, 2007, p7)The systematic integration of information technology and network planning technology can achieve the information sharing; make the information transmission more convenient, fast and accurate. It can also synchronize the commercial flow, capital flow, and information flow, increase the integrative benefits of production, circulation and consumption, and eventually optimize the logistics network. The application of barcode technology, RFID (Radio Frequency Identification), GPS (Global Positioning Satellite) technology, and GIS (Geographic Information System) technology can lead to the automatic recognition, picking, loading, unloading, placing and fetching of goods, greatly increasing the efficiency of logistics operation. The logistics information and function sharing between logistics enterprises, and between logistics enterprises and customers, can be achieved through the public logistics information platform.

Furthermore, the wide application of advanced modern logistics technology, such as intelligent transportation, automatically guided vehicle, automatic picking and classifying systems, paperless office systems, modularization technology and simulation technology can further improve the level of mechanization, automation, intellectualization of logistics systems, improve the supply chain management, and make the development of our international logistics industry enter into a new stage. (Lin Donghua \& Sun, Ye, 2008, p37)

\section{Conclusions}

It is an arduous task to build a perfect logistics system and provide high level international logistics services. This goal cannot be achieved at one step. The devotion and cooperation of all the related parties are indispensable. Our international logistics industry should tightly seize the development opportunity given by the economic globalization with long term eyesight, accelerating the infrastructure construction, talents education and training, administration system reform, legal system establishment, logistics information network building and advanced technology application.

With the endeavor of all the parties, the development of China's international logistics industry can scale a new height at an early date.

\section{References}

Lin, Donghua \& Sun, Ye. (2008). The Developing Trend of International Modern Logistics and Revelation to China. Journal of Yantai Vocational College, 14, 37.

Liu, Hanyun. (2008). On the Situation and Development of China's International Logistics Industry. Mordern Business Trade Industry, 5, 6.

Liu, Zhixue. (2001). Modern Logistics Handbook. China Logistics Publishing House. 51.

Yang, Tailun. (2007). Current Status Analysis and Core Competitive Power Research on the International Logistics in

China. Southwest JiaoTong University, 7.

Zhang, Guoqing. (2008), The Developing Trend of International Logistics in the Future. International Business Daily. 1 July. 


\title{
Emotional Intelligence and Employee Performance
}

\section{as an Indicator for Promotion, a Study of Automobile Industry in the City of Belgaum, Karnataka, India}

\author{
Praveen M.Kulkarni (Corresponding author) \\ Karnatak Law Society's, Institute of Management Education \& Research \\ Sy. No. 77, Adarsh Nagar, Hindwadi \\ Belgaum 590011, Karnataka State, India
}

Tel: 91-831-2405-511Ｅ-mail: praveenmkulkarni@gmail.com

B. Janakiram

Department of Master of Business Administration (M.B.A), M. S .Ramaiah Institute of Technology

Vidya Soudha, MSRIT Post, MSR Nagar, Bangalore 560054. Karnataka State, India

Tel: 91- 80- 2360-0822Ｅ-mail: drbjanakiram@gmail.com

D.N.S. Kumar

Alliance Business School

19th Cross 7th Main B T M I Stage, 34th main, Dollar Colony, Bangalore 560068. Karnataka State, India

Tel: 91- 80- 2668-4369 E-mail: dnsk2000@yahoo.com

\begin{abstract}
This study is undertaken to understand the performance level of managers and supervisors at an automobile retailer in the city of Belgaum, the study focuses on understanding the emotional intelligence of the managers and supervisors and its link to their performance level on the job. The findings of the study indicate that emotional intelligence has an impact on the performance level of the managers and supervisors.
\end{abstract}

Keywords: Emotional intelligence, Performance appraisal

\section{Introduction}

In this complex scenario organization both public and private sector have to manage change in an effective way. Emotional Intelligence plays an important role in helping the managers and employees to cope with this dynamic change in the business environment.

Dalip Singh, (2001) mentioned that application of emotional intelligence supports the managers and employees to recognize and understand emotions and using emotional intelligence to manage oneself and his/her relationship with others.

The application of emotional intelligence in the organization includes the areas like personnel selection, development of employees, teams and the organization. The organizations must coach their employees in developing their interpersonal skills and coach them to perform effectively on the job with other employees in the organization.(Reuven Bar-On et al, 2007).

Employees need to enhance their emotional intelligence skills, apart from technical skills, which in turn will enhance their productivity on the job. Management of emotional intelligence by the team members will help in developing interpersonal skills of the team members. Organization's to be successful, need to develop employee's emotional intelligence skills to work effectively in the organisation. (Bob Wall, 2008).

\section{Review of literature}

In the past fifteen years, much has been written about emotional intelligence and its role in the workplace. The experts in the field of emotional intelligence have offered definitions and models to understand the concept of emotional 
intelligence and its impact on employee's life and work. The theory of emotional intelligence is developed and conceptualized into three models ability model, traits model and mixed model.

According to John Mayer and Peter Salovey emotional intelligence is the ability to accurately identify and understand one's own emotional reactions and those of others. It also involves the ability to regulate one's emotions to use them to make good decisions and to act effectively.

Further, Reuven Bar-On defined emotional intelligence as being concerned with effectively understanding oneself and others, relating well to people and adapting to and coping with the immediate surroundings to be more successful in dealing with environmental demands.

Daniel Goleman defined emotional intelligence as a capacity for recognizing our own and others feeling for motivating our self and for managing our emotions, both within ourselves and in our relationship. (Neal M. Ashkanasy et al, 2000). The above definitions indicate that, for an employee to perform effectively on the job emotional intelligence abilities are required by the employee. The employees who have the ability to manage their emotions in an effective way are more successful on the job.

Models of emotional intelligence have been developed on three aspects that is, ability, traits and combination of ability and traits called as mixed model of emotional intelligence.

Ability model of emotional intelligence described emotional intelligence as the "ability to monitor one's own and others' feelings and emotions, to discriminate among them, and to use the information to guide one's thinking and actions.

Traits model of emotional intelligence viewed emotional intelligence and included non-cognitive competencies such as self-esteem, self-actualization, general mood, and general well-being. As would be expected, measures based on trait approaches to emotional intelligence do not correlate highly with measures of intelligence. However, they strongly correlate with personality measures, leading researchers to refer to this approach as emotional intelligence -as-personality.

Mixed Model of emotional intelligence is a combination of ability model and traits model of emotional intelligence. The mixed model denotes the idea that emotional intelligence assesses aspects of personality and cognitive intelligence in addition to the emotional intelligence. (Schutle, 2006).

\subsection{Historical Perspective of Emotional intelligence}

David. Wechsler, (1940) viewed intelligence as an effect rather than a cause and believed that assessments of general intelligence is not sufficient but also non-intellectual factors, such as personality, influence the development of an individual's intelligence. H.Gardner, (1983) developed social intelligence and referred to two types of personal intelligences interpersonal and intrapersonal. Payne, (1986) coined the term, emotional intelligence, in a doctoral dissertation. This qualitative study proposed that one can overcome deficiencies in emotional functioning and regulation by showing strength in the face of fear or desire. Reuven Bar-On, (1997) developed the term "EQ" ("Emotional Quotient") and described his approach to assess emotional and social competence. He created the Emotional Quotient Inventory (EQ-i), which is the first test of emotional intelligence. Psychologists John Mayer and Peter Salovey, (1990) published their article, "Emotional Intelligence," in the journal Imagination, Cognition and Personality. Daniel Goleman, (1995) brought emotional intelligence to the mainstream. He reviewed the work of John Mayer and Peter Salovey and developed his own model of emotional intelligence.

\subsection{Models of Emotional Intelligence}

John Mayer and Peter Salovey developed ability model of Emotional Intelligence, this model mentioned that emotional intelligence is the ability to perceive and to express emotions, assimilate emotions in thought, understand and reason with emotion and regulate emotion in self and others. The major areas are (1) perception and expression of emotion (2) assimilating emotions in thoughts (3) understanding and analyzing the emotion (4) Reflective regulation of emotion. Reuven Bar-On developed mixed model of emotional intelligence is an array of non- cognitive capabilities competencies and skills that influence one's ability to succeed in coping with environmental demands and pressure. Major areas are intrapersonal skills, interpersonal skills, adaptability, stress management and general mood. Daniel Goleman developed mixed model of emotional intelligence and focused on the abilities, which include self control, zeal and persistence and the ability to motivate oneself. Major areas are (1) knowing ones emotions (2) Management of emotions (3) Motivating oneself (4) Recognizing emotions(5)Handling relationship. (R. Sternberg, 2000).

Dr. Peter Jordon developed ability model of emotional intelligence, this model is based on the emotional intelligence model of Peter Salovey and John Mayer. The models consist of three main constraints (1) Ability to deal with own emotions (2) Ability to deal with other's emotions and (3) the use of emotions in problem solving. (Jordan, P.J et al, 2002). 
Schutte and Malouff developed ability model of emotional intelligence. This model is developed based on John Mayer and Peter Salovey model of emotional intelligence. The scale is developed on four-factors that are (1) Optimism (2) Social Skills, (3) Emotional Regulation (4) Utilization of Emotions. (Nicola S. Schutte et al, 1998).

Petrides and Furnham developed traits model of emotional intelligence, they mention that traits emotional intelligence is more comprehensive because the construct consists of self-perceptions and behavioral dispositions, which are compatible with the subjective nature of emotions. (Petrides et al, 2003).

Dr. Wong Chi Sum developed ability model of emotional intelligence based on the four ability dimensions described in the domain of emotional intelligence (1) appraisal and expression of emotion in the self (2) appraisal and recognition of emotion in others (3) regulation of emotion in the self (4) use of emotions to facilitate performance. (Law K.S, et al, 2004).

Ben Palmer and Con Stough developed mixed model of emotional intelligence to assess the five dimensions of emotional intelligence, they are (1) Emotional Recognition and Expression, (2) Understanding Emotions External (3) Emotions Direct (4) Cognition(5) Emotional Management and Emotional Control. (Palmer, B.R. et al, 2002).

\subsection{Emotional intelligence at the workplace}

The study undertaken by Lisa. Gardner and Con.Stough, (2002) applied emotional intelligence test to predict transformational, transactional and laissez-faire leadership styles through multifactor leadership questionnaire among 110 senior level managers. The results indicate that emotional intelligence correlated highly with components of transformational leadership. William. Leban and Carol. Zulauf, (2004) studied project management and role of leadership. The study addressed 24 project managers and their associated projects in six organizations from varied industries. The results of the study found that a project manager's transformational leadership style has a positive impact on actual project performance, which also indicate that emotional intelligence ability has an impact on the project manager's transformational leadership style and subsequent on actual project performance. F. William Brown et al, (2006) studied to examine the relationships between emotional intelligence, leadership, and desirable outcomes in organizations. Sample of 2,411 manufacturing workers, engineers, and professional staff were included in the study. However, in this study no support was found for relationships between emotional intelligence and desirable outcomes or a significant relationship between emotional intelligence and transformational leadership. D. Jamali, et al, (2008) studied emotional intelligence in the Lebanese context, and investigated emotional intelligence competency scores that is (Self-awareness, Self-regulation, Self-motivation, Social awareness and Social skills) in a sample of 225 Lebanese employees and managers. A questionnaire-based measure was developed to capture the basic competencies on a self-report basis. The findings suggest differences in emotional intelligence scores across different emotional intelligence competencies for males and females, with males scoring higher on self-regulation and self-motivation, and females scoring higher on self-awareness, empathy and social skills, and that emotional intelligence levels increase significantly with managerial position. David. Rosete and Joseph. Ciarrochi, (2005) studied to investigate the relationship between emotional intelligence, personality, cognitive intelligence and leadership effectiveness. Senior executives $(\mathrm{n}=41)$ completed an ability measure of emotional intelligence John Mayer and Peter Salovey-Caruso Emotional Intelligence Test (MSCEIT), a measure of personality 16 Personality Traits, $5^{\text {th }}$ edition (16PF5) and a measure of cognitive ability through Wechsler Abbreviated Scale of Intelligence (WASI). Leadership effectiveness was assessed using an objective measure of performance and a $360^{\circ}$ assessment involving each leader's subordinates and direct manager $(n=149)$. Correlation and regression analyses revealed that higher emotional intelligence was associated with higher leadership effectiveness, and that emotional intelligence explained variance not explained by either personality or intelligent quotient.

\section{Theoretical framework}

Emotional intelligence is a set of competencies, which direct and control one's feelings towards work and performance at work. These set of competencies are the ability of the individual to control and manage his or her moods and impulses on the job. Knowing one's emotions and feelings as they occur, and tuning one's self to the changed situation, requires the emotional competency, emotional maturity and emotional sensitivity that are demanded on the job. In a work situation, performance of the employees depends on working with group of people with different ideas, suggestions, and opinions. Effective use of emotional intelligence gives better team harmony.(Ashforth et al,1995)

Leaders, in particular, need high emotional intelligence, because they represent the organization to the customers, they interact with the highest number of people within and outside the organization and they set the tone for employee morale. Leaders with high emotional intelligence are able to understand their employee's needs and provide them with constructive feedback. Success in sales requires emotional intelligence ability to understand the customer and provide service to customers. (Bridget Murray, 1998). Emotional intelligence in the organization supports in identification of employees emotional intelligence level and its impact on employee performance on the job. This would act as an indicator for promotion of employees in the organization. 
The present study addresses such a novel area and attempts to find out how far the organization would be able to identify emotional intelligence of the employee's and relate it to their performance on the job. Hence the study is conducted to measure the emotional intelligence level among the managers and supervisors and compare with their performance in the organization at a large automobile dealership at Belgaum, Karnataka State, India. The objectives of the study are as follows

1) To understand the level of performance of the managers and supervisors.

2) To understand the level of emotional intelligence of the managers and supervisors.

3) To study the impact of emotional intelligence on the level of performance and their ability to take higher level jobs in the organization.

The present study is confined to measure emotional intelligence among the managers and supervisors and compare the performance level of the employees in the study organization which is located in the city of Belgaum, Karnataka State, India. The study only considers managers and supervisors working in all the branches of the organization.

Emotional intelligence represents a set of competencies that perceive, understand and regulate emotions in ourselves and in others. These emotional competencies are learned capabilities based on emotional intelligence that lead to superior performance. The emotional intelligence model developed by Daniel. Goleman is applied to understand the emotional intelligence of the employees at the study organization. According to Daniel. Goleman, emotional intelligence as shown in figure 1 can be organized into four dimensions representing the recognition of emotions in ourselves and in others, as well as the regulation of emotions in ourselves in others. Each dimension consists of a set of emotional competencies that people must possess to fulfill that dimensions of emotional intelligence. The dimensions are as under:-

- Self awareness: It refers to having a deep understanding of one's own emotions as well as strengths, weaknesses, values and motives.

- Self management: This represents how well we control or redirect our internal states, impulses and resources.

- Social awareness: It is mainly about empathy, having understanding and sensitivity to the feelings, thoughts and situations of others.

- Relationship management: It refers to managing other people's emotions.

\section{Refer to Figure 1}

The present study model which is shown in figure 2 on emotional intelligence has been linked and correlated with performance of managers and supervisors. (McShane and Steven,2008)Emotional intelligence correlates with job success of leaders. Sosik and Megerian, (1999) found leaders high on emotional intelligence outperformed when measured by organizational performance data. Study conducted by Lam and Kirby, (2002) have shown positive correlation between emotional intelligence and performance on job. Cavallo and Brienza, (2002) conducted the study and assessed the leadership behavior of 358 leaders at Johnson and Johnson Corporation, at locations across the globe. The study found the best performers were those high in emotional intelligence as rated by their supervisors, peers, and subordinates in the Emotional Competency Inventory (ECI), a 360-degree feedback instrument based upon Goleman's model of Emotional intelligence competencies. From the above studies, it can be observed that many of the researchers have argued emotional intelligence is an important aspect for improving performance. Therefore, we can formulate the following hypothesis

(1) Null Hypothesis $\left(\mathrm{H}_{\mathrm{o}}\right)$. There is no significant difference between managers and supervisors with respect to performance appraisal score.

(2) Null Hypothesis $\left(\mathrm{H}_{\mathrm{o}}\right)$. Managers and supervisors performance appraisal scores don't correlate with emotional intelligence score

\section{Refer to Figure 2}

\section{Participants, Measures and Methodology}

\subsection{Participants}

The organization is a partnership firm situated at Belgaum, Karnataka, India. The firm was established in the year 1920. They started their concern with rice mill at Belgaum. In the year 1930, they diversified their business activities and started a soap factory in Belgaum.

In the year, 1935, they started an edible oil mill at Belgaum .They further diversified their business into automobile sector, in the year 1956 with dealership of Ashok Leyland Vehicles.

In the year 1991 they got dealership for TELCO, vehicles and spare parts for North Karnataka region. The total workforce has increased from 10 in the year 1920 to 1200 in the year 2008.

The total number of branches as of 2008 is four situated at Hubli, Belgaum, Bagalkot and Bijapur. The total turnover for the financial year 2006- 2007 in Indian Rupees is 4500 million. 
The data collection for the research was undertaken from both primary and secondary sources. Primary data was collected by survey method using structured questionnaire on emotional intelligence and Secondary data was collected from various journals, magazines, newspapers and websites like Human Resource Management International Digest, Human Capital, and HR.com.

Sample was drawn from a population of employees working in the automobile retailer in the city of Belgaum, Karnataka India. As per the latest employee record of 2008, there are 1200 employee of whom there are 320 are managers and supervisors. The sample size was calculated and the number of the employees to be assessed and interview was one hundred twenty five employees in the designation of managers, which is more than $10 \%$ of the total population. Out of this, one hundred twenty five were selected through simple random sampling method using random table.

In the study of the emotional intelligence and employee performance, the respondents include managers and supervisors in the dealer organization. The age composition of the respondents is in the age group of 25-55 years. With regard to gender $90 \%$ of the respondents were male and $10 \%$ were female. The average experience level of managers and supervisors was 9.5 years.

\subsection{Measures}

The employee performance appraisal was collected for one year that is November 2007- November 2008. The performance appraisal is in the format of 360 degree appraisal. The score range on the scale of 1 to 5 , where in 1 indicates low and 5 indicates high. Employees are rated on this scale on their level of performance. The employee's performance was rated by self, to executives and directors of the organization.

Emotional intelligence scale was developed after studying various factors on the emotional intelligence model of Daniel. Goleman. This questionnaire was pre-tested by the researcher by administrating it to a sample of twenty five managers and supervisors to check its construct validity. The construct validity was tested using cronbach's alpha test. The result of the test showed that some of the questions had cronbach coefficient alpha less than 0.70 and those questions were removed from the questionnaire.

\subsection{Methodology}

Following the collection of data. The data was processed was processed by applying descriptive statistics, t- test and correlation. Descriptive statistics was applied understand the level of managers and supervisor performance and level of emotional intelligence among managers and supervisors. T-test was applied to understand the comparison between managers and supervisors level of performance on the job. Finally, correlation was derived between emotional intelligence and performance level of managers and supervisors.

\section{Results}

\subsection{Level of employee performance of manager and supervisor}

The performance level of managers and supervisors is depicted in the table.1 and 2, the level of performance is assessed on the scale of 1 to 5 , where in 1 is equal to low and 5 is equal to high.

The average level of mean score and standard deviation is indicated at 2.371 and .4152. The mean and standard deviation score of supervisors are 2.563 and .4839. Table 3 shows the overall performance of the employee in the organization is low, therefore performance appraisal mean score of 2.467 is indicated which falls under the lower end of the scale.

Table 4 shows test of averages to compare the performance appraisal score of the managers and supervisors. The test takes into consideration variance structure Levene's test for quality of variance is applied. At 5\% level of significance, we observe that the $\mathrm{P}$ Value is greater than the level of significance that is $(0.992>0.05)$, thus we consider that the facts of the two groups assume equal variance. Under this assumption, we observe that $\mathrm{P}$ Value for test for means is less than the level of significance $(0.019<0.05)$, and hence we can reject Null Hypotheses No.1 at 5\% level of significance, which indicates that there is no significant difference between managers and supervisors performance appraisal scores.

\subsection{Level of emotional intelligence among the managers and supervisors}

The study on level of emotional intelligence of the managers and supervisors is shown in table.5, the analysis of the managers level of emotional intelligence indicates that managers are moderate on emotional awareness, self esteem, flexibility, adaptability, innovation, initiative, opportunity taking, developing others, service orientation, political awareness, two way communication, building relationships and collaborative flexibility.

The managers are low on accurate self assessment, self control, trustworthiness, conscientiousness, responsibility, achievement drive, organizational commitment, optimism, understanding others, developing diversity, influence and persuasion, conflict management, leadership, change catalyst and team building. The level of performance of the supervisors shows low level of emotional intelligence on all the variables. 


\subsection{Correlation analysis between emotional intelligence and the performance level of managers and supervisors}

Correlation analysis was done which is shown in table.6, to understand the impact of emotional intelligence on performance of the managers and supervisors. The results show that there is no significant correlation between the emotional intelligences score and performance appraisal scores, as the co-efficient correlation is assuming a very ungeneralizable value of 0.080 , further, the Null Hypothesis No.2 is accepted which implies that performance of managers and supervisors are not as per the expectations of the management as they are not able to manage their emotional intelligence on the job.

\section{Discussions}

The managers and supervisors show lower level of performance in the organization. The company has to take measures to upgrade their technical and soft skills to enhance their performance on the job. The managers show lower level of emotional intelligence in key areas that is achievement drive, teambuilding, flexibility and adaptability, as these factors are very much critical for the job. The organisation has to arrange for a training program on how to develop emotional intelligence and apply it on the job for higher managerial skills. The supervisors show a lower level of emotional intelligence on the job, which would have greater impact on the performance on job, the supervisors are to be enlightened about the importance of emotional intelligence for higher performance on the job. The managers and supervisors are not able to meet the expected level of performance on the job, as they are not able to manage their emotions. The key areas that are service orientation, leadership, customer relationship which is the most important aspects for retails sector, therefore they have to groom on these aspects for higher performance. The managers and supervisors have to take higher level roles and responsibility in the organisation in the future and for this they have to develop their skills in the area of self esteem, self control, innovation and developing others. The organization at the time of employee selection, must adapt administering emotional intelligence test for selecting right person for the right job and this would enhance the performance of the employee on the job and the organization.

\section{Limitations and future research}

The present research is concerned with the study of emotional intelligence and its impact on performance. As such, there are many areas for improvement and for further research. In particular, we recognize that our study is subject to some important limitations. The first and most obvious limitation of the present study is limited by cost and time. A second limitation concerns the suggestions made by the study may require policy decisions and top management support for implementations. Finally, the findings of the study can be generalized only to likewise industry and organization of the same size.

The findings from the current study have important implications on application of emotional intelligence on employee performance, there remain a number of other functions of Human Resource Management in Indian automobile retail sector where the implementation of emotional intelligence could be equally beneficial. Hence there lies the scope of further study in those areas. The subsequent are those other areas in relation to emotional intelligence and employee, firstly, the emotional intelligence has a direct impact on the employee job satisfaction, as employees who are able to manage emotional are able to perform effectively on the job and there by derive satisfaction on the job. Studies on the effects of the emotional intelligence of team leaders may also be of interest to understand the development of effective team in the organization. The application and impact of emotional intelligence on developing interpersonal skills among the employees and finally, understanding employees Work Life Balance through emotional intelligence.

\section{Implications and conclusions}

The present study has produced some important results that have implications for both research and practice. The study on managers and supervisors emotional intelligence and their ability to perform effectively on the job is identified as they are not able to manage their emotional intelligence, which has a direct impact on their job. Further, the level of emotional intelligence and performance level of the managers and supervisors is moderate to low, these skills are to be developed for achieving higher employee productivity and to enhance the image of the organization. A particularly interesting finding of the present study was that low emotional intelligence of managers and supervisors had an impact on their level of performance on the job. This has implications for management, suggesting that organizations could be profitable by identifying the level of emotional intelligence of managers and supervisor and apply interventions that are focused on the developing emotional intelligence among the employees in the organization.

\section{References}

Ashforth, B.E., \& Humphrey. R..H. (1995). Emotion in the workplace. A reappraisal. Human Relations, 48(2), 97-125. Bar-On, R. (1997). The Bar-On Emotional Quotient Inventory (EQ-i): Toronto, Canada. Technical Manual Multi-Health Systems, 56-78.

Bob. Wall. (2008). Working Relationships Using Emotional Intelligence to Enhance your Effectiveness with Other (1st ed.). USA: Davies Black Publishing.(Chapter2).

Bridget Murray. (1998). The APA Monitor, 29, 7, 3-4. 
Cavallo, K. \& Brienza, D. (2002). Emotional competence and leadership excellence at Johnson and Johnson: the emotional intelligence leadership study. [Online] Available: http://www.eiconsortium.org

D. Jamali, Y. Sidani \& D. Abu-Zaki. (2008). Emotional Intelligence and management development implications: Insights from the Lebanese context. Journal of Management Development, (27) 3, 348 - 360.

Dalip Singh. (2001). Emotional Intelligence at work (1st ed.). New Delhi: Response Books. (Chapter 2)

David Rosete \&Joseph Ciarrochi. (2005). Emotional Intelligence and its relationship to workplace performance outcomes of leadership effectiveness. Leadership and Organization Development, (26)5, 388 - 399

F. William Brown, Scott E. Bryant\& Michael D. Reilly, Does. (2006). Emotional Intelligence - as measured by the EQI - influence transformational leadership and desirable outcomes. Leadership and Organization Development, (27) 5, 330 -351 .

Gardner. H. (1983). Frames of Mind: The theory of Multiple Intelligences. (10th ed.). New York: Basis Books.(Chapter 3)

Goleman, D. (1995). Emotional intelligence. (1st ed.) New York: Bantam. (Chapter 1).

Jordan, P.J., Ashkanasy, N.M., \& Hartel, C.E.J. (2002). Emotional intelligence as a moderator of emotional and behavioral reactions to job insecurity. Academy of Management Review, 27, $1-12$.

Lam, L.T. \& Kirby, S.L. (2002). Is emotional intelligence an advantage? An exploration of the impact of emotional and general intelligence upon individual performance. The Journal of Social Psychology, 142, 133-143.

Law, K. S, Wong, C. S, \& Song, L. J. (2004). The construct and criterion validity of emotional intelligence and its potential utility for management studies. Journal of Applied Psychology, 89(3), 483-496.

Lisa Gardner., \&Con Stough. (2002). Examining the Relationship between Leadership and Emotional Intelligence in senior level managers, Leadership and Organization Development, (23) 2, 68 - 78.

McShane \& Steven. (2008). Organizational Behavior (4th ed.). New Delhi: Tata McGraw-Hill Publication. (Chapter 8). Neal M. Ashkanasy., Charmine E. J., Härtel., \& W. J. Zerbe. (2000). Emotions in the Workplace: Research, Theory, and Practice, (1st ed.). United Kingdom: Greenwood Publishing Group.(Chapter 4)

Nicola S. Schutte., John M. Malouff., Lena E. Hall., Donald J. Haggerty., Joan T. Cooper., Charles J. Golden., \& Liane Dornheim. (1998). Development and validation of a measure of emotional intelligence, Personality and Individual Differences, (25) 2, 167-177.

Palmer, B.R., Donaldson, C. \& Stough, C. (2002). Emotional intelligence and life satisfaction. Personality and Individual Differences, 33, 1091- 1100.

Payne.W.L. (1986), A Study of Emotion, Developing Emotional Intelligence, Self integration relating to fear, pain and desire. Dissertation Abstracts, International, 47 (01) P 203A (University Microfilms No AAC 8605928).

Peter Salovey, \& John Mayer, (1990). Emotional Intelligence, Imagination, cognition, and personality, 9(3), $185-211$.

Petrides, K. V. \& Furnham, A. (2003). Trait emotional intelligence: Behavioural validation in two studies of emotion recognition and reactivity to mood induction. European Journal of Personality, 17, 39-57.

R. Sternberg. (2000). Handbook of Intelligence. (1st ed) New York: Cambridge University Press. (Chapter 6).

Reuven Bar-On., J.G.Maree., Maurice., \& Jesse Elias. (2007). Educating People to Be Emotionally Intelligent, (1st ed.). United Kingdom: Greenwood Publishing Group. (Chapter 3)

Schutle. Maloof., \& Kevin. Murphy, (2006). A critique of Emotional Intelligence, What are the Problems and How can they be fixed(1st ed.). United Kingdom: Routledge. (Chapter 6)

Sosik, J.J. \& Megerian, L.E. (1999). Understanding leader emotional intelligence and performance: the role of self-other agreement on transformational leadership perceptions. Group and Organization Management, 24, $367-390$.

Wechsler. D. (1940). Non intellective factors in general intelligence. Psychological Bulletin, 37, 444-445.

William Leban \& Carol Zulauf. (2004). Linking Emotional Intelligence Abilities and Transformational Leadership Styles. Leadership and Organization Development Journal, (25) 7554 - 564. 
Table 1. Managers average level of performance

\begin{tabular}{|c|c|c|c|}
\hline & $\mathrm{N}$ & Mean & Std. Deviation \\
\hline Average Performance score for the year & 63 & 2.371 & .4152 \\
\hline Valid N (list wise) & 63 & - & - \\
\hline
\end{tabular}

Source: Field survey

Table 2. Supervisor average level of performance

\begin{tabular}{|c|c|c|c|}
\hline & $\mathrm{N}$ & Mean & Std. Deviation \\
\hline Average performance score for the year & 62 & 2.563 & .4839 \\
\hline Valid N (list wise) & 62 & - & - \\
\hline
\end{tabular}

Source: Field survey

Table 3. Overall performance of the managers and supervisors

\begin{tabular}{|c|c|c|c|c|c|}
\hline & $\begin{array}{c}\text { Designation of the } \\
\text { Employee }\end{array}$ & $\mathrm{N}$ & Mean & Std. Deviation & Std. Error Mean \\
\hline $\begin{array}{c}\text { Average score for the } \\
\text { year }\end{array}$ & Manager & 63 & 2.371 & .4152 & .0523 \\
\cline { 2 - 6 } & Supervisor & 62 & 2.563 & .4839 & .0615 \\
\hline & Total & 125 & 2.467 & .44955 & .29225 \\
\hline
\end{tabular}

Source: Field survey

Table 4. Comparison between the managers and supervisor on Performance level

\begin{tabular}{|c|c|c|c|c|c|c|c|c|c|c|}
\hline & $\begin{array}{l}\text { Levene's } \\
\text { Test for } \\
\text { Equality }\end{array}$ & \multicolumn{8}{|c|}{ t-test for Equality of Means } \\
\hline & & $\mathrm{F}$ & Sig. & $\mathrm{t}$ & df & $\begin{array}{c}\text { Sig. } \\
\text { (2-tailed) }\end{array}$ & $\begin{array}{c}\text { Mean } \\
\text { Difference }\end{array}$ & \multirow[t]{2}{*}{$\begin{array}{l}\text { Std. Error } \\
\text { Difference }\end{array}$} & \multicolumn{2}{|c|}{$\begin{array}{c}95 \% \\
\text { Confidence } \\
\text { Interval of the } \\
\text { Difference }\end{array}$} \\
\hline & & & & & & & & & Lower & Upper \\
\hline \multirow{2}{*}{$\begin{array}{l}\text { Average } \\
\text { score } \\
\text { for the } \\
\text { year }\end{array}$} & $\begin{array}{c}\text { Equal } \\
\text { variances } \\
\text { assumed }\end{array}$ & .000 & .992 & -2.375 & 123 & .019 & -.1915 & .0806 & -.3510 & -.0319 \\
\hline & $\begin{array}{c}\text { Equal } \\
\text { variances } \\
\text { not } \\
\text { assumed }\end{array}$ & & & -2.372 & 119.628 & .019 & -.1915 & .0807 & -.3513 & -.0317 \\
\hline
\end{tabular}

Source: Field survey 
Table 5. Emotional Intelligence Mean S core of level of managers and supervisors

\begin{tabular}{|c|c|c|c|c|c|c|}
\hline & \multicolumn{3}{|c|}{ Managers } & \multicolumn{3}{|c|}{ Supervisor } \\
\hline & $\begin{array}{c}\text { High } \\
>4\end{array}$ & $\begin{array}{c}\text { Moderate } \\
\text { 3-4 }\end{array}$ & $\begin{array}{c}\text { Low } \\
<3\end{array}$ & $\begin{array}{c}\text { High } \\
>4\end{array}$ & $\begin{array}{c}\text { Moderate } \\
\text { 3-4 }\end{array}$ & $\begin{array}{c}\text { Low } \\
<\mathbf{3}\end{array}$ \\
\hline Emotional awareness & & 3.174 & & & & 2.647 \\
\hline Accurate self-assessment & & & 2.841 & & & 2.605 \\
\hline Self-esteem & & 3.000 & & & & 2.507 \\
\hline Self-control & & & 2.952 & & & 2.605 \\
\hline Trustworthiness & & & 2.984 & & & 2.253 \\
\hline Conscientiousness \& responsibility & & & 2.777 & & & 2.464 \\
\hline Flexibility $\&$ adaptability & & 3.142 & & & & 2.563 \\
\hline Innovation & & 3.079 & & & & 2.45 \\
\hline Achievement drive & & & 2.952 & & & 2.464 \\
\hline Organisational commitment & & & 2.761 & & & 2.704 \\
\hline Initiative \& opportunity taking & & 3.063 & & & & 2.492 \\
\hline Optimism \& resilience & & & 2.936 & & & 2.591 \\
\hline Understanding others & & & 2.968 & & & 2.577 \\
\hline Developing others & & 3.047 & & & & 2.478 \\
\hline Service orientation & & 3.158 & & & & 2.563 \\
\hline Developing diversity & & & 2.841 & & & 2.521 \\
\hline Political awareness & & 3.253 & & & & 2.746 \\
\hline Influence and persuasion & & & 2.952 & & & 2.704 \\
\hline Two-way communication & & 3.174 & & & & 2.619 \\
\hline Conflict management & & & 2.761 & & & 2.647 \\
\hline Leadership & & & 2.698 & & & 2.507 \\
\hline Change catalyst & & & 2.873 & & & 2.436 \\
\hline Building relationships & & 3.158 & & & & 2.577 \\
\hline Collaborative flexibility & & 3.206 & & & & 2.121 \\
\hline Team building & & & 2.762 & & & 2.761 \\
\hline
\end{tabular}

Source: Field Survey.

Table 6. Correlation between emotional intelligence and the performance level of managers and supervisors

\begin{tabular}{|c|c|c|c|}
\hline & & $\begin{array}{c}\text { Emotional } \\
\text { intelligence scores }\end{array}$ & $\begin{array}{c}\text { Performance } \\
\text { appraisal scores }\end{array}$ \\
\hline \multirow{3}{*}{$\begin{array}{c}\text { Emotional } \\
\text { intelligence Score } \\
\text { employees }\end{array}$} & Pearson Correlation & 1 & .080 \\
\hline & Sig. (1-tailed) & & .188 \\
\hline & $\mathrm{N}$ & 125 & 125 \\
\hline \multirow{3}{*}{$\begin{array}{c}\text { Performance } \\
\text { Appraisal Score of } \\
\text { employees }\end{array}$} & Pearson Correlation & .080 & 1 \\
\hline & Sig. (1-tailed) & .188 & \\
\hline & $\mathrm{N}$ & 125 & 125 \\
\hline
\end{tabular}

Source: Field Survey 
Self

(Personal

Others

\begin{tabular}{l|l|l|}
\multirow{2}{*}{$\begin{array}{l}\text { Recognition } \\
\text { of emotions }\end{array}$} & $\begin{array}{l}\text { Self awareness } \\
\text { Emotional self awareness } \\
\text { Accurate self assessment } \\
\text { Self confidence }\end{array}$ & $\begin{array}{l}\text { Empathy } \\
\text { Organizational awareness } \\
\text { Service }\end{array}$ \\
\cline { 2 - 3 } $\begin{array}{l}\text { Regulations } \\
\text { of emotions }\end{array}$ & $\begin{array}{l}\text { Emotional self control } \\
\text { Transparency }\end{array}$ & $\begin{array}{l}\text { Inspirational leadership } \\
\text { Influence } \\
\text { Adaptability } \\
\text { Achievement } \\
\text { Initiative }\end{array}$ \\
Optimism & $\begin{array}{l}\text { Change catalyst } \\
\text { Conflict management } \\
\text { Building bounds } \\
\text { Teamwork and collaborating }\end{array}$ \\
\hline
\end{tabular}

Figure 1. Emotional intelligence competencies model

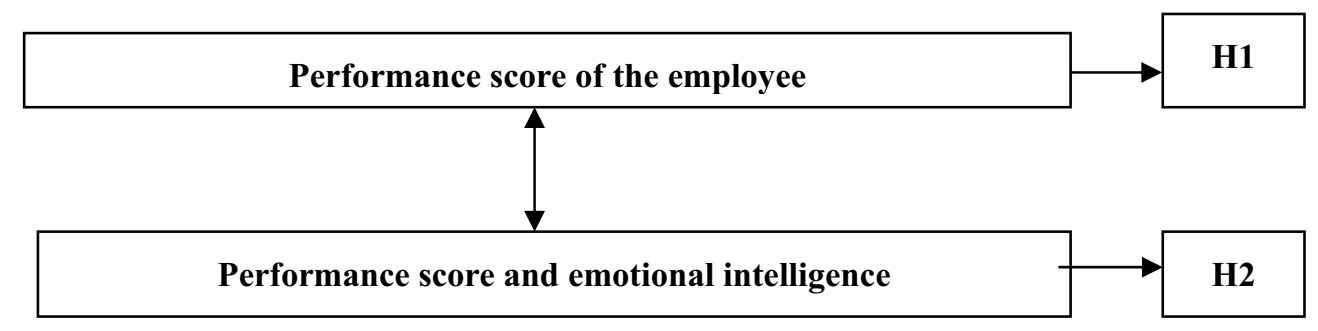

Figure 2. Model of the study 


\title{
The Quality of Learning Environment
}

\section{and Academic Performance from a Student's Perception}

\author{
Rohana Kamaruddin, Nor Rashidah Zainal \& Zaidi Mohd Aminuddin \\ Department of Economics, Faculty of Business Management, Universiti Teknologi MARA \\ 404500 Shah Alam, Selangor, Malaysia \\ Tel: 60-3-5544 $4935 \quad$ E-mail: rohana070@salam.uitm.edu.my
}

Kamaruzaman Jusoff (Corresponding author)

Tropical Forest Airborne Observatory (TropAIR), Faculty of Forestry, Universiti Putra Malaysia

UPM 43400 Serdang, Selangor, Malaysia

Tel: 60-3-8946 7176 E-mail: kamaruz@putra.upm.edu.my

\begin{abstract}
The study determined how students assess the various components of their learning environment. It also identified how the learning environment affects students' learning outcomes. A sample of 370 randomly selected students was taken from a population of Bumiputera's students. Data analysis was done using descriptive statistics and Product Moment Correlation. Findings revealed that students could assess the four components that contribute to their academic performance, which is: facilities provided (11 items), housing environment, parents motivation, school and teacher factors. Housing environment and parent's motivation has the highest assessment while facilities provided at home have the least. The results also showed that only two components of the learning environment are positively correlated with students' academic performance that is housing environment and school/teacher involvement. The findings are discussed with a view to improve the quality of the learning environment, subsequent academic performance.
\end{abstract}

Keywords: Quality, Learning, Environment, Facility, Conception

\section{Introduction}

Intelligence is not the only determinant of academic achievement of a student. Academic achievement of a student is always associated with the many components of learning environment. According to Bosque and Dore (1998), learning and teaching environment ought to implement six functions: inform, communicate, collaborate, produce, scaffold, and manage. They added that conceptually speaking, the learning environment refers to the whole range of components and activities within which learning happens. Based on the Sandberg's (1998), the definition on the functions of a learning environment can be quoted as "Teacher component's role is to provide something between loose guidance and direct instruction. It can be a human agent (present or distant), an intelligent agent, and instructions like some text books provide. This component provides information from the syllabus to the task level"

Student's motivation for learning is also generally regarded as on of the most critical determinants, which contribute to the success and quality of any learning outcome (Mitchell, 1992). Research shows that student's perceptions of academic competency decline as they advance in school (Eccles, Wigfield, \& Schiefele, 1998). Schunk and Pajares (2002) attribute this decline to various factors, including greater competition, less teacher attention to individual student progress, and stresses associated with school transitions.

Another important determinant, which shouldn't be neglected, is the family. Family is the primary social system for children for all cultures across the region. Rollins and Thomas (1979) found that high parental control were associated with high achievement. Religiosity as an aspect of the family environment is another independent variable possibly influencing academic achievement (Bahr, Hawks, \& Wang, 1993). Cassidy and Lynn (1991) explored how family environment impacts motivation and achievement. This means that motivation served as a mediating variable between home background, personal characteristics, and educational attainment. Higher-achieving students are likely to have the following characteristics: positive feelings about their school experiences; attribute their success in high school to such things as hard work, self-discipline, organization, ability, and high motivation; tend to watch relatively little television 
during the school week; tend to associate with students who also were successful in school; and avid readers (WEAC, 2005).

A study by Niebuhr (1995) examined relationships between several variables and student academic achievement. His findings suggest that the elements of both school climate and family environment have a stronger direct effect on academic performance. Academic performance is typically assessed by the use of teacher ratings, tests, and exams (Howse, 1999). Students were usually more motivated by teachers who cared about student learning and showed enthusiasm. According to Niebuhr (1995) there is no significant effect on the relationship of individual motivation and its effect on academic achievement. Another study by Boggiano et. al. (1991), regarding differences in gender in motivation, found that females were significantly more extrinsic than males. Male students' performance accords their interest level more than is the case for female students. Specifically, female students' academic performance is less associated with their interests than male students' academic performance (Schiefele et. al., 1992).

Study done by Hammer (2003) the home environment is as important as what goes on in the school. Important factors include parental involvement in their children's education, how much parents read to young children, how much TV children are allowed to watch and how often students change schools. Achievement gap is not only about what goes on once students get into the classroom. It's also about what happens to them before and after school. Parents and teachers have a crucial role to play to make sure that every child becomes a high achiever. Parental influence has been identified as an important factor affecting student achievement. Phillips (1998) also found that parental education and social economic status have an impact on student achievement. Students with parents who were both college-educated tended to achieve at the highest levels. Income and family size were modestly related to achievement (Ferguson, 1991). Peng and Wright's (1994) analysis of academic achievement, home environment (including family income) and educational activities, concluded that home environment and educational activities explained the greatest amount of variance.

Therefore, this paper is designed specifically to study the conception of Bumiputera students on what are the facilities that help learning, housing environment, parent's motivation, school and teacher factor on their academic achievement. Research in this area should increase the awareness to concentrate on student's motivation in an effort to increase effective institutional, family and support system functioning in the later years and eventually improve our educational stature.

\section{Methodology}

\subsection{Instrument and variables}

An instrument was given to a student randomly to measure the variables of the study. It is divided into 5 parts. The first and second parts, deals with the background of the student and the family, third part on the housing conditions- type of house, number of bedrooms, electrical items (11 items) etc in the house, fourth part on the high school grade and the learning factors that contribute to the grade, and the last part on the higher education factors, two example of question: "Why they choose to further their study?, Why they choose the program? Some of the item use yes or no and some of the item was measured using a Likert scale that ranged from "strongly disagree" (1 point) to "strongly agree" (5 points). Academic achievement was measured using the number of A's during high school examination.

\subsection{Respondents}

The study was conducted at UiTM, main campus Shah Alam and six affiliated colleges of UiTM., namely Institut Professional Baitulmal, Institut Teknologi Perak, Kolej Unikop, Kolej Yayasan Terengganu, Kolej Shahputra, Kolej Teknologi Timur. A total of 370 students (75 males and 296 females) with average age of 20.5 years responded to the items of the instrument. Respondents were guaranteed confidentiality, and the instrument was filled in anonymously with no identification information.

\subsection{Procedure}

Reliability of each part of the instrument was assessed through calculating the Cronbach Alpha realibility test. Relationship between parents motivation, family/housing environment, student/teacher environment and academic achievement were assessed by using product moment correlation correlations among these variables.

\section{Results and discussion}

The internal reliability of each of the three scales in the instrument was estimated. Table 1 shows number of items, Cronbach's alpha reliability for each scale. Considering that reliability is a function of number of items in an instrument and that number of items is relatively small, the three scales were considered internally reliable.

$$
<<\text { Table 1. Reliability of the items }>>
$$

Table 2 provides the demographic profiling of a respondent. The female respondent is $80 \%$ and male respondent $20 \%$, which reflect the current enrollment situation in most IPTA and IPTS. Majority of the respondent age 18-22 (91\%) and 
only (9\%) age of 23-30 years old. Most of the respondent staying with their parents (86\%), and range of siblings from $1-4(45 \%)$ and $4-8(49 \%)$.

$<<$ Table 2. Demographic profiling of a respondent $>>$

Table 3 summarizes the result of facilities in 11 categories. These finding shows that school play an important role that contributed to the student's performance, where school tuition/ extra class (65\%) and school motivation program (67\%) reflects the highest percentage. Distance form school (46\%) and own study table (46\%) and followed by having their own room (43\%). Thus from this result we can conclude that school as an organization is a crucial element in determining the success of the student (Calbaugh \& Rozyeki, 1990).

Comparisons from the other three components, the finding reveal that housing environment, basic needs (97\%) and study needs (88\%) shows high contribution to the academic performance of the student during their high school year. This followed by school/teacher involvement $(82 \%)$ in their study, and encouragement by parents to enroll to university (78\%).Wang et. al. (1996) indicate that parent encouragement are strongly related to improved student achievement.

$<<$ Table 3. Descriptive result of facilities that contribute to student academic performance $>>$

$<<$ Table 4. Pearson product moment correlations among achievement, housing environment, parents motivation, school/teacher environment>>

Table 4 shows the correlations between achievement and housing environment $(0.195)$ and between achievement and school/teacher environment (0.166) were statically significant, these values were still practically small. Achievement and parent's motivation were not correlated. Cassidy and Lynn (1991) included a specific factor of the family's socioeconomic status, crowding, as an indicator of how being disadvantaged. They found that a less physically crowded environment, along with motivation and parental support, were associated with higher educational levels of children.

\section{Conclusion}

The purpose of this study was to explore the Bumiputera's student's conception on what they perceived is important to achieve good academic performance. The results revealed that the key element that contributes to their achievement is the organizational factors, the extra class and motivational programmes provided by the school. The teacher involvement in their study is also very importance determinant that associated with the student academic performance. On the social factors, by having their own study table, own room and computer will be an added advantage to their achievement in school.

\section{References}

Bahr, S., Hawks, R., \& Wang, G. (1993). Family and religious influences on adolescent substance abuse. Youth and Society, 24, 443-465.

Basque, Josianne \& Sylvie Doré. (1998) Le concept d'environnement d'apprentissage informatisé. Journal of Distance Education/Revue de l'enseignement à distance, 13(1), ISSN 0830-0445.

Boggiano, A. K., Main, D. S., \& Katz, P. (1991). Mastery motivation in boys and girls: The role of intrinsic versus extrinsic motivation. Sex Roles, 25, (9/10), 511-520.

Cassidy, T., \& Lynn, R. (1991). Achievement motivation, educational attainment, cycles of disadvantage and social competence: Some longitudinal data. British Journal of Educational Psychology, 61, 1-12.

Clabaugh,G.K., \& Rozyeki, E., (1990). The school as an organization. Understanding school: The foundation of education. Harper \& Rowe. New York

Eccles, J. S., Wigfield, A., \& Schiefele, U. (1998). Motivation to succeed. In W. Damon and N. Eisenberg (Eds.). Handbook of Child Psychology, 3, 1017-1095.

Ferguson, R. (1991). Paying for public education: New evidence of how and why money matters. Harvard Journal on Legislation, 28, (Summer 1991): 465-98.

Hammer, B. (2003). ETS identifies affecting student achievement-Washington update.

Mitchell, J. V. Jr. (1992). Interrelationships and predictive efficacy for indices of intrinsic, extrinsic, and self-assessed motivation for learning. Journal of Research and Development in Education, 25 (3), 149-155.

Niebuhr, K. (1995). The effect of motivation on the relationship of school climate, family environment, and student characteristics to academic achievement. (ERIC Document Reproduction Service ED 393 202).

Peng, S. S., \& Wright, D. (1994). Explanation of academic achievement of Asian -American students. Journal of Educational Research, 87 (6), 346-352. 
Phillips, M. (1998). Family background, parenting practices, and the black-white test score gap. The black-white test score gab, Washington, D.C., Brooking Institution Press.

Rollins, B. C., \& Thomas, D. L. (1979). Parental support, power, and control techniques in the socialization of children. In W. R. Burr, R. Hill, F. I. Nye, \& I. L. Reiss (Eds.), Contemporary theories about the family, Vol. L (pp. 317-364). New York: The Free Press, Macmillan.

Sandberg, J. A. (1994). Educational paradigms: issues and trends. In Lewis, R. Mendelsohn, P., (ed.), Lessons from Learning, (IFIP TC3/WG3.3 Working Conference 1993), pages 13--22, Amsterdam. North-Holland.

Schiefele, U., Krapp, A., \& Winteler, A. (1992). Interest as a predictor of academic achievement: A meta-analysis of research. The role of interest in learning and development (pp. 183-212). Hillsdale, NJ: Erlbaum.

Schunk, D. H., \& Pajares, F. (2002). The development of academic self-efficacy. Development of achievement motivation (pp. 15-32). San Diego, CA: Academic Press.

Wang, J., Wildman, L., \& Calhoun, G. (1996). The relationship between parental influences and student achievement in seventh grade mathematics. School Science and Mathematics, 96 (8), 395-400.

WEAC. (2005). Variables affecting student achievement. [Online] Available: http://www.weac.org/ resource/primer/variable.htm.

Table 1. Reliability of the items

\begin{tabular}{ccc}
\hline & & Cronbach \\
& Items & Alpha \\
\hline A. Facilities provided & 10 & 0.58 \\
B. Housing environment & 2 & 0.73 \\
C. Parents motivation & 2 & 0.67 \\
D. School/ teacher environment & 2 & 0.40
\end{tabular}

Table 2. Demographic profiling of a respondent

\begin{tabular}{cr}
\hline Items & Percentag \\
\hline Gender & 20 \\
Male & 80 \\
Female & \\
& Race \\
Melayu & 98
\end{tabular}

Bumiputera Sabah/ Sarawak 2

Age

$18-22$

23-30

\section{Staying with}

Parents $\quad 86$

Mother $\quad 9$

Farther $\quad 2$

Relatives 3

\section{No of siblings}

1 to $4 \quad 45$

5 to $8 \quad 49$

9 to $13 \quad 6$ 
Table 3. Descriptive result of facilities that contribute to student academic performance

\begin{tabular}{|c|c|c|c|c|c|c|}
\hline Components & \multicolumn{3}{|c|}{ Percentage } & & & \multirow[t]{2}{*}{$100 \%$} \\
\hline A. Facilities provided & Yes & No & \multicolumn{2}{|l|}{ Not sure } & & \\
\hline Distance of school from house & 46 & 51 & \multicolumn{2}{|l|}{3} & & 100 \\
\hline School bus & 27 & 71 & \multicolumn{2}{|l|}{2} & & 100 \\
\hline School tuition/extra class & 65 & 32 & \multicolumn{2}{|l|}{3} & & 100 \\
\hline House tuition/ tuition centre & 38 & 60 & \multicolumn{2}{|l|}{2} & & 100 \\
\hline Computer in school & 37 & 61 & \multicolumn{2}{|l|}{2} & & 100 \\
\hline Computer at home & 41 & 57 & \multicolumn{2}{|l|}{2} & & 100 \\
\hline Own room & 43 & 54 & \multicolumn{2}{|l|}{3} & & 100 \\
\hline Own study table & 46 & 52 & \multicolumn{2}{|l|}{2} & & 100 \\
\hline School motivation program & 67 & 31 & \multicolumn{2}{|l|}{2} & & 100 \\
\hline Parents motivation program & 16 & 84 & \multicolumn{2}{|l|}{0} & & 100 \\
\hline Government financial & 13 & 84 & \multicolumn{2}{|l|}{3} & & 100 \\
\hline B. Housing environment & Strongly Agree & Agree & Not sure & Disagree & \multicolumn{2}{|c|}{ Strongly Disagree } \\
\hline Basic needs are fulfill & 70 & 27 & 2 & 1 & 0 & 100 \\
\hline Study needs are fulfill & 48 & 40 & 6 & 6 & 0 & 100 \\
\hline \multicolumn{7}{|l|}{ C. Parents motivation } \\
\hline Concern about my study & 62 & 36 & 1 & 1 & 0 & 100 \\
\hline Encouragement to university & 78 & 20 & 1 & 1 & 0 & 100 \\
\hline \multicolumn{7}{|l|}{ D. School/ teacher environment } \\
\hline School Infrastructure & 19 & 45 & 19 & 14 & 3 & 100 \\
\hline Teachers involvement & 37 & 45 & 14 & 3 & 1 & 100 \\
\hline \multicolumn{7}{|l|}{ E. Other } \\
\hline Private Tuition & 17 & 45 & 23 & 12 & 2 & 99 \\
\hline \multicolumn{7}{|c|}{$\begin{array}{l}\text { Table 4. Pearson product moment correlations among achievement, housing environment, parents motivation, } \\
\text { school/teacher environment }\end{array}$} \\
\hline & \multicolumn{6}{|c|}{ Achievement } \\
\hline Achievement & \multicolumn{6}{|c|}{1} \\
\hline Parents motivation & \multicolumn{6}{|c|}{-0.89} \\
\hline School/teacher environment & \multicolumn{6}{|c|}{$-0.166^{* *}$} \\
\hline Housing environment & \multicolumn{6}{|c|}{$-0.195 * *$} \\
\hline
\end{tabular}

** Correlation is significant at 0.01 level (2 tailed) 


\title{
Research on Evaluation of Intensive Use
}

\section{of Agricultural Landunder the New Countryside Construction}

\author{
Hongxia Xue \\ Working Doctor Student of School of Economics of Wuhan University of Technology \\ E-mail: gdxue@126.com
}

\begin{abstract}
This paper is on the basis of the former evaluation system of intensive use of agricultural land, unifying the actual situation of new countryside construction in our country, to analysis the intensive use degree of every province's agricultural land in our country using the method of principal and factor analysis. The research, melting into the agricultural industry target in the former evaluation system of intensive use of agricultural land, connecting the land product with the market price, establishes the new evaluation system of intensive use of agricultural land, which purpose is increase the value of the land product and increase the income of the farmers. Based on the data of every province in 2005, the article founds that the investment factor of land production, the additional income factor of farmers and the financial payout for supporting agriculture play the comparatively major role in the intensive use of the agricultural land. And the article also puts forward several advises.
\end{abstract}

Keywords: New countryside construction, The Intensive use degree of agricultural land, The Method of principal and factor analysis

\section{Introduction}

On May 4,2005,General Secretary $\mathrm{Hu}$ Jintao in his letter to the rural youth of Xinjiang province put forward to construct new socialist countryside.And on June $4^{\text {th }}$ of the same year, Premier Wen Jiabao raised to "construct new countryside and change the backward appearance of some villages" in his inspection of rural tax reform in Gao Town in Hebei Province. Leading comrades of the central authorities require the Ministry of Construction to earnestly strengthen the construction of villages and towns and building of new socialist countryside. Construction of new countryside should be based on development of the first industry---agriculture, on increase in peasants' income and on solution of the "three agricultures" problem. Although China is rich in aggregate of land resources, yet it has a large population, it needs to feed over $20 \%$ of the world population by less than $10 \%$ of the world cultivated land and the area of its per-capita cultivated land is less than half of the world level.According to the investigation result of national land use change carried out by the Ministry of Land and Resources in 2005, by October 31,2005, the area of China cultivated land is 122.0827 million $\mathrm{hm}^{2}$, its per capita arable land area is only $0.093 \mathrm{hm}^{2}$, less than $40 \%$ of average level of world, equal to $1 / 8$ of U.S.A and 1/2 of India. Moreover, China's cultivated land is distributed mainly in hilly, mountainous and plateau areas, and the cultivated land distributed in plains and basins only occupies $30.73 \%$ of the total cultivated land. To build new countryside, increase the peasants' income and solve the problem of "three agricultures" on the basis of the existing cultivated land, it is necessary to change the original extensive farming way of land, to invest more labor, fund and technology in less land, to raise land production rate and to use less agricultural land to produce more agricultural products, therefore, intensive use of agricultural land has become an objective requirement for development of social economy.

Now, the Party Central Committee puts forward to build new countryside and to increase the peasants' income, this raises new requirements for agricultural land intensive use. Agricultural land intensive utilization requires less investment but more output, more output does not mean more earning of the peasants, and sometimes more output may bring less earning of peasants. Therefore, to increase more benefit, intensive use of agricultural land, while stressing less investment but more output, should adjust the varieties of planting in accordance with change of the market. Industrialization of agriculture is a fundamental change of traditional agricultural farming system under the conditions of market and an effective means to raise intensive use of agricultural land. At present, the core of agricultural industrialization is, around a certain leading industry or some relevant key products, to connect and combine all links of preproduction, mid-production and postproduction into a new industrial system to realize integration of planting, breeding and processing; production, supply and sale; and trade, industry and farming. Therefore, industrialized framing 
is a double-directional continuation and extension of agricultural chains, an optimized combination of elements and a united farming system of economic, ecological and social benefits.

In this thesis, the author, under the prerequisites of new countryside construction, puts the conditions of agricultural industrialization into the evaluation system of agricultural land intensive use, adopts the principal component analytic method to analyze the agricultural land intensive use of 30 provinces, cities, autonomous regions and municipalities under the Central Government in 2005 and in accordance with the factor scores, conducts sequencing of agricultural land intensive use of each province, city, autonomous region and municipality under the Central Government.

\section{Establishment of Index System of Agricultural land Intensive Use under the Condition of New Countryside Construction}

\section{Traditional Index System of Agricultural land Intensive Use}

Intensive land farming is relative to extensive farming. The concept of intensive land farming first came from such economists as Ricardo (David Ricardo) in their land lease theory of study on agricultural land use. It is a farming way to centrally invest more production means and labor in a certain area of land and to use advanced technology and management method to seek high profits from smaller area of land. It can be divided into several types, such as fund intensive type, labor intensive type, technology intensive type, etc.

For the implication and formula of agricultural land intensive use, scholars from different countries have their different understandings. Scholars from Japan define land intension from the angle of land output, its formula is:

$$
\text { Land intension=land farming area/pure farm production }
$$

Formula (1) means the needed farming area of land of unit production, the less the land intensity is, the more intensive the land use is; contrary, the more the land intensity is, the more extensive the land use is.

Scholar Tadur.Blinkeman from Germany defines land intension from the angle of land investment. He calls labor and fund invested in unit land as land intension.

$$
\mathrm{I}=\left(\mathrm{A}+\mathrm{K}+\mathrm{Z}^{2}\right) / \mathrm{F}
$$

In this formula, I-land intensive use, the bigger the $\mathrm{I}$ is, the bigger the land intensive use is, the smaller the $\mathrm{I}$ is, the bigger the land extensive use is; A - salary and expenses; K-capital consumption; Z-interest needed to pay farming capital; F-area of use land.

The types of the above two formulas are different, but the actual implication is the same. Because the law of reasonable use of land is that less investment results in less output and more investment brings more output. Japanese scholars regard more output of unit area as intension while German scholar more investment in unit area as intension, their conclusions are the same.

\section{Land Intensive Use Index System under New Countryside Construction}

According to the content of land intension, land intensive use can be divided into labor intension, technology intension and fund intension. Three intensions have different focuses in investment content, but they are mutually related, especially the two latter ones, sometimes they cannot be distinguished. Because application of new technology normally accompanies increase of investment fund - technology itself has value, and at the same time technical investment must take material investment as carrying body. Therefore, we can discuss together technology intension and fund intension, naming fund and technology intension.

\section{Determination of Labor Intension Evaluation Index}

Labor intension means the value of labor invested in unit-area of agricultural land within certain time (generally taking year as unit, its formula is:

Labor intension=invested labor salary and expenses/area of agricultural land

Invested labor salary and expenses=labor force invested in agricultural land*annual average salary of the district

In formula 4, the number of labor invested in agricultural land is determined by the labor number of the first industry in the rural area, and the average annual salary of the district can be replaced by the per capita salary of the peasants of the district.

\section{Determination of Fund and Technology Intension Evaluation Index}

Fund and technology intension means the total value of fund and technology invested in unit-area of agricultural land within a certain time (generally taking year as unit, its formula is:

Fund and technology intension=total value of invested fund and technology and/area of agricultural land. 
Of which, in most previous researches, the invested capital only calculating the peasants' own investment and not calculating financial investment of the country. Because this thesis has considered the factor of agricultural industrialization and financial support fund to agricultural industrialization which have obvious promoting function and can raising the peasant's income. Therefore it considers financial support fund. Capital invested by peasants themselves means mainly such expenses for purchasing seeds, fruit saplings and simple agricultural tools. Invested technical value mainly includes funds for purchasing chemical fertilizers, pesticides, plastic films, etc, and farm production tools for raising work efficiency. In practice, it is difficult for peasants to distinguish the above expenses. Therefore, this thesis calls all the expenses for purchasing pesticides, chemical fertilizers, seeds and plastic films as expenses of agricultural expenses. Annual expenses for purchasing agricultural production machinery can be expressed by the current year un-purchased production fixed assets. Financial farm supporting expenses include expenses in agricultural, forestry, animal husbandry and fishery industries, fund of land use are all expressed with financial supporting agricultural expenses on unit-area of agricultural land.

Index of Agricultural Industrialization Level

Here we use the scale of agricultural industrialization to indicate agricultural industrialization level, and total output value index of agricultural industrialization to express scale of agricultural industrialization. In this thesis, the index of the total output value of agricultural industrialization means the proportion of the total output value of agricultural industrial chains of the township enterprises in the total output value of agricultural industry and all township processing industries which use agricultural products as materials. At present, solution of China's "three agricultural" problem mainly relies on head township enterprises to lead other enterprises and take the road of agricultural industrialization. According to the implication of agricultural industrialization, the total output value of agricultural industrialization chain in this thesis is expressed by the total output value of other related township enterprises except industrial and building industries, and the total output value of agricultural by-product processing enterprises is expressed by the total output value of township agricultural product processing enterprises. Its calculating formula is:

Total output value index of agricultural industrialization=total output value of industrial chains of agricultural industrialization/ (total output value of all agricultural +agricultural product processing enterprises) (6).

Index of farm product processing industry of the district means the proportion of farm product processing industry in the total output value of the agriculture, its calculating formula is:

Index of processing enterprises=total output value of farm product processing industry of the district/ (total output value of farm product processing industry +total output value of agriculture) (7).

\section{Analysis of Agricultural land Intensive Use under the Background of New Countryside Construction Method of Analysis}

According to the above index system, we select the original index data of year 2005 of China's main provinces from the 2006 Statistic Yearbook and through screening and sorting get data in Table 1. Then we use statistical software SPSS to conduct principal component analysis and obtain characteristic value and contributive ratio of each factor and then, in accordance with the principle of accumulated contributive ratio bigger than $70 \%$, extract 2 common factors. To better explain the load of each factor, we, in accordance with the principle of biggest variance and on the basis of principal component analysis, conduct rotary analysis and finally decide the index variables of each common factor. The accumulated contributive ratio of the two common factors reaches $72.836 \%$, this indicates the extracted factors can better explain all variables.

\section{Analysis of Data}

\section{Analysis of Extracted Factors}

The load matrix of the two factors to index variables is showed in Table 2. From Table 1, we can see that the contributive ratio of explanation by factor 1 of agricultural land intensive utilization under the condition of new countryside construction is $50.872 \%$, its contribution is biggest; the contributive ratio of explanation by factor 2 of agricultural land intensive utilization under the condition of new countryside construction is $21.964 \%$, that is to say Factor 1 includes $50.872 \%$ of information of index, while factor 2 includes $21.964 \%$ of information of index. The contributive ratio of the two factors has already reached $72.836 \%$, they can basically represent the information of all indexes and can reflect the general situation of agricultural land intensive utilization under the condition of new countryside construction.

\section{Insert Table 1 here}

\section{Analysis of Factor Load Matrix}

Factor principal component analytic load matrix is showed in Table 2. Because principal component analysis of factor load cannot better explain the load of each factor, it is necessary to conduct orthogonal rotation on the basis of principal component analysis and get Table 3. From Table 3, we can see that indexes entered into factor 1 are labor integration 
situation, average land production expenses, average land fixed assets expenses, etc. these are peasants' investments of chemical fertilizers, seeds, fruit saplings plastic films and farm tools in order to improve soil quality and raise output, so it can be named as factor of agricultural land production investment $\left(\mathrm{f}_{1}\right)$. Indexes entered into factor 2 are average land financial expenses, index number of total industrial output value, index number of total output value of agricultural product processing enterprises, etc. these are factors which can raise output and price of agricultural products and increase income of peasants, so it can be named as income-increasing factor of peasants $\left(\mathrm{f}_{2}\right)$. According to the farm land intensive utilization and the requirements of accumulated contribution, the quantity of principal component $=7$, accumulated contributive ratio is $72.83 \%$, the formula of general evaluation value is: $F=0.50872 \mathrm{f}_{1}+0.21964 \mathrm{f}_{2}$

\section{Insert Table 2 and Table 3 here}

When further analyzing the influence of each index on factors, we find that in analysis of factors, the after-rotation factor load matrix can better explain the load situation of each factor, but cannot better explain the information quantity represented by index in the factor, therefore, we still use the (non-rotated) factor load of principal component analysis to analyze the influence, because when non-rotation, factor 1 has already represented the 50.872 information quantity of the original index, so focus on $\mathrm{f}_{1}$ analysis. From Table 2, we can see that the influences of such indexes as labor intensive situation, average land production expenses, average land fixed assets expenses, average land financial expenses and agricultural product processing total output value index on $\mathrm{f}_{1}$ are all above 0.5 , this illustrates each factor has comparative influence on factor 1, of which, the influence coefficient of labor intensive situation, average land production expenses are above 0.80 ; the influence coefficient of agricultural product processing total output value index and average land fixed assets expenses are 0.70; and then the influence coefficient of average land financial expenses is 0.549 , and the influence coefficient of Industrial total output value index is 0.133 .

\section{Scores of Factors}

According to the analytic result of SPSS statistic software, the factor scores of each region are showed in Table 4.

\section{Insert Table 4 here}

According to the scores of factors in Table 4, a line graph can be made and Figure 1 can be got. This figure shows comprehensive scoring situation of agricultural land production investment factor, peasant income increasing factor and agricultural land intensive utilization factor.

\section{Insert Figure 1 here}

\section{Conclusion}

\subsection{Agricultural land production investment factor still play key role in agricultural land intension}

The variance contributive ratio of agricultural land production investment factor reaches $50.872 \%$, that is to say that under the condition of new countryside construction, peasant labor intension situation, average land production expenses, average land fixed assets invested in land production and raising of peasants' income still play bigger role. Analysis indicates that raise of China's agricultural land output still in bigger extent relies on fine seeds and saplings, fine cultivation and peasant investment for purchasing production tools. Therefore improvement of the quality of seeds and saplings and raising of working efficiency of production tools has bigger influence on raising of agricultural land intension.

4.2 Under the background of new countryside construction, development and strengthening of farm product processing enterprises plays significant role in raising agricultural land intension and increasing peasants' income.

From Table 2, we can see that the influence coefficient of total output value index of farm product processing enterprises reaches 0.794 , just following labor intensive situation and average land production expenses, this indicates township farm product processing enterprises play comparatively bigger role in increasing of peasant income.

\subsection{Financial farm-supporting expenses play important supporting role in raising agricultural land intension}

From Table 2, we can know that the influence coefficient of financial farm-supporting expense on factor 1 comes up to 0.549 , this shows that the present financial farm-supporting expense has bigger influence on agricultural land intension.

\section{4}

In analysis of agricultural land intension scores of each province, Zhejiang, Anhui, Guangdong and Fujian get comparatively higher score in agricultural land intensive use, showing that the agricultural land intension of these four provinces is comparatively higher, while Zhejiang, Beijing, Shanghai, Guangdong, Jiangsu and Fujian have higher score of factor 1, indicating that these regions invest more in agricultural land production, namely investing higher labor intension, production expenses and fixed asset expenses. Viewing China's agricultural statistic data, we can know that because Tianjin and Shanghai belong to industrial cities, their township enterprise only have industrial enterprise and building enterprise total output value and output value of other industries is zero, so their score of factor 2 is lower. Zhejiang, Anhui, Liaoning and Hunan have higher scores of factor 2, indicating the level of agricultural industrialization 
of these four provinces is higher.

\section{Suggestions}

In line with the above analyses and combination of the present China new contryside construction situation, the following suggestions are made:

First of all, it is necessary to increase agricultural land production investment and raise agricultural land output.

From the above conclusion, we can see that investment in agricultural land production exerts greater influence on agricultural land intension. Therefore, increasing investment in agricultural land production is needed. At present, among the agricultural land production investment, production investment and fixed asset investment, such as buying farm machines and tools still need to be paid by the peasants themselves, but most of the peasants won't be able to purchase these high-efficient farm machines and tolls due to their own economic conditions, this will in great extent restrict use efficiency of agricultural land. Moreover, raising of land output still needs relying on research and development of fine seeds and fruit saplings and needs support of agricultural science and technology, so, we should increase agricultural research investment to raise the per-mu output of the land.

Energetically support the development of head enterprises, especially development of head farm product processing enterprises

From the above analytic conclusion, we can know that head enterprises, especially head farm product processing enterprises have greater influence on raising the agricultural industrialization level, increasing the peasants' income and upgrading agricultural land intension. At the present time, China takes the road of agricultural industrialization and adopts the mode of head enterprises leading development of local industrialization. Development of head enterprises can increase numbers of agricultural orders, expand purchasing amount of agricultural products and gradually raise the price of agricultural products. At the same time head enterprises connect with market, which can guide peasants to grow products needed by markets, to upgrade land output value and indirectly raise per capita salary of the peasants, thus increasing the peasants' income. Therefore, local governments should greatly support the development of the head enterprises, especially development of head agricultural farm product processing enterprises.

\section{Increase financial expenses to support agriculture and raise agricultural land intensive use}

Since reform and opening to the outside world, due to the difference of diadactic structure between town and countryside, the proportion of financial farm supporting fund in gross national product has been comparatively small. In $2000,2001,2002,2003,2004$ and 2005, the national financial expenses on agriculture is $7.8 \%, 7.7 \%, 7.2 \%, 7.1 \%$, $8.3 \%, 5.3 \%$ respectively. National financial expense is very limited. Agricultural land fund is mainly invested by peasants themselves. From the result of analyses, we can see that increase of financial fund on agriculture has comparatively bigger influence in raising agricultural land intensive use, so under the background of new countryside construction, governments at different levels should gradually increase investment in agricultural land so as to raise agricultural land intensive use.

\section{Each province should increases agricultural land intensive use in accordance with its actual conditions}

It is known from the above scores of provincial factors that because agricultural land intensions of regions are different, the land production investment factors are different, and peasant income factors are different as well. Beijing, Zhejiang and Guangdong get higher scores of land production investment factors, but lower scores of peasant income increasing factors, and peasant income increasing factors of most regions are very low. Therefore, governments in all regions should energetically invest in land production and at the same time raise the peasants' income in accordance with their actual situation and guide the peasants to grow market products, raise product output and price so to raise the peasants' income while upgrading agricultural land intensive use.

\section{References}

Cui, Li \& Xu, Yueqing. (2007). Space -time Variant Analysis of Hebei Agricultural land Intensive Utilization. Progress of Geography Science, (2), 116-125.

Hao, Fanghua, Chang, Ying and Ning, Datong. (2003). Challenge Faced by China Land and Resource and Sustainable Development. Natural Ecological Protection, (4), 11-14.

Liu, Xinwei. (2006). Introduction to China Land and Resource Intensive Utilization. Land and Resource Information, (3), 7-13.

Tian Shuxi \& Fu, Ling. (2004). Study on Evaluation System of Development Level of Agricultural Industrialization. Hubei Agricultural Science, (3), 8-10.

Wu, Jianqin. Report of Land and Resource Ministry-For ten years, China agricultural land has decreased by 120 million mu, Xinhua Net. [Online] Available: http://news.xinhuanet.com/house (Retrieved from March 2006). 
Xie, Zhengfeng. (2002). Elementary Introduction to Land Intension and Sustainable Use. Land and Natural Resource Research, (4), 31-32.

Yan, Liqin \& Wang, Zhanqi. (2007). Study on Evaluation of Agricultural land Intensive Utilization-Taking Changyang Tujia Autonomous County as Example. Study on Farm Mechanization, (6), 22-24.

Zhang, Fugang, Hao, Jinmin \& Jiang, Guanghui. (2005). Space -time Variant Analysis of China Urban Land Intension. China Land Science, 19 (2), 23-29.

Zhu, Hugen. (2007). Contributive Analysis of the Influence of China Finance Supporting Agricultural Industrialization on the Growth of Peasant Income. Agricultural Technical Economy, (4), 103-109.

Table 1. Extraction of Factors

\begin{tabular}{|c|c|c|c|c|c|c|c|c|c|}
\hline \multirow[b]{2}{*}{$\begin{array}{c}\text { Varia } \\
\text { ble }\end{array}$} & \multicolumn{3}{|c|}{ Initial Factors } & \multicolumn{3}{|c|}{ Extracted Factors } & \multicolumn{3}{|c|}{ Rotary Extracted Factors } \\
\hline & $\begin{array}{l}\text { Characteri } \\
\text { stic value }\end{array}$ & $\begin{array}{l}\text { Contribu } \\
\text { tive } \\
\text { ratio }(\%)\end{array}$ & $\begin{array}{l}\text { Accumu } \\
\text { lated } \\
\text { contribu } \\
\text { tive } \\
\text { ratio }(\%)\end{array}$ & $\begin{array}{l}\text { Characteri } \\
\text { stic value }\end{array}$ & $\begin{array}{c}\text { Contribu } \\
\text { tive } \\
\text { ratio }(\%)\end{array}$ & $\begin{array}{l}\text { Accumu } \\
\text { lated } \\
\text { contribu } \\
\text { tive } \\
\text { ratio( } \%)\end{array}$ & $\begin{array}{c}\text { Characte } \\
\text { ristic } \\
\text { value }\end{array}$ & $\begin{array}{l}\text { Contribu } \\
\text { tive } \\
\text { ratio( } \%)\end{array}$ & $\begin{array}{l}\text { Contribu } \\
\text { tive } \\
\text { ratio }(\%)\end{array}$ \\
\hline 1 & 3.052 & 50.872 & 50.872 & 3.052 & 50.872 & 50.872 & 2.320 & 38.672 & 38.672 \\
\hline 2 & 1.318 & 21.964 & 72.836 & 1.318 & 21.964 & 72.836 & 2.050 & 34.165 & 72.836 \\
\hline 3 & .800 & 13.336 & 86.172 & & & & & & \\
\hline 4 & .489 & 8.146 & 94.318 & & & & & & \\
\hline 5 & .280 & 4.664 & 98.983 & & & & & & \\
\hline 6 & .061 & 1.017 & 100.000 & & & & & & \\
\hline
\end{tabular}

Table 2. Factor load matrix of principal component analysis

\begin{tabular}{|c|c|c|}
\hline & \multicolumn{2}{|c|}{ Factors } \\
\hline & 1 & 2 \\
\hline Labor intensive situation & .949 & -.131 \\
\hline Average land production expenses & .828 & .408 \\
\hline Average land fixed assets expenses & .720 & .360 \\
\hline Average land financial expenses & .549 & .655 \\
\hline Industrial total output value index & .133 & .712 \\
\hline Agricultural product processing total output value index & .794 & -.262 \\
\hline \multicolumn{3}{|l|}{ Table 3. Rotary factor load matrix } \\
\hline & \multicolumn{2}{|c|}{ Factors } \\
\hline & 1 & 2 \\
\hline Labor intensive situation & .736 & .516 \\
\hline Average land production expenses & .894 & .228 \\
\hline Average land fixed assets expenses & .781 & .193 \\
\hline Average land financial expenses & -.008 & .855 \\
\hline Industrial total output value index & .564 & .755 \\
\hline Agricultural product processing total output & .434 & .715 \\
\hline
\end{tabular}


Table 4. Factor Scores of Each Region

\begin{tabular}{cccccccc}
\hline Region & Factor 1 & Factor 2 & Score & Region & Factor 1 & Factor 2 & Score \\
\hline Beijing & 1.40932 & -1.65969 & 0.352415 & Hubei & -0.36484 & 0.37697 & -0.1028 \\
Tianjin & 0.24602 & -1.90509 & -0.29328 & Hunan & 0.4632 & 0.84153 & 0.420473 \\
Hebei & -0.25325 & 0.60676 & 0.004435 & Guangdong & 1.54905 & 0.30254 & 0.854483 \\
Shanxi & -0.90684 & 0.27444 & -0.40105 & Guangxi & -0.30107 & 0.46238 & -0.0516 \\
Inner & -0.77365 & 0.11356 & -0.36863 & Hainan & -0.9378 & -0.54 & -0.59568 \\
Liaoning & 0.27619 & 0.93618 & 0.346126 & Sichuan & -0.3659 & 0.13393 & -0.15672 \\
Jilin & -0.74346 & 0.35934 & -0.29929 & Guizhou & -0.74576 & 0.14573 & -0.34737 \\
Heilongjiang & -0.97023 & -0.13116 & -0.52238 & Yunnan & -0.77471 & 0.23769 & -0.3419 \\
Shanghai & 1.43225 & -3.72579 & -0.08972 & Xizang & -0.87325 & -1.03423 & -0.6714 \\
Jiangsu & 0.85444 & 0.13594 & 0.464529 & Shanxi & -0.72886 & 0.15014 & -0.33781 \\
Zhejiang & 2.87696 & 1.25029 & 1.738181 & Gansu & -0.97163 & 0.09891 & -0.47256 \\
Anhui & 1.39521 & 1.34933 & 1.006138 & Qinghai & -0.89868 & 0.06285 & -0.44337 \\
Fujian & 1.0911 & 0.56183 & 0.678465 & Ningxia & -0.44213 & -0.03085 & -0.2317 \\
Jiangxi & 0.07259 & 0.34722 & 0.113191 & Xinjiang & -1.06613 & -0.6074 & -0.67577 \\
Shandong & 0.54998 & 0.49392 & 0.38827 & & & & \\
Henan & -0.09812 & 0.39271 & 0.036339 & & & & \\
\hline
\end{tabular}

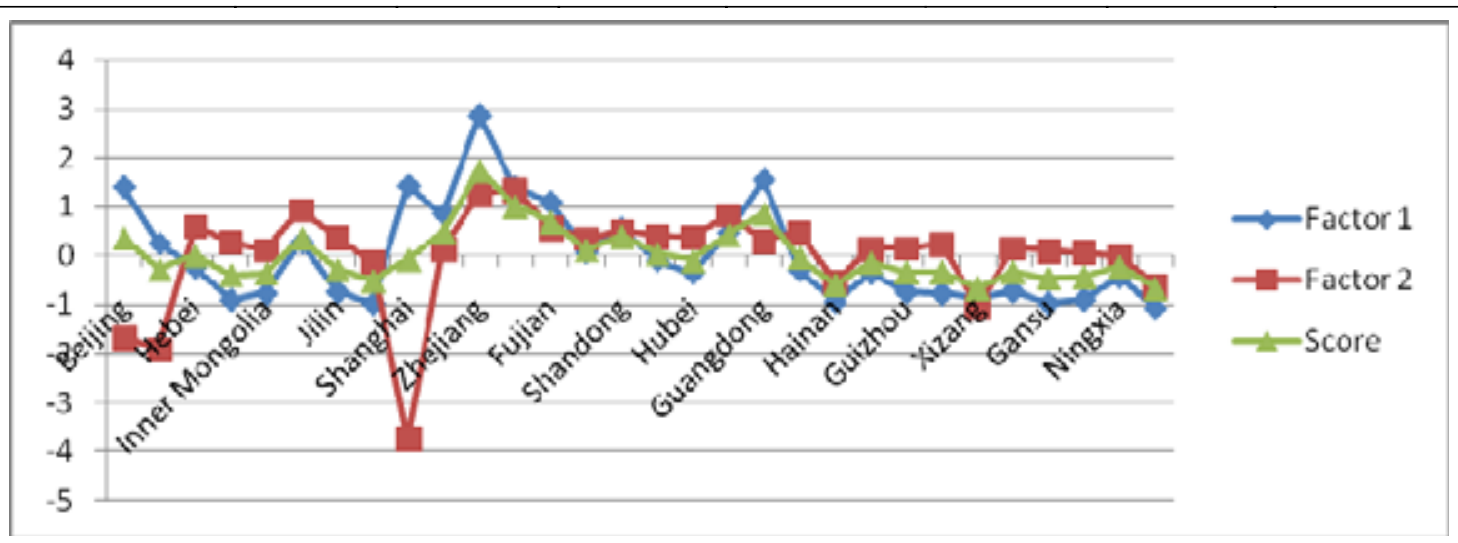

Figure 1. Analytic line graph of factor score 


\title{
The Root Analysis and the Impact on China of Sub-loan Crisis
}

\author{
Lei Zhang \\ Department of Accounting, Shandong Economic University \\ Jinan 250014, China \\ E-mail: zhangleilei23@163.com \\ Yuanyuan $\mathrm{Yu}$ \\ Department of Accounting, Shandong Economic University \\ Jinan 250014, China \\ E-mail: starfishyyy@126.com
}

\begin{abstract}
From 2007, a subprime storm began to blows from the US, and sweep across the whole world with a rapid speed. It makes the world economic growth slow -down, even Iceland and a fraction of the world's countries fall into bankrupt. Behind this, the dollar hegemony of which the United States has been proud is exactly the main reason. Actually, the appreciation of RMB and the interest rates raised by the U.S. Federal Reserve have triggered the subprime mortgage crisis. Although the direct impact on China is not extremely great, the indirect influence can't be underestimated. Face to the crisis, China should learn this lesson from it, control the real estate bubble, expand domestic demand and reduce the gap between rich and poor in order to realize the economy transformation.
\end{abstract}

Keywords: Sub-loan Crisis, Dollar Hegemony, Expand Domestic Demand

February 13, 2007, the United States the risk of mortgage loans began to surface, and soon evolved into a so-called "once-in" sub-loan crisis. The two largest U.S.A mortgage finance institutions - Fannie Mae and Freddie Mac, as the loans serious shrunk, liabilities rose rapidly, by the U.S.A government to take over; the fifth-largest U.S. A investment bank Bear Stearns low-cost easy to master; the fourth largest investment Lehman Brothers filed for bankruptcy protection; third-largest investment bank Merrill Lynch \& Co. was acquired by Bank of America; Goldman Sachs and Morgan Stanley transformed into bank holding companies, the top five investment banks dropped across the board. The world's largest insurance agency, American International Group (AIG) are also in a precarious, the United States government has an emergency to the American International Group, 85 billion U.S.A dollars to provide bridging loans. In subprime mortgage crisis effect of the more obvious, we try to sub-loan crisis by the root of the matter, and explore this by many people since the last century known as the 30's "Great Depression" the most serious financial crisis with the revelation to be able to draw lessons from them, clarifying the continued reform and opening up of China's financial industry development

\section{The root of sub- loan crisis}

\subsection{The ultimate root of sub-loan crisis}

About the root of sub-loan crisis, domestic and foreign scholars have done a full demonstration, formed a relatively consistent view, that is "sub-loan crisis is essentially a credit risk from the cumulative lead to a credit crisis, but then developed capital markets led to a variety of asset prices generally fall in asset prices caused by the crisis."(Zhang Ming, 2008) However, poking the fog of superb financial operations of the Wall Street financial speculator, we can be sure to find: uncontrolled innovative financial instruments and the resulting credit risk is only triggered this "once-in" sub-loan crisis. The direct cause of the root causes is not an end. America's long-pursued by the neo-liberal economic and market fundamentalism, and the resulting "U.S.A hegemony", is the main reason.

In today's global competition pattern, China and other developing countries had no money, nor technology, nor business 
management experience. To achieve economic development, only through the active introduction of foreign investors, while the development of export-oriented economy in exchange for the necessary foreign exchange. In the "U.S. hegemony" led the world's financial system, these hard-earned foreign exchange can not be used to continue to develop the domestic economy, they are compelled to buy a large number of U.S. dollar assets such as U.S. bonds, for the United States to provide economic development debt financing, there has been "poor subsidizing the rich creditors," the strange phenomenon. This will definitely lead to China and other developing countries into the domestic shortage of public facilities, education, medical care, such as the lack of social security investment, the quality of our people can not be effectively improved, thus the division of labor in the global industrial chain to be firmly nailed to the added value of the minimum, waste of resources and environmental damage manufacturing the most serious of this aspect, while others can produce the most valuable surplus up to six components: product design, raw material procurement, Logistics and transport, order processing, wholesale operations, Retail terminal in the hands of Europe, mainly the United States. It is precisely because of the tragedy that industrial chain positioning in the end, China and other developing countries is extremely low wage level of workers, the average wages of U.S. workers less than 1 / 30 .

Nature of capital is chasing high profits. Sino-US countries such as the existence of huge wage differentials have attracted a lot of capital into China and other developing countries, and as a result of China's political stability, at all levels of government also issued a series of preferential measures to attract foreign investment, China has become the world's most suitable for foreign investment in developing countries. In the global wage arbitrage and preferential policies driven by the majority of these foreign investment flowing into the export enterprises, control more than half of China's exports, in snatched the high profits, it also brought a large number of China's foreign currency reserves. These foreign currency flows back to the United States again for the U.S. consumer-based economy provides a huge source of debt capital.

A large number of inexpensive Chinese-made goods were exported to the United States, on the one hand, the United States to reduce the prices of consumer goods, making a majority of Americans to reduce the cost of living, the middle class to enjoy the high quality of life; but on the other hand, massive transfer of capital has not driven the transfer of labor. This allows the United States, the shrinking manufacturing sector, a large number of manufacturing workers are unemployed. Bernard - U.S. House of Representatives, Mr Saunders said: "only in the past two years, we have lost two million manufacturing jobs, which is equivalent to $10 \%$ our workforce. Wal-Mart has replaced General Motors to become the United States, a major employer to pay is a matter of subsistence wages, rather than living wage. "These unemployed people mainly affected by low levels of education, minority groups and families mainly lack of funds. And their sub-loan crisis is mainly the repayment of housing loans.

The beginning of this century, with the IT bubble burst, the U.S.A government takes the real estate as a new engine of the economic development. China and other developing countries use the huge foreign exchange reserves to buy U.S. A treasury bonds and other investment products for the Wall Street Financial speculators have provided a rich source of funds. Surplus funds inevitably lead to chase higher profits, while risks increase. Thus, in the past is impossible to obtain housing loans to low-income, low levels of education, minority groups and individuals are relatively poor credit records who received mortgage loans, subprime mortgage market flourished. Wall Street had a classic saying: as long as there is an asset to generate cash flow, it can be securitized. With the subprime mortgage securities, the Wall Street investment banks, hedge funds, insurance companies and credit rating companies and other institutions also get involved the Subordinated Debt Market. In the so-called "Wall Street financial genius" under the careful packaging, MBS, CDO and CDS complex and even Warren Buffett also can not read a large number of financial products available, and increasing the size of the issue. The continued development of the U.S. economy and China State Administration of Foreign Exchange continued to provide debt financing funds made financial products sub-price bubbles as snowballed into snowball has reached the brink of bursting. U.S.A financial markets have been sitting on a powder keg, the little mars is likely to trigger a huge disaster.

\subsection{Sub- loan crisis triggering factors}

From the above analysis we can see, wage differences between China and USA is the main reason of trade imbalance and a large number of unemployed workers in the manufacturing. The United States in order to reduce rising unemployment rate, narrowing the gap between the rich and the poor, the fundamental approach should be to increase the wages of the workers in China. To do so, China's exports will create a large number of foreign exchange from the U.S.A economy back RMB economies, although in the short term would threaten U.S.A hegemony, but in the long term, this will help raise the employment rate of the United States and income of low-income and low educational level, help the U.S.A economy healthy and stable development, China and the United States economy to achieve "win-win" situation. But the world of someone who used to lead the United States, China and the United States coupled with ideological differences, the United States always has been, wearing tinted glasses to view China ,taking China as rivals rather than partners, for a long time the "containment China "as a national policy. Under such circumstances, the United States will not allow a large human resources in China to raise the wages of the workers to challenge their economic 
advantage. Thus, the loss of people to force themselves to the appreciation of the RMB has become an inevitable choice of the error. In 1985, the United States forced Japan to sign "Plaza Accord" has basically destroyed the economy of Japan's exports, but also the U.S.A economy is in recession long-term embarrassment, and ultimately caused the U.S.A stock market collapse in 1987 of "lose-lose" tragedy again.

RMB appreciation, coupled with the Fed's continued rate increases, has greatly improved the U.S. A economy, inflation and U.S.A interest rates, deeply stung by the U.S. consumer debt-based economy. U.S.A general population, especially low-income people an increasing proportion of consumer spending, rising costs of mortgages, mortgage repayment pressures increasing, and ultimately can not afford to repay loans because the emergence of a large number of break for the phenomenon of real estate by banks as collateral Commodities recovery, which ignited the second loan crisis first fire.

U.S.A economist Paul Krugman once said: "The United States has become such a country: people make a living by selling, and people buy the money from China." This phrase describes the two facts .First, the U.S.A economy driven by real estate, and the other is the United States supported by the Chinese real estate. Due to the appreciation of the RMB, China's export economy is slowing down, exports have been greatly affected, making China the ability to buy dollar assets decreased, China has not the market for the entire Subordinated Debt inject new capital, to maintain Subordinated Debt cash flow chain fracture, in the final sub-loan crisis will inevitably have taken place

\section{Sub -loan crisis on China's influence}

\subsection{Direct impact}

Due to China's regulatory authorities outside of financial institutions engaged in credit derivatives has always been more stringent controls, although some domestic financial institutions had bought some part of Subordinated Debt products, but the amount of investment accounted for a small proportion of total assets, not the company have a significant impact on overall operations, investment losses in the tolerable limits.

\section{Insert Table 1 here}

From the table I we can see that the Chinese-funded banking institutions held by Lehman Brothers and the "two rooms" related assets to total assets ratio is not great, the highest total proportion of the Bank of China also, however only 1.71 $\%$, for banks in general the impact of operational risks is not serious. In addition to the official foreign exchange reserves is concentrated in the form of holding the "two rooms" bonds over 3000 billion U.S.A dollars, in the United States Government announced the takeover of the "two rooms", the payment risks have also greatly reduced.

\subsection{Indirect impact}

Because of sub-loan crisis, the U.S.A consumer market flagging (Reuters / University of Michigan in mid-October consumer confidence index to 57.5 preliminary data, and in September compared to the same period dropped by 12.8 points in the history of the consumer confidence index drop reached or exceeded 10 points in the case, there were only 4 times.), on China's demand for imports of goods compared to the same period in previous years have come down to varying degrees. According to the General Administration of Customs statistics show that the January to August this year, Sino-US bilateral trade total value of 219.7 billion U.S.A dollars, an increase of 13.3 percent over the same period last year dropped 3.1 percentage points. In Guangdong, exports to the United States weakening trend more evident, Guangzhou Customs statistics report, January to July this year, Guangdong's exports to the U.S.A by 6.3 percent year-on-year growth rate than the same period last year dropped 7.5 percentage points, of which, clothing and clothing accessories, plastic products and toys exports registered a negative growth, exports were down 25.1 percent year-on-year, $12.4 \%$ and $4 \%$. China's coastal regions of the large number of export enterprises are facing a difficult or even bankruptcy, many companies moved to more countries and regions and with low human capital such as Vietnam. According to the National Bureau of Statistics October 9, 2008 released data show that the third quarter of the national business climate index the same period last year, were down more than Central. Export enterprises gathered in the eastern part of the climate index fell the most serious. The eastern, central and western region business climate index 128.1,131.7 and 126.8, respectively, than the second quarter and 5.5 points down 11.7,6.0; with a year earlier than eased between the range of 10-20 points. In addition, by the impact of domestic inflation, since 2007, China has been using a tight monetary policy, bank interest rates and deposit reserve rate rising, it also makes the plight of the export rise in the cost of corporate finance, financing more and more difficult, business difficult. Complex economic situation and unfavorable international economic environment, our country's monetary policy is currently facing a hard choice, the slightest mistake, it is possible to achieve economic "hard landing."

\section{Our response on sub- loan crisis}

\subsection{Adjustment "in real estate finance" policy}

The direct cause of sub- loan crisis is the base of loan products - the United States real estate market bursting of the bubble, and China's real estate bubble compared favorably with the United States. Although our country has not 
produced the soil of sub- loan crisis, but real estate prices have remained high over long-term affordability of ordinary consumers (Table II can be seen from Beijing's housing prices up 18.7 income, that is a 3 of home in the absence of any other consumer spending, the need for 18.7 years to buy a 100 square meters of housing), the real estate market will be detrimental to the healthy and stable development and the stability of financial markets and the possibility of making greater financial risk. By the end of 2007 on "real estate agent or bank first to die " controversy, as well as in some cities early in 2008 after another break for emerging phenomenon indicates that China's financial market stability and the situation is not optimistic. Urgent need is to strictly control the over-inflated real estate prices in line with economic development and the purchasing power of consumers to match with the monitoring capabilities, to develop affordable housing and low-cost housing construction, establishment and perfection of the real estate market information systems. At the same time also need to avoid big ups and downs of real estate prices, real estate adjustments should persist in being "steady" in giving priority to guard against a variety of adverse factors caused the market Superposition overshooting.

\section{Insert Table 1 here}

\subsection{The development of Waste Management is the prerequisite for the policy of expanding domestic demand}

China is a current over-dependence on foreign trade country. In 2005, China's per capita GDP for 1231 U.S.A dollars, but the per capita foreign trade volume reached 1000 U.S.A dollars, minus the part of foreign trade, and the per capita GDP was only 231 U.S.A dollars, or 63 cents a day, and the world poverty line is 2 U.S.A dollars a day. That is to say, if there is no foreign trade, China will enter the ranks of poor countries. U.S.A-led hegemony in the international financial system, earned the huge foreign exchange at the cost of wasting resources, damaging environment, reducing the real income of workers and quality of life for the U.S.A economy provided the debt financing. "China relies on exports, economic growth policies are causing growing and serious social and political factors of instability" (Liao Light, 2006). After China's reform and opening "Only GDP theory" increasingly obvious shortcomings revealed out of the growing gap between rich and poor, environmental deterioration, moral indifference growing, more and more serious corruption among officials. 2005 China's Gini coefficient has reached 0.45 , while the international warning line is 0.4 , more than 0.4 , will lead to social instability, economic inefficiency.

China has completed after 30 years of primitive accumulation, and now reached the crossroads of transition to choose the path of what kind of transition, not only determines the future development of China also decides to a considerable extent, the United States and even the direction of the global economy. Dependent on foreign trade in the traditional export-led economic growth model has drawbacks when doing now to expand domestic demand will become an inevitable choice for China. However, the lack of a complete medical education to let people come up with the protection of bank savings and more of this not to the consumer is very difficult. Future uncertain let more people keep bank life insurance money, rather than a lot of consumption, revitalizing the economy. Therefore, the key to expanding domestic demand is the stimulation of low-income people, especially farmers consumer demand. Stimulate consumer demand is an important measure for improving the social security system, reforming pensions and health care system, reducing the cost of education for pupils and students, large-scale farming subsidies to farmers to increase infrastructure investment. Realize human-based, implementing the scientific development concept. The purpose of economic development is to increase revenue, improve the quality of life, rather than to pay cuts, relying on low labor costs do for others are awake. China is currently along this goal, the Third Plenary Session of the CPC 17 clear that China must "adopt flexible and prudent macroeconomic policies, strive to expand domestic demand, especially consumer demand," Prior to this in our country have also abolished the agricultural tax, relief of the primary and secondary school tuition fees, an increase of farmers farming subsidies, reform of the medical system have begun to move forward in groping. Believe that China will certainly be able to calmly deal with the financial crisis sweeping through the world, seize the opportunity to achieve economic restructuring, keep the economy healthy and stable development.

\section{References}

It is a Wonderful Mess. (2007). The Economist, Oct.13th.

Lang, Xianping. (2008). He jumped off the industrial chain of the worst location. China Logistics and Purchasing, (3).

Li, Jun \& Wang, Li. (2008). U.S. A loan crisis meeting on the impact of China's exports and coping strategies . International Trade, (8).

Liao light. Financial war. (2008). Linxiaofang, Cha junhong translation. Beijing: Central Press.

Zhang, Ming. (2008). " U.S. A Sub-loan crisis and China" Symposium on. International Economic Review, (3).

Zhang, Ming. (2008). On the second loan crisis on the international financial system, the international situation and China's economic impact . International Economic Review, (2).

Zheng, Binxi. (2007). Perspective of the U.S. A sub-loan crisis and the Enlightenment to China. Economic and Management Research, (11). 
Table 1. As of 2008 June 30 Chinese-funded bank Lehman Brothers and the "two rooms" related assets overview

\begin{tabular}{|c|c|c|c|c|}
\hline & \multicolumn{2}{|c|}{$\begin{array}{c}\text { Related assets held by Lehman } \\
\text { Brothers }\end{array}$} & \multicolumn{2}{c|}{ Holders of the "two rooms" bonds } \\
\hline & $\begin{array}{c}\text { The total amount } \\
\text { (100 million } \\
\text { U.S.A dollars) }\end{array}$ & $\begin{array}{c}\text { The proportion of } \\
\text { total assets }\end{array}$ & $\begin{array}{c}\text { The total amount } \\
\text { (100 million } \\
\text { U.S.A dollars) }\end{array}$ & $\begin{array}{c}\text { The proportion of } \\
\text { total assets }\end{array}$ \\
\hline $\begin{array}{c}\text { Bank of China } \\
\text { Commercial Bank } \\
\text { of China }\end{array}$ & 1.2882 & $0.01 \%$ & 172.86 & $0.15 \%$ \\
\hline $\begin{array}{c}\text { Construction Bank } \\
\text { China Merchants } \\
\text { Bank }\end{array}$ & 1.516 & $0.01 \%$ & 27.16 & $0.32 \%$ \\
\hline $\begin{array}{c}\text { China CITIC } \\
\text { Bank }\end{array}$ & 0.7 & $0.019 \%$ & 2.55 & $0.13 \%$ \\
\hline $\begin{array}{c}\text { Bank of } \\
\text { Communications }\end{array}$ & 0.7 & $0.03 \%$ & 15.84 & $0.9 \%$ \\
\hline
\end{tabular}

Table 2. 2007 house prices in major cities of China's income table

\begin{tabular}{|c|c|c|c|c|c|}
\hline City & $\begin{array}{c}\text { Capita } \\
\text { disposable } \\
\text { income(yuan) }\end{array}$ & $\begin{array}{c}\text { The average selling } \\
\text { price of } \\
\text { commercial } \\
\text { housing (yuan / sq } \\
\text { m) }\end{array}$ & $\begin{array}{c}\text { Household } \\
\text { disposable } \\
\text { income (at 3.1 } \\
\text { per household } \\
\text { basis) }\end{array}$ & $\begin{array}{c}\text { Price of } \\
\text { commercial } \\
\text { housing units } \\
\text { (100 square } \\
\text { meters each) }\end{array}$ & $\begin{array}{c}\text { Rates } \\
\text { revenue }\end{array}$ \\
\hline Beijing & 19978 & 11553 & 61931.8 & 1155300 & 18.7 \\
\hline Shanghai & 23623 & 8361 & 73231.3 & 836100 & 11.4 \\
\hline Tianjin & 16357 & 5794 & 50706.7 & 579400 & 11.4 \\
\hline Wuhan & 14358 & 4664 & 44509.8 & 466400 & 10.5 \\
\hline Chongqing & 12591 & 3385 & 39032.1 & 338500 & 8.8 \\
\hline Nanjing & 19600 & 5304 & 60760 & 530400 & 8.7 \\
\hline Nanjing & 21689 & 11054 & 67235.9 & 1105400 & 16.4 \\
\hline Guangzhou & 22469 & 7993 & 69653.9 & 799300 & 11.5 \\
\hline Shenzhen & 24870 & 13376 & 77097 & 1337600 & 17.3 \\
\hline Average & 19503.9 & 7942.7 & 60462.1 & 794270 & 13.1 \\
\hline
\end{tabular}

Date Sources: National Bureau of Statistics, the real estate industry development research report in China and major cities, 2008. 


\title{
Analysis and Strategy of the Chinese Logistics Cost Reduction
}

\author{
Xiaofeng Zhao \& Qi Tang \\ School of Management, Tianjin Polytechnic University \\ Tianjin 300384, China \\ E-mail: zhaoxiaofeng49501@sina.com
}

\begin{abstract}
The logistics industry is an important driving force for national economic development, and the cost of logistics is an important factor to measure the level of development of the logistics industry. The economical and social benefits due to the effective logistics cost control are notable, and it becomes the most direct means in extending the third-part profit. Therefore, how to implement the rationalization of logistics cost control has been increasingly focused, explored and fulfilled. In this paper, by analyzing the current cost of logistics in China as well as the factors which affect the status of the logistics industry, we put forward an effective strategy based on the view of logistics level which is appropriate to the current situation to reduce the logistics cost.
\end{abstract}

Keywords: Logistics, Logistics cost, Strategy

\section{Introduction}

At present, it is common to take the proportion of the logistics costs accounting for GDP as a key indicator to measure the efficiency and effectiveness of logistics. In most developed countries and regions, it has been controlled around $10 \%$ and even lower. But as for China, the developing country, whose the modern logistics industry scale is still relatively small, and the added value in GDP is less than one-third of that in the developed countries, while the logistics cost is twice than them. Presently, the mode of operation in most logistics enterprises remains in the extensive and primary stage, concept of the modern logistics has yet to take shape, and their service capacity, quality and effectiveness are far more behind the advanced ones. Therefore, it is necessary to strengthen the logistics cost management, analyze and implement the effective strategy to reduce the logistics cost of the enterprises, so as to reduce the overall logistics cost and improve the quality of logistics.

\section{Influencing Factors of the Logistics Cost}

From the view of the logistics level, the influencing factors of the logistics cost can be divided into macro, micro and industry (See figure.1). The macro level mainly refers to a country or a region's overall level of logistics development. The improper implementation of the government functions and the irrational industrial structure are important factors that constrain the reduction of the overall logistics cost. As for the industry logistics, it is an activity that mainly refers to a particular industry or a certain category of goods, organize and distribute according to the goods' characteristics. Only by constantly promoting the industry logistics rationalization and standardization, can we achieve the effective control of logistics costs. At last, the micro refers to the enterprises, as the main body of logistics business, the management level of the enterprises will directly influence the cost of logistics.

\section{Insert Figure 1 here}

\section{Macro influencing factors}

\subsection{Government}

1) Government planning and logistics industry

Industrial development planning, which includes industrial scale, structure and the location of the main producing area directly affect the logistics distribution, scale, level and is the key influencing factor of the logistics cost.

2) Policy support and protection

The government's plan to reduce the logistics cost is only the basis, it still need the government to secure the implementation. Government policies of logistics include logistics infrastructure construction policy, industrial control and guide policy, open market policy, land policy, financial policy, encouraging investment policy, modern logistics business cultivation policy, logistics personnel training policies, customs policy and so on. 


\section{3) Orderliness of government management}

In China, the phenomenon of cross-department, cross-industry and cross-regional is very prominent. Right now, the serious fragmentation problem among the industries or sectors has hampered the scientific and rational allocation and the full play of the social advantages of the existing logistics resources, which bounds the development of logistics industry. And it is contradicting with the modern logistics' systematic and network operation. As a result, it has caused the poor logistics system compatibility, information blockade and increased cost. Furthermore, it is not conducive to the integration of logistics resources and form the large-scale enterprises.

\subsection{Industrial Structure}

A country's industrial structure is also an important factor that affects proportion of the logistics cost accounting for GDP. In the composition of the cost of logistics, transportation and stock cost can account for $85 \%$. So it can be proved that if the logistics cost is high, the transportation and stock cost is also high, and vice versa. From various industry's demand for the logistics services, The manufacturing and mining industry which belong to the secondary industry provide the physical shape products that they can not be separated from the transportation and storage in the process of production and consumption. In consequence, the secondary industry demands for greater transportation and storage, and its logistics cost is relatively high. On the contrary, the tertiary industry which is service-oriented, the output value mainly from the intangible services, is less dependent on the logistics. Therefore the logistics cost is low and compared with output value it represents part a very small proportion.

So that we can come to the conclusion that the logistics cost of the regions which are orientated by the secondary industry accounts for larger proportion of GDP than the ones which is orientated by the tertiary industry. Even if the two regions have different levels of logistics development, the part of the logistics costs proportion is bound to be influenced by industrial structure.

\subsection{The Strategy of the macro logistics cost reduction}

Government should do overall planning, increase the investment and support the development of logistics enterprises. The rationality of Logistics system planning, distribution, as well as the convenience of distribution channels is of vital importance to logistics costs. Logistics system plan and management as a whole must be carried out scientifically and effectively. And with the use of advanced logistics technology, it can ensure the whole logistic system efficient and low-cost.

Therefore the Government should do a good job in the city and the whole country's logistics development planning first. The logistics development planning involves in making coordinate and matched strategy among the industrial structure, economic and social development and the logistics, the logistics infrastructure planning, logistics distribution system planning, logistics information platform planning, establishing the logistics development policy. Then on the basis of the appropriate logistics development policy, the government should also set up the specialized logistics management department and logistics trade associations. So that the government can achieve overall coordination in logistics planning, logistics policy establishing, implementing and logistics services, and ultimately reduce the macro logistics cost.

Second, the government should also increase the investment in logistics infrastructure, introduce advanced equipment to improve the existing logistics level, optimize and integrated the existing infrastructure, transform and upgrade the existing resources and give full play to the comprehensive effectiveness of existing facilities.

Finally, the government should support the development of logistics enterprises in order to promote the optimization of industrial structure. Firstly, it is necessary to encourage the manufacture and circulation enterprises business to transform their processes, separate and outsourcing non-core business, so that can focus on developing the core business; second, it is essential to speed up the development and cultivation of the professional logistics service businesses, and relax the market access; encourage the transportation, warehousing, distribution, freight forwarders, multimodal transport enterprises through equity participation, mergers, joint venture and other forms to carry out the asset restructuring, gradually build up some cross-border, cross-ownership of large-scale professional logistics business which is high-level service and international competitive; the third is to use information technology to promote Logistics modernization, largely develop the e-logistics and prompt the information sharing; the last is to positively develop the transportation service mode that meets the logistics operation. Through developing multimodal transport, container transport, bulk cargo transport, air transport, using a variety of special vehicles, speeding up the building the transit point for container and bulk terminal, we can make more specialized logistics enterprises achieve rapid development, so that the scale of operation, the use of the advanced technology and automation equipment are all possible and feasible. At the same time, these large-scale logistics enterprises a gradually form a network of logistics and economic union and ultimately enhance their competitiveness, based on these to optimize the industrial structure of the region. 


\section{Influencing Factors of Industry}

\subsection{Logistics Standardization}

Logistics standardization which includes the standardization and systematic of package of products, the bar coding of logistics information, and the container unitization of loading, unloading, transportation, storage and so on is an effective measure to reduce the logistics cost and improves the efficiency. Logistics is a comprehensive industry, which involves transportation, packaging, storage, loading, unloading, handling, distribution processing, distribution and information and so on. Chinese modern logistics industry is developed on the basis of the traditional industry. As the traditional logistics were artificially separated for a lot of stages and all them can not converge and coordinate well, combined with the blocked information sharing, low level of standardization of the industrial logistics, decentralized management and small-scale, so resulting in inefficient and high costs.

\subsection{The Strategy of the Industrial Logistics Cost Reduction}

The establishment of the standardization of the logistics facility should be in accordance with prevailing international practice and national standard-setting. Then take the whole logistics system as a starting point to study the coordination of the technical and work standards in the various sub-systems and sub-fields, so that to uniform the standard for the entire logistics system. Meanwhile study the coordination between the logistics system and other related systems, to seek the uniform standard for the large logistics system. The specific measures include logistics facility and related technical equipment normalization, implementation of the standard terms of logistics, unified technical standards and technical management standards for the industrial logistics, the unification of industrial equipment standard, the adoption of the same summons, and specification of goods, policy and regulation as well as the reunification of the tray.

\section{The Influencing Factor of Micro Logistics Cost}

\subsection{Enterprises}

1) The level of the information and integrated management of enterprises in China is generally low. Moreover, the enterprises are lack of infrastructures and logistics talents, and have the poor technology and equipment.

2) The low level of logistics management and service, which lead to high cost. Given the lack of unified planning, it results in the redundant construction. Due to the Market development lagging behind, the most logistics enterprises are in small, many, scattered and weak condition, they don't form an effective social service network.

3) Logistics companies generally do not adopt the total cost control, which has lead to logistics cost fuzzy, logistics cost accounting system guidelines and reputations unclear. When the cost is checked by different sectors, it is not clear enough. The scope and content of logistics cost are not comprehensive, only involve in part of logistics cost, which affect the authenticity of accounting information and is not conducive to the stakeholders to make the right decisions. At the same time, in many enterprises the logistics cost is only a part of the indirect cost of them.

These factors have seriously hampered the development of the logistics business, so it is high time that took effective measures to change this situation.

\subsection{The Strategy of the Micro Logistics Cost Reduction}

\subsubsection{The Implementation of the Total Supply Chain Management}

Firms today increasingly consider total supply chain management to be a major vehicle to gain a competitive advantage in turbulent markets. By implementing the total supply chain management, the flow of goods especially the unnecessary duplication processes can be streamlined. For example, through adopting the total supply chain management in the circulation of goods, the supply chain composed by the manufacturers, third party logistics companies, sales businesses and consumers can become a whole system, and then achieve the integrated logistics. To link the logistics activities from the total supply chain, and focus on the interaction and coordination among various logistics links, especially on the middle links(such as the scientific inventory management which can reduce the inventory cost; outsourcing which can shorten the in-transit time of goods, reduce the flow of goods and the cost and losses of this process; efficient distribution which can reduce the distribution cost of transportation by decreasing the transport, increasing the rate of loading, arranging reasonably for the allocation plan of vehicles and choosing the best routes and means of delivery, etc.). On this basis above and with the help of the modern information management system to achieve the optimal control for all as the logistics links, and make all the links processing become more accurate and fast.

\subsubsection{Virtual Logistics Enterprises Strategy Alliance and Prompt the Development of the Third party Logistics}

Logistics outsourcing is beneficial to the enterprises to reduce the logistic cost effectively and develop their core businesses, accelerate restructuring and achieve scale benefit with the limited resources. As a result, the logistics business outsourcing is an inevitable choice for enterprises to reduce the cost, while the vigorous promotion of development of third party logistics will play a key role. 
Accelerating the development of third party logistics enterprises is a requirement to achieve the logistics socialization and specialization and the fundamental way to reduce the cost. Now in China, small-scale, narrow scope of business, poor management, low level of logistics information and technology and the lack of personnel is a widespread problem in the third party logistic. In order to change this situation, the traditional ways are to change the management idea, strengthen the management foundation, introduce logistics personnel and advanced logistics technologies, and optimize the allocation of logistics resources. But there is another effective new way which is to form virtual logistics strategic alliance between the third-party logistics companies. Inline with the "complement each other and benefit-sharing "principle, the enterprises cooperate each other, expand logistics market and improve the logistics efficiency, so that cultivate an internationally competitive third party logistics group and finally reduce the logistics cost.

\subsubsection{Strengthen the Logistics Cost Checking}

Through the logistics cost checking, we can fully reveal the full cost of logistics activities, and raise the person awareness for the importance of logistics cost, thus to achieve the aim of prompting logistics management, reducing the cost and improving the efficiency. So in order to carry out logistics cost control better, and propose logistics cost improvement measures, we must accurately implement the logistics cost checking as follows:

1) The norms and calculation standard of logistics cost checking should be made as soon as possible, which can provide timely and accurate information support for the logistics management and decision-making.

2) Setting up a specialized logistics accounting management and supervision institution. The logistics accounting management is an important part of the logistics industrial management, so the specialized institution should be set up timely to supervise and manage the logistics accounting.

3) Enterprises should establish and perfect the personal responsibility for logistics cost control and regulate the operation of the cost control, including the logistics cost forecast, check, control, analysis and logistics cost information feedback, and so on.

4) Enterprises should build specialized channels to disclose the logistics accounting information to enable the accounting information be completely, timely and accurately received by the business management and relative government administration, which is helpful to implement the proactive monitor and management.

\section{References}

Beamon and B. M. (1998). Supply chain design and analysis: models and methods. International Journal of Production Economics, 55, 281-294.

Chopra S. (2001). Supply Chain Management: Strategy, Planning and Operation. New York: Prentice hall, $268-274$.

Martin Christopher. (1998). Logistics and Supply Chain Management-Strategies for Reducing Cost and Improving Service. New York: Prentice Hall, 266-269.

Muckstadt, J. A., Murray, D. H., Rappold, J. A., \& Collins, D. E. (2001). Guidelines for collaborative supply chain system design and operation[Special issue: supply chain management. Information Systems Frontiers, 3(4), $427-453$.

Yim Yu Wong, Thomas E. Maher et al. (2000). Strategic Alliances in Logistics Outsourcing. Asia Pacific Journal of Marketing and Logistics, 3-17.

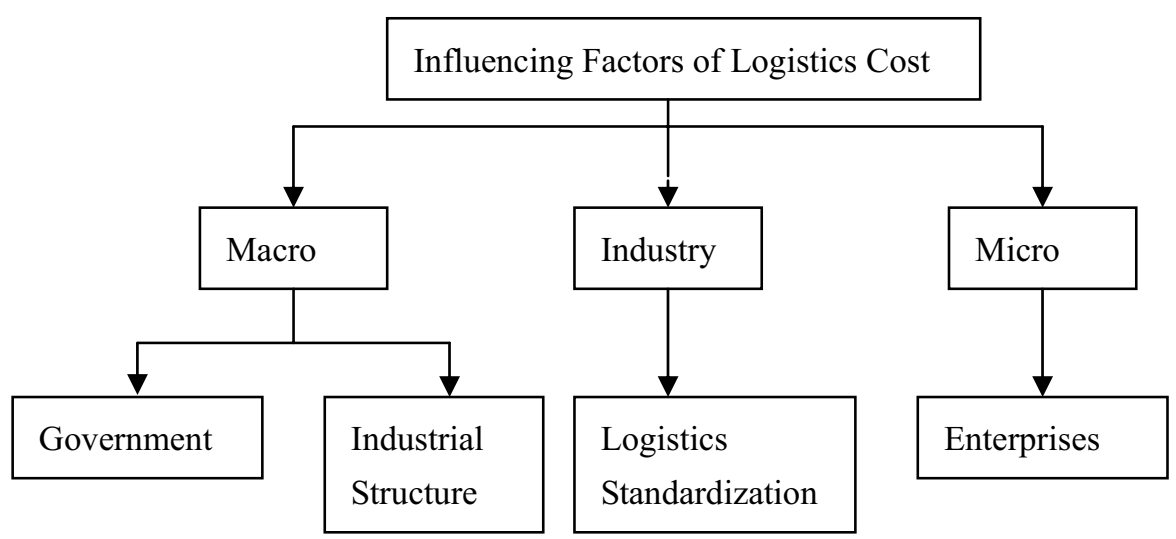

Figure 1. The Analysis of Influencing Factors 


\title{
Impact of Trade Liberalization and SAFTA
}

\author{
on Pakistan's Economy by Using CGE Model
}

\author{
F.M.Shaikh \\ Assistant Professor, SZABAC-Dokri.Sindh.Pakitan \\ Tel: 92-3133-113-244Ｅ-mail: faizshaikh@hotmail.com
}

M.Saleem Rahpoto

Assistant Professor, SALU-Khairpur

\begin{abstract}
The aim of this paper is to quantify and analyze the relative impact of South Asian Free Trade Agreement (SAFTA) over the global economic welfare. This research analyzes the potential economic costs and benefits of Pak-India trade in exporting various consumer goods. The first scenario is when normal trading relation with India will be restored; it means that both countries will give the MFN (Most Favored Nations) status to each other. In the second scenario, the SAFTA will be operative and there will be free trade between India and Pakistan and both countries will remove all tariffs and custom duties from each others' imports. The Global trade analysis GTAP model is used to analyze the possible impact of SAFTA on Pakistan in a multi country, multi sector applied General equilibrium frame work. After employing the simplified static analysis framework, the analysis based on simulations reveals that current demand for Pakistani dates and other consumer items like leather and cotton-made garments will expand after the FTA and consumer surplus will increase. The drop in the domestic prices of dates will increase the production of many downstream industries, which will have pleasant multiplier effects on the economy of Pakistan. The government may reduce MFN tariffs on industrial dates before implementing the FTA. A key rule of multilateral trade system is that the reduction in trade barriers should be applied on a most-favored nation basis (MFN) to all WTO members. The only exception to the MFN principle built into the GATT legal framework is the provision for reciprocal free trade within customs unions and free trade areas (GATT article XXIV). The objectives of the present study are to analyze and quantify the potential economic cost and benefits of the prospective trade between India and Pakistan to consumers, producers and government of the two countries. The export of Dried dates, leather and cotton-made garments may be conducted by two scenarios, i.e. when normal trading relations between Pakistan and India will be restored and when there will be a free trade between Pakistan and India in the presence of South Asian Free Trade Agreement (SAFTA). Following the analytical framework discussed by PO managerial (20001), we employ the simplified static analysis by using CGE model for policy implication, which reveals that Pakistan will gain benefit from Pak-India trade on SAFTA. Results based on this research reveal that on SAFTA, grounds, here will be net export benefits in Pakistan's economy.
\end{abstract}

Keywords: Trade liberalization, FTA, FAFTA, Welfare gain, Economy, Pakistan

\section{Introduction}

The objective of this study is to present a quantitative assessment of trade liberalization exercises in Pakistan in terms of economic welfare, trade, and the intersectional allocation of resources. This paper begins with a review of Pakistan's economic reforms and their coverage. Section II discusses the methodology, offering a brief description of CGE Modeling including the GTAP. The experimental designs are discussed in Sections III. Apart from unilateral and regional trade liberalization, as a founding member of the WTO, Pakistan remained firmly committed to the multilateral trading system and has already established a large number of reforms in keeping with the GATT/WTO principles. However, the paper does not review the outcome of multilateral trade Liberalization. In Section IV, GTAP model simulation results are analyzed. Section V concludes.4 Section I Until the late 1970s, Pakistan's economic development centered on an inward-oriented development strategy based on import substitution industrialization performed mainly by state owned firms. Both tariff and non-tariff barriers were widely used to protect domestic economic activities. Trade restrictive policies were accompanied by other regulatory policies such as control on foreign exchange, finance and foreign direct investment. These restrictive economic policies had severe adverse implications on overall economic growth, in particular growth of exports. Pakistan introduced extensive economic reforms in 1971-72 becoming the first 
country in the South Asian region to do so. The economy was freed from the inward-oriented strategy, and adopted an outward-oriented export-led development strategy, which was followed by many East Asian countries at that time. Trade liberalization was the key element of this new policy package and it entailed reliance on tariffs, replacement of quantitative restrictions including import licensing by a revised system of tariffs as well as the relaxation of other controls on trade. In order to encourage both domestic and foreign investment, the Government offered a series of incentives, while attempting to create an environment conducive to investment. In recent years, however, the focus of Pakistan's trade policy has seemingly shifted towards regionalism, which Pakistan considers a springboard for broader trade liberalization. The rationale for regional cooperation is based on a number of factors, not all of which are necessarily economic in nature. The formation of EU, NAFTA, MERCOSUR and ASEAN, and the recent emergence of other regional trading blocs may have given rise to a revival of interest in regionalism in Pakistan. This also explains the country's desire to avoid marginalization as more and more countries become members of various RTAs (Baldwin, 1993). Further, an RTA facilitates the choice of a selective liberalization policy as mutually agreed by all member economies, keeping them protected from global competition. Thus, Pakistan continued to 5 promote international trade through active participation in several regional trading agreements such as South Asian Preferential Trading Agreement (SAPTA),7 India-Sri-Lanka Free Trade Agreement (ILFTA), 8 Bangkok Agreement (BA)9, the Bay of Bengal Initiative for Multi sectoral Technical and Economic Cooperation (BIMST-EC) 10 comprising Bangladesh, India, Myanmar, Pakistan and Thailand and Indian Ocean Rim Association for Regional Cooperation (IORARC). The Free Trade Agreement (FTA) between Pakistan and Pakistan (PLFTA) became operational from June 2005.12 SAFTA was the first major step in moving towards a free trade area and higher forms of regional economic integration among the member states of the South Asian Association for Regional Cooperation (SAARC). SAARC was established in 1985 by member countries consisting of Bangladesh, Bhutan, India, Maldives, Nepal, Pakistan and Pakistan. The population of SAARC countries accounts for one fifth of the world population and almost half of the world's poor. The original rationale for preferential trading among SAARC countries stems from the conviction that these countries needed to pursue a policy of rapid industrialization in order to overcome their economic backwardness. Both industrial and agricultural sectors of the SAARC countries need vast technological improvements to take advantage of the global market. It is also expected that regional co-operation in South Asia will become an important means of accelerating trade and investment in the region. The agreement on SAFTA was signed in Dhaka in April 1993 by the SAAC members, providing a legal framework for trade liberalization and strengthening intra-regional economic cooperation. In 1995, SAFTA had been ratified by all contracting states and in accordance with Article 22 of the agreement SAFTA became operational on 7th December 1995. SAFTA followed a positive list approach, including flexible provisions for least developed countries (LDCs). At the Ninth SAARC Summit held in Male in 1997, the Heads of Governments decided to accelerate the pace of transition of SAFTA to South Asian Free Trade Agreement (SAFTA) by the year 2001 or Consumption is also quite high during Christmas. Similarly, the fruit enjoys enormous significance on the occasion of Dial and such festivals another religion. In Europe and North America, the fruit is particularly preferred during the dark winter month. Usual sales of dates are spread to a period from October to April.

\section{Methodology}

It is widely acknowledged that applied general equilibrium (AGE) or computable general Equilibrium (CGE) modeling has become the tool of choice for analysis of a wide range of trade policy issues such as tariffs and non-tariff barriers (NTBs) in both developed and developing countries in a variety of settings. In particular, AGE modeling is useful for analyzing the welfare effect of trade policy that needs to address second-best issues, where there are significant interactions between policy measures for one sector and distortions elsewhere in the economy. Such models have two distinctive features: they incorporate a number of distinct sectors, and the behavioral equations of the model deal with the response of industries and consumers to changes in relative prices (Adams et al., 1998). This development is explained by the capability of CGE models to provide an elaborate and realistic representation of the economy, including the linkages between all agents, sectors and other economies (Brockmeier, 1996) AGE analysis also provides a valuable tool for putting things in an economy-wide perspective (Hertel, 1999). The general equilibrium framework contains all commodities, factor markets together with decision-making agents who respond to price signals and are internally consistent 7 through capturing the many important feedback effects. Therefore, conceptually, these models can explicitly capture all the economy-wide interactions and inter-sectoral linkages. Hence, these models are very useful for analyzing the changes in sectoral output, product prices, factor usage, and factor prices as well as changes in national welfare measures consequent to changes in trade regimes. CGE evaluations typically work with theoretical models, and allow for more interaction among endogenous variables in that they can capture the numerous complex relationships between variables of policy interest in the model economy. The usefulness of a partial equilibrium approach is limited in analyzing the effect of trade policy changes, which are propagated throughout the economy. For example, the changes of tariff policy affect the consumption, production and relative prices of imports and their domestic equivalents, and ultimately, allocation of resources within the policy-changing country. Partial equilibrium approach can not capture these market interactions and quantify in a sensible way the impact of policy changes on all 
affected economic agents in the economy under consideration. On the other hand, economy-wide econometric models pay less attention to economic theory and more attention to time series data and typically manage to estimate all parameters by focusing on only a few endogenous variables. Econometric evaluations can be appraised with standard statistical criteria but they do not capture the complicated interactions in product and factor markets throughout the economy.

\subsection{Limitations of the CGE Models}

Despite the importance of CGE modeling in policy analysis, a series of questions have been raised about the empirical validity of these models. The core of the critique is focused on unsound parameter selection criteria, because the choice of elasticity values critically affects the results of policy simulations generated by these models. In the calibration method, some parameters are determined on the basis of a survey of empirical literature, some chosen arbitrarily, and the remainders are set at values, which force the model to replicate the data of a chosen benchmark year (Shoven and Whalley, 1992). Most often the estimated elasticities for commodity and/or industry classifications are based on econometric studies, which are not totally consistent with the countries represented in the model or they may even be "guesstimates" when no published figures are available. Therefore these models face two trade-offs, between transparency and complexity because on one hand, to implement large complex models the researchers are forced to choose parameters using ad hoc methods and, on the other, it is hard to understand what is driving the results in such complex models (Baldwin and Venables, 1995). Hence, one key issue with these models is how robust the results are to alternative parameter values, because there is no meaningful statistical method to test the significance of the calibrated benchmark parameter values in CGE models. Another critique related to the calibration procedure of the contemporary CGE modeling focuses on the over-reliance on non-flexible functional forms (those in the Constant Elasticity of Substitution (CES) class), and a convenient separability structure on technologies that imposes influential restrictions on the model's structure. McKitrick (1998) found that the choice of functional structure strongly influences the results from a policy simulation at both the industry specific and macroeconomic levels. Despite all these criticisms, however, the CGE models have already made contributions to trade policy issues in a wide variety of settings and therefore one can argue that these criticisms are somewhat misguided. The database and numerical results of the CGE models are intended to be more than merely illustrative and provide the internal consistent framework for policy evaluation with many implications and feedback effects that are based on solid microeconomic foundations. The key behavioral parameters in these models are related to econometric work in the literature and the careful use of a systematic sensitivity analysis approach would clearly indicate how robust the findings are with respect to the uncertainty in parameter values. An evaluation of the robustness of model results can certainly help to increase the creditability of model conclusions. As Scollay and Gilbert (2000, p. 177) point out "Distortions in an economic system will generally have repercussions far beyond the sector in which those distortions occur, and where the distortions are wide-ranging, general equilibrium is perhaps the only method which is capable of capturing the relevant feedback and flow-through effects."

\subsection{The GTAP Model}

In this study, the widely used Global Trade Analysis Project (GTAP), a multi-country, multisector AGE model (Hertel, 1997) 14 has been employed to empirically assess the impact of trade liberalization reforms in Pakistan. Multi-country, economy-wide CGE models are designed to work out the relative prices of various inputs and outputs mixes of the economies of interest as well as indicating the global changes in world trade patterns. Thus, the strength of a global AGE model lies in its ability to help us understand the linkages between sectors, countries and factors on a global scale. The general equilibrium structure recognizes that all parts of the world economy hinge together in a network of direct and indirect linkages. This means that any change in any part of the system will, in principle, have repercussions throughout the entire world. As McDougall (1995, p. 88) clearly points out "its characteristics are that it is economy-wide, it is multi-sectoral, and it gives a central role to the price mechanism. These characteristics differentiate it from partial equilibrium modeling (not economy-wide), macroeconomic modeling (not multi-sectoral), and input-output modeling (agents don't respond to price signals)."'The GTAP model was designed for comparative-static analysis of trade policy issues in an economy-wide framework. Since the changes in trade policies and production levels in any of the regions and sectors will have impacts on other regions and sectors, even though my main focus of this study is on results for Pakistan, it is possible to incorporate the policy changes of other countries within a global CGE modeling framework. It is only through a general equilibrium evaluation that economic policies can be assessed in terms of their impacts on welfare. It is also easy to make a comparison between different trade policy options through a global CGE model. The GTAP facilitates such multi-country, economy-wide analysis. Since this study focuses on global trading relations and detailed sectoral and regional trading activities of the Pakistan economy, many of the simulations we need to consider require a global perspective. For example, in the case of membership of SAFTA, it is needed to consider the effects on Pakistan of a reduction of domestic import tariffs on other SAFTA members. I also need to assess the impact of the reduction or elimination of import tariffs on Pakistan's exports by SAFTA members on the Pakistan economy and on its sectoral distribution. Using a global model like GTAP, we can endogenously capture 
the effects of policy changes of other countries explicitly on Pakistan. This ensures that changes abroad in combination with Pakistan's changes are used to generate new terms of trade for Pakistan.

Figure 1 gives a graphical exposition of the GTAP model structure by focusing on the accounting relationship of all agents in the multi region open economy. There is a regional household associated with each country or composite region of the GTAP model. Firms (producers), private households, and governments are represented as economic agents in each region of the model. The regional household collects all income that is generated in the economy. Regional income consists of VOA (Value of Output at Agent's prices) paid by producers for the use of endowment commodities (factor income), and the sum over all taxes net of subsidies. All taxes (TAXES) levied in the economy always accrue to the regional household. In each region, a regional household allocates regional income over the three forms of final demand: private household expenditure (PRIVEXP), government expenditure (GOVEXP), and savings (SAVE). Thus the final demand is represented by total utility, which is derived with a simplified Cobb-Douglas utility function to aggregate total household consumption, total government spending, and total saving. This approach represents the standard aggregation of GTAP, in which each component of final demand gets a constant share of total regional income. Thus, an increase in regional income causes an equipropotional change in private expenditures, government expenditures and savings. Each region of the GTAP model has a single representative private household. The private household supplies endowment commodities to producers, and obtains factor income in return. In GTAP, endowment commodities are non-tradable goods, which include land, unskilled labour, skilled labour, capital, and natural resources. Within each region, the model distinguishes between primary factors that are perfectly mobile across productive sectors and those that are sluggish. In the standard aggregation of the GTAP database, skilled and unskilled labour and capital are treated as perfectly mobile across industries within each region, whereas natural resources and land are treated as sluggish factors of production. The responses of the supply of factors to changes in relative sectoral returns depend on the value of the transformation elasticities parameters. The household buys bundles of commodities to maximize utility, subject to its expenditure constraint. The bundles are nested CES combinations of domestic goods and import bundles, with the import bundles being CES aggregations of imports from each region. The elasticity of substitution between imported and domestically produced goods in this composite nest of the utility tree is assumed to be equal across uses. In GTAP, the government revenues come from household income taxes, producers' taxes, and taxes on international transactions (minus subsidies, if they exist). As can be seen from Figure 1, 12 the government spends its income on domestically produced goods-VDGA (value of domestic government purchases, evaluated at agents' prices) and imported goods - VIGA (value of expenditure on imported tradable commodities by the government). The total government expenditure on each commodity category i.e. domestically produced and imported supplies, is allocated across commodities by a Cobb-Douglas constant budget share. In GTAP, savings is derived by assuming a Cobb-Douglas utility function and is treated as a function of regional total income and price, so that all savers in the model face a common price for the savings commodity $(P S A V E)$. In particular, savings enter a regional utility function, along with composite private consumption and aggregate government purchases. This reflects an implicit assumption of fixed savings rates. Savings are included as GLOBAL Savings in Figure 1. Thus, the regional income in excess of regional expenditure is saved and used as investments by producers. In the GTAP model, economic welfare is measured in terms of EV (equivalent variation), which indicates the reduction/increase in the external transfer, which would be equivalent in its effects to the tariff increase/decrease. Thus EV takes the old equilibrium incomes and prices, and computes the change needed to achieve new equilibrium utilities. There are two global sectors in the GTAP model for international consistency of trade and financial flows. The global transportation sector that provides the services account for the difference between fob and cif values for a particular commodity shipped along a specific route. The global banking sector intermediates between global savings and investment. Investment in each region is financed from a global pool of savings. Each region contributes a fixed proportion of its income to the savings pool. Thus, regional savings are gathered by the global banking sector to create composite investment good (GLOBINV), based on a portfolio of net regional investment (NETINV), and offers this to regional households in order to satisfy their savings demand (Hertel and Tsigas, 1997). Since the size of the portfolio of global investment adjusts to accommodate changes in global savings, the global closure in this model is neo-classical. Thus, when global equilibrium is reached, all firms earn zero profits (including the global transport sector), and all households are on their budget constraint, then global investment must equal global savings and Walras' Law will be satisfied. Both factor and commodity markets are assumed to be perfectly competitive in the GTAP model. The representative firm in each industry produces goods subject to constant returns to scale technology, and every sector produces a single output. In this model, firms' behavior depends largely on the assumption of separability in the production structure. It is assumed that primary factors of production and intermediate inputs are separable, and hence, there is no substitution between primary factors and intermediate goods. The overall elasticity of substitution among primary factors determines the ability of the economy to alter its output mix in response to changes in relative prices, or changes in the endowments of these factors. Thus, primary factors are assumed to substitute for one another according to the constant elasticity of substitution, while composite value added and intermediates are used in fixed proportions (Table 5 reports the elasticities of substitution in the GTAP model). Separability in production also means that the elasticity of substitution between any individual 
primary factor, on the one hand, and intermediate inputs on the other, is equal. The production technology in GTAP is represented by a set of nested CES and Leontief (fixed) functions. As shown in Figure 2, at the first level of the production tree, producers use a composite unit of intermediate inputs and primary factors in fixed proportions according to a Leontief function. At the second level, firms purchase composites of primary factors and composites of intermediate inputs that are obtained as combinations of domestic goods and imported bundles of the same commodity category. Domestic and imported intermediate inputs can be substituted according to a CES form. At the third level, a CES form is also assumed to capture the degree of substitutability between imports of different origin. Employing the Armington assumption, the GTAP model assumes that goods from different sources are imperfect substitutes. Thus the imported commodities are separable from domestically produced goods. Similarly, imported intermediates are also assumed to be separable from domestically produced intermediates. Accordingly, there are two sets of Armington or source substitution elasticities in the GTAP database. One of these relates to the substitution between domestic and imported composites (domestic-import substitution elasticity) - ESUBD.

The other one relates to the substitution among imports from different sources (import-import substitution elasticity) -ESUBM. In GTAP, these elasticities are defined separately for each of the representative agents within each region rather than referring to single economy-wide demand behavior. For cross-regional behavior, the model assumes that for each commodity all agents in all regions display the same substitution elasticity. In GTAP, international trade is included by the addition of a region, namely, the Rest of the World $(R O W)$. The ROW is the source of imports into the regional economy, as well as the destination for its exports. Figure-1 indicates that firms on one side get additional revenues for selling commodities to the ROW (VXMD). On the other side, the producers spend their revenues not only on primary factors and domestically produced intermediate inputs, but also on intermediate imports (VIFA), and an additional consumption tax on imports to the regional household, denoted as TAXES. Furthermore, both the government and private household have to pay additional commodity TAXES on imports. Thus, the ROW gets payments for selling its goods to the private household, the government, and the firms. These revenues will be spent on commodities exported from the single region to the rest of the world (VXMD), and on import taxes, (MTAX), and export taxes (XTAX) paid to the regional household. As can be seen from Figure 7.2, imports are traced to specific agents in the domestic economy, resulting in distinct import payments to ROW from private households (VIPA), government households $(V I G A)$, and firms (VIFA). In the GTAP model, the additional value flows denoted as taxes (TAXES) arise due to various policy interventions. The TAXES flow from private household, firms and government to the regional household (Figure .1). Due to the policy intervention, the government pays consumption taxes on commodities it purchases, and commodity taxes on imports. In contrast to that, taxes paid by the private household cover consumption taxes, commodity taxes on imports and income tax net of subsidies. In GTAP, producers also pay taxes to the regional household. These value flows represent taxes on intermediate inputs, consumption tax on imported inputs, and production taxes net of subsidies.

\section{The GTAP Data Base}

The GTAP database is the database for the GTAP model of the world economy, which is publicly available. The main data source for this model is "The GTAP 4 Data Base" (McDougall et. al., 1998), which refers to the year 1995 and therefore, all of the analysis in this study was taken from this base year. The benchmark equilibrium data set serves as a description of the economy in the initial equilibrium before any policy changes have been made. The database covers the 50 sectors within each of the 45 regions. The centerpiece of the GTAP database consists of input-output (I/O) data for each region, which account for inter-sectoral linkages within regions, detailed bilateral trade, transport, and protection data that link 45 country/regional economic databases. Thus, the GTAP database is easy to adapt to appropriate sectoral and regional aggregations that allow one to focus on specific policy questions. The regional databases in the model are derived from individual country input-output (I/O) tables that provide information about the individual regional economies in the model. The bilateral trade data was primarily derived from the United Nations COMTRADE (Commodity Trade) database. The Economic Research Service (ERS) of the United States Department of Agriculture (USDA) supplied the missing information in the UN trade data

\subsection{The Regional and Commodity Aggregation in the Model}

Since the full GTAP database contains 45 regions and 50 commodities, it is generally necessary to aggregate regions and commodities to a higher level for reason of computational efficiency. Therefore, the database is aggregated to 10 regions and 10 commodities, which emphasizes sectors and countries of interest for this study. Accordingly, the 10 regions of the model constitute Pakistan (LKA), India (IND), Rest of South Asia (RAS), Association of South East Asian Nations (ASEAN-5), Rest of Asia (ROA), Japan (JPN), and countries in the European Union (EU), countries in the North American Free Trade Area (NAFTA), Middle East (MIE) and Rest of the World (ROW). The regional aggregation scheme is presented in Table .6. The country aggregation is chosen to reflect Pakistan's major trading partners. Thus India and Japan separated from the rest of the world because of the growing importance of these 
countries as sources of imports to Pakistan. The database disaggregates data at a country level but not for all countries. Thus, country level data exist for India and Pakistan but not for the rest of the

SAARC countries. These countries (Bangladesh, Bhutan, Maldives, Nepal and Pakistan) have data as a group under "Rest of South Asia." Therefore, these countries are included as the Rest of South Asia (RAS). The East and Southeast Asian countries are aggregated into two groups as ASEAN-5 (Indonesia, Malaysia, Philippines, Singapore, and Thailand) and Rest of Asia (China, Hong Kong, Korea and Taiwan) because these two regions are also major sources for Pakistan's imports. While the member countries of the European Union (United Kingdom, Germany, Denmark, Sweden, Finland and the Rest of European Union) are aggregated as the EU, the United States, Canada and Mexico are aggregated as NAFTA. Moreover, all the countries in the Middle East included as Middle East. The EU, NAFTA and the Middle East countries are major destinations for Pakistan's exports. Similarly, the ten commodity categories in this model are intended to represent the commodities that are of major interest to the Pakistan economy. The commodity categories in the model are: Agriculture, Forestry and Fishing (AGRI); Mining and Quarrying (MINQ); Processed Food (PROF); Textiles (TEXT); Wearing Apparels (WEAP); Petroleum and Coal Products (PECP); Machinery and Equipment (MAEQ); Transport Equipment (TREQ); Other Manufactures 17 (OTHM) and Services (SERC). The commodity aggregation chosen and detailed in each of the above commodity categories are shown in Table .7.

\section{Experimental Designs}

All experiments were conducted with the standard general equilibrium closure 25 of the GTAP model. According to the standard closure of the model, prices, quantities of all non-endowment commodities and regional incomes are endogenous variables. Conversely, exogenous variables in this closure include population, the numeraire price of savings, all technological change variables, and all slack variables except the Walrasian slack variable, all policy variables, and all endowments. If the value of the walraslack is zero, then global savings equals global investment and the solution is consistent in a general equilibrium sense. Finally, the global bank's allocation of investment across region is flexible (RORDELTA=1). Thus the rate of return to investment is allowed to equalize across countries, so that savings demand can be met by investment in other countries, as well as by the country's own investment. The elasticity of the expected rate of return to investment with respect to end-of-period capital stocks (RORFLEX) is set at 10 (the default setting for this parameter), making the supply of new capital goods quite insensitive to the expected rate of return. As shown in Table. 8, trade liberalization policy analysis for Pakistan proceeds with six scenarios of alternative trade policy options. The first scenario (Experiment-1) was undertaken in the context of Pakistan's unilateral trade liberalization. Since the Government of Pakistan is committed to continue trade reforms with the aim of introducing a uniform tariff rate (15 percent) over the medium term (Government of Pakistan, 1995)., this experiment is based on the assumption that Pakistan unilaterally reduces its import tariffs to 15 percent, to maintain a uniform tariff structure on a global basis. In this case, we assume that the rest of the world does not reciprocate. The second trade reform scenario (Experiment-2) was conducted under the regional trade liberalization policy option to examine the impact of South Asian Free Trade Agreement- SAFTA in different contexts from the perspective of Pakistan. As a member of the SAPTA, Pakistan is committed to continue major trade liberalization measures, to establish and promote free trade arrangements for strengthening inter-regional economic co-operation and the development of national economies. In this experiment, it was assumed that Pakistan and each of the SAARC member countries in the model (India and the Rest of South Asia comprising Bangladesh, Bhutan, Maldives, Nepal and Pakistan) remove their tariffs against each other, while maintaining their tariffs against the rest of the world. The third scenario (Experiment-3) was conducted to combine the unilateral trade liberalization policy option (15 per cent uniform tariff for the rest of the world) with the regional trade liberalization policy option (SAFTA with SAARC countries). The rationale for this scenario is that the Pakistan government envisages introducing a uniform external tariff of 15 per cent while having free trade agreement with SAARC countries under the SAFTA. In this experiment, we assume that Pakistan and each of the SAARC countries remove their tariffs against each other, but Pakistan maintains a 15 per cent uniform import tariff for the rest of the world.

\subsection{Sensitivity Analysis}

Sensitivity analysis for AGE models is critical for establishing the robustness and obtaining the acceptance of model results. Although AGE models have become important tools of analysis in the quantitative evaluation of trade policy, the solutions obtained from these models are conditional on many assumptions. Among many assumptions, one set of assumptions-the values of model parameters such as elasticities-are amenable to "sensitivity analysis." Evaluation of the robustness of the model results can also help to increase the credibility of the conclusions of the study. In the GTAP model, the substitutability among imported commodities from different sources is determined by the Armington elasticity of substitution parameter called ESUBM. According to the Armington assumption, each country has some degree of market power over its products and can influence its terms of trade because that goods from different sources are treated as imperfect 19 substitutes. Hence, to reduce Pakistan's market power, it is necessary to increase the substitutability among imports from different origins because the terms trade effects largely depend on the 
import-import substitution elasticities (McDougall et al., 1998). This kind of experiment could also be interpreted as a form of conditional systematic sensitivity analysis (CSSA). Under the CSSA; each parameter is separately perturbed from its central value conditional on all the other parameters remaining at their central values. The robustness of the model results is then revealed by comparison of the simulation results with the central case. Thus, three additional experiments are undertaken under the sensitivity analysis to reduced Pakistan's market power by increasing the values of ESUBM to capture the effect of possibly different adjustment capacities as a small country. Though this will affect all countries/regions' market power in the model, it will have most effect on the small countries like Pakistan. The first experiment under the sensitivity analysis (Experiment 4) deals with the unilateral trade liberalization scenario. (15 percent uniform import tariff). The second experiment (Experiment 5) related to the regional trade liberalization (SAFTA by itself) and the third one (Experiment 6) conducted under the unilateral trade liberalization with combination of regional trade liberalization (SAFTA cum 15 percent uniform import tariff). To make these experiments manageable, two separate experiments are conducted under the Experiments 4, 5 and 6 respectively. Thus, under the first experiment, the parameter ESUBM was perturbed from its central value and then increased its value by 50 per cent in the first three scenarios-Experiments 4-1, 5-1 and 6-1 respectively. Under the second experiment, the value of ESUBM was doubled (100 percent increase) for the other three scenarios-Experiments 4-2, 5-2, and 6-2 respectively. With these six scenarios, it was assumed that all other parameters (except ESUBM) in the model remain at their central values.

\section{Simulation Results}

\section{Experiment-5.1: Reduction of Import Tariffs to 15 percent}

The first experiment considered the Pakistan's reduction of import tariffs to 15 percent under the unilateral trade liberalization. The impact of this scenario on regional welfare and the resulting percentage changes in sectoral output and trade are reported in Table 9 and 10 respectively. Accordingly, if Pakistan (LKA) reduces its import tariffs to 15 percent unilaterally on a global basis to maintain a uniform external tariff rate, Pakistan experiences a welfare gain around US\$ 20201 million (1.53 percent of the GDP). Under this scenario, Pakistan's volume of imports rises by 3.3 percent while its volume of exports falls slightly by 0.3 percent reflecting the fact that the pressure to increase imports is stronger than the increase in demand for Pakistan's exports by unilateral liberalization. However, as a result of the composite export price increase by 1.1 percent, Pakistan experiences a small improvement in the terms-of-trade of 1.5 percent and the real GDP by 0.8 percent. The welfare gains or losses for other regions are quite varied under this simulation. However, since Pakistan is a small country, the impact of Pakistan's unilateral reduction of import tariffs to 15 percent will not affect other region's real GDP or terms-of-trade significantly. As shown in Table 9, the 15 percent uniform tariff will adversely affect most of the sectoral output in Pakistan because of the increased competition for import competing industries. As shown in panel (a) of Table 9, the most affected industry is the transport equipment (TREQ) sector (18 percent), followed by machinery and equipment (MAEQ) sector (16 percent). It is noteworthy that these sectors expand significantly under the regional liberalization scenarios, particularly under the SAFTA scenario. The textiles (TEXT) sector (8 percent), processed food (PROF) sector (8 percent), mining and quarrying (MINQ) sector (8 percent), other manufactures (OTHM) sector (5 percent), and agriculture (AGRI) sector (1 percent) also report a decrease in output. However, there is a considerable increase in the wearing apparel (WEAP) sector (21 percent) and marginal increases in both the petroleum and coal products (PECP) sectors ( 2 percent), and the services (SERC) sector (1 percent). Similarly, as can be seen from panel (b) of Table 9, export sales also decline considerably in almost all the sectors except petroleum products ( 25 percent) and wearing apparel (21 percent). The largest decline in export sales occurs in machinery and equipment (22 percent) followed by transport equipment (19 percent), processed food (16 percent) and services (15 percent). As shown in panel (c) of Table 9, Pakistan's sectoral imports expand mainly in processed food (26 21 percent), wearing apparel (20 percent), and textiles (19 percent) while imports contract mainly in agriculture ( 9 percent), services ( 7 percent) and petroleum products ( 5 percent) under this policy reform. Accordingly, the results suggest that a reduction of import tariffs to 15 percent will increase Sri Lanka's welfare and terms-of-trade as well. Although one might expect that the reduction of import tariffs would increase the domestic output and therefore increase export sales, this policy reform would adversely affect Pakistan's domestic output in most of the sectors because of foreign competition. A similar impact can be seen in export sales too.

\section{Experiment-5.2: South Asian Free Trade Agreement-SAFTA}

As shown in Table-10, the welfare effects of the SAFTA scenario will be quite varied across the members, although removing barriers to trade will significantly expand the volume of trade within the region. The welfare gains from regional trade liberalization are the sum of trade creation benefits (generated new trade within the area from free trade); minus the trade diversion losses (caused by replacing more efficient nonmember suppliers with less efficient preferred member countries); plus the terms-of-trade gains associated with increased market access. It appears from Table -10, that the SAFTA will generate significant benefits for both Pakistan and India, but a loss for the countries in the RAS. Pakistan's welfare gain from the SAFTA is around US\$254 million (1.92 percent of the GDP) reflecting the fact that consumers will enjoy a shift of consumption from domestically produced goods to cheaper imports, and producers from 
cheaper imported inputs as well. Pakistan's composite export price increases by 5 percent, and in turn this leads to the terms of trade improvement by 4 percent. However, there is only a small increase in Pakistan's volume of exports $(0.9$ percent), but the volume of imports will increase considerably by 7.5 percent, and this will lead to only a marginal improvement of the real GDP by 0.1 percent. In this experiment, India stands to gain most from the improved market access that SAFTA promises to deliver. As shown in Table 10, the welfare gain for India is around US\$ 4445 million (1.35 percent of the GDP). This will be accompanied by an improvement of the terms-of-trade by 3.6 percent. Thus, the impact of the SAFTA on India's welfare is larger given its smaller share of imports from the members of the SAFTA (Schiff, 1996). In contrast, the SAFTA will have an adverse impact on the RAS, as representatives of the other SAARC member countries because of trade diversion. The estimated welfare loss for the RAS is around US\$1575 million (1.72 percent of the GDP). This situation is further aggravated by the deterioration in the terms-of-trade by 3.9 percent. Thus, the trade-diverting effects of the formation of a FTA are likely to outweigh trade creating effects for these countries, so, there may be efficiency loss which may lead to reduced welfare. Although the simulation results capture only a comparative static analysis of trade liberalization, it may suggest that this type of FTAs would promote welfare in some regions, but this could be at the expense of other regions. For example, as shown in Table 10, Japan, the largest single importing country of Pakistani goods would no doubt lose from the SAFTA by around US\$799 million because of the loss of not only Pakistan's market for her exports, but also the South Asian market as well. Table 11 presents the percentage changes in sectoral output, and trade by region under the SAFTA liberalization. The percentage changes in industry output in Pakistan, as shown in panel (a) of Table 11, the performance of the transport equipment sector is remarkable, reporting about 85 percent increase, due mainly to the advantages by the cheaper imported intermediate inputs from the SAARC region. The industry output of other manufacture ( 5 percent), manufacturing equipment (4 percent), and agriculture (2 percent) also increase but to a lesser extent. However, Pakistan's industry output in wearing apparels (11 percent), mining and quarrying ( 9 percent), textiles ( 93 percent) and processed food ( 2 percent) decline as the domestic market is opened up to more efficient overseas producers. The removal of import tariffs under the SAFTA will adversely affect India's domestic output of apparels (12 percent), mining and quarrying ( 2 percent), processed food ( 2 percent) and agriculture ( 0.4 percent). Only the transport equipment sector increases by 16 percent under this policy reform which is an indication of the availability of cheaper imports that are used by the sector itself as intermediate inputs following trade liberalization. In contrast, the RAS reports the increase of industry output in wearing apparel (16 percent), machinery and equipment ( 6 percent), petroleum product ( 4 percent), textiles ( 4 percent) and processed food ( 2 percent). It also experiences a significant decrease in industry output in transport equipment by 50 percent followed by a small reduction in mining and quarrying ( 3 percent) and agriculture $(0.4$ percent) due to increased competition. As can be seen from panel (b) of Table 11, there is a substantial increase in transport equipment exports by Pakistan of around 801 percent, indicating that Pakistan will benefit immensely, by exporting these items under the SAFTA, although these items are not currently important in its export basket. The export sales of agriculture (33 percent) other manufactures (16 percent), textiles (13 percent), processed food ( 9 percent) and manufacturing equipment ( 8 percent) also increase their sales as a result of induced competition, while the services sector (17 percent), wearing apparel (12 percent) and mining and quarrying (11 percent) decline under this trade liberalization. In contrast, there is a substantial increase in India's export sales in transport equipment (228 percent) followed by machinery and equipment (44 percent). The other manufactures ( 9 percent) and textiles ( 9 percent) also increase considerably while all the other sectors report decreases in export sales. The sectors that report the highest decreases are wearing apparel (27 percent), services (15 percent) and processed food (15 percent). However, the RAS reports a substantial increase in export sales in almost all the sectors because of the preferential access to the vast SAFTA market. The largest increase occurs in the transport equipment sector (448 percent) followed by machinery and equipment (103 percent), petroleum products (102 percent), mining and quarrying (72 percent), agriculture (71 percent), and other manufacture (44 percent). As shown in Table 11 (panel c), Pakistan's aggregate imports increase considerably in agriculture (32 percent), processed food (18 percent) and transport equipment (14 percent), while both the textile and apparels imports decrease slightly by 2 percent. All the other sectors report a small increase in imports under the scenario. Not surprisingly, India's aggregate imports will increase in all the sectors with the largest increase recorded for wearing apparel (75 percent), transport equipment (27 percent), agriculture (23 percent), and textiles ( 21 percent) and processed food ( 16 percent).Thus, the simulation results seem to suggest that having a FTA with SAARC countries is a wise Strategy for Pakistan, because it provides access to the vast market of the SAARC countries. Competitive suppliers in Pakistan will enjoy a greater market share and consumers will have access to variety of cheaper and better quality goods. Trade liberalization permits Pakistan to expand its export sectors at the same time that all sectors compete more closely with a larger number of competing varieties from SAFTA countries. Productive resources would then get allocated more efficiently as compared to the pre-liberalization situation as Pakistan would specialize in the sectors where it has comparative advantage. Therefore, Pakistan will enjoy immediate benefits from the SAFTA. Although India gains the most from the SAFTA scenario, it would not be beneficial for the RAS. However, the SAFTA will generate more production and trade opportunities for the region as a whole. 


\section{Experiment-5.3: SAFTA cum 15 percent Uniform External Tariff}

This experiment considered the impact of combined trade policy of unilateral cum regional trade liberalization on Pakistan's welfare and trade. As shown in Table 12, the simulation results indicate a considerable increase in welfare for Pakistan, around US\$442 million (3.35 percent of the GDP) under this scenario, reflecting that both consumers and producers are able to benefit from the removal of trade barriers. Indeed, this simulation represents the highest welfare gain for Pakistan among the three trade liberalization experiments presented. Apparently, there are two trade-creation effects from this scenario. First, trade creation that results from Pakistan's own trade liberalization, and second, that which results from the regional liberalization under the SAFTA. Pakistan also experiences the highest terms-of-trade improvement of 5.2 percent under this policy reform, as the economy would be expected to gain from the increased composite exports price of 5.4 percent, relative to a small increase in the price of imports of 0.3 percent As might be expected, Pakistan's volume of imports increases significantly by 9.0 percent, but the volume of exports decreases slightly by 0.3 percent. As a result, there is only a marginal improvement in the real GDP by 0.98 percent. Not surprisingly, India, as Pakistan's major import source, would also gain considerably under this policy reform by around US $\$ 4398$ million (1.34 percent of the GDP). The reported terms-oftrade improvement for India is 3.6 percent. However, this policy reform also leads to a considerable welfare loss for the RAS of approximately US\$1592 million (1.74 percent of the GDP). The RAS also experiences a deterioration of the terms-of-trade by 3.9 percent. Table 13 highlights the estimated percentage changes in regional output and distribution of sales under this policy reform. Accordingly, Pakistan's domestic output in the transport equipment sector rises considerably, by 53 percent and 625 percent respectively, as a result of the easy access to cheaper raw materials from the world, and preferential access to the SAFTA market. Both agriculture and petroleum product exports also rise considerably, by 23 percent. However, there is a notable decrease in domestic output and export sales in mining and quarrying (16 percent and 18 percent respectively) machinery and equipment (12 percent and 13 percent respectively), and processed food ( 9 percent and 6 percent respectively). Pakistan's domestic output in textiles decreases by 11 percent while the exports of textiles increase by 6 percent. The export sales in services also decrease by 27 percent As shown in panel (c) of Table 13. Pakistan's aggregate imports increase in almost all sectors under trade liberalization, with the exception in petroleum products (4 percent) and services ( 3 percent). The largest increase occurs in the processed food sector ( 41 percent), followed by agriculture (20 percent), transport equipment (13 percent), textiles (12 percent), machinery and equipment ( 7 percent) and wearing apparel ( 7 percent). Thus, the results suggest that if Pakistan implements the SAFTA with SAARC countries, while having a 15 percent uniform external tariff for the rest of the world that will improve Pakistan's welfare and the terms-of-trade more than any other trade policy reform that we considered. Thus, Pakistan gains from both unilateral and regional trade liberalization simultaneously under this scenario. Although this policy reform provides incentives to some domestic industries to increase their output and export sales, there are some industries that will reduce production and export sales because of the increased competition.

The GTAP model assumes constant returns to scale and perfect competition in all sectors.

Instead, if we allow for increasing returns to scale and imperfect competition in some sectors of our model, we can raise significantly the estimated welfare gains of trade liberalization. As far as liberalization stimulates investment and technology provided by the enlargement of the market, the welfare effects reported in this study are underestimates of potential gains. Moreover, we have not incorporated the effects of non tariff barriers (NTBs) in our trade liberalization simulations; instead we assumed that all other distortions remain constant except tariffs. Therefore, the omission of NTBs surely leads to an underassessment of the impacts of trade reforms on efficiency and trade.

\section{Experiments 4, 5 \& 6: Sensitivity of the Results}

As described previously, to quantify the impact of trade policy reforms on Pakistan, three additional experiments were undertaken with an increased elasticity value for the import-import substitution parameter (Armington parameter)-ESUBM, to consider Pakistan as a small country Accordingly, under these three experiments, first, the size of the ESUBM increased by 50 percent, and then doubled the value (100 percent increase) to reduce Pakistan's market power in the world market. This would provide an opportunity to examine the sensitivity or robustness of the model predictions with respect to the change in the underlying parameters.

Table 15 presents the results of these three experiments with the central elasticity value scenarios. Thus, under the 15 percent uniform external tariff scenario (E-4), if we reduce Pakistan's market power by increasing the value of ESUBM by 50 percent (E-4.1), it would increase welfare gain around US\$247 million (1.87 percent of the GDP). Similarly, doubling the value (100\%) of ESUBM (E-4.2) would increase Pakistan's welfare by around US\$296 million (or 2.24 percent of the GDP). In the former case, the increase in welfare from the central value is 22 percent, and in the latter case, it is approximately 47 percent. Although these changes are relatively small, it would suggest that even as a small country, Pakistan would be in a position to gain from the unilateral trade liberalization. The welfare increases for the country as the elasticities increase. However, under these two scenarios, we see a slight decline in Pakistan's terms-of-trade as elasticities increases. Moreover, under these scenarios, the impact on terms-of-trade is not much 
different from the central scenario case similarly, experiment 5 (E-5) deals with the SAFTA scenario. As shown in Table 15, with the increase of the value of ESUBM, both the welfare and the terms-of-trade will increase linearly from the central scenario case. Thus, the welfare gain for Pakistan under the 50 percent increase in ESUBM (E-5.1) is approximately US\$340 million (2.58 percent of the GDP), whereas under the 100 percent increase scenario (E-5.2), it is around US $\$ 422$ million ( 3.19 percent of the GDP). Thus in the former case, Pakistan's welfare will increase by 42 percent from its central value scenario, and in the latter case it will increase by 76 percent. Thus, welfare increases as elasticities increase. Thus, the gains are rather linear with both the cases reflecting the robustness of the model results. Experiment 6 (E-6)considered the combined policy of SAFTA cum 15\% uniform import tariffs scenario Thus, 50\% increase of the value of ESUBM (E-6.1), would increase welfare gain around US\$592 million (from US\$443 million at the central scenario) or 4.4 percent of the GDP. Here, the increase in welfare from the central value is 33 percent. Similarly, doubling the value of ESUBM (E-6.2) would increase Pakistan's welfare by around US\$743 million or 5.6 percent of the GDP. In this case, the increase in welfare from the central value is 67 percent. Moreover, under these two scenarios, the increase in terms-of-trade is 5.9 and 8.8 respectively. Thus the improvements in the terms of trade from the central value are 1.7 and 3.6 percent respectively. Although these welfare and terms-of-trade gains are not almost linearly related to the changes in the Armington elasticity ESUBM, the result would suggest that unilateral trade liberalization in combination with regional trade liberalization permits Pakistan to expand its export sectors at the same time that all sectors compete more closely with a larger number of competing varieties from abroad.

Table 16 highlights Pakistan's sectoral output, exports and imports under the sensitivity analysis scenarios. Accordingly, Pakistan's industry output falls significantly in all most all the sectors except for significant increases in transport equipments and wearing apparels. Pakistan's export sales also decrease considerably under all the experiments as shown in panel (b) of Table 16, except the transport equipments petroleum products and apparel sectors under E-4, transport equipments, machinery and equipment, other manufacture and textiles sectors under E- 5 and transport equipments, petroleum products, other manufacture and textiles sectors under E-6. Pakistan's aggregate imports(panel(c) in Table 16)) increase considerably in all sectors except agriculture, services, petroleum products, mining and quarrying under E-4, wearing apparels, and textiles under E-5, and petroleum products and services under E-6.

\section{SAFTA}

A free trade area is an agreement among countries where by tariffs and non-tariff barriers for instance quotas, licensing requirements and products safety regulation are abolished among members. Compared to customs unions and common market, a free trade area is the least institutionalized form of economic integration, where each member of the FTA keeps its own external tariffs and other regulations for trade with non-member countries. An FTA may offer advantages to all member countries. An FTA is likely to increase interregional trade and enhances competitiveness, productivity and efficiency. Trade creation, trade diversion, and terms of trade are the components of static effects. When the removal of trade barriers promotes trade among the members (trade creation effect), it sometimes does so at the expense of imports from non-members (trade diversion effect). If an FTA leads to a reduction in imports from non-members, FTA members are likely to experience improvement in their terms of trade vis-à-vis non-members (terms of trade effect). The trade creation effect and terms of trade effect lead to an increase in economic welfare of the members, while the trade diversion effect is likely to reduce economic welfare of the members because imports from most efficient suppliers in non-members are replace by imports from less-efficient member producers. It is important to note that for non-economic welfare.The free trade scenario analysis assumes that there will not only be normal trading relations with India but SAFTA will also be operative and there will be no tariff or custom duty on imports from India. However, the domestic taxes at the border level would continue to prevail. Besides, duty drawback and other tariff neutralization measures for inputs as well as export incentives would be available. It will be useful to mention that the trade diversion means that a free trade area diverts trade, away from a more efficient supplier for example from rest of the world (ROW), towards a less efficient supplier within the FTA for example India. The trade3 diversion may reduce a country's national welfare but in some cases national welfare could improve despite the trade diversion, depending upon the particular situation. In contrast, trade creation implies that a free trade area creates trade that would not have existed otherwise. As a result, supply occurs from a more efficient producer of the product.

\subsection{Non Economic Benefits}

Besides the welfare and terms of trade gains suggested by the simulations, regional trade liberalization under SAFTA may have many non-economic benefits to a small country like Pakistan, particularly social and political benefits; those are difficult to account for in a quantitative way. For example, SAFTA can help its members to speak with one voice in global negotiations and develop a common understanding on several global trade-related issues. It could also reduce the political disputes among members and make the region a more attractive location for foreign direct investments. This is critical for a developing country like Pakistan as it is typically unable to fully finance its growth in investment with domestic savings. Since absorptive capacity in Pakistan is crucial for obtaining significant benefits from FDI, liberalization of trade and FDI policies needs to be complemented by appropriate policy measures with respect to 
education, R\&D, and human capital accumulation if Pakistan is to take full advantage of increased trade and foreign investment. Since the proximity, history and cultural familiarity associated with trade are important determinants of foreign trade, the expansion of the neighboring market following trade liberalization could be more important for Pakistan to exploit economies of scale and able to avoid transport and other costs of trade to more distant markets. It is widely believed that the outcome of an RTA depends mainly on the membership, the policies intended to pursue and the effectiveness of the proposed institutional mechanism. Therefore, member countries of SAFTA should set their own agenda and priorities as a bloc, in order to face the impact of future trade issues under the global framework without jeopardizing their growth prospects and interests. Moreover, political willingness and commitments are equally important for the success of any trade agreement. Lastly, to be consistent with the multilateral process RTAs should be outward looking and that they are more likely to facilitate liberal multilateral trade. The outward orientation of any RTA is judged on the basis of its consistency with Article XXIV of the GATT.As results suggest; that the increase in volume of imports under all the trade liberalization scenarios will have an adverse impact on the competitiveness of some domestic industries, and hence export sales. Since Pakistan's industries are still developing, policy makers should ensure that domestic production is not severely affected from foreign competition, and that exports remain competitive on the world market. Therefore, governments should adopt selective trade policy instruments to protect domestic industries and expand production, while yielding the benefits of trade liberalization in the presence of economies of scale. A policy maker might want to consider the other socio-economic objectives of trade policy such as the development of labour intensive and high value added industries. The reduction of the overall dependence on imported inputs cannot be over-emphasized. As with any other policy, trade policy must necessarily be pro-people to reduce inequalities and enhance economic development. The challenge for policy makers in Pakistan is thus to design trade policy to improve the welfare of citizens and take advantage of new opportunities that would be created by trade liberalization, while protecting most vulnerable groups in the economy from possible adjustment costs and insecurities. Thus, the provision of a basic safety net would be needed to ensure that individuals and families do not fall below minimum standard of living which is an important ingredient in ensuring equity and political acceptability of the trade reforms.

\section{Conclusions}

The simulation results presented and analyzed here demonstrate the importance of experimental designs, and the usefulness of the global CGE modeling framework for examining the impacts of the different types of trade policy reforms for Pakistan. Although, the GTAP model cannot capture the dynamic effects of trade liberalization, it is a useful tool for generating comparative static results for a variety of trade reform scenarios. It also identifies the industries that will expand, and those that will contract, and the size of these changes as a result of various trade liberalization scenarios. The results suggest that Pakistan would experience the highest welfare gain under the combined policy reform of the SAFTA cum 15 percent uniform external tariffs while the SAFTA on its own gives the second highest welfare gains. SAFTA allows the participating countries to achieve larger economies of scale in production, attain specialization, increase competitiveness and diversify their export basket, thus assisting domestic economic reform. Therefore, harmonizing economic policies among neighboring countries must receive higher priority in the policy making process. Although, simulation results are highly sensitive to the underlying data and assumptions regarding the reference scenarios, the results clearly provide an assessment of the implications of SAFTA.

\section{References}

Centre for Monitoring Indian Economy. (2004). Annual report on Corporate Sector.

Government of Pakistan (Various Issues). Census of Manufacturing Industries, Islamabad: Federal Bureau of Statistics.

Government of Pakistan (Various Issues). Economic Survey, and Islamabad: Economic Advisor's Wing, Ministry of Finance.

Government of Pakistan (Various Issues). Monthly Statistical Bulletin, and Islamabad: Federal Bureau of Statistics

Government of Pakistan (Various Issues). Pakistan Custom and Tariffs year Book Islamabad: Central Board of Revenue (CBR).

Government of India, Annual Report 2003-04, Department of Commerce and trade.

Pakistan gulf economist December. (2002). report By M.E JALBANI, Director, EPB.

Government of India, (Various Issues). Economic Survey, New Delhi: Economic Division, Ministry of Finance.

Government of India, directorate General of foreign Trade, Ministry of Commerce. [Online] Available: www.dgft.delhi.nic.in.

International Financial Statistics, CD-ROM. (2004). International Monetary Fund, Washington DC. 
Ju, Jiandong and Kala Krishna. (1998). Firm Behavior and Market Access in a Free Trade Area with Rules of Origin. NBER working Paper, No. 6857.

Panagariya, A. (1994). East Asia and the New Regionalism. World Economy, 17:6, 817-39.

Panagariya, A. (1995). Rethinking the New Regionalism', Paper Presented at the UNDP World Bank Trade Expansion Conference, January, World Bank, Washington DC.

Panagariya, A. (2000). Preferntial Trade Liberalization: The Traditional Theory and New Developments. Journal of Economic Literature, 38, June, 287-331.

Purcell, Garry. (2004a). Analyzing the Economic Welfare Consequences of A Fare Trade Agreement: Partial Equilibrium Methods for Industry Level Studies, Manuscript Presented at World bank Dhaka Office.

Purcell, Garry. (2004b). An India-Bangladesh Free Trade Agreement? Some Potential Economic Costs and benefits, presented during the workshop held at World Bank, Islamabad Office.

Summers, L. (1991). Regionalism and the World Trading Systems, Federal Reserve Bank of Kansas City, Policy Implementation of Trade and currency zones.

Table 1. Key Economic Indicators data for SAARC countries-2005-06

\begin{tabular}{|c|c|c|c|c|c|c|c|c|c|c|}
\hline $\begin{array}{c}\text { Countr } \\
y\end{array}$ & $\begin{array}{c}\text { Mid } \\
\text { Year } \\
\text { Populati } \\
\text { on }\end{array}$ & $\begin{array}{c}\text { Population } \\
\text { in Growth } \\
\text { rate }\end{array}$ & $\begin{array}{c}\text { GDP } \\
\text { US\$ M } \\
n\end{array}$ & $\begin{array}{c}\text { GNP } \\
\text { Per } \\
\text { capit } \\
\text { a } \\
\text { US\$ }\end{array}$ & $\begin{array}{c}\text { Literac } \\
\text { y rate }\end{array}$ & $\begin{array}{c}\text { Life } \\
\text { expectan } \\
\text { cy }\end{array}$ & $\begin{array}{c}\text { Crude } \\
\text { birth } \\
\text { rate } \\
\text { per(00 } \\
0)\end{array}$ & $\begin{array}{l}\text { Crude } \\
\text { death } \\
\text { rate } \\
\text { export } \\
\text { s }\end{array}$ & $\begin{array}{c}\text { Export } \\
\text { s } \\
\text { USS M } \\
\text { n }\end{array}$ & $\begin{array}{l}\text { Impor } \\
\text { ts US\$ }\end{array}$ \\
\hline $\begin{array}{c}\text { Pakista } \\
\mathrm{n}\end{array}$ & 148.8 & 1.92 & 93,908 & 600 & 48.7 & 63 & 36 & 36 & 13,375 & 17,954 \\
\hline Bhutan & 0.8 & 2.5 & 657 & 760 & 47.0 & 63 & 35 & 9 & n.a & n.a \\
\hline $\begin{array}{c}\text { Bangla } \\
\text { desh }\end{array}$ & 135.2 & 1.3 & 585,68 & 440 & 41.1 & 63 & 29 & 8 & 6,608 & 11,276 \\
\hline India & $1,086.0$ & 1.6 & 686,08 & 620 & 61.0 & 63 & 24 & 8 & 71,763 & 94051 \\
\hline Maldev & 0.3 & 1.5 & 719 & 24,10 & 97.2 & 67 & 36 & 6 & 122 & \\
\hline Nepal & 24.7 & 2.2 & 6,685 & 250 & 48.6 & 62 & 33 & 10 & 756 & 1,869 \\
\hline $\begin{array}{c}\text { Sri } \\
\text { lanaka }\end{array}$ & 19.5 & 1.1 & 19,224 & 1,010 & 92.1 & 74 & 16 & 7 & 5,757 & 8000 \\
\hline
\end{tabular}

Note: ADB key economic indicators -2006-07 
Table 2. Gross National Product of Pakistan Rs.Million939

\begin{tabular}{|c|c|c|c|c|c|c|c|c|c|}
\hline S.No & Sectors/Sub-sectors & 1999-00 & $2000-01$ & $2001-2002$ & $2002-03$ & $2003-04$ & $2004-05$ & $2005-06$ & $2006-07$ \\
\hline \multirow[t]{7}{*}{ A. } & Agricultural sector & 923609 & 945301 & $968291^{\prime}$ & 1059316 & 1164751 & 1314234 & 1382660 & 1608522 \\
\hline & 1.Crops & 467879 & 456258 & 449993 & 500370117 & 538208 & 651774 & 666727 & 1608522 \\
\hline & 1.1.Major crops & 342200 & 325579 & 316857 & 370117 & 411836 & 497556 & 496841 & 579996 \\
\hline & 1.2.Minor crops & 125679 & 130679 & 133136 & 130450 & 126372 & 154218 & 169886 & 191835 \\
\hline & 2.Livestock & 417120 & 446058 & 476310 & 512976 & 578218 & 621170 & 678033 & 794987 \\
\hline & 3.Fishries & 15163 & 16546 & 16377 & 16625 & 16728 & 17490 & 22230 & 243559 \\
\hline & 4. Forestry & 23447 & 26439 & 25611 & 29148 & 31597 & 23800 & 15670 & 17345 \\
\hline B. & Industrial Sector & 830865 & 942263 & 989349 & 1083914 & 1416986 & 1659285 & 1939160 & 2203490 \\
\hline $\mathrm{A}+\mathrm{B}$ & $\begin{array}{l}\text { Commodity } \\
\text { producing Sectors }\end{array}$ & 1754474 & 1887564 & 1957640 & 2143230 & 2581737 & 2973519 & 3321820 & 3812012 \\
\hline $\mathrm{C}$ & Services Sector & 1807546 & 2035680 & 2188527 & 2390988 & 2668790 & 3149049 & 3807356 & 4414507 \\
\hline $\mathrm{D}$ & $\begin{array}{l}\text { Gross Domestic } \\
\text { Product (GDP) }\end{array}$ & 3562020 & 3923244 & 4146167 & 4534218 & 5250527 & 6122568 & 7129176 & 8226519 \\
\hline E. & $\begin{array}{l}\text { Net Factor Income } \\
\text { from Abroad }\end{array}$ & -47956 & -54482 & 23665 & 151812 & 124478 & 134461 & 149901 & 160738 \\
\hline F. & $\begin{array}{l}\text { Gross National } \\
\text { Product(GNP) }\end{array}$ & 3514064 & 3868762 & 4169832 & 4686030 & 5375005 & 6257029 & 7279077 & 8387257 \\
\hline G. & $\begin{array}{l}\text { Population in } \\
\text { Million }\end{array}$ & 137.53 & 140.36 & 143.17 & 146.75 & 149.65 & 152.53 & 155.37 & 158.17 \\
\hline H. & $\begin{array}{l}\text { Per capita Income } \\
\text { (Rs.) }\end{array}$ & 25551 & 27563 & 29125 & 31933 & 35917 & 41022 & 46850 & 53027 \\
\hline
\end{tabular}

Source. http://www.statpak.gov.pk/depts/fbs/statistics/national_accounts/table12.pdf 
Table 3. Regional Aggregation 10 Regions of the Model

\begin{tabular}{|c|}
\hline $\begin{array}{c}\text { Aggregated Regions } \\
\text { GTAP Region }\end{array}$ \\
\hline
\end{tabular}

1. Pakistan

Pakistan

2. India (IND)

India

3. Rest of South Asia

Bangladesh

Bhutan

Maldives

Nepal

Sri lanka

4. Association of South East Asian Nations ASEAN-5

Indonesia

Malaysia

Philippines

Singapore

Thailand

5. Rest of Asia

Hong kong

Korea

Taiwan

Chaina

6. Japan (JPN)

Japan

7. European Union

United Kingdom

Germany

Denmark

Sweden

Finland

Rest of European Union

8. North American Free Trade Area

NAFTA

USA

Canada

Mexico 
Table 4. Commodity Aggregation: 10 Sector Model

\section{Aggregated Regions}

GTAP Region

1.

Agriculture Forestry

and Fisheries (AGRI)

2. Mining and Quarrying (MING)

4. Textile (TEXT)

5. Petroleum and Coal Products

6. Services (SERC)
Paddy rice (pdr)

Wheat (wht)

Cereal grains nec (gro)(v_f)

Vegetable, Fruits, nuts

Oil seed (osd)

Sugar cane, sugar beet (c_b)

Plant based fibres (pfb)

Crops (nec)

Raw milk (rmk)

Wool (wol)

Forestry (for)

Fisheries (fis)

Coal (co)

Oil (ol)

Gas (gas)

Minerals (min)

Vegetable oil (voil)

Dairy products (mil)

Sugar cane (sgr)

Food products nec (ofd)

Beverages and tobacco products $\left(b \_t\right)$

Textile (tex)

(PECP) Petroleum and coal product (p_c)

Electricity (ely)

Gas, manufacture (gdt)

Water (wt) 
Table 5. Experiment-1 15\% uniform Import Tariffs Estimated Welfare Trade Effect

\begin{tabular}{|c|c|c|c|c|c|c|c|c|c|}
\hline Region & EV-US\$Mil. & \%GDP & $\begin{array}{c}\text { Of } \\
\text { QGDP }\end{array}$ & TOT & $\begin{array}{c}\text { Volume } \\
\text { of } \\
\text { Exports }\end{array}$ & $\begin{array}{c}\text { Volume } \\
\text { of } \\
\text { Imports }\end{array}$ & $\begin{array}{c}\text { Of } \\
\text { Export } \\
\text { Price }\end{array}$ & $\begin{array}{c}\text { Import } \\
\text { Price }\end{array}$ & $\begin{array}{c}\text { DTBAL } \\
\text { US\$mil. }\end{array}$ \\
\hline ASEAN & 4.73 & 0.00 & 0.00 & 0.00 & 0.00 & 0.00 & 0.00 & 0.00 & 2.78 \\
\hline EU & -88 & 0.00 & 0.00 & 0.00 & 0.00 & 0.00 & 0.00 & 0.00 & 29.0 \\
\hline IND & -0.76 & 0.00 & $0 ., 00$ & 0.00 & 0.00 & 0.00 & 0.00 & 0.00 & 10.6 \\
\hline JPN & 12.7 & 0.00 & 0.00 & 0.00 & 0.00 & 0.00 & 0.00 & 0.00 & 18.0 \\
\hline PAK & $\mathbf{2 3 1 . 8 7}$ & $\mathbf{1 . 4 4}$ & $\mathbf{0 . 8 4}$ & $\mathbf{1 . 5 0}$ & $\mathbf{0 . 7 6}$ & $\mathbf{1 . 6 0}$ & $\mathbf{1 . 0 8}$ & $\mathbf{0 . 0 1}$ & $\mathbf{- 1 2 3 . 9 0}$ \\
\hline LKA & 13.67 & 0.00 & 0.00 & 0.00 & 0.00 & 0.00 & 0.00 & 0.00 & -6.90 \\
\hline MIE & 11.7 & 0.00 & 0.00 & 0.01 & 0.02 & 0.00 & 0.00 & 0.00 & -3.89 \\
\hline NAFTA & -33.20 & 0.00 & 0.00 & 0.00 & 0.00 & 0.00 & 0.00 & 0.00 & 29.90 \\
\hline ROW & -45.7 & 0.00 & 0.00 & 0.00 & 0.00 & 0.00 & 0.00 & 0.00 & 34.54 \\
\hline
\end{tabular}

Table 6. Experiment-1 15\% uniform Import Tariffs. Estimated Percentage Changes in Regional Out put in agricultural trade liberalization

\begin{tabular}{|c|c|c|c|c|c|c|c|c|}
\hline $\begin{array}{l}\text { SECTORS } \\
\text { (A) Industry } \\
\text { Out Put }\end{array}$ & ASEAN & $\mathbf{E U}$ & IND & JPN & PAK & LKA & NAFTA & ROW \\
\hline AGRI & -0.00 & 0.02 & 0.02 & 0.002 & -9.0 & 0.00 & 0.01 & 0.00 \\
\hline MINQ & -0.02 & 0.01 & 0.02 & 0.00 & -8.90 & 0.00 & 0.01 & 0.00 \\
\hline PROF & 0.02 & 0.01 & $0 . .01$ & 0.02 & -7.65 & 0.00 & 0.02 & 0.01 \\
\hline TEXT & -0.06 & -0.01 & 0.00 & 0.00 & -9.10 & 0.03 & 0.02 & 0.02 \\
\hline PECP & -0.12 & -0.02 & -0.10 & 0.00 & 30.2 & -0.09 & -0.07 & 0.06 \\
\hline MAEQ & 0.02 & 0.00 & 0.00 & 0.01 & -13.90 & 0.00 & 0.00 & 0.00 \\
\hline ОТНМ & 0.01 & 0.00 & 0.01 & 0.00 & -5.90 & 00 & 00 & 0.00 \\
\hline SERC & -0.00 & -0.00 & -.0. & 0.00 & 0.80 & 0.00 & -0.00 & 0.00 \\
\hline \multicolumn{9}{|l|}{$\begin{array}{l}\text { B-Aggregate } \\
\text { Exports }\end{array}$} \\
\hline AGRI & -0.00 & 0.02 & 0.02 & 0.002 & -8.90 & 0.00 & 0.01 & 0.00 \\
\hline MINQ & -0.02 & 0.01 & 0.02 & 0.00 & -8.54 & 0.00 & 0.01 & 0.00 \\
\hline PROF & 0.02 & 0.01 & $0 . .01$ & 0.02 & -17.90 & 0.00 & 0.02 & 0.01 \\
\hline TEXT & -0.06 & -0.01 & 0.00 & 0.00 & -6.78 & 0.03 & 0.02 & 0.02 \\
\hline PECP & -0.12 & -0.02 & -0.10 & 0.00 & 34.20 & -0.09 & -0.07 & 0.06 \\
\hline MAEQ & 0.02 & 0.00 & 0.00 & 0.01 & 13.8 & 0.00 & 0.00 & 0.00 \\
\hline ОТНМ & 0.01 & 0.00 & 0.01 & 0.00 & -11.75 & 00 & 00 & 0.00 \\
\hline SERC & -0.00 & -0.00 & $-.0 .$. & 0.00 & -15.0 & 0.00 & -0.00 & 0.00 \\
\hline
\end{tabular}


Table 7. 15\% Percent Uniform Percentage Changes in Regional Output and Trade

\begin{tabular}{|c|c|c|c|c|c|c|c|c|}
\hline $\begin{array}{c}\text { SECTORS } \\
\begin{array}{c}\text { A) Industry } \\
\text { Out Put }\end{array}\end{array}$ & ASEAN & EU & IND & JPN & PAK & LKA & NAFTA & ROW \\
\hline AGRI & 0.00 & 0.00 & -.00 & 0.00 & $\mathbf{- 9 . 5 0}$ & -6.90 & -0.43 & -0.04 \\
\hline MINQ & -0.0 & 0.01 & 0.02 & 0.00 & $\mathbf{- 1 . 9 0}$ & 0.00 & 0.01 & -0.00 \\
\hline PROF & 0.02 & 0.01 & $0 . .01$ & 0.02 & $\mathbf{2 3 . 6 0}$ & 0.00 & 0.02 & -001 \\
\hline TEXT & -0.03 & -0.01 & 0.00 & 0.00 & $\mathbf{1 9 . 0}$ & 0.03 & 0.02 & -0.02 \\
\hline PECP & -0.01 & -0.02 & -0.10 & 0.00 & $\mathbf{2 0 . 0}$ & -0.09 & -0.07 & -0.06 \\
\hline MAEQ & 0.02 & 0.00 & 0.00 & 0.01 & $\mathbf{- 6 . 9 0}$ & 0.00 & 0.00 & -0.00 \\
\hline OTHM & 0.01 & 0.00 & 0.01 & 0.00 & $\mathbf{4 . 0}$ & 00 & 00 & -0.00 \\
\hline SERC & -0.00 & -0.00 & $-.0 .$. & 0.00 & $\mathbf{- 7 . 9 0}$ & 0.00 & -0.00 & -0.00 \\
\hline
\end{tabular}

Table 8. Combined Trade Policy SAFTA cum 15\% Uniform Import TariffsEstimated Welfare and Trade Effects

\begin{tabular}{|c|c|c|c|c|c|c|c|c|c|}
\hline Region & $\begin{array}{c}\text { EV-US\$Mil. } \\
\text { Percentage } \\
\text { Changes }\end{array}$ & \%GDP & $\begin{array}{c}\text { Of } \\
\text { QGDP }\end{array}$ & TOT & $\begin{array}{c}\text { Volume } \\
\text { of } \\
\text { Exports }\end{array}$ & $\begin{array}{c}\text { Volume } \\
\text { of } \\
\text { Imports }\end{array}$ & $\begin{array}{c}\text { Of } \\
\text { Export } \\
\text { Price }\end{array}$ & $\begin{array}{c}\text { Import } \\
\text { Price }\end{array}$ & $\begin{array}{c}\text { DTBAL } \\
\text { US\$mil. }\end{array}$ \\
\hline ASEAN & -134.87 & -0.02 & 0.00 & 0.03 & -0.08 & -.0 .1 & 0.03 & -0.02 & 90.0 \\
\hline EU & -737 & 0.00 & 0.00 & 0.00 & 0.00 & 0.00 & 0.00 & 0.00 & 896.0 \\
\hline IND & -0.76 & 0.00 & $0 ., 00$ & 0.00 & 0.00 & 0.00 & 0.00 & 0.00 & -1098.00 \\
\hline JPN & 12.7 & 0.00 & 0.00 & 0.00 & 0.00 & 0.00 & 0.00 & 0.00 & 473.00 \\
\hline PAK & $\mathbf{5 6 6 . 9 0}$ & $\mathbf{4 . 4 5}$ & $\mathbf{0 . 8 9}$ & $\mathbf{6 . 8 9}$ & $\mathbf{- 0 . 4 4}$ & $\mathbf{9 . 8}$ & $\mathbf{7 . 8}$ & $\mathbf{0 . 2 9}$ & $\mathbf{- 3 6 7 . 9 0}$ \\
\hline LKA & -113.67 & 0.00 & 0.00 & 0.00 & 0.00 & 0.00 & 0.00 & 0.00 & 167.60 \\
\hline MIE & -511.7 & 0.00 & 0.00 & 0.01 & 0.02 & 0.00 & 0.00 & 0.00 & 234.80 \\
\hline NAFTA & -133.20 & 0.00 & 0.00 & 0.00 & 0.00 & 0.00 & 0.00 & 0.00 & 356.90 \\
\hline ROW & -109.9 & 0.00 & 0.00 & 0.00 & 0.00 & 0.00 & 0.00 & 0.00 & 4555.23 \\
\hline
\end{tabular}

Table 9. Sensivity Analysis Estimated Percentage Change in Pakistan's Output \& in Agriculture Trade Liberalization

\section{5\% Uniform Import Tariff SAFTA SAFTA cum 15\% Uniform Tariff}

\begin{tabular}{|c|c|c|c|c|c|c|c|c|c|}
\hline & Central & $50 \%$ & $100 \%$ & Central & $50 \%$ & $100 \%$ & Central & $50 \%$ & $100 \%$ \\
\hline & Scenario & $\begin{array}{c}\text { Increase } \\
\text { In } \\
\text { ESUBM }\end{array}$ & $\begin{array}{c}\text { Increase } \\
\text { In } \\
\text { ESUBM }\end{array}$ & Scenario & $\begin{array}{c}\text { Increase } \\
\text { In } \\
\text { ESUBM }\end{array}$ & $\begin{array}{c}\text { Increase } \\
\text { In } \\
\text { ESUBM }\end{array}$ & Scenario & $\begin{array}{c}\text { Increase } \\
\text { In } \\
\text { ESUBM }\end{array}$ & $\begin{array}{c}\text { Increase } \\
\text { In } \\
\text { ESUBM }\end{array}$ \\
\hline $\begin{array}{c}\text { (a) } \\
\text { Industry } \\
\text { Output }\end{array}$ & & & & & & & & & \\
\hline AGRI & -0.98 & -1.33 & -1.89 & -3.1 & 3.88 & 5.66 & 2.45 & 3.39 & 5.66 \\
\hline MINQ & -8.56 & -8.89 & -13.01 & -8.98 & -12.40 & -18.88 & -16.93 & -23.04 & -34.90 \\
\hline PROF & $0-8.56$ & -7.78 & -8.67 & -2.56 & -3.44 & -14.36 & -18.88 & -9.45 & -8.56 \\
\hline TEXT & -6.76 & -6.67 & -7.78 & -2.56 & -3.62 & -7.90 & -10.0 & -12.4 & -14.8 \\
\hline PECP & 1.78 & 1.78 & 2.56 & 1.08 & -21.94 & -39.0 & 4.5 & -2.59 & -15.80 \\
\hline MAEQ & -16.97 & -23.66 & -28.6 & 4.45 & -2.56 & 4.7 & 4.7 & -2.33 & -13.5 \\
\hline TREQ & -17.08 & -19.75 & -21.0 & 81.6 & 131.6 & 207.6 & 50.7 & 81.3 & 120.4 \\
\hline
\end{tabular}


Table 10. Sensitivity Analysis, Estimated percentage change in Pakistan's output and Trade

15\% Uniform Import Tariff

\section{Uniform Tariff}

SAFTA cum 15\%

(b) Aggregate Exports

\begin{tabular}{|c|c|c|c|c|c|c|c|c|c|}
\hline & Central & $50 \%$ & $100 \%$ & Central & $50 \%$ & $100 \%$ & Central & $50 \%$ & $100 \%$ \\
\hline & Scenario & $\begin{array}{c}\text { Increase } \\
\text { In } \\
\text { ESUBM }\end{array}$ & $\begin{array}{c}\text { Increase } \\
\text { In } \\
\text { ESUBM }\end{array}$ & Scenario & $\begin{array}{c}\text { Increase } \\
\text { In } \\
\text { ESUBM }\end{array}$ & $\begin{array}{c}\text { Increase } \\
\text { In } \\
\text { ESUBM }\end{array}$ & Scenario & $\begin{array}{c}\text { Increase } \\
\text { In } \\
\text { ESUBM }\end{array}$ & $\begin{array}{c}\text { Increase } \\
\text { In } \\
\text { ESUBM }\end{array}$ \\
\hline AGRI & -7.9 & -11.23 & -12.41 & 33.12 & -54.12 & 67.89 & 22.5 & 54.0 & 50.89 \\
\hline MINQ & -8.53 & -12.34 & -14.45 & -9.89 & -17.03 & -23.54 & -18.45 & -26.56 & -45.78 \\
\hline PROF & -17.45 & -23.56 & -28.97 & 8.89 & 25.27 & 71.4 & -5.78 & 2.56 & 29.63 \\
\hline TEXT & -6.79 & -10.78 & -14.67 & -14.78 & 23.44 & 27.05 & 6.4 & 12.43 & 16.67 \\
\hline РECP & 23.56 & 43.56 & 56.6 & -0.76 & -1.65 & -2.3 & 22.4 & 41.90 & 68.90 \\
\hline MAEQ & -17.09 & -27.78 & -34.6 & -26.78 & 70.1 & 12.50 & 56.9 & 67.2 & 43.8 \\
\hline TREQ & -18.9 & -27.8 & -34.7 & 65.6 & 67.9 & 78.6 & 52.6 & 71.0 & 65.0 \\
\hline
\end{tabular}

(C) Aggregate Imports

\begin{tabular}{|c|c|c|c|c|c|c|c|c|c|}
\hline AGRI & -7.89 & -9.8 & -6.78 & 32.7 & -49.0 & -71.0 & 20.9 & 37.9 & 58.7 \\
\hline MINQ & -1.56 & -3.78 & -3.54 & 2.34 & 6.54 & 8.76 & -.0 .67 & 2.89 & 6.43 \\
\hline PROF & 23.6 & 27.90 & 34.5 & 41.0 & 31.0 & 19.11 & 31.8 & 40.8 & 50.89 \\
\hline TEXT & 30.8 & 23.6 & 30.1 & -3.03 & -12.5 & -14.98 & 12.6 & 2.6 & 4.12 \\
\hline PECP & -5.18 & -7.56 & -8.67 & 0.78 & 0.88 & 0.65 & -4.78 & 8.8 & 11.3 \\
\hline MAEQ & 3.04 & 4.64 & 5.78 & 7.90 & 8.89 & 7.14 & 7.98 & 8.66 & 11.3 \\
\hline TREQ & 4.69 & 5.45 & 6.00 & 12.66 & 17.10 & 23.90 & 22.0 & 16.8 & 18.04 \\
\hline
\end{tabular}


A journal archived in Library and Archives Canada

A journal indexed in Canadiana (The National Bibliography)

A journal indexed in AMICUS

A journal archived in National Library of Australia

A journal indexed in APAIS (the Australian Public Affairs Information Service)

A journal included in DOA.J (Directory of Open-Access Journa1)

A journal included in Google Scholar

A journal included in LOCKSS

A journal included in PKPOpen Archives Harvester

A journal listed in Journalseek

A journal listed in UIrich's

A peer-reviewed journal in business and management

\section{International Journal of Business and Management}

Publisher Canadian Center of Science and Education

Address 4915 Bathurst St. Unit \#209-309, Toronto, ON. M2R 1 X9

Telephone 1-416-208-4027

Fax 1-416-208-4028

E-mail ijbm@ccsenet.org

Website www.ccsenet.org

Printer William Printing Inc.

Price CAD. $\$ 20.00$

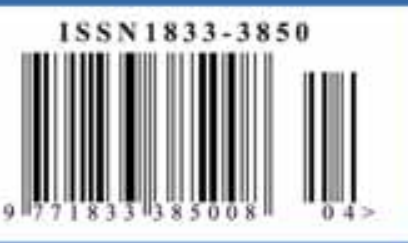

